\title{
CREATING NEW ZEALAND: \\ PĀKEHĀ CONSTRUCTIONS OF NATIONAL IDENTITY \\ IN NEW ZEALAND LITERARY ANTHOLOGIES
}

\author{
A thesis \\ submitted in partial fulfilment \\ of the requirements for the Degree \\ of \\ Doctor of Philosophy \\ at \\ Victoria University of Wellington
}

by

SUSAN WILD

Victoria University of Wellington

2015 


\section{ACKNOWLEDGEMENTS}

I would like to express my grateful thanks for the support and assistance of my two supervisors at Victoria University, Professors Mark Williams and Peter Whiteford, who have provided invaluable guidance in bringing the thesis to its completion; Professor Vincent O'Sullivan and Dr. Brian Opie provided early assistance; I am appreciative also for the helpful advice and encouragement given by Ed Mares, and for the support and patience of my family. This was especially helpful during the disruptive period of the Christchurch earthquakes, and in their long aftermath. I wish also to state my appreciation for the services of the staff at the National Library of New Zealand, the Alexander Turnbull Library, the MacMillan Brown Library, the Mitchell Library, Sydney, and the libraries of Victoria University of Wellington and the University of Canterbury - the extensive collections of New Zealand literature held at these institutions and others comprise an enduring taonga. 


\begin{abstract}
The desire to construct a sense of home and the need to belong are basic to human society, and to the processes of its cultural production. Since the beginning of New Zealand's European colonial settlement, the determination to create and reflect a separate and distinctive collective identity for the country's Pākehā population has been the primary focus of much local creative and critical literature. Most literary histories, like those of Patrick Evans (1990) and Terry Sturm (1991), have followed the narrative of progression established initially in E.H. McCormick's Letters and Art in New Zealand (1940) - away from colonial dependency through delineated stages from provincial and cultural nationalist phases to the achievement of a bicultural and multicultural consensus in a globalized, international context.
\end{abstract}

This thesis questions the progressivist assumption which often informs that narrative, arguing instead that, while change and progress have been evident in the development of local notions of identity in the country's writing over time, there is also a pattern of recurrent concerns about national identity that remained unresolved at the end of the last century. This complex and nuanced picture is disclosed in particular in the uncertain and shifting nature of New Zealand's relationship with Australia, its response towards expatriates, a continuing concern with the nature of the 'reality' of 'New Zealandness', and the ambivalence of its sense of identity and place within a broader international context. New Zealand's national anthologies of verse and short fiction produced over the twentieth century, and their reception in the critical literature that they generated, are taken in the thesis as forming a microcosmic representation of the major concerns that underlie the discourse of national identity formation in this country. I present an analysis of the canonical literary anthologies, in particular those of verse, and of a wide range of critical work focused on responses to the historical development of local literature. From this, I develop the argument that a dual, interlinked pattern, both of progress and of reversion to early concerns and uncertainties, is evident.

The thesis is structured into six chapters: an introductory chapter outlines the national and international historical contexts within which the literary contestation of New Zealand identity has developed; the second outlines the contribution of influential literary anthologies to the construction of various concepts of New Zealandness; three chapters then address particular thematic concerns identified as recurring tropes within the primary and secondary literature focused on the discourse of national identity - the 'problem' of the expatriate writer, the search for 'reality' and 'authenticity' in the portrayal of local experience, and New Zealand's literary response towards Australia; and the Conclusion, which summarizes the argument presented in the thesis and provides an assessment of its major findings. A Bibliography of the works cited in the text is appended at the end of the thesis. 


\section{CONTENTS}

Acknowledgements

$\begin{array}{ll}\text { Abstract } & 2\end{array}$

Contents 3

CHAPTER 1. Introduction - Creating New Zealand 4

CHAPTER 2. Versions of 'New Zealandness' in national anthologies of verse 44

CHAPTER 3. 'What is a New Zealander?' - The problem of the expatriate writer 105

CHAPTER 4. 'True vision’ - The literary construction of New Zealand 'reality’ 154

CHAPTER 5. 'The loathsome Australasian' - The role of Australia in the creation of New Zealand 212

CHAPTER 6. Conclusion - Becoming New Zealand: 'A process never completed' 270

Bibliography 282 


\section{CHAPTER ONE: INTRODUCTION - CREATING NEW ZEALAND}

Strictly speaking, New Zealand doesn't exist yet, though some possible New Zealands glimmer in some poems and on some canvases. It remains to be created ... by writers, musicians, artists, architects, publishers.

(Allen Curnow, 1945b, 2).

The need to identify and define a concept of 'home', and a desire for belonging, are fundamental to human societies. These desires find particularly strong expression in the art and literature of those nations, such as New Zealand, whose origins and narratives of identity are founded on a history of migration and colonial settlement. ${ }^{1}$ Benedict Anderson, in Imagined Communities (1991), proposes that in order for a nation to be constructed it is first necessary to 'think' it into existence, suggesting that it comprises the collective perception of self-identity of the society from which it is structured, and is both formed from and represented by the cultural expressions of nationhood that it produces $(15,28)$. Reflecting on the role of literature in these processes, Anderson considers that the act of constructing a nation requires a 'narrative of identity', and that a community's creative and imaginative writing are crucial for formulating and conveying such a narrative (205). The nature of New Zealand's 'narrative of identity' and the processes of its construction, particularly over the twentieth century, form the primary interests of this thesis.

I present in the thesis an analysis of Pākehā ${ }^{2}$ constructions of New Zealandness, as this notion has been reflected in the country's national anthologies of verse and short fiction

\footnotetext{
${ }^{1}$ See, for example, Barbara Einhorn's studies focused on the impact of migration on identity construction, especially 'Gender, Nation, Landscape and Identity in Narratives of Exile and Return' (2000).

${ }^{2}$ In the thesis, the currently accepted spelling of 'Māori', which employs a macron over the first vowel of the diphthong, is used except in cases of direct quotation where the spelling 'Maori', without the macron, has been used in the original text. A similar approach in regard to 'Pākehā' has been used. Also, in direct quotation, the original usage of upper or lower case and italicization in these words has been retained.
} 
over the twentieth century and in their critical reception over that period. ${ }^{3}$ This analysis identifies and examines a number of repeated tropes of identity that have been expressed frequently in the words of New Zealand writers and that, despite evidence of movement and change in the nation's sense of self-conception over time - through stages of colonialism, provincialism, nationalism, internationalism, and towards a wider globalization and multiculturalism - have formed recurrent echoes in the literary account of its history. The argument is developed that these tropes represent problematic issues of identity that have arisen from conflicting responses towards the country's colonial beginnings and its subsequent difficulties in determining its cultural 'place' in relation to its international environment, and that these remained largely unresolved at the end of the past century.

The thesis is arranged into six chapters. The first, this Introduction, provides an outline of the historical and cultural contexts in which local writers have engaged in the imperative task to create a distinctive New Zealand identity and a national literary canon, and it identifies the major protagonists in the discourse of identity-construction. This chapter introduces the aims, theoretical framework and method of the thesis, and identifies the particular thematic concerns that form its primary focus. It also specifies the media that form the subjects of its analysis, being the 'iconic' national anthologies of New Zealand verse and short fiction produced over the twentieth century, and the critical literature that these generated. This analysis illustrates the processes by which the discourse of New Zealand national identity has been correlated with the development of a local literature. It identifies a set of dichotomized positions that have been expressed in creative and critical writing, relating these to the complexities and uncertainties that are inherent in constructions of concepts of New Zealand. In particular, it presents the argument that, rather than a unitary,

\footnotetext{
${ }^{3}$ The thesis is focused on questions of identity evident in the literature of the country's European/Pākehā population, and does not consider issues of Māori identity or literature.
} 
progressivist historical narrative of achievement, a pattern of interlinked elements both of progress and of reversion to early concerns and uncertainties can be seen in the development of the country's self-perception.

The second chapter analyzes the content of authoritative national anthologies of verse produced over the period 1906 to 1997, and their related secondary literature, examining their contribution towards the construction of specific models of national identity. It also assesses the intervention of influential anthologists within the discourse of identity construction, in their role of promoting and shaping particular representations of New Zealandness. It outlines the literary contestations that arose between proponents of competing versions of New Zealand, in particular the impact of the cultural nationalists of the 1930s and 1940s on the formation of a local canon and their subsequent influence on the form of the country's selfperception. The following three chapters analyse particular aspects of the development of New Zealand identity that are underlying concerns identified as frequently reiterated themes in local literature.

Chapter Three considers the various critical responses made towards the concepts 'New Zealand writer' and 'expatriate writer', and how the question, 'what is a New Zealander?', has been one of the dominant concerns in the discourse of national identity. The determination of the answer to this question has been fundamental to notions of cultural identity, and of particular concern to compilers of overtly national literary anthologies, notably Allen Curnow. The critical argument around the issue of who 'belongs' in New Zealand, for the purposes of inclusion within (or exclusion from) the anthologies, has illustrated differing underlying concepts of collective self-perception, which have been subject to shifts and change over time, and in different contexts.

Chapter Four focuses on the continued emphasis in the literature upon efforts to identify and promote an autochthonous canon, in the form of an ongoing critical dispute 
regarding the characteristics of 'authenticity' and 'truthfulness', as these terms have been applied to the portrayal of New Zealand experience. This section examines the competing claims asserted by advocates of localism or internationalism as to which more accurately represents the proper site of New Zealand 'reality', a dispute related in particular to the growth of literary nationalism in the 1930s and 1940s. Also examined in the chapter is the associated debate relating to the oppositional and often contradictory arguments promoting different conceptualizations of reality, as they have been represented in New Zealand literature. These have included depictions of the local landscape in various forms, including, among others, that of a tabula rasa - a remote and empty space, distant and isolated from its overseas cultural centre - or as the site of a unique and authentic new society, engaged in the universality of human experience and located both physically and emotionally in a distinctive Pacific setting.

These different, shifting concepts of local reality, as they were promoted by various groups of New Zealand writers and critics, were also related to intergenerational changes for example, from the Georgianism adopted by local writers in the early twentieth century, including Charles Marris, Alan Mulgan, John Schroder (and evident also in the early work of some of those later favoured by Curnow, including Charles Brasch, Denis Glover and D'Arcy Cresswell), to the Modernism of Auden, Pound, Spender and Yeats incorporated into the work of Curnow, A.R.D. Fairburn and other 'Caxton' poets, and then to an adaptation of postmodernism to New Zealand's late-twentieth century literary context. The particular styles and concerns of the verse and fiction that dominated the local canon changed over time, with the assimilation of contemporary overseas modes that differed between successive generations of writers, so that the literature produced in New Zealand at the end of the century appears markedly different, both stylistically and in the scope of its interests, from that of the colonial period. As discussed in later chapters, however, these shifts in mode and 
focus did not simply represent straightforward, progressive directional transformations and unqualified evidence of increasing national self-confidence and cultural independence. These changes also indicated a continuing pattern of literary mimesis and simulation, and ongoing dependence upon overseas models and movements that were indicative of the cultural uncertainty that had been intrinsic to colonial writing in this country, and had remained, in different forms, an underlying characteristic of much of that produced during the twentieth century.

Chapter Five provides a case study of a particular example of the complexities of identity construction, in the form of an analysis of the continuing ambivalence that has characterized New Zealand's literary relationship with its main cultural Other, Australia. Since the earliest stages of this country's colonial settlement, which was governed initially from the Port Jackson penal colony in Australia, the association with its geographic neighbour has been complex and problematic, and represented variously by sentiments of closeness, indifference, rivalry and antagonism. The trans-Tasman relationship had a significant role in shaping New Zealand's identity in the early period of the country's settlement in particular, and was strongly influential in the development of a separate, distinctively different local literature; however, their early association is now a largely neglected aspect in the cultural memories of both countries.

In the mid-decades of the twentieth century, this formerly close relationship was subject to the growth of literary nationalism, represented primarily by the group of poets and critics associated with Curnow. This determined that rather than incorporation into a broad, regional 'Australasian' literature, the two countries would, on a formal level, adopt distinctively different cultural paths, even while other aspects of the relationship, such as trade and commerce, have grown inevitably closer and more interrelated over time. The several strands of the trans-Tasman relationship were reflected in the various critical 
responses to the series of Oxford 'Australasian' verse anthologies that were produced until the last of these appeared in 1950, after which it diverged into quite different, separate formal literary paths. However, outside the imprimatur of the national anthologies produced in the two countries after that date, a secondary, more diverse literary stream that recognized their close proximity in both geographical and human terms, continued at the cultural margins. Finally, Chapter Six evaluates the extent to which the country's literary anthologies, and the impact of the interventions of Curnow and others in the discourse of identity construction, contributed towards shaping its sense of collective self-perception. It also provides an assessment of the nature of New Zealand's national identity at the conclusion of the twentieth century (with some reference to the following decade), as this was represented in the country's creative and critical literature at that time, and identifies the extent to which the major concerns regarding identity that had permeated the country's colonial writing continued also to be a preoccupation of later creative and critical work.

In the thesis, while some aspects of a number of the iconic anthologies of short fiction are considered, the primary focus is on anthologies of verse - these have formed the sites of the most contentious and vigorous conflicts underlying the literary arguments around New Zealand national identity. This is due in particular to the dominance of the cultural nationalist position of the 1930s and 1940s that was promoted by Curnow and others within the country's literary hierarchy, and the influence this had upon later writers and critics. The emphasis in the thesis has been on verse collections because those anthologists - in particular Curnow, but others also - were more explicit in their intention that their work should form part of the discourse of national identity, and in their desire to shape the form of that identity to their own views of how New Zealandness should be reflected. While anthologies of short fiction, in particular those such as Speaking for Ourselves (1945), the Oxford series and the several editions of Some Other Country, that became an enduring part of the local canon, 
certainly contributed towards the development of a sense of collective identity, their compilers did not engage directly in the contentious discourse that is inseparable from any consideration of the verse anthologies. The prose anthologies have therefore been referred to in the thesis, but with less emphasis, and discussed in terms of their various contributions to the several themes identified within the general discourse of identity.

The approach adopted in the thesis is to analyze the editorial stance that is evident in the anthologies, and in a range of associated critical writing focused on responses to the historical development of local literature and its relation to concepts of New Zealand's national identity. The thesis does not aim to present literary criticism focused on the detailed creative content of the anthologies - instead, it has focused on the anthologists' stated intentions and the secondary literature the anthologies provoked, in particular the critical comment that itself illustrates and forms part of the discourse of identity.

The selection of the period and the concluding date that form the bounds of this study was based on a view that the end of a century is culturally and emotionally symbolic, and gives rise to natural sentiments of reflection and assessment. Also, as Keith Sinclair stated in his A History of New Zealand (1988), itself a major contribution to the narrative of the country's identity, the construction of a sense of nation 'is a process never completed' (231) so in this sense, any 'cut-off' date for analysis is arbitrary, but also necessary for any analysis to be conducted at all. Also, the present time allows now for a sufficient period to have elapsed for meaningful reflection upon, and assessment of, the events of last century, including its cultural developments and achievements.

There have been a great many anthologies of local literature of various types, quality and foci produced since the beginning of the twentieth century - too many for them all to be included for consideration in this thesis. The selection of anthologies I have made to form its 
subjects of analysis, therefore, comprises those that I consider to have been the major contributors towards, and most engaged, directly or indirectly in, the discourse of identity.

The study is underpinned by theories of national identity construction and the nature of collective identity, and applies a range of procedures, including critical analysis, literature review, presentation of case studies, and discussion of archival material. The thesis quotes widely from a range of both primary and secondary texts that are analyzed to illustrate and develop its particular arguments. The extensive use of quotation selected from diverse sources and different periods is presented in order to demonstrate the pervasiveness of the specific themes and concepts over time that are identified in the thesis, and to emphasize their frequent reiteration throughout different literary genres and within different contexts over the whole of the historical period under review.

A concern with national identity has always been a focus of New Zealand's creative writing, as well as an emphasis in the country's critical work - Vincent O'Sullivan, for example, reflects in his introduction to the Oxford Anthology of Twentieth Century New Zealand Poetry (1970) that it is 'self-definition that occupies the greater part of our poetry' (xx). Similar comments, relating local literature to the construction of the country's collective identity, are pervasive - they form a persistent, identifiable theme, which has been evident since the earliest writing was produced in this country. This sense of introversion and national self-focus were particular features of the work of Scottish settler William Golder in the early 1850s, the first published creative New Zealand literature, and underlies much of the local literature that evolved since; it was important in the anthologies of poetry and short fiction produced over the twentieth century, particularly the verse collections of Curnow and the others that followed.

That this concern with defining New Zealand identity remained a dominant preoccupation in the country's literature until at least the end of last century is indicated in 
the editorial comments, as well as the contents, of the Oxford Anthology of New Zealand Poetry in English (1997), compiled by Jenny Bornholdt, Gregory O’Brien and Mark

Williams. The editors state that the poems they have selected tell 'the story of struggle and interaction between different versions of where we are and how we perceive ourselves' (xxi). The contents of the anthology, as well as the tone of the editors' comments, indicate that the 'struggle' to define 'how we perceive ourselves', that had earlier dominated the work of nineteenth-century settler writers such as Golder, still remained a major preoccupation at the end of the twentieth century.

In the thesis, the term 'national identity' indicates an intangible, collective feeling and a shared sense of belonging within, and being encompassed by, a conceptualized nation. It is the nature of this 'shared sense of belonging', as it has been expressed in various literary representations in New Zealand, that underlies the argument of this thesis. The following discussion draws upon the work of a number of theorists to produce a conceptual framework within which to set an analysis of the anthologies and related secondary literature.

Over the two hundred years since its first European contact, much of New Zealand's creative and critical literature has formed a cultural discourse focused towards the goal of formulating and reflecting a desired representation of Pākehā settlement and dominance. The imperative that a distinctive local literature should be developed purposefully to construct and reflect this form of essential ${ }^{4}$ New Zealandness has been repeated throughout the country's literary record. In 1852, Golder had published New Zealand Minstrelsy, a collection of overtly chauvinistic verse, in order to 'endear our adopted country the more to the bosom of the bona fide settler', and to induce 'a people to take a firmer hold of their country ... making them the more connected as a people in the eyes of others' (Preface to New Zealand

\footnotetext{
${ }^{4}$ The terms 'essential', 'essentialism' and 'essentialist' in regard to definitions of national identity are used in the thesis as descriptive terms that imply a set of innate, commonly-held national characteristics and qualities. See, for example, Andrew Sayer's 'Essentialism, Social Constructionism, and Beyond' (1997), 456.
} 
Minstrelsy, 1852, n.p.). Assertions of such an explicit intention to apply creative literature to the function of influencing a sense of collective identity have been common in local writing.

Editors of influential local literary magazines have, in different ways, displayed similar aspirations to encourage the development of the notion of a 'home' located culturally and emotionally, as well as physically, in New Zealand rather than overseas, and encouraged an undertaking to apply literature to the project of establishing a locally-oriented identity. For example, eight decades after the publication of Golder's work, the editors of The Phoenix 5 asserted: 'We [New Zealanders] are hungry for the words that shall show us these islands and ourselves; that shall give us a home in thought'. ${ }^{6}$ Brasch, in Landfall in 1947, also expressed concern that "[a] country without literature of its own is only half alive, for it must lack selfknowledge and critical sense and the pride of the imagination. ... [T] he community ... should do what it can to encourage literature as one of its chief means of ... knowledge and growth' (240). Other authoritative commentators, also, frequently asserted the view that the development of local literature and the construction of concepts of national identity were, and ought to be, intrinsically related. An example of this is evident in Curnow's observation in his Note to the second edition of his Caxton anthology that 'the condition of being a New Zealander should occupy much of a New Zealand poet's mind' $(1951,48)$.

In 1940 New Zealand celebrated its centenary, and the New Zealand government actively promoted the centennial events as a means of fostering the development of national identity, encouraging its portrayal in a locally-oriented literature. These events included literary competitions and the publication of a range of cultural surveys, including

\footnotetext{
${ }^{5}$ The first three issues of the magazine were entitled The Phoenix; for the subsequent, final issue the definite article in the title was dropped.

${ }^{6}$ This statement of the publication's aims was set out in its Introduction to the second issue in July 1932, quoting from an essay by E.K. (Eric) Cook which was published in Canta, the magazine of the Students' Association of Canterbury University College, in the issue of 9 May 1932. Cook's comments are cited in W. L. Renwick, 1987, 199.
} 
E. H. McCormick's Letters and Art in New Zealand (1940). Curnow's verse anthologies - the first of which was published in 1945 - were produced in the period of nationalistic spirit that followed the symbolic marker of the country's collective progress and development that the centennial celebrations represented.

However, Curnow, together with McCormick and the few others whose perspective was critical and deprecatory rather than laudatory of much of the country's claim to cultural achievement at that time, presented an account of the national character quite divergent from the self-confidently progressivist and positive portrayals that were being officially promoted, and which informed much of the local literature then being produced. In contrast, Curnow's Book of New Zealand Verse (1945) included an extensive introduction in which he set out at length his own prescription for literary nationalism, and for what he considered appropriate to the correct 'nature and uses of poetry' (15). The book was published by the Caxton Press in Christchurch, and, despite the tone of Curnow's introductory comments, which suggested a focus on a wider audience, the fact of its local publication enhanced the effect of its being more directly addressed to a New Zealand readership, and towards influencing the development of local literature, rather than aiming primarily at overseas acceptance and affirmation. $^{7}$

Clearly Curnow intended his collection, which covered verse produced over only a two decade period from the 1920s, and imposed very selective criteria for the small number of contributors it included, to supplant its predecessors as the authority for an indigenous literature and a local canon. The version of New Zealandness that he presented in his commentary, and in many of the choices of the selections he included, was markedly different from that which had been promulgated by earlier anthologists. In 1974, reflecting on

\footnotetext{
${ }^{7}$ Several earlier New Zealand anthologies had been published in England. An exception was Alexander and Currie's A Treasury of New Zealand Verse (1926), which was published locally by Whitcombe and Tombs.
} 
his purpose in producing the 1945 collection, Curnow stated that it was to make a 'contribution to the anti-myth about New Zealand', and to reflect his views of 'antipathy to almost everything ... that satisfied an older generation' (1974, xiii). He made clear that his anthology was not intended to be generally representative of the verse produced in New Zealand at that time, but was highly selective and carefully constructed to present his own perspective, and with the specific objective of influencing the process of nation-formation. The country's commemorative events of 1940 had evoked a range of literary responses, that Lawrence Jones describes in his essay 'Myth and Anti-myth in Literary Responses to the Centennial' (2004) as being 'decidedly mixed in tone' (208). These responses presented contesting versions of a mythologized concept of New Zealandness, with Curnow and a new group of literary nationalists, including McCormick, Roderick Finlayson, M.H. Holcroft, and Frank Sargeson, along with a small group of others, asserting a critical view that challenged the 'old myths' proposed by the country's early literary establishment, underpinned as they were by the myth of inexorable material and cultural progress, with the intention of replacing them with those of their own construction (207).

Over subsequent decades the country's creative and critical literature became a significant ground for the factious discourse on national identity that developed around several influential figures. In particular, Curnow's verse collections, with their combative editorial stance, became the focus for a clash of cultural positions, with local anthologies, in particular those of verse, becoming a pivotal medium that was utilized for the promotion of contending versions of New Zealandness. For a time, Curnow's nationalistic intervention crystallized the often robustly-expressed debate over identity, and the strength of his articulation of his views provided an impression, for a time, that the country's underlying uncertainties of self-perception and its insecurities regarding its identity had been positively resolved. However, as discussed in the following chapters of the thesis, this appearance of the 
resolution of the nation's identity into a unitary, strongly-defined concept was largely illusory, and it is evident that these concerns regarding New Zealand's self-perception had persisted into later decades, being repeatedly reasserted, often in different forms of expression.

From the 1930s in particular, in literary magazines, articles, essays, introductions to anthologies and other media local writers were exhorted to focus their work on creating and reflecting a distinctive New Zealand collective character. Attributions of literary value, inclusion in national anthologies, and acceptance into the local canon were all firmly linked to particular notions of identity. Local literature has been fundamental to the processes of legitimating and authenticating a sense of Pākehā belonging in a land expropriated through the processes of colonization, and also to addressing the subsequent anxieties and disquiet evoked by ongoing existential and emotional concerns with geographical and cultural dislocation. The desire for the attainment of a state of legitimacy underlies the major themes that recur throughout the twentieth-century literary accounts of the development of European settlement that record a narrative of progression through its material to its intellectual phases, from colonialism to the postcolonial. A sense of collective unease is marked in local creative work by repeated motifs of displacement and detachment, distance from a perceived centre, isolation, remoteness, aloneness, smallness, and the recentness, illegitimacy and insubstantial nature of the origins of Pākehā settlement.

New Zealand was annexed by Britain in the nineteenth century during the course of aggressive colonial expansion driven by the imperial economic interests of the major European powers. This country's continuing ambivalence towards its historical links to its political and cultural beginnings has been a principal source of difficulty and complexity in the construction of a distinct national identity. Its colonial origins remain a cause of contention in the formulation of the narrative of New Zealand's development as a nation, and 
in the postcolonial reassessment of the place of early local writing within its literary history. Pākehā anxieties regarding their identity and status in this country have been the focus of much of the body of local critical analysis, and have been represented in the literature in similar, recurring terms over time. Such expressions, which illustrate the persistence of their underlying concerns, can be found in the work of a range of commentators - Curnow, for example, expressed the view in his 1945 Caxton anthology that New Zealanders imagined themselves to be 'interlopers on an indifferent or hostile scene' (1945a, 52). This perception of the continuing sense of dislocation and alienation of the European settlers in a distant land is a common theme underlying the contents of the anthology. O'Sullivan, similarly, in his introduction to his 1970 Oxford anthology, reflected on the extent to which a heritage of colonial guilt 'that comes with a coastline appropriated through bloodshed' is imbued within New Zealand verse (xix).

Instead of attaining resolution, such concerns regarding fundamental issues of identity, expressed in comparable terms, continued to pervade later cultural analyses, often forming the central focus of critical work. Examples of this include Trudie McNaughton's comments in Countless Signs (1986) that she saw, as an 'an obsession in much twentiethcentury New Zealand literature', the fervent desire of 'Pakeha writers ... to feel "native" to the country', and of their 'struggling to inhabit a country imaginatively' $(1986,8,9)$; Mark Williams, also, in Leaving the Highway (1990), reflected upon what he observed to be the 'deep-seated unease about New Zealand's cultural situation' that was conveyed in local literature, and commented that 'since the nineteenth century the question of national identity has been a continual problem to which New Zealand writers ... have offered various solutions' $(9,10)$. There were many similar, frequently reiterated expressions of concern about the proper 'place' of Pākehā in New Zealand, statements which were still appearing in the literature in the 1990s, indicating that, rather than achieving resolution at the end of the 
century, such concerns regarding a sense of insecurity of belonging had remained intrinsic to New Zealand's self-perception.

A major contributing factor to this sense of 'deep-seated unease' regarding identity and belonging is that New Zealand, unlike other comparable former colonial societies, lacks in its narrative of national development a commonly-accepted seminal originating point from which to locate its historical initiation, ${ }^{8}$ and is therefore subject to unresolved concerns regarding its social, cultural and political legitimacy. Because of the particular manner and context of European settlement of this country, and the subsequent pattern of international historical events, New Zealand has never been subject to a war of liberation or other determinative event of origin that separates distinctly its earliest beginnings from the later stages of the country's maturation. This lack of focus forms a critical difference in the cultural development of this country from those whose histories have been marked by an identifiable breach from their colonizing parent, or clearly expressed assertion of separate identity, such as the United States, Canada, South Africa and Australia, among other former British colonies. Australia, for example, while never undergoing a violent detachment from British domination, constructed a myth of rebellion around the Eureka Stockade incident in 1854. In 1901 Australia underwent a significant, symbolic separation in the form of enacting the federation of its six separate colonies into its own Commonwealth. New Zealand can draw upon no comparable single historical event - one involving the community in an act of collective national re-imagining and beginning - as an emblematic assertion of its independence from Britain. Rather than an abrupt political and emotional rift, the account of

\footnotetext{
${ }^{8}$ While the 1840 Treaty of Waitangi made between the British Crown and Māori tribes is officially regarded as the point of commencement of the British colony of New Zealand, its terms were disregarded by the subsequent settler governments. Although the Treaty of Waitangi Act 1975 provided legal recognition of the principles of the Treaty, it is a source of ongoing political and social contention among many Pākehā, as well as Māori, New Zealanders.
} 
New Zealand's path towards separate nationhood has been one of gradual constitutional change.

The argument in the thesis accepts the view of national identity proposed by Frantz Fanon, and in slightly varying forms, as outlined by the other theorists referred to in the next part of this chapter. Fanon, in his essay 'On National Culture' (1991), examines the historical and social processes of constructing the concept of 'nation', and the complexities inherent in the cultural evolution of national consciousness. Fanon emphasizes the importance to the processes of formation of national essentialism and a unique identity of a specific, commonly accepted 'origin event', a significant defining historical incident or collective experience (such as a war of separation or declaration of independence from a colonial power), which a new nation can incorporate into its originating narrative for the purpose of identifying its 'critical moment' of creation (155).

Others, also, stress the importance to the formation of self-identity of the collective recognition of a specific causal event that initiates the processes of social and cultural development. Michael Moon and Cathy Davidson, for example, in Subjects and Citizens (1995), claim that, as a nation, 'where we find our origins is always a matter of how we define ourselves' (2). However, attempts to locate such a generally accepted, singular source of genesis for New Zealand as a nation have always been subject to complexities. For much of the last century, Pākehā records of the settlement of New Zealand focused on concerns regarding the country's links to European events, not the local wars of colonization fought against Māori, as the primary focal points for the construction of a narrative of identity. ${ }^{9}$ The absence of a generally acknowledged originating event creates a problematic lacuna in New

\footnotetext{
${ }^{9}$ There has been an increased focus on locally-situated historical events in recent decades. These studies have included extended analyses of cross-cultural interaction during the early colonial period by influential historians including James Belich, Michael King, Anne Salmond, Keith Sinclair, Ranginui Walker, Matthew Wright and others.
} 
Zealand's historical account of its development as a nation, which local writers and historians have sought, in various ways, to resolve. ${ }^{10}$

Origin events serve for the modern nation a function analogous to that of creation myths in older established traditional societies. Koenraad Kuiper, in his 2007 essay, 'New Zealand's Pakeha folklore and myths of origin', discusses the function of narrative in constructions of collective identity, providing an analysis of how European fictional forms, themes and symbolism have been adapted and applied in structuring various historical accounts of New Zealand's beginnings, and of the utilization of cultural production in efforts to create and promote perceptions of selected founding events. Kuiper analyzes aspects of New Zealand's search to locate a suitable origin event in its history that can be applied to support claims to particular (desired) characteristics of national identity. He identifies a shift in focus over time from external to internal sources of location for the initiation of the entity 'New Zealand', as distinct from its European colonial history, including those represented in local literature $(2007,174)$. Kuiper observes, however, that while specific features of the country's collective self-narrative have altered and developed in response to its changing international context, so that its present forms of representation are significantly different from those of its past, there remain identifiable traces of underlying uncertainties and anxieties that indicate the persistence of earlier insecurities of identity.

All attempts at 'inventing' a definitive point of origination for the new country have become unsatisfactory, failing to provide an adequately substantial or ideologically acceptable foundation upon which to base the legitimation of a society derived at its roots from the forceful imposition of the British colonial settlement project. The instability caused

\footnotetext{
${ }^{10}$ The place of the ANZAC experience in the development of New Zealand identity has been analyzed by a number of local historians, including in particular Christopher Pugsley in Gallipoli (1984) and The Anzac Experience (2001), and Jeff Hopkins-Weise, in Blood Brothers (2009). New Zealand's international sporting achievements, also, notably those of the All Blacks, have been emphasized by Lloyd Jones, among others, as being important to the construction of the country's self-identity.
} 
by this gap in its founding narrative has been an obstacle to the formation of New Zealand's collective identity, forming a central element in the structure of the nation's historical record and invoking a range of critical comment. Brasch, in Indirections (1980), for example, reflecting on the country's history since its settlement, and on the relationship of local literature to European culture, observed that (Pākehā) New Zealand had not 'fought for its liberties', so that discernible attributes of a separate identity remained provisional and indeterminate (310). Keith Sinclair similarly remarked that New Zealanders 'were not born to it and did not achieve it, but had nationalism thrust upon them' $(1988,337)$. These statements by Brasch, Sinclair and others imply that New Zealanders do not feel - or do not have a right to feel - that they have 'earned' their nation. This also suggests that the notion of a national identity attained by this country in the process of its colonial separation from Britain was an immature construct that was of itself incomplete as a foundation for nationhood, and left significant issues unresolved.

From different perspectives, others, also, have reflected on the problematic gaps that prevail in this country's narrative of identity. Claudia Bell, for example, in Inventing New Zealand: Everyday Myths of Pakeha Identity (1996), considers the extent to which a strong sense of anxiety and unease regarding the legitimacy of a Pākehā colonial settlement situated physically within a Pacific rather than European context, has permeated the country's cultural production. Commenting that within New Zealand society 'self-examination' is a 'national preoccupation', Bell concludes that New Zealand is a country exhibiting an anxious compulsion to 'constantly tell itself who it is', in order 'to know just who we are' (17). Bell states that New Zealand's creative and critical literature has been applied to the functions of constructing an affirmative founding myth as this is essential to a 'collective egoism' necessary for maintaining 'morale' in 'an otherwise remote ... globally insignificant group of islands' (ibid). 
Similar, repeated statements of such sentiments, which were common in local historical and critical analyses at least until the end of the twentieth century, expose underlying concerns regarding the insecurity and fragility of the nation's sense of identity, and its failure to reach a state of maturity. They indicate that there remained a continuing uncertainty relating to self-perception that contradicts the progressivist views and deterministic attitude of confident optimism that were expressed by writers such as Guy Scholefield in Making a Nation (1907). In this, Scholefield presented a detailed account of what he viewed to be an inexorable sequence of positive stages in New Zealand's development, based upon particular social, economic, commercial and cultural contributions made by each ethnic group of settlers, in particular the benefits to the nation of its links to its English cultural heritage. This narrative of development portrays a version of Pākehā identity not as one separate and distinct from its colonial origins, but as a continuation of them, as a minor, inevitably inferior offshoot within the international context of the greater British imperial project, inseparable from its European cultural base. Scholefield's perception of the condition of New Zealandness, as being dependent, provisional, largely unformed and culturally immature, typified that of the majority of the early local creative and critical writers, who envisioned a New Zealand literature that was modelled on English values and forms, relocated to an exotic setting. This view is represented in the contents and editorial position of New Zealand Verse (1906), compiled by W.F. Alexander and A.E. Currie, who saw that the country's cultural 'foundations were set by its fathers', and that in due course this country's writing would be 'assigned a place ... in the civilized world' (1906, xiv, xv).

Others later who felt driven to distance New Zealand literature from its colonial background and to establish an alternative representation of the nation's identity, one that was independent and distinct from its overseas antecedents, sought a quite different basis upon which to construct a narrative of development. This has been particularly difficult in this 
country due to the particular complexities of its historical background. It has lacked a structure of strongly defined and unique identifiers of its own, from which possible markers of New Zealand exceptionalism ${ }^{11}$ might be distinguished. As a result, New Zealand identity is commonly described not as a unitary set of positive defining characteristics, but in terms of a plurality of various descriptors, which are often antithetical. Tony Ballantyne and Brian Moloughney, in Disputed Histories (2006), illustrate with a range of specific cases the gap that exists between the variety of myths and proposed realities of New Zealand's historical development - such as in the example of the seemingly contradictory claims made for an egalitarian or elitist basis for the country's character, qualities which have both been promoted in accounts of the country's origins. The lack of congruity between these various versions of the 'real' that have, at different times, been presented as authentic representations of New Zealandness, contributes to a sense that all notions of local identity are imprecise and unfixed, being subject to different interpretation according to a particular advocate's ideological and ontological perspective, and to the different mythologies of the country's identity that they have promoted.

While many critics and commentators, in particular Curnow, have recognized the function of literary notions of New Zealand in constructing a framework of national mythology, and have themselves contributed towards this role, they commonly rejected alternative, contradictory narratives of identity with the claim that they were inauthentic portrayals that failed to represent the reality of local experience. The determination to promulgate a particular characterization of New Zealandness has been a common aim of local literary anthologies, and dominant versions of identity have been linked to assessments of literary value. Owen Marshall, for example, commented that '[a]ny collection is of its time',

\footnotetext{
${ }^{11}$ The terms 'exceptionalist' and 'exceptionalism' are used in the thesis in the sense that they are utilized by Miles Fairburn in his article, 'Is There a Good Case for New Zealand Exceptionalism?' (2006); that is, as descriptors for the theoretical concept that a nation can be defined by a set of characteristic differences, or by its lack of conformity to a norm, that distinguish it from others.
} 
acknowledging that versions of the local canon have correlated with notions of national identity, shifting over time and context, and between proponents of varying, and competing, aesthetic, political, social and cultural perspectives, as well as external influences $(2002,12)$.

This is illustrated, for example, in the later responses towards the representation of New Zealand as a progressive, proto-socialist and egalitarian utopia that was expressed in the verse of William Golder and most other Victorian settler poets. This version of New Zealandness, although common in the nineteenth and early twentieth centuries was rejected by the cultural nationalists of the 1930s and 1940s, in particular, as being inauthentic, and was excluded almost entirely from subsequent national anthologies. Despite its place as being New Zealand's earliest literary production, none of Golder's work was anthologized until a century and a half after its original publication in New Zealand, when several selections of his verse were included in Harvey McQueen's collection, The New Place: the Poetry of Settlement in New Zealand, 1852-1914 (1998). However, within this anthology, Golder's work, all of which had been produced in New Zealand, was classified as 'Victorian' literature, and therefore associated with an overseas rather than a local literary tradition. This treatment of Golder's verse provides an example of how particular forms of expression of New Zealand's national identity and its literary evaluation have been correlated with the country's response to its colonial history. While it is not proposed that all selections for inclusion within anthologies have been made solely for ideological reasons - clearly the literary tastes and personal preferences of particular anthologists have also played a part in influencing their choices - a concern with presenting a particular impression of national identity has been an important consideration in determining the contents of collections.

The European settlement of New Zealand occurred in the historical context of a broader international colonial diaspora, of which the British settlement of New Zealand in the nineteenth century formed a later part. Ernest Gellner, in Nations and Nationalism (1983) 
discusses the impacts of the timing and circumstances of the initial formation of nations on the subsequent nature and 'shape' of their development of self-identity. New Zealand's settlement occurred during the period of European history when the ideal of a stronglydefined centralized state structure dominated political and economic ideology and practice. In Gellner's view, the construction of a defined sense of nationhood and the specific form this takes are driven in particular by historically-located psychological and emotional imperatives, and that 'national belonging', as a distinct concept, came to appear in the nineteenth century as being an essential and 'inherent attribute of humanity' (4). Gellner's definition of the 'idea of a nation' identifies two essential elements:

[men are of the same nation] ... if they share the same culture, where culture in turn means a system of ideas and signs and associations and ways of behaving and communicating. ... [and] if they recognize each other as belonging to the same nation ... nations are the artefacts of men's convictions and loyalties and solidarities [original emphasis] (7).

In New Zealand's case, however, these attributes of the nation have not been fully realized nor become 'solidarities' - while some consensus has existed as to which particular cultural characteristics are essential to form a recognizable sense of New Zealandness, and which poets and authors to recognize as being canonical New Zealand writers, there has been uncertainty around those located at the boundaries of the country's identity. While, as an island nation, the country's physical extent is clearly demarcated, the historical borders of its associations with its European past are more vaguely marked. The thematic concerns that have since dominated local literature can be traced back to this initial unstable and imprecise foundation based on the disruptive processes of colonization, and how the country has since been able to relate, as an entity, to its international cultural environment. 
Sinclair, reflecting in his History on these uncertainties of self-identification that were evident in the literature of the $1930 \mathrm{~s}$ and $40 \mathrm{~s}$, remarked that while 'these writers had at last accepted that they were New Zealanders', the question remained, however: 'what was the New Zealander?' Sinclair concluded that 'no ... stereotype exists' $(1988,336,337)$. His query remains unresolved - views as to which specific identifiers are to be deemed to epitomise New Zealandness have been diverse, mutable and often strongly contested among varying protagonists. Distinctly different and often irreconcilable versions of New Zealand national identity have dominated at different times and in varied contexts - for example, the contradictory essentialist mythology that the country represents both the meritocracy of an egalitarian workers' paradise and a physically and morally elite outpost of the European colonial project.

The narrative of this country's history is different in significant aspects from other comparable settler communities, including its closest neighbour in geographical place and time of settlement, Australia, and other earlier British colonies such as Canada. A major determinant of this difference was the timing of New Zealand colonization, which did not take place until the nineteenth century when British attitudes towards indigenous people, among other factors, had altered in some significant aspects from its earlier expansionist ventures. This historical difference, which occurred within the context of the larger international framework of Empire, and the effects that it had upon the development of New Zealand culture and the specific characteristics of local identity, have been the focus of several critical analyses.

Hugh Roberts, for example, in 'The Same People Living in Different Places: Allen Curnow's Anthology and New Zealand Literary History' (2003), assesses the influence of the circumstances of the country's history upon the 'shape' of the local canon, particularly in regard to the impact of Curnow's Book of New Zealand Verse (1945) within the body of local 
literature. Roberts reflects on the challenges of developing a distinctive New Zealand literature in an environment where the construction of a separate national identity has been complicated by a range of cultural, political, racial and aesthetic complexities and anxieties, without the occurrence of a defining act or event that indicates either its separation from, or its relationship to, its European heritage. He comments that, 'New Zealand is a country that fits awkwardly, if at all, in most theories of the origins of nationalism' $(2003,222),{ }^{12}$ because of its differences from otherwise analogous former colonies. This suggests that, in some respects, at least, the events of this country's history have been unique, and their impact on the development of a sense of identity has created complex issues that have not been experienced in the same way in other societies.

In the case of other nations constructed by European colonialism, indigenous populations have formed an effective Other in the historical processes of identity-formation of the dominant societal group (for example, the constructions in fictional and non-fictional accounts of native American peoples within the mythologies of the settlement of the American West in the nineteenth and early twentieth centuries). However, New Zealand's Māori population, after the period of initial colonial domination and suppression of effective resistance in the nineteenth century, has not been assimilated into this role as the reflected opposite of the settler European society. As Roberts points out, 'The Maori ... are a socially, culturally, and ethnically distinct group that has served as the focus of various anxieties for the pakeha community, but once dispossessed of most of their land, they were not seen as a threat to pakeha control of cultural and economic capital' [original emphases] (ibid). Pākehā New Zealanders sought other, external sources for a reflection of their difference and essential nature.

\footnotetext{
${ }^{12}$ Stephen Turner, in 'Settlement as Forgetting' (1999), and Patrick Evans, in The Long Forgetting (2007), are among others who have commented specifically on the differences between New Zealand's settlement process and that of other British colonies, and how in their perception this has influenced the development of a distinctive culture in this country.
} 
In the period from the nineteenth until the end of the twentieth century, there has been uneven reference to Māori culture and language in conventional New Zealand literary anthologies. Verse and short fiction by Māori writers commonly has been regarded as belonging within a specialist, exotic genre outside the mainstream of New Zealand literature, but not one that has provided a significant centre of positive interest for conventional critics. Alexander and Currie provided a Notes section in their 1906 and 1926 anthologies containing details of the Māori myths and words, and various local flora and fauna that were utilized as sentimental local referents in much of the verse collected. Some later twentieth century verse anthologies, including Curnow's Penguin Book of New Zealand Verse (1960), included acknowledgement of a separate Māori aesthetic form, adding brief sections of Māori-themed poetry in English translation. All three editions of Vincent O'Sullivan's Oxford Anthology of Twentieth Century New Zealand Poetry (1970, 1976 and 1987) included poems in English by Māori poet Hone Tuwhare, together with a glossary of Māori words and phrases used in the collection.

Ian Wedde and Harvey McQueen, in their 1985 edition of The Penguin Book of New Zealand Verse, expanded on Curnow's 1960 section on 'The Maori Tradition', including selections of Māori verse in both its original form as well as in English translation, an innovation which drew significant critical attention. ${ }^{13}$ The 1989 Penguin Book of Contemporary New Zealand Poetry: Nga Kupu Titohu o Aotearoa, compiled by Miriama Evans together with McQueen and Wedde, emphasized its incorporation of Māori literature within a mainstream anthology. Their selections included a large proportion of verse in Māori (drawing on work from twenty-five writers, almost a third of the total). This illustrated the editors' deliberate aim of promoting an alternative, future-oriented bicultural version of the

\footnotetext{
${ }^{13}$ C.K. Stead's strongly negative response towards Wedde and McQueen's 1985 anthology is discussed in Chapter Two.
} 
country's identity, as a challenge to the conventional monocultural characterization that dominated the canon. In the following decade, Bornholdt, O'Brien and Williams included selections of verse (in English) by Māori poets Keri Hulme, Roma Potiki, J. C. Sturm, Apirana Taylor and Hone Tuwhare in their Oxford Anthology of New Zealand Poetry in English (1997). In their act of specifying in the collection's title that its contents included only selections from the country's English-language tradition (including those from the several Māori poets it presented), the editors recognized tacitly that another tradition - that of the country's indigenous population - also existed in parallel with, or alternative to, that of the Pākehā.

However, with few exceptions, where references in 'New Zealand' anthologies to the existence of Māori culture have appeared, commonly that culture has been contextualized as a separate, distinct and minor artistic form, not one that is presented as an alternative or significant parallel to the mainstream of local literature. While this has been in part due to the difficulties of incorporating the oral tradition of its literary forms into a text-based medium, it emphasizes the extent to which the presence of Māori culture has been disregarded as an influence among the concerns of the development of a distinctive 'national' (that is, Pākehā) literature. The Māori population has not served as a defining Other for Pākehā New Zealanders - however, other countries, in particular Australia, have performed this role. In its particular historical and social context, that of a European settlement physically located in the far margins of the South Pacific, the concept of New Zealandness is commonly described in negative rather than positive descriptors (that is, it is defined in terms of what it is not).

This expression of identity in the form of its difference from other nations is a repeated trope in local writing. Frank Sargeson, for example, stated in his 1981 memoirs: 'Like so many of my fellow countrymen I had to visit Europe to discover that I was truly a 
New Zealander' $(1981,112)$. This illustrates the common experience of many New Zealanders of being able to identify and detail their national identity only in terms of distinguishing themselves from other national and ethnic groups. Other commentators also have commented that New Zealand is commonly styled in local literature in terms of its difference from other countries, rather than in discrete, positive national characteristics. For example, Māori scholar Jonathan Mane-Wheoki, reflecting on the nature of the selfidentifiers of European identity in New Zealand, concludes that 'Pakeha are the people who define themselves by what they are not. Who want to forget their origins, their history, their cultural inheritance ... to deny their origins so that we can all start off afresh' $(2010,10)$.

This desire of a people wanting to 'forget their origins', or at least to create an obliquely reformulated narrative of their beginnings here, is often attributed to the 'newness' of New Zealand - its lack of time to develop a clearly defined, sufficiently extensive history since its colonial period - expressed as placing the historical beginnings of local settlement within a tabula rasa, rather than as an inevitable product of its colonial history. There is, however, ambivalence evident in local historical and literary accounts of the country's commencement. While there is present the desire, observed by Mane-Wheoki and others, for New Zealand to deny or obscure the limiting aspects of its origins as a colonial settlement, there is also expressed an aspiration to claim its heritage and assert its association with the centre of European culture. These apparently contradictory aims contribute to the uncertainty and lack of clarity that are features of attempts to construct a discrete local representation of identity, and of the multiple forms in which it is portrayed.

While New Zealand's Māori population did not form an internally-located Other for the Pākehā community, Australia - both as a literary construct and in the form of its perceived political, economic, cultural and geographical 'reality' - has functioned in this role. Alan Mulgan, for example, noted this in Literature and Authorship in New Zealand (1943), 
referring to Australia's influence in constructing a sense of New Zealand's distinctiveness and commenting that ' $[\mathrm{y}]$ ou identify an Australian rather easily, but not a New Zealander, whom you probably place by a process of elimination. He is not an Australian ... therefore he is a New Zealander' (57). Similar statements that identify New Zealand in terms of its difference from Australia are common in the literature. Keri Hulme, for example, when asked in 1989 whether in her view there existed 'an identifiable New Zealand literature', described the notion of local writing only in terms of its difference from the Australian model, reflecting that: 'The language and the characters and the concerns are different, are literal worlds apart. Where the voice of the land in Australian novels comes through, it is very different from the voice of the land in New Zealand' $(1989,102,108)$. While significant uncertainties remain as to confirming other aspects of this country's self-perception, the literature indicates that, despite a past close relationship, there is now a firm consensus regarding the descriptor that, in cultural terms, New Zealand is 'not Australia' ${ }^{14}$

Frequently in the literature the condition of New Zealandness has been defined not in terms of a set of unique, positive characteristics, but by outlining its differences from other nationalities, suggesting that it is difficult to formulate the characteristics of the country's identity. Miles Fairburn, for example, in 'Is There a Good Case for New Zealand Exceptionalism?' (2006), argues against the case for the existence of a separate and distinctive New Zealand identity, asserting the view that this country's culture comprises a 'pastiche' that has been dominated by the influence of other countries, in particular Australia (2006, 146). Shaun Goldfinch, similarly, comments in 'Doing Business', an essay in Remaking the Tasman World (2008), that 'New Zealand's history and institutions ... are overwhelmingly derivative of Australia, Britain and North America. ... New Zealand's

\footnotetext{
${ }^{14}$ The extent and nature of New Zealand's past literary relationship with Australia is discussed in Chapter Five.
} 
uniqueness lies perhaps paradoxically in its unusual dominance by others' cultures' (161). These observations emphasize the extent to which the exigencies of the historical and social context within which New Zealand's development has taken place have formed barriers and complexities that have impeded significantly the ability of the country's Pākehā community to construct a distinct and separate identity. There have been a number of influential creative and critical writers over the nineteenth and twentieth centuries who have purposefully intervened in this process, attempting to influence its direction in promoting a particular concept of New Zealandness.

The country's cultural nationalists, including Curnow, utilized locally-produced cultural artefacts to construct a mythology of the nation's collective identity, and to mould and shape it into a specific form. This desire to promote a particular version of the country's self-perception has been a particular preoccupation of national anthologists, who often have regarded this explicitly to be the primary function of their position. Curnow asserted that the proper role of local writers was that of constructing literary versions of (desirable) 'possible New Zealands' $(1945 b, 1)$. Powerful figures in local literature, such as Curnow, employed the country's creative writing in the construction of their own versions of a national creation myth. These processes of mythologizing have been important to identity-construction beyond this initial stage of promoting particular narratives of the nation's genesis, and also have been applied to the formation and shaping of a conception of a New Zealand 'character'. Bell, for example, argues that New Zealand's sense of collective self-recognition has developed not 'organically' - that is, driven according to the influences and exigencies of historical events and social phenomena - but as an outcome of purposeful 'invention and myth-making' (1996, 3). That is, this country's self-perception is a construct, the result of interventions and narratives constructed by influential actors in the discourse of identity, not the outcome of the unmediated responses of a society to its history and context. 
Others have used similar terms to emphasize the view that concepts of New Zealand identity have been intentionally constructed and shaped by advocates of specific cultural positions - in particular Curnow - rather than occurring as spontaneous collective responses towards local circumstance. Roger Horrocks, in 'The Invention of New Zealand' (1983), discusses the ways in which Curnow sought to craft a specific version of New Zealandness in the editorial comment and the carefully selected contents of his anthologies, as well as his critical writing, referring to his part as having been that of 'a magician, a maker of fictions' (10). James Belich, also, in Making Peoples (1996), refers to the early effect of 'inventions' and 'myths' in New Zealand history and how these have been integral to the construction of particular portrayals of local identity. The concept that a major aim of New Zealand writers should be to actively engage in 'inventing' New Zealand was one that Curnow promoted specifically in his own role as an anthologist and critic. He stated the view in 1945, in his 'Dialogue by way of Introduction' in the first issue of the Year Book of the Arts in New Zealand, that at that time, 'New Zealand doesn't exist yet', and that it was to be 'created' by those involved in literature and the other arts $(1945 \mathrm{~b}, 2)$. It was to be the function of writers, among others, to purposefully construct a concept of a distinctive nation, and to determine the characteristics of how it was to be properly represented.

The particular context in which New Zealand has evolved as a nation, having a background of a colonial history that has been the source of continued uncertainty and ambiguity, and the difficulties of establishing its 'place' as a small, new, relatively isolated nation within an international cultural environment, have together undermined the processes of its development of a distinctive, unified identity. Within this complex social and cultural environment, the country's national anthologies of verse and short fiction have played a significant role, both in their content and reception, in the creation and shaping of the concepts 'New Zealand' and 'New Zealandness', in their various historical and contemporary 
perceptions. Along with a range of other modes of cultural expression, the anthologies have contributed to the development of New Zealand's collective identity over the twentieth century, and have been a determinant also in moulding particular aspects of the reflection of that self-identification. They have played a crucial part in the historical development of a local literature, being influential not only through the agency of the perceptions of New Zealandness reflected in their contents, but also those projected in editorial stances, and in the anthologies' critical reception.

These national anthologies have become the subject of competing discourses as to the existence of, and particular constructions of, New Zealand essentialism, and presented disputed notions of authenticity (autochthony) in local writing. An instance of this is provided in Vincent O'Sullivan's critique, presented in 'Funnier, meaner Sargeson beyond this good life' (1997), of the version of New Zealandness that was constructed in the creative and critical work of Frank Sargeson and his supporters. O'Sullivan considered that, rather than presenting a 'real' interpretation, as often claimed, Sargeson instead 'moulded a prescriptive view of what New Zealand writing should be', imposing 'a template on what [he] thought appropriate in depicting the country he was ... at odds with' (38). Such comments indicate that there has been no consensus among local writers as to which literary portrayals represent 'authentic' New Zealand experience; instead, a broad range of different, competing, versions of New Zealandness have been claimed over time by various creative writers and critics as being representations of its 'reality'. 15

The processes of reflecting upon and analysing this diversity of literary concepts of New Zealand identity have themselves become common preoccupations of local criticism. Alex Calder, for example, in The Writing of New Zealand: Inventions and Identity (1993),

\footnotetext{
${ }^{15}$ A discussion of the contention expressed in regard to the determination of what constitutes the 'real' in local literature, and defining an 'authentic' version of New Zealandness, is presented in Chapter Four.
} 
comments upon the disparity in imagery and narrative models of belonging that have been evoked in the discourse on national identity, and the multiplicity of ways in which 'various New Zealands have been invented and reinvented in writing', so that 'there are many descriptions, many ways of belonging' $(1993,9,12)$. Calder's analysis identifies the existence of a wide variety of different literary versions of New Zealand experience that have been promoted. Miles Fairburn, also, in his 1997 essay 'Mything our myths', discusses the wide variation in the range of different concepts of New Zealandness that have been portrayed in the local literature, observing that 'New Zealand did not have a unitary past, but a multitude of different local or regional pasts' - that is, there existed 'multiple "New Zealands". ${ }^{16}$

These competing narratives of identity have been mediated through differing literary forms and conventions (150). However, rather than the distinctiveness of regional variants in identity, such as those that have arisen in the diverse social and geographical areas of England - and even in those of a relatively newly settled country such as Australia - the array of formations in which New Zealandness has been defined in its literature has not, in general, illustrated clearly differentiated specific local 'types'. Instead this has caused a blurring of clarity in its features of identification, evading precise features of characterization. ${ }^{17}$

Most influential accounts of this country's historical literary development refer to a series of distinctive and increasingly diverse stages, commencing from an initial state of colonial dependence and immaturity, and progressing to a present achievement of distinctive cultural autonomy. Curnow, for example, outlined a version of this pattern in his 1960 Penguin anthology, referring to the beginnings of New Zealand literature as being inherent in

\footnotetext{
${ }^{16}$ Curnow had recognized the possibility that multiple versions of New Zealandness might exist, in his comment that 'some possible New Zealands glimmer in some poems', made in the introduction to the first Year Book of the Arts (1945b, 2).

${ }^{17} \mathrm{~A}$ number of regional anthologies of New Zealand verse were published in the late nineteenth and twentieth centuries. These are discussed in Chapter Two.
} 
'the Maori tradition, which is rooted in the antiquity of New Zealand'; this was followed by the 'colonial phases of the nineteenth century'; then, '[t]owards the end of that century there were surges of "national sentiment"'; subsequently, '[i]n the early part of the present century, poems by Katherine Mansfield, Eileen Duggan, and D’Arcy Cresswell may be said to mark the beginning of a true reorientation - away from colonialism and on towards the island nation of the past three or four decades' (19). In Curnow's view, it was in this latest period that the majority of the 'best' New Zealand verse was produced (ibid).

The concept that Curnow advances in his anthologies is that the development of national identity and of a separate New Zealand literature constituted a progressive move away from the 'falsity' of earlier notions of self-representation, and towards the achievement of cultural independence and the attainment of 'authenticity' in local literary expression. Patrick Evans, in his Penguin History of New Zealand Literature (1990), similarly outlines an account of the country's cultural progression that originates in a condition of colonial dependence, then moves through stages that culminate in the attainment of biculturalism, feminism and internationalism. A form of this evolutionary view is presented in Lawrence Jones's chapter 'The Novel', in The Oxford History of New Zealand Literature in English (1998) - his rubric lists 'The Pioneer Period, 1861-1889'; 'The Late Colonial Period, 18901934'; 'The Provincial Period, 1935-1964'; 'The Post-provincial Period, from 1965'; 'The 1970s and after'; and ends in a period of 'Internationalization'.

Other references to this concept of the generally progressive nature of New Zealand literature are made at different times in the various typologies of Eric McCormick, Alan Mulgan, H. Winston Rhodes, Keith Sinclair, Joan Stevens, Vincent O’Sullivan, Terry Sturm, Peter Gibbons, Owen Marshall and Fiona Farrell, as well as others. A particular example is evident in the form of the bicultural and bilingual organization of Wedde and McQueen's 1985 Penguin New Zealand Verse, which portrays a view that asserts the achievement, at the 
end-point of its period of review, of a distinctive and fully realized postcolonial identity. This presents a perspective of the country's historical development that outlines a steady progression towards greater openness and diversity, and waning provincial insecurity, as a mature sense of place is attained. It structures a chronological narrative that emphasizes developmental stages of (European/Pākehā) national identity that proceed through phases identified as settler/colonial (dependence), nationalist (provincial), and postcolonial (postprovincial), to the present 'bicultural' (independence).

Similar views have been presented in commentaries on local fiction as well as verse. Owen Marshall, for example, observes a pattern of achievement linking changes in the country's literature to developments in local identity:

Our writers today are free of the responsibility to create a unique national literature .... They have at once a greater confidence and sense of New Zealandness, and increased ability to be part of global literature including the use of overseas trends, issues and locations .... [O]ur first written fictions showed a British view of New Zealand, our contemporary writing shows a Kiwi view of our own country and the world $(2008,14)$.

Fiona Farrell, also, pictures a series of developmental literary stages commencing with the colonialist in the mid-nineteenth century and culminating in the internationalist in the late twentieth century. She construes New Zealand fiction as changing successively in response to

subtle shifts of influence - from the frilly Wordsworthian effusions of Maoriland to the clean, Deco lines of Mansfield, through the New Deal working-man monotone of Sargeson to Frame's transformative synthesis of narrative and metaphor to seventies feminist introspection to the cinematic cut and edit of 
more recent writing: a rich fusion of European, America and the Pacific $(2007,16)$.

While most historical analyses have identified in various ways this generally positive and inexorable progressive pattern of the development of New Zealand identity from colonial immaturity towards cultural self-determination, pluralism and independence, there is also evident in the literature an undercurrent that is less assured and more nuanced in its evaluation of present achievement. Towards the end of the twentieth century, some critics expressed a more cautious and less certain view regarding the inevitability of positive cultural progress and of the country's having reached a state of a distinct and definitive national identity. These suggest a model that, while acknowledging the country has progressed in concurrence with overseas developments and with internal economic, political, and social changes, also recognizes that early concerns and insecurities related to the country's recent colonial origination, its relative smallness in size of population, and its distance from larger cultural centres, as well as to other situational and historical factors, have remained integral to the nature of New Zealandness. These concerns are characteristically referred to only obliquely, yet they have at times been reflected openly in local literature - the editors of the 1997 Oxford Anthology, for example, refer to the poetry in its contents as portraying a narrative not of the 'triumphant evolution of consciousness from colonial dependence towards postcolonial national maturity', but 'a story of struggle ....' (xxii).

Patrick Evans, also, in The Long Forgetting: Post-colonial literary culture in New Zealand (2007), acknowledges that the development of local identity is subject to 'a much larger pattern, and ... a much longer process' than often are asserted in earlier accounts, in particular those of the cultural nationalists of the mid-decades of the twentieth century and their later adherents. The view of this process that Evans sets out in this later narrative differs from that which he outlined previously in his Penguin History (1990), presenting a more 
complex and layered portrayal of the country's social and cultural progress. In The Long Forgetting, he illustrates the broad range of factors, both internal and external, that have influenced the construction of a variety of different, often contradictory and conflicting, versions of New Zealandness in the changed context of the uncertainties and challenges confronting a small, distant, former colonial settlement located within a highly globalized environment.

This thesis examines these influences on the construction of differing concepts of New Zealandness, proposing an interpretation of the pattern evident in the development of New Zealand literature that presents it as an amalgam of progressivist with more diverse and multiform views. While progress and change can be perceived, as in any society open to natural processes of cultural maturation, there is also a coincident, iterative pattern of specific tropes of identity that are recurrent over time. This periodic returning to earlier questions of identity discloses, in the ongoing failure of their resolution, an underlying, persistent sense of insecurity and anxiety regarding the country's self-perception. Particular concerns that are intrinsic to the construction of New Zealand identity have been repeated, sometimes in different forms, throughout the body of local literature, so that notions of 'reality' are subject constantly to potential reconfiguration, rather than representing a condition of fulfilment, completeness and resolution.

The assumptions adopted in the thesis are informed by theoretical concepts proposing that notions of 'reality' are socially constructed. Representations of national identity, rather than being objective, naturally-arising accounts, are instead considered to be primarily subjective, resulting from the production of processes of interaction between perceiving subjects and their historical, social and natural environment. Formations of identity are plastic and mutable, and reactive to changes in socio-cultural variables as well as to the interventions of dominant individuals, while themselves impacting upon and influencing the context within 
which they are formed. ${ }^{18}$ In the case of New Zealand, its origins in colonization and subsequent processes of settlement have evoked a number of competing, antithetical strands in the narrative of its self-construction, which have undermined attempts to construct a unitary, generally accepted concept of national self-perception in the present.

The complexities and multiplicities evident in the pattern of the development of New Zealand identity are presented, for example, in the findings of James Belich in Paradise Reforged: A History of the New Zealanders from the 1880s to the Year 2000 (2001). In Belich's view, this development - a process referred to as 'the making of Pakeha' (16) underwent a series of recognizable 'great transitions' following the early settlement period from the 1880 s to the 1900 s, which 'saw the demise of the remarkable system of "progressive colonization" that created the Pakeha people and marginalized the Maori people in less than half a century' (11). Belich sees this period as being characterized initially by the achievement of a level of relative independence of nationhood, then a return to a state of lesser independence towards the end of this period (29).

Next, Belich observes the occurrence of 'recolonization', a process during which New Zealand's economic and ideological links were reinforced so that the country reverted to being a 'semi-colony of Britain' (11). He uses the term recolonization to imply 'the tightening of relations between "metropolis" and "periphery" after an era of mass settlement', and recognizes parallels with New Zealand's development in the colonial histories of Australia and Canada (11). In this phase, Belich observes that '[f]or a time, neo-Britons of the "white dominions" [including New Zealand] also saw themselves as "metropolitan"; they were co-owners of the British Empire and of Old British culture and heritage' (12). This era was followed by a period of 'decolonization' in the 1970s to 1990s, which Belich describes

\footnotetext{
${ }^{18}$ A discussion of the principles of this theoretical perspective is presented in Peter L Berger and Thomas Luckmann's The Social Construction of Reality (1966).
} 
as being a period of the country's internationalization, economic diversification, greater independence in foreign policy and collective identity, a 'broad socio-demographic "coming out" of difference', and an indication of an increasing degree of intellectual and emotional self-confidence.

However, this attainment of greater autonomy and economic self-determination was accompanied by what Belich viewed as a sense of 'insecurity, trauma and challenge', rather than the ultimate stage of achievement of national independence and cultural fulfilment (ibid). This period, which Belich terms '[r]ecolonial transnationalism' was followed at the end of the twentieth century by increasing internationalization and globalism, an environment which has challenged New Zealand's fragile cultural and economic maturity, which risks being 'washed away or made redundant by globalizing tides' (12). Belich therefore ends his assessment of New Zealand's development in 2001 on a note of uncertainty as to the determination of its status and achievement at that time, and to the nature of its future direction.

The account that Belich provides sets out the range of multiple and varied influences upon the formation of a New Zealand 'character' and identity - 'transnational and global streams join local and regional ones in the national whirlpool' - so it can be seen that both internal and external forces have shaped the structure of its national psyche and temperament, as well as its perceptions of landscape and sense of distance and apartness (19). This view outlines a complex and less deterministic account of the movement of events, in which earlier concerns regarding identity are repeatedly readdressed. While he outlines the evidence of progress that the country has made since its colonial settlement, there is also present the constant, lingering shadow of the problematic issues of the country's genesis.

This thesis argues that this pattern, of progress accompanied by a sense of anxiety related to its inception, is evident in the country's literature. New Zealand's national 
anthologies of verse and short fiction, together with the related discourse contained in the body of secondary literature incorporating their critical reception, have represented in microcosm the range of thematic issues confronting the development of contrasting versions of New Zealand's national identity over the past century. Its particular focus is on three major concerns identified within the literature surveyed: this country's unresolved determinations of the existence and particular characteristics of New Zealandness; the contestation between internationalism and provincialism (localism) as the site of New Zealand 'authenticity'; and New Zealand's ambivalent relationship with Australia. This analysis will illustrate the underlying uncertainties and anxieties inherent in the nature of a New Zealand identity, that, rather than having attained resolution in the achievement of qualities of internationalism, multiculturalism and independence at the conclusion of the century, remained inextricably bound upon the unstable foundations arising from its colonial history and subsequent insecurities related to its physical separation from the European cultural mainstream.

The thesis is structured to provide both a comparative analysis of the nature and context of selected iconic national anthologies over the period 1906 to 1997, and a thematic overview of the anthologies' contribution to the historical debate over claims to representations of national identity. New Zealand Verse (1906) was the first anthology for which the claim of being a national representation of local writing was made, and marked the site of commencement for the potential establishment of a distinctive New Zealand literature. The publication of this early collection formed a reference point against which the later anthologies defined their own particular editorial stance. At the end of the century, the 1997 Oxford Anthology of New Zealand Poetry in English provides a fin de siècle counterpoint to New Zealand Verse. It commences with selections from the late twentieth century and moves backwards in time to incorporate poetry from earlier periods, concluding with some of the 
country's earliest colonial verse. This retrospective format, together with the anthologists' editorial comments, suggests that the collection represents a point of an interim conclusion, offering an opportunity for self-reflection and reassessment of the status of the nation's search for identity, as New Zealanders 'looked to the past to find pertinent or viable meanings for the present' (1997, xxii).

The thesis seeks to fill a present gap in the historical record of the development of New Zealand literature, as, while a number of publications are available that provide substantial studies of other genres comprising this country's creative literature, and a range of monographs on individual anthologies and writers, there exists no comprehensive study focused on New Zealand's national literary anthologies, nor a separate consideration of their place in the historical development of the country's literature and its relationship to issues of national identity. The development of literary nationalism in New Zealand, and the dominant influence of Curnow during this period, have been the subject of analysis in a number of other major historical studies, including Stuart Murray's Never a Soul at Home: New Zealand Literary Nationalism and the 1930s (1998), and Lawrence Jones's Picking Up the Traces: The Making of a New Zealand Literary Culture, 1932-1945 (2003).

However, while these studies provide significant contributions towards the understanding of these aspects of local literary history and indicate the impact of this period of literary nationalism on the later development of New Zealand literature, their particular focus is on a more defined historical period (the 1930s and 1940s), and on broader aspects of New Zealand literature more generally during these decades. This thesis is different in its aims, in that it examines a longer period - the whole of the twentieth century - and has a specific focus on the country's national literary anthologies. The next chapter provides an analysis of the contribution of these collections to the development of New Zealand's sense of self-identity and of what should comprise a local literary canon. 


\title{
CHAPTER TWO: VERSIONS OF NEW ZEALANDNESS \\ IN NATIONAL ANTHOLOGIES OF VERSE
}

\author{
A nation is the same people living in the same place. \\ (James Joyce, Ulysses, 1922; cited in Curnow, 1945a, 25) \\ The ideas of nation, nationality and the like are \\ 'essentially contested' because any particular definition of \\ them will privilege some collectivities, interests and \\ identities and damage the claims of others. \\ (Calhoun, 1997, 98)
}

In the previous chapter, the historical context within which New Zealand literature has developed since the period of the country's first colonization, and the relationship of local literature to the processes of constructing national identity, were discussed. This chapter analyzes a specific aspect of that relationship - the association between New Zealand's canonical verse anthologies and changes in perceptions and representations of the country's national identity during the twentieth century. Over that period these anthologies made a major contribution, both in their content and critical reception, towards the construction of a distinctive sense of the concept 'New Zealandness', in its literary representations and also in the country's broader understanding of its meaning. They were also significant in formulating the notion of an identifiable New Zealand literature as an entity distinct from other literatures in English, and by determining its appropriate content.

The anthologies conveyed varying impressions of the nation's collective identity, and were important agents in shaping the particular forms in which, at different times, New Zealandness has been represented, rather than merely reflecting them. The often contentious reception and considerable body of critical discourse that some of the anthologies, in particular, invoked - such as that arising from Curnow's 1945 Caxton and 1960 Penguin verse collections, and later, with the publication of Wedde and McQueen's 1985 Penguin - 
were illustrative of the broader concerns and uncertainties of identity that were present in the country's self-perception that had persisted from the mid-nineteenth century, and had lingered, unresolved, until the end of the twentieth. While the terms of the discourse of identity and the variety of kinds of creative literature produced over that period clearly indicated cultural movement and change and a consolidating sense of nationhood, they were also, conversely, indicative of continuing concerns and insecurities linked to the circumstances of the country's colonial beginnings, and to unresolved issues of identity. These apparently contradictory aspects of New Zealand's self-perception are evident in the contents of the anthologies and in their editors' comments, as well as in the criticism they attracted.

At times anthologists have commented on the impact of their own role in shaping perceptions of national identity. Curnow, in particular, explicitly linked the development of what he considered real local literature, including his own, with the construction of a 'correct' portrayal of the country's national identity. He stated in his Introduction to the 1945 Caxton anthology that

We have begun ... to correct misconceptions of the nature and uses of poetry, the causes of which - like the causes of other national failings - lie in the less tangible circumstances of our first settlements and subsequent development (1945a, 14-15).

Reflecting in 1968 on his own editing and criticism, and what he termed the 'correct view' of the 'birth of poetry in New Zealand', Curnow stated: 'I am aware that my own writings ... have had a good deal to do with getting it established' $(1987,214) .{ }^{19}$ Vincent O'Sullivan, when reflecting on his selection criteria for his 1970 Oxford verse collection,

\footnotetext{
${ }^{19}$ Curnow's comment was first made in a 1968 conference paper, 'Distraction and Definition: Centripetal Directions in New Zealand Poetry'; this was later reprinted in Look Back Harder (1987).
} 
commented ironically that ' $[\mathrm{t}]$ hose writers without the true markings - traces of the vernacular, images of local density, evidence of Polynesian awareness, or whatever - may be less likely to be favoured when nationally-minded critics make their round-up' (xxiv). As well as providing an assessment of the role of others in shaping versions of New Zealandness, this also suggests that in his choices for his own anthologies O'Sullivan avoided privileging poems exhibiting such 'markings', applying different selection criteria as a corrective to those who produced accounts that he viewed as inauthentic. The editors of the 1997 Oxford Anthology of New Zealand Poetry claimed similarly that in national collections, 'what has been excluded or given prominence has often had to do with the progressive efforts to construct a satisfactory identity or contest existing formulations' (xxxv).

As the following sections of this chapter illustrate, some influential anthologists have promoted particular concepts of New Zealandness by accentuating specific aspects of local identity when selecting the contents of their collections, as well as in their editorial comments. They have advanced their own accounts as being accurate representations of New Zealandness, and have then utilized them as a filter for the measurement of literary value. Conflicting notions of the editor's responsibility towards reality and authenticity in local writing have been applied, in conjunction with aesthetic criteria, in determining which particular selections of authors and their work to include in national anthologies, and which to exclude, as well as in influencing the way in which New Zealand's literary history should be read. The versions of local identity that were constructed by dominant anthologists over the twentieth century determined not only the structure of a local literary canon but also acceptance of a particular set of imagery and a mythology that has influenced perceptions of the nature of New Zealand experience. 


\section{Major New Zealand Verse Anthologies 1906-1997}

\section{New Zealand Verse (1906), and A Treasury of New Zealand Verse (1926)}

The concept that a literary anthology should function as a specific locus for the representation of the nation's identity was first promoted by W.F Alexander and A.E. Currie in New Zealand Verse (1906), which formed part of the Canterbury Poets series of 'national' anthologies produced by the London-based Walter Scott Publishing Company. Alexander and Currie made explicit that their aim with New Zealand Verse, and its revised and expanded edition, A Treasury of New Zealand Verse (1926), was to contribute towards constructing in what they termed the 'new land' a distinctive, separate character, and proposed that a new nation required its own literature (1906, xiv, xv). They dedicated the book 'For New Zealand', and in their introductory comments outlined their purpose that the anthologies would contribute to the progress of nation-building, as well as to developing a body of identifiably local writing:

The second generation has still before it the task of establishing the nation whose foundations were set by our fathers.... There is a time ... when New Zealand will be assigned a place among the nations ... when New Zealand books ... will gain some repute and note in the civilized world. ... and may be helped by the labour of ... [its seers of visions] towards the deep-breasted fullness of mature nationality (1906, xiv, xv).

Prior to the publication of New Zealand Verse a number of collections of regional writing had been produced, indicating that cultural and emotional identity in the nineteenth century, particularly in South Island communities, was focused more strongly on closely-held social and geographical affiliations rather than identification with a sense of the entire country as an entity. These included the anonymously compiled Literary Foundlings: Verse 
and Prose collected in Canterbury, New Zealand (1864); ${ }^{20}$ A Book of Canterbury Rhymes (1866), compiled and edited by W.P. Reeves and J. Ward; a second, enlarged edition of Canterbury Rhymes, by Reeves, in 1883; O.T.J. Alpers's The Jubilee Book of Canterbury Rhymes (1900); and the annual poetry supplement of the Otago Witness. A number of early magazines such as Zealandia, New Zealand Illustrated Magazine, Triad, The Spike (Victoria College Review), Canterbury College Review, and Otago University Review had included a variety of regionally-oriented creative writing.

At the time that New Zealand Verse was published in 1906, a range of expressions of nationalism and the desire to construct a recognizable collective identity, distinct in particular from Australia (albeit one retaining indispensable cultural, political, trade and commercial links to Britain), were being asserted by the settlement, which was then still a British crown colony. Earlier, Thomas Bracken's verse collection with a national interest, Musings in Maoriland (1890), had been published in Dunedin, with an extended introduction by Sir Robert Stout entitled 'The Rise and Progress of New Zealand' which outlined the development of the settlement's character and the 'growth ... of a nation' (1). In 1901, New Zealand had declined an invitation to join the Federation of Australian States, choosing to remain politically independent from a broader Australasian region, until in 1907 it was granted Dominion status by the British government. The International Exhibition, held in Christchurch from November 1906 until April 1907, provided a significant forum for demonstrating the country's developing cultural nationalism, as well as its agricultural and other achievements, attracting a large number of visitors, both local and overseas, over the five-month period that it was open. ${ }^{21}$ At the event, the country's sense of growing cultural

\footnotetext{
${ }^{20}$ Literary Foundlings has the subtitle: Published with an anonymous editor in Christchurch by The Times Office in 1864.

${ }^{21}$ See, for example, J.O.C. Phillips’s essay, 'Exhibiting Ourselves: the Exhibition and National Identity’, in Farewell Colonialism: The New Zealand International Exhibition, Christchurch, 1906-07, ed. John Mansfield Thomson, 1998.
} 
maturity was depicted in displays of local fine art and artistic performances such as those by New Zealand's first professional symphony orchestra. These were intended to illustrate the new Dominion's cultural accomplishments and to attain recognition within the mainstream of European artistic traditions (even if as an imitative, very minor and distant participant). Alexander and Currie's anthology appeared in this context of the country's emergence from a sense of colonial dependence, and reflected its sentiments of ambivalence both towards its colonizing parent and its own geographic and social reality.

While a range of earlier publications, both in New Zealand and Australia, ${ }^{22}$ had provided a variety of outlets for locally-produced poetry, New Zealand Verse was the first major collection intended to be broadly national in its scope, the editors stating that its aims were to be 'representative of the full body of New Zealand verse' from its beginnings, ${ }^{23}$ and to help the future 'progress of New Zealand literature' (1906, xxxii). Despite the country's small population at that time,${ }^{24}$ the contents of the anthology comprised contributions by fifty-five individual poets, a third of whom were women. The selections were drawn from New Zealand, Australian and English publications, dating from 1861 with early verse by Charles Bowen and John Barr, and concluding in 1903 with that of Blanche Baughan and Will Lawson.

The arrangement of the contents within the collection makes no distinction between writers of the early or late colonial period - they commence with William Pember Reeves's 'New Zealand', and thereafter the selections are arranged loosely by topic, theme and type, the editors stating that ' $[\mathrm{n}] \mathrm{o}$ attempt has been made at chronological arrangement $\ldots$ as dates

\footnotetext{
${ }^{22}$ Refer to Chapter Five for a discussion of the role of Australia in the development of New Zealand literature.

${ }^{23}$ This statement is made in the Preface to the second edition of the anthology (n.p.).

${ }^{24}$ Census data at the turn of the century indicate that the country's total population at that time was under one million - refer to the demographic study of this period provided in Rogers, 2008.
} 
would only mislead' (xviii). ${ }^{25}$ Asserting the collection's status as being representative of the nation, they state that '[a]11 the verse in this book is written by New Zealanders', and that they excluded those who 'in leaving New Zealand practically shook off their nationality'. However, within this criterion they had accepted the work not only of those they termed 'natives' but also of 'pilgrims' and 'New Zealanders by adoption' (xvi). Six of the poems included were noted as being previously unpublished.

Earlier anthologies that included local verse either were limited in their scope to specific New Zealand provinces, or were 'Australasian' in nature, being inclusive both of Australian and New Zealand work. In the tone of their introductory comments, the editors of New Zealand Verse made implicit claim that their book represented the literature of the nation, a contention they made explicit in the Preface to the 1926 second edition. In its use of the term 'New Zealand' in the anthology's title, and its dedication to the country collectively, its publication could be considered as a significant symbolic cultural act indicating affirmation of the country's identity as a separate entity, which, in its historical context, indicated the country's first step in literary form towards its emotional secession from a colonial parent.

While the anthology did signify some aspects of an assertion of independence, however, these were limited, and the sentiments expressed by its editors were more indicative of a strong desire for acceptance and inclusion within the body of English literature, even as an inferior sub-stream, than for the representation of separation, exclusion and an emphasis on difference. It was published in London and New York, and despite the suggestion in its dedication, the editors' introductory comments indicated that its intended audience was overseas rather than in New Zealand. The portrayal of the country's identity presented in its

\footnotetext{
${ }^{25}$ The final poem in the anthology is Seaforth Mackenzie's 'L'Envoi', an ode to the game of rugby, which already at that time had become an important focus of New Zealand's self-representation.
} 
contents clearly was intended primarily to be directed outwards, to an English readership, rather than internally to function as a speculum reflecting a self-image towards the nation itself. Much of the verse presented an idealized, scenically colourful and sentimental construct of 'Maoriland', ${ }^{26}$ which would collectively portray to an outside readership a depiction of a remote English settlement located in an exotic Pacific landscape, translated into conventional Victorian literary modes as an imitative, minor current within the mainstream of English culture. At the time of its publication, the majority of the country's Pākehā population were locally-born, ${ }^{27}$ but its cultural and social institutions remained firmly structured on a foundation of English principles, values and tastes, and these were reflected in the anthology. For example, for the assistance of the overseas reader, or a new settler, additional material provided in the anthology included a section of explanatory notes, with details of Māori myths and words and a guide for their correct pronunciation, as well as factual information regarding New Zealand flora and fauna, local figures and landmarks, and historical events. $^{28}$

The later evaluation of Alexander and Currie's contribution to local literature was mixed. In his Introduction to his 1945 Caxton Verse, Curnow stated that their aim of being 'representative of the full body of New Zealand verse' was 'sensible and practical ... modestly pursued and (for the time) largely achieved' (19). However, he was dismissive of the significance of their collections with his comments that while " $t]$ here were good reasons of an historical kind for the bulk and inclusiveness of the Treasury ... those reasons are not available now', and that 'precedent ... has been no guide in planning a New Zealand anthology' $(14,16)$. O'Sullivan, in his 1987 Oxford Twentieth Century New Zealand Poetry, commented that while 'Alexander and Currie's New Zealand Verse in 1906 [was] New

\footnotetext{
${ }^{26}$ Jane Stafford and Mark Williams provide an extensive analysis of this genre and period, and its place in New Zealand's cultural history, in Maoriland: New Zealand Literature 1872-1914 (2006).

${ }^{27}$ Refer to Frank Rogers, 'The New Zealanders: the decline of immigrant dominance in New Zealand' (2008).

${ }^{28}$ The practice of including such explanatory information continued until the early 1980s.
} 
Zealand's "first anthology", [it] presents a "vision" of New Zealand that is "false" (xviii). O'Sullivan's assessment implies that while he considers Alexander and Currie's construction of the local landscape and experience, mediated through the colonists' distorted lens, to be flawed and inaccurate, he proposes instead that there does exist a 'vision of New Zealand' that is 'true' - and that this correct and accurate vision is one that is properly portrayed in other, later anthologies, including his own. ${ }^{29}$

The depiction of the country's literary identity proposed by Alexander and Currie was substantively different from that presented by the cultural nationalists of a later generation. The colonial and early twentieth-century poets they had included in their two collections were almost entirely excluded from later national anthologies. Arnold Wall, who was included by Alexander and Currie in both their 1906 and 1926 collections, and J. C. Beaglehole, who appeared in the second of these, were the only poets they had selected who were also chosen by Curnow for his 1945 anthology, for which he included only work published from 1923. Later, in addition to Wall, Curnow included in his 1960 Penguin collection only five other poets who had also appeared in the 1906 New Zealand Verse: Arthur H. Adams, Baughan, Charles Bowen, Alfred Domett, and Reeves ${ }^{30}$. Of the additional poets Alexander and Currie had included in the 1926 Treasury, only Edward Tregear and Mansfield also appear later in Curnow's 1960 Penguin anthology.

In his almost complete rejection of this earlier, formative literary tradition, Curnow produced the illusion of distinct, discretely-bounded historical eras - the sense that New Zealand as an identifiable nation was created not during the early nineteenth-century processes of its British cultural and political colonization, but much later, commencing only from the 1920s and 1930s. When colonial verse 'reappeared' in the literary record in the late

\footnotetext{
${ }^{29}$ Chapter Four presents an analysis of competing versions of 'reality', as these have been constructed in New Zealand literature.

${ }^{30}$ Beaglehole was not included by Curnow in his 1960 Penguin anthology.
} 
twentieth century, it was separately categorized and isolated from the mainstream of local literature. This is evident, for example, in the publication of McQueen's The New Place (1993), where colonial verse is treated not as a vital part of the country's formative literature but as a distinct (and somewhat quaint) sub-genre, separate and fundamentally different from later twentieth-century work. Recent analyses that contextualize colonial verse within the history of the country's (Pākehā) origins, and consider its place in the development of a local literature since that time, are provided in Jane Stafford and Mark Williams's Maoriland: New Zealand Literature 1872-1914 (2006), and their Auckland University Press Anthology of New Zealand Literature (2012).

\section{Kowhai Gold (1930)}

Four years after the publication of Alexander and Currie's 1926 Treasury, Quentin Pope brought out Kowhai Gold (1930), which was subtitled 'An Anthology of Contemporary New Zealand Verse'. As with its predecessors, it was published overseas, in this case by Dent of London and Dutton of New York, and Pope's brief introductory comments indicate that it was directed primarily at an audience outside New Zealand. In his Introduction, in which he set out his purpose in its compilation, Pope indicated his view that the poems in his collection represented not a separate local literature but one that properly belonged within the body of 'Modern English verse', albeit as merely its minor sub-stream (vii, viii). Pope distinguished the poets he selected from those published in earlier collections (vii, viii). Unlike Alexander and Currie, who had claimed their anthologies to be 'representative' of the entirety of local poetic achievement, and had included selections drawn from a broad range of nineteenthcentury poets, Pope incorporated verse only from the previous decade, from those that he claimed to portray the "poetic impulse which has visited the country in the few years since the 
[Great] war' (ibid, viii). He considered that with his own more qualitative and exclusive collection, 'the foundations of a New Zealand literature are being laid' (vii, viii).

Pope intended with the publication of Kowhai Gold to encourage the development of a national literature, and to contribute towards moulding and shaping a new canon of verse based on recent work produced after the colonial period. It comprises selections from the work of fifty-six poets, nine of them women, drawn both from local and overseas publications produced over the period 1899 to 1929, with the earliest being Adams's Maoriland, and the most recent, Robin Hyde's The Desolate Star and Duggan's New Zealand Bird Songs. Thirty of the poets chosen by Pope had not appeared in Alexander and Currie's 1926 Treasury. A significant number of the poems had been published previously in Australian publications, indicating their generic form and content, and acceptability to a trans-Tasman readership. ${ }^{31}$ In the range of material Pope selected, some attempt is made at diversity of subject matter and style, but in its emphasis on presenting verse imitative of Georgian themes, tone and forms in a local setting, the overall effect is of a view of New Zealand that is not 'contemporary', even at the time of its publication, but one translated into an already outdated English poetic mode.

After its publication, Kowhai Gold became a negatively-inscribed focal point for subsequent anthologists, a marker of difference against which they defined their own selections. Glover in 1935 expressed his derision in Tomorrow for the local strain of the 'Georgians and their hothouse tradition', associating Pope's book with what he termed the 'feminine-mimsy' ${ }^{32}$ style of Charles Marris's series New Zealand Best Poems, which appeared from 1932 to 1943 (17). Curnow castigated Kowhai Gold for what he considered its failure of selectivity, its falsity and the inauthenticity of its representations of New

\footnotetext{
${ }^{31}$ Refer to Chapter Five for a detailed discussion of the trans-Tasman literary relationship.

${ }^{32}$ Glover used this descriptor in Hot Water Sailor (1962), 94.
} 
Zealandness (1945a, 56). Dismissing it in 1945 as being 'trivial if sincere', Curnow concluded that there were no valid reasons to justify what he regarded as the excessively large number of 'versifiers' included by Pope, in contrast to his own, highly selective collection, in which he considered he had applied 'a maturer, more exacting criticism in ... parallel with and in part a consequence of the appearance of more hopeful verse' $(1945 \mathrm{a}, 14)$. Later, he referred to Pope's book as comprising 'insipidities mixed with puerilities', and being a 'lamentable anthology' $(1960,22,57)$. Most others have registered a similar response towards the anthology, and have utilized it as symbolic of what was problematic with verse written prior to that which Curnow set as being the standard for what was 'true' in local writing. Stead, for example, in an article in Landfall, contemptuously compared Wedde's Penguin Book of New Zealand Verse with Pope's collection, stating: 'It is Kowhai Gold 1985 style - New Zealand poetry with Maori in its hair' $(1985,298)$. Wedde referred to 'the derisive function' that the kowhai flower 'had come to have in our literary indexing' (1985, 24). O'Sullivan also was dismissive of Pope's anthology, and of what he considered the failure of its contributors to look 'squarely at what was done, thought and felt' in the reality of New Zealand life (1987, xviii).

One of the few critics to provide an alternative, more positive assessment of Pope's collection was Trixie Te Arama Menzies, in a 1988 article in Landfall, 'Kowhai GoldSkeleton or Scapegoat?'. In this, Menzies responded to the earlier criticisms of Curnow and others by providing a contextualized assessment of the place of Pope's book within the cultural and literary history in which it was produced, and a detailed comparative analysis of its contents relative to that of other earlier and subsequent verse anthologies, including Curnow's, illustrating their commonalities in terms of the poets included. She concluded that, rather than being an unnecessary aberration, and the end marker of a literary 'divide' between stages in local literature, Kowhai Gold formed 'a valuable link in the continuum of 
anthologies' which commenced with New Zealand Verse in 1906 (Menzies, 1988, 20). Further, in Menzies' view, Curnow had not begun his own critical work in 1945 in a literary 'vacuum' (as Stead had asserted in 1985), ${ }^{33}$ but was instead 'continuing and shaping a considerable poetic tradition already in existence' (26). While Curnow's negative judgement of Kowhai Gold was in part based on the weak sentimentality of its vision of New Zealand, together with the generally poor quality of much of that anthology's contents, it was also bound up with his own views regarding the place of his own anthologies within a developing local literature, and in constructing a particular literary version of the nature of the country's identity that differed markedly from that which Pope had portrayed.

\section{A Book of New Zealand Verse (1945 and 1951), and New Zealand Verse (1960)}

Curnow's intention that his Book of New Zealand Verse 1923-1945 (1945) was to be substantively different from the several national anthologies that preceded it was made explicit in his editorial statements, as well as in the particular poets and selections of their work that he included. That it was directed principally at a local rather than overseas readership was evident in its being published not in England, like its predecessors, but by the Caxton Press in Christchurch, as well as in his extensive Introduction. In this, he cited Holcroft's declaration in The Waiting Hills (1943) that the task of New Zealand writers was 'to acclimatise the muse, to open their minds and the minds of their readers to influences that can be found in this country and nowhere else' ${ }^{34}$ Curnow stated that the book represented the point of commencement of a new, distinctively local literature, the first to portray in its contents a 'real' version of national identity - for its epigraph, he selected from W.B. Yeats's

\footnotetext{
${ }^{33}$ Stead's comment was made in Landfall 155, 1985, 294.

${ }^{34}$ Cited in Curnow, 1945a, 48.
} 
autobiographical work The Trembling of the Veil (1922) the line: 'my country was not [yet] born at all' (13). Of his own role, he wrote:

An anthologist may approach his task in the confidence, which he could not have had ten years ago, that verse has begun to be recognised as purposive, a real expression of what the New Zealander is and a part of what he may become $(1945 \mathrm{a}, 14,15)$.

In this and his two subsequent verse anthologies - a revised Caxton volume (1951), updated to 1950, and later the Penguin Book of New Zealand Verse (1960), which was published in England, Curnow set out his assertion of cultural nationalism. He formulated two major aims - to establish his own collections as the primary markers of the development of New Zealand national identity in literature, and to promote a particular version of the specific characteristics of that identity that he considered to represent New Zealand 'reality'. In the 1945 collection, Curnow's Introduction comprised almost a quarter of the total volume of pages of the anthology. In addition he allocated a further thirteen pages to his own verse, which, with those of R.A.K. Mason and Ursula Bethell, was the largest section dedicated to any of the poets in the collection. Clearly he intended that the book would be not only reflective of his concept of New Zealandness, but would contribute purposefully towards creating it.

The publication of his Caxton anthologies was received both by contemporary and subsequent critics (with some exceptions) as marking the point of commencement of New Zealand literature and the establishment of Curnow as its dominant figure. Peter Simpson, for example, in a review in Islands of Wedde and McQueen's 1985 Penguin anthology, assigned Alexander and Currie's anthology to 'pre-history', and asserted that 'one can date the modern history of New Zealand poetry (in so far as it is encapsulated in anthologies) from $1945^{\prime}$ ', referring to Curnow's first Caxton collection as being 'seminal' to the development of 
a local canon (Simpson, 1985, 156). Curnow's status was later reinforced with the appearance of his 1960 Penguin collection, which, while more inclusive than his earlier anthologies, and covering a more extensive period, continued his policy of limiting its selections to those that conformed with his clearly expressed criteria for a New Zealand literature.

In producing his 1945 anthology, Curnow firmly distinguished his collection from its predecessors, stating that his 'intention has been to cut our losses; to provide some ground upon which the worth of our verse can be estimated' (1945a, 15). Curnow's decision to commence the period covered in his selections only from 1923 was based on his assessment that 'Out from Sea-bondage', a sonnet which first appeared in Mason's manuscript collection In the Manner of Men in that year, was the earliest marker of an authentic local literature - of 'a facing up to reality' $(1945,16)$. In justifying his rejection of earlier work, Curnow asserted in regard to Mason that 'no New Zealand poet has proved so early his power to say and his right to speak' (ibid, 55). Applying a highly selective policy to the work he deemed to be fit for inclusion in his anthology, Curnow stated that his aim was to include only 'those poets whose work seems to me to serve, in New Zealand, what I take to be the purposes of good verse' (ibid, 15). In his judgement, this descriptor applied to the work of only the sixteen poets whose selections he included in the 1945 anthology, including himself. The only women among that very select group were Bethell and Hyde; to these two, Curnow added only Ruth Dallas in his 1951 revised edition.

Mansfield's Poems had been published posthumously in 1923, the year of her death, ${ }^{35}$ thereby appearing within the period Curnow set for the scope of his 1945 and 1951 Caxton collections, but none of Mansfield's verse was included in either book; she was later

\footnotetext{
${ }^{35}$ Mansfield's Poems was published initially in London by Constable in 1923, and in New York by Knopf in the following year.
} 
represented by a single poem, 'To Stanislaw Wyspianski', in his 1960 Penguin anthology. ${ }^{36}$ Eileen Duggan did not appear in any of Curnow's collections; however, despite referring to her work as having the 'effect ... of an emotional cliché' and being 'strained', he stated in a footnote that he had wished to include particular selections of her poems, but that she had refused her permission for him to do so $(1945,25) .{ }^{37}$ Curnow's almost complete exclusion of women poets was one of the factors underlying the lasting, and often rancorous criticism provoked by his particular concept of the 'reality' of New Zealand experience portrayed in his anthologies.

In 1951 Caxton produced a revised and updated edition of the 1945 anthology. This added a separate section of 'Additional Poems' to the contents of the earlier volume. The period covered by the later collection extended its scope to end in 1950, and added a further seven poets ${ }^{38}$ and forty additional poems, while leaving in all the original selections with the exception of several changes to Brasch's section. ${ }^{39}$ Curnow also added on to his original Introduction a two-page editorial 'Note on the Second Edition', in which he further emphasized the view expressed in the earlier collection that the major function of the anthologist was to critique and correct erroneous literary versions of national identity, and to promote instead an 'authentic' account. He stated that a 'dilemma' confronting poets in their attempts to properly reflect New Zealandness in their verse had arisen, 'with that long refusal or inability to engage in poetry as a present adventure, so that outworn fashions were mistaken for traditional values, and the paraphrasing of scenery for a native poetry' (1951, 48).

\footnotetext{
${ }^{36}$ Refer to Chapter Three for an analysis of Mansfield's problematic place within New Zealand literature.

${ }^{37}$ Peter Whiteford notes in his 2008 biographical essay on Duggan that in a letter to W.F. Alexander explaining her decision, she had stated that 'their New Zealand is not mine' (123).

${ }^{38}$ These additional poets are Rewi Alley, Arthur Barker, Ruth Dallas, William Hart-Smith, Keith Sinclair, Kendrick Smithyman and Charles Spear.

${ }^{39}$ Curnow states in his 'Note' to the 1951 edition that the changes were initiated by Charles Brasch, 'to whose wishes I have deferred' (48).
} 
In Curnow's view, it was necessary that 'the shallower sentiments' prevalent in earlier anthologies of verse were to be 'expelled', so that a 'mature' ... "New Zealandness" might follow' (ibid). This extended to his inclusion in both the 1945 and 1951 Caxtons, and his 1960 Penguin, of selections from Cresswell, whose verse, Curnow suggested, had an 'affinity with Blake' (ibid, 30). His choice of Cresswell, and some others including Arthur Barker, are difficult now to reconcile with Curnow's own exacting criteria for what he termed 'good verse', particularly upon the basis of some of the particularly florid selections included in his anthology, such as 'Time Lags Abed' and 'O England' of the former, and the 'Ballad of Florentin Prunier' of the latter. ${ }^{40}$

With the 1960 Penguin Book of New Zealand Verse, Curnow continued and enhanced his tightly exclusive selection policy, presenting only thirty-six poets including himself as being representative of the more than a century of the country's production of verse. ${ }^{41}$ In addition, he included a section of seven early Māori poems in their English translations, which commence the arrangement of the contents, preceding a small selection of nineteenthcentury verse. He stated in his introduction that among its contributors whose work he considered to epitomize the search for 'reality' in local experience, the anthology presented a 'ground-pattern' that comprised only sixteen poets whose work comprised two-thirds of what he considered to be the 'best poems' that made up its contents (19). This particular group of poets, supplemented with a number of subsequent additions, provided what Curnow referred to as a 'core tradition' $(1960,19)$, and formed the basis of a canon of local poetry that, with only few exceptions, remained in existence at the end of the century.

\footnotetext{
${ }^{40}$ Barker appears in the 1951 Caxton.

${ }^{41}$ Curnow refers in his Introduction to there being 'thirty-eight names' comprising the number of contributors to the anthology $(1960,19)$; however, in its published version, there are only thirty-six, including himself. Curnow noted that he had wished to include selections of Eileen Duggan's verse in the 1960 collection, but he regretted that 'this could not be arranged' (ibid, 67). As noted on page 59 supra, in the Introduction to his Caxton anthology Curnow had made a similar comment about Duggan's absence from that work.
} 
The 1960 Penguin was initially published in England, and later reprinted in its original version by Blackwood and Janet Paul in Auckland in 1966. In his fifty-one page introduction, in which he described at length his purpose in compiling the collection, Curnow claims that he was making the 'first really comprehensive anthology of my country's verse' (17), a statement dismissive both of earlier anthologists and of the large number of local poets ignored in its relatively sparse contents. His enduring influence over the structure of the local canonical group and the continuing legacy formed by the contents of his three collections can be observed in the selection policies and editorial comments of subsequent anthologists. C.K. Stead, in a contemporary review in Landfall of McQueen and Wedde's 1985 Penguin anthology, entitled 'Wedde's Inclusions', compared the relative prominence given to the twenty-two major poets in Curnow's 1960 collection (determined according to the space their work was allocated within the contents) with the contents of other major verse anthologies, noting that this was closely replicated by the compilers of the following major national collections - Vincent O'Sullivan, in his 1970 and 1976 Oxford anthologies, and also by McQueen and Wedde in their 1985 Penguin (the latter despite their self-proclaimed independence from Curnow's assertively nationalist literary manifesto) (295).

The majority of Curnow's 'core' group remained as a key foundational component of O’Sullivan's 1987 anthology, and also, later, of the 1997 Oxford Anthology of New Zealand Poetry in English - of Curnow's twenty-two 'foundational' contributors, only Charles Spear and Hubert Witheford were not included in the latter - so that these poets can be seen to comprise an enduring nucleus that forms the basis of a local canon. The changes over time in the composition of the anthologies are, therefore, due primarily to generational changes, with the work of more recent poets being added into the later anthologies as they appear, rather than any ideological difference on the part of the anthologists at variance with Curnow's prescription. 
In the representation of New Zealandness that Curnow portrayed in his introduction to the anthology and in its particular selections, he indicated that it was focused towards an overseas readership at least as much as to New Zealanders, an objective which was noted by contemporary commentators. Stead, for example, observed in a 1985 article in Landfall that Curnow's statements on national identity had been expressed not merely for the consumption of the local literary scene but were 'addressed to a wider world' (290). The anthology includes a section entitled 'Some New Zealand Words and Names', which includes a summary of historically important New Zealand figures, including its past premiers, geographical places of interest, and descriptions of New Zealand fauna and flora. In addition, a ten-page 'Note on 'New Zealand Verse and the Maori Tradition', and a section discussing 'Maori poetry', are provided, which set out a detailed summary of Māori pronunciation, a history of the scholarship and literature focused on Māori verse, its translation and publication, and an account of the portrayal of Māori legends and mythical figures in Pākehā verse.

In his inclusion of a selection of indigenous verse (in its English translation) in the anthology, Curnow suggests that in its contents he has sought to provide an inclusive coverage of all that is of value in the history of New Zealand verse from its earliest beginnings up to the time of the book's publication. However, the vision of New Zealandness that Curnow presented was not one that was universally accepted, either at the time of its publication or subsequently, and it provoked a range of dissenting voices. Keri Hulme, for example, commented in Landfall in 1985 that she considered the version of New Zealandness that Curnow had portrayed in the contents of his anthology to be unrecognizable, being 'quaint and removed from my reality' (303). Also inciting contention was Curnow's continuation of his pattern of finding only few women poets within whose verse he felt able to recognize 'something of ourselves' (Curnow, 1964, 87). Although in the 1960 Penguin he 
had extended the number of women to seven, ${ }^{42}$ having included only two in his 1945 anthology, this remained a small fraction of the number of poets represented in the 1960 anthology, and also of all the female writers whose verse had been published over the more than a hundred year period of the anthology's scope.

Louis Johnson was among the group of local poets whose perception of local experience contrasted strongly and openly with the view that Curnow portrayed in his anthologies, although Curnow did include a section of Johnson's work in his 1960 Penguin anthology. In direct response to the particular 'mythologizing' of New Zealandness that Curnow presented, and the rejection from Curnow's 1951 Caxton anthology of a number of new poets whose work failed to conform with Curnow's view of what represented the 'reality' of a 'genuine' local literature, Johnson established the New Zealand Poetry Yearbook series which ran from 1951 to 1964 . Over this period, the Yearbook published a number of the new poets who were excluded by Curnow, including more women and a wider range of male poets, and a greater variety of topics and styles of poetic expression. His focus was also on the group of Wellington poets who saw their interests as being displaced by the publishing dominance of those of Auckland and Christchurch.

However, apart from providing a venue for publication of a large number of writers rejected by Curnow, such as Peter Bland, Elsie Locke and Barry Mitcalfe, among many others, Johnson was unable, eventually, to provide any serious challenge to Curnow's position of authority. Johnson's choices for publication often were selected on the basis of his policy of inclusivity rather than their literary value; the Yearbook received a mixed contemporary critical response, and its reputation diminished with the end of the series in the mid-1960s.

\footnotetext{
${ }^{42}$ As referred to previously, Curnow had wished to include an eighth, Eileen Duggan.
} 


\section{An Anthology of New Zealand Verse (1956)}

The first of the Oxford University Press series of New Zealand verse anthologies was Robert Chapman and Jonathan Bennett's An Anthology of New Zealand Verse (1956), which was published both in Wellington and London. The editors stated that their aim was that of 'surveying New Zealand verse from its beginnings' to present a broadly inclusive overview of local poetry produced over the period commencing with early colonial writers and continuing up to the present to include those contemporary with the time of its publication (xix). Rejecting the limitations of the cultural nationalist paradigm imposed in Curnow's Caxton anthologies, Chapman and Bennett's collection was more closely attuned with Johnson's focus on 'universal concerns', the editors stating that local poets now 'feel so at ease with their environment that they can simply assume it', writing poetry in which 'New Zealand patterns of life and thought are fused without effort' (xxiv). Chapman had earlier set out, in his 1953 essay in Landfall, 'Fiction and the Social Pattern', his own view that the proper function of literature should be to present a normative mirror to society in the form of critical realism.

The editors' range of selections, unlike Curnow's 1945 Caxton anthology, included a sample of nineteenth century and a number of early twentieth century poets. It was also more representative of the work of younger, contemporary poets, many of whom had not been included by Curnow. In their Introduction they considered the issues, '[w]hat do the words 'New Zealand verse” mean?', and what 'distinctiveness' should portray in a local literature concluding that "what we share with the English-speaking world in general is far more important than the ways in which we differ' (xxiv). In their view, the construction of a New Zealand literature involved the 'task of modification' of the 'shared stock' of the 'Englishspeaking world', and that its 'beginnings' in this country could be dated from the writing of 
the colonial period (xxv). In the explicit expression of this perspective, together with their particular choices of poets and their work comprising its contents, they had aligned their anthology with the model of New Zealand literature presented earlier by Alexander and Currie, rather than that of Curnow in his 1945 and 1951 collections.

\section{An Anthology of Twentieth Century New Zealand Poetry $(1970,1976,1987)$}

The later Oxford verse anthologies that Vincent O'Sullivan edited and compiled presented a position on local literature quite different from that of Chapman and Bennett, whose 1956 Oxford was aimed at chronological inclusivity and had encompassed the early colonial period with selections from the poetry of the 'pioneers'. The three successive editions of O'Sullivan's Oxford Anthology of Twentieth Century New Zealand Poetry commenced their scope with verse dating from the early 1900s, with 'Te Whetu Plains', a frequently anthologized poem by Tregear, ${ }^{43}$ and with selections from Baughan and Adams. In regard to whether, as an anthologist he observed a discernible 'tradition' in New Zealand verse, O'Sullivan considered instead that he saw 'strong individual poets working on their own terms' rather than 'a drift towards collective evidence' (1987, xxiii). O'Sullivan's aim was not directed towards presenting an inclusive general survey of local verse, nor entirely indicative of the exclusivist selection policy of Curnow's 1960 Penguin collection; instead his choice of selections reflected a position somewhere between these two, that O'Sullivan referred to as a necessary 'winnowing' (1976, xxix).

However, while the bulk of O'Sullivan's selections from the decades up to 1960 conform with Curnow's choices in terms of particular poets, as discussed earlier in this chapter, he also made a number of idiosyncratic choices of less mainstream writers, for

\footnotetext{
${ }^{43}$ K.R. Howe discussed the dating of 'Te Whetu Plains' in a 1987 essay in Journal of New Zealand Literature.
} 
example Peter Bland and Raymond Ward who, although having been published prior to 1960, had not been included by Curnow. Also, the relative prominence O'Sullivan accorded to individual writers, in terms of the number of poems selected, varied from Curnow's in some cases. For example, O'Sullivan allotted approximately the same space to Charles Spear (with twenty poems) as Curnow (twenty-two poems), and Baxter (twenty-one), while more than Brasch (eighteen poems) and Mason (seventeen).

The contents of the first (1970) edition of O'Sullivan's Oxford anthology, comprising work from forty individual poets, provided the foundation also for the second (1976) and third (1987) editions. The two later versions were updated with additional poets selected from subsequent years, so that by 1987 the contents had been increased in size with a further seventeen added, to conclude with a total of fifty-seven contributors. Emphasizing the anthology's focus on more recent decades, O'Sullivan noted that the majority of the poets were still living at the time of publication (1987, xxiii). O'Sullivan's two later Oxford collections were published in New Zealand, but, as in the case of earlier anthologists, he indicated an awareness of their potential for an overseas readership, including, for example, a two-page glossary of basic Māori terms.

Whereas Curnow and most other anthologists explicitly outlined their particular view of the nature of a 'genuine' New Zealand literature, and applied it in their selection policies, O’Sullivan denied adopting this approach, claiming that instead of selecting 'a body of verse on lines that follow the contours of the country's development ... that provides material for the sociologist and historian', he had included work 'simply because it seems good poetry' (1987, xvii). However, O’Sullivan's claim ignores the fact that during the twentieth century much of what was deemed by anthologists to be 'good poetry' was based upon a measure of literary value that was related, overtly or obliquely, to concepts of national identity, as in the case of Curnow's own assessments. 


\section{The Oxford Book of Contemporary New Zealand Poetry (1982)}

Fleur Adcock's Book of Contemporary New Zealand Poetry (1982), following in the contours of O'Sullivan's 1970 and 1976 anthologies of twentieth century verse (which were in turn succeeded by his 1987 updated edition), continued the pattern of the authoritative national collection of local verse that was established in the Oxford series, albeit one that was considerably smaller in size and more self-limiting in terms of the period of its focus. In her role as editor, Adcock makes particular reference to the influence of the contents of O'Sullivan's earlier collections on her own selection decisions, and emphasizes their commonalities (ix). With its focus on contemporary work, however, the chronological range in Adcock's anthology is much narrower than O'Sullivan's - whereas the latter encompasses selections drawn from the whole of the twentieth century up to the time of its publication, Adcock's focus is on later work.

The concept of 'contemporary' that Adcock has applied is not explicitly defined in her Introduction, but its focus is on verse from the 1970s and early 1980s. The anthology comprises selections from the work of twenty-one poets, and provides the impression that a conscious attempt is made to present a 'balance' in regard to the representation of New Zealand writing in other anthologies. While the largest of the sections is allocated to Curnow (with eleven poems), this is closely matched by those of Lauris Edmond and Bill Manhire (nine poems each). The collection provides a varied range of selections, including a number of traditional 'iconic' pieces by Curnow and Brasch from their early collections, small sections from frequently anthologized poets James K. Baxter, Louis Johnson, Vincent O’Sullivan and Kendrick Smithyman, and newer writers including Murray Edmond, Alan 
Loney, Sam Hunt, Rachel McAlpine, Cilla McQueen, Elizabeth Smither, and Hone Tuwhare, among others.

In limiting its consideration only to work deemed by the editor as being ‘contemporary', Adcock was able to avoid an expectation of inclusiveness and representativeness, and for placing later writing in the historical and cultural context of its earlier phases of development. In this respect, it has some association of aim with Pope's Kowhai Gold (1930), Curnow's Book of New Zealand Verse (1945), Charles Doyle's Recent Poetry in New Zealand (1956), and Alistair Paterson's Fifteen Contemporary New Zealand Poets (1980), rather than those which encompassed a broader scope such as Alexander and Currie's New Zealand Verse (1906), Chapman and Bennett's Anthology of New Zealand Verse (1956), and Curnow's Penguin Book of New Zealand Verse (1960). Despite limiting her focus to contemporary work, Adcock in her Introduction acknowledges an awareness of an editor's essential duty in undertaking the role of national anthologist, and its important contribution to the construction of New Zealand's national identity. She emphasizes the necessity of an anthologist defining the particular characteristics and 'geographical guidelines' (ix) that comprise New Zealandness, and of establishing clear criteria for the 'rigid boundaries' required to identify her 'field of selection', which forms the basis for her collection (viii).

Adcock's view of her role as anthologist - that of being an active participant in shaping and defining a local literary canon - falls within the tradition of exclusivism that had been established earlier by Curnow, and followed by subsequent editors of 'national' collections. In a clear reference to Curnow's earlier manifesto defining local literature, Adcock sets out the criteria for her selection policy, outlining what she determines to be the purpose of such a collection in portraying an 'authentic' version of New Zealandness. In determining which particular verse to include, and which to exclude, Adcock's stated aim is 
to compile 'an anthology of native New Zealand poetry', in which 'the word "indigenous" needs to be understood as silently present in the title', seeing this not as 'chauvinism' but 'honesty' (ibid). Adcock discusses the problematic issue of the place of the expatriate writer within the local canon, concluding that her own work, along with that of 'several others' should be excluded as it 'has for many years been published abroad and belongs to a different tradition'. Adcock clearly did not extend her view regarding the problem of expatriatism to disqualifying herself from the role of editor of the anthology, a position with which some others took exception. Keri Hulme, for example, commented in a review in Landfall that Adcock's overseas base and 'lack of knowledge of who is writing what in New Zealand now' (original emphases) rendered her 'unsuitable' for that function (Hulme, 1985, 303). ${ }^{44}$ Adcock's Oxford University Press collection was published in Auckland, but it is indicated in its introductory comments and its selections that it was intended for a readership that extended beyond the local market, including aids for overseas readers such as glossaries of Māori words, phrases, place-names and mythology.

\section{The Penguin Book of New Zealand Verse (1985)}

Twenty-five years after Curnow brought out his 1960 Penguin volume, published in Harmondsworth, England, a new Penguin Book of New Zealand Verse (1985), compiled by Ian Wedde and Harvey McQueen, was published in Auckland. The editors of this later, locally-published Penguin clearly acknowledge Curnow's continuing legacy; references to Curnow's extensive influence over New Zealand letters have a prominent place in Wedde's lengthy, twenty-six page Introduction. Wedde links the contents of the later Penguin to the authoritative literary tradition established by Curnow, and also follows Curnow's pattern of

\footnotetext{
${ }^{44}$ For a fuller consideration of the place of the expatriate writer within the 'New Zealand tradition', refer to Chapter Three.
} 
setting out, in a lengthy introductory statement, a clearly-outlined manifesto for what constitutes a 'genuine' local literature.

However, Wedde also asserts that the later collection was intended to represent a distinct departure from the particular ideology of identity that Curnow had espoused. $\mathrm{He}$ refers to what he calls the "'here-anywhere" controversy' that Curnow's nationalist stance had provoked, stating that the 'problems [Curnow] raised are dynamic rather than soluble' (Introduction, 1985, 23). Wedde discusses the effects of the history of colonialism on the development of a local literature, and on New Zealand's wider identity in its international cultural context, implying that a consideration of all aspects of New Zealand experience are important in an assessment of how it should be expressed. He states that the anthology is aimed at a broadly representative inclusivity in its scope, as an alternative to Curnow's exclusivist focus. The implication of this different emphasis in approach is that the editors intended to present a revision of Curnow's policy, and to recover what they saw to be important developmental aspects of local literary history that Curnow had rejected. A significant part of their proposition was that an identifiable New Zealand literary tradition originated with the creative work of the country's indigenous inhabitants in their original Māori language, not merely from verse translated into the language of the settlers from the colonial period. In common with Curnow's 1960 Penguin, Wedde and McQueen's 1985 collection includes a section of early Māori verse. However, unlike the former, Wedde and McQueen present this verse initially in Māori, with a following translation in English. In addition, the 1985 Penguin includes a number of later Māori poets interspersed among the other selections. A nine-page introductory section entitled 'The Maori Tradition', by Margaret Orbell, is also provided.

While the editors attracted some positive response for their aim to present a collection more inclusive of poets peripheral to the mainstream, as well as what they considered to be a 
more equitable representation of the verse of Māori and women - Wedde referred, for example, to their aspiration to adjust the "context of a "New Zealand poetry" where ... [Pakeha] male hegemony has achieved the dubious status of orthodoxy' $(1985,51)$ - the anthology also invoked critical rebuke, notably a vitriolic response from Stead. In 'Wedde's Inclusions', Stead compared the 1985 Penguin anthology unfavourably with its 1960 predecessor by Curnow, stating that Wedde and McQueen had crossed 'battle lines' (Stead, 1985, 302). This censure was focused particularly on their inclusion of Māori verse in its original language, but also at what Stead refers to as Wedde's editorial claim that the contents of the anthology were intended to represent a challenge to the existing literary 'hegemony' and its basis in an accepted cultural 'orthodoxy' (Stead, 1985, 290). Stead dismissed the anthology with the assertion that

behind every word of Wedde's introduction quivers his fear of the charge of elitism, racism, sexism. It is a fear that clouds the vision, makes discriminations shifty, and blurs the edges of the prose ( ibid).

The acerbic tone of Stead's comments provided an illustration of the continuing power of the divisiveness within the New Zealand literary community that Curnow's legacy had sustained well into the late twentieth century, and the strong contention that it was still able to generate, even though, in his own creative and critical work, Curnow himself had moved on to addressing different questions of identity.

\section{An Anthology of New Zealand Poetry in English (1997)}

The last national anthology of New Zealand verse published in the twentieth century was the 1997 Oxford Anthology of New Zealand Poetry in English, compiled and edited by Jenny Bornholdt, Gregory O'Brien and Mark Williams. The editors' intention to differentiate their 
anthology from previous collections is firmly emphasized in its editorial stance, as well as its particular choice of contents and their unusual structuring, and also the explicit acknowledgement of its Pākehā orientiation in its inclusion of 'in English' in its title. In the arrangement of its selections, the contributors are presented in reverse chronological order working backwards from verse published in 1994 and ending with pieces from the early nineteenth-century period of European contact, and selections from John Barr and James Fitzgerald's settlement writing. In this way, the anthology provides a retrospective summary of New Zealand verse commencing with poetry from the late twentieth century and working backwards to conclude with selections from the early period of contact. Together, these effects suggest a reckoning with the state of development of New Zealandness, an attempt at a coming to terms with historical precedents, and a reflective assessment of what has been achieved in the present, forming a tentative statement regarding the position of the country's collective sense of self at the end of the century. This sense of summative review - an evaluative assessment of the achievement of the Pākehā colonial project in New Zealand - is indicated in the editorial statement that the anthology represents 'a whole history of poetry reflecting on the nature and usefulness of the cultural baggage brought with settlement' (Introduction, $\mathrm{xxi}$ ).

The editors are clear in their aim of linking the development of New Zealand's literature over time to changes in perceptions of the country's national identity since the time of its earliest settlement - they state in their Introduction:

By moving backwards in time we sought to reflect the energies, the tremors, that recent poets send back into the past. While the anthology contains a narrative, it is not one of the triumphant evolution of consciousness from colonial dependence towards postcolonial national maturity, but rather the story of struggle and interaction between different versions of where we are and 
how we perceive ourselves. The poems, however, are not simply the record of their historical occasions, part of the tale of the nation's unfolding history. They talk to each other as well as addressing the world, its history and its particulars (xxii).

This statement expresses a view of New Zealandness that rejects a singular, reductive vision of 'how we perceive ourselves', and is substantively different in tone from those of the rigid certainties of identity that were prescribed in Curnow's earlier Caxton and Penguin anthologies. The editors' aim is to present a view of 'a "New Zealand tradition", not as a single line of established greatness but as a field of multifarious influence, where the imagery and meanings of the past are continually being revised, revalued and recycled' (ibid, xxx). The characteristics of New Zealandness that are suggested in this 1997 collection do not reflect a straightforward narrative of progress and emancipation from the country's colonial legacy, and a clearly defined concept of nation, but one more complex, multi-stranded and imprecise.

The concerns expressed in the editors' reflections indicate that, in presenting a multiplicity of conflicting perceptions of self-representation, the anthology also reflects the insecurity, unease and dependency portrayed in earlier collections, rather than signalling a new, more relaxed attitude towards the old anxieties about identity and traditions. These problematic issues are illustrated in the editors' selection policy, which attempts a broad inclusivity of content both in terms of historical range and breadth of literary representation. The anthology includes work from ninety-seven individual poets, of whom thirty-three approximately one-third - are women. Unlike most of its predecessors, this collection does not provide a glossary of Māori terms or a separate section of Māori verse, with the work of Keri Hulme, Roma Potiki, J.C. Sturm, Apirana Taylor, and Hone Tuwhare incorporated into 
the main body of the selections, along with that of Pacific writers Albert Wendt and Alistair Te Ariki Campbell.

In the particular selections made and their arrangement within the anthology, the editors articulate a view that a sense of New Zealandness, at the end of the twentieth century, included the achievement of bicultural and international inclusivity. In this aspect, as well as the full historical scope of the verse selected, and in their editorial comments, the editors have expressed, although in different form, the goal prescribed by Curnow and other influential anthologists, that a national collection of verse should construct and promote, not merely reflect, a particular (desired) perspective of national identity.

\section{Critical Reception of the Anthologies, and Curnow's Legacy}

The preceding discussion has shown that Curnow has had an important and lasting impact on the nature of New Zealand verse anthologies. As Stead pointed out in Landfall in 1985, 'Curnow was the one who (in 1945) began in something like a vacuum. The others have had him as a point of reference, a place to take off from, a statement to argue with' (298). Curnow's particular translations of the condition of New Zealandness provoked a mixed response, and provided a focal point for subsequent criticism, both approving and antithetical. Frank McKay (1970) considered that it was Curnow, particularly through the agency of the exclusive editorial policy he implemented in his two influential national anthologies of verse, who was seminal in defining 'the nature and reasonable goals of NZ poetry'; that it was Curnow's imperative that 'suggested a sense of direction, of identity, that retains its relevance' (44). Janet Frame, in similarly eulogistic tone, extolled Curnow's 1945 anthology as the distillation of expressions of imagery and feelings 'which only we [New Zealanders] 
could experience' $(1989,192) .{ }^{45}$ Not all responses to Curnow's stance were positive Kendrick Smithyman, for example, in A Way of Saying (1965) was critical of his insistence on a regional focus and emphasis on depicting the 'reality' of New Zealandness, which he considered to be imposed at the cost of the variety of artistic expression (40).

Curnow's anthologies have been referenced as the primary literary markers and standards of value against which other versions of local identity have been measured and contrasted. In promoting differing views, however, the anthologies have generated sites for competing discourses as to the existence of, and particular constructions of, New Zealand identity, and presented disputed notions of authenticity (autochthony) in local writing. Simpson refers to the 'canonical jockeying' for influence and control that was conducted between the opposing local literary 'camps', and describes the local literary scene as comprising '[a] complex network of aesthetic and philosophical differences and affinities' which were complicated by 'the regional and generational distinctions which constituted the evolving poetic discourse' $(1993,96,97)$.

The quarterly Numbers (1954-1959), although less artistically radical than later 'alternative' magazines, had been initiated purposely to contest the literary conformity and accepted conventions of 'received' representations of local identity established by Curnow and others. James K. Baxter, in a polemical editorial in Numbers $4(1955,2,3)$, entitled 'The Critic as Schoolmaster', was strongly disparaging of the hegemonic conservatism, exclusivity and limiting 'sameness' represented by Curnow's canonical publishing and critical establishment, including within his negative descriptors Brasch's Landfall and Holcroft's New Zealand Listener in particular, as well as those other critics whom Baxter considered to be in a state of thrall to Curnow's repressive influence.

\footnotetext{
${ }^{45}$ This comment was made in An Angel at My Table, which was first published in 1984 and reprinted, together with the other two books of Frame's trilogy, To the Is-land and The Envoy from Mirror City, in An Autobiography (1989).
} 
Lauding what he viewed as the liberal and progressive intentions of those involved with Numbers (including himself) in the challenge they presented to the restrictive orthodoxy of the older and outmoded cohort, Baxter derided what he saw as Curnow's egotism and its detrimental influence on the development of local literature: '[A]n editor or critic, intoxicated with the very real power of his position, may consider himself the literary mentor of a nation. Certainly Mr. Curnow has shown signs of this delusive state' (3). Baxter slated the actions of those he regarded as being Curnow's literary oligarchy in their aims to promote their own position of arbiters of value over local literature, stating: 'Mr Brasch ... has been led to a false position by the solitary eminence of Landfall as light-bearer in the dark antipodes'; and while '[Curnow, Brasch and] Holcroft ... have each on occasion talked horse sense ... I consider the potential freedom and fertility of New Zealand writers a far more important matter than the final accuracy of their opinion or my own'; their position has inhibited 'the growth of the younger writer', and encouraged 'anxious dependence upon the opinion of critic and editor' $(1955,2)$.

Curnow's anthologies, together with his editorial comments as well as his other critical writings, at least until the end of the twentieth century, provided sites of strong dissension and contestation for those whose concepts of New Zealandness and of New Zealand verse were markedly different from those Curnow espoused. This dissent was evident in the appearance of anthologies which promoted an alternative model for local literature, such as Arthur Baysting's The Young New Zealand Poets (1973), Murray Edmond and Mary Paul's The New Poets (1987), Lydia Wevers' Yellow Pencils (1988), and Mark Pirie's New Zealand Writing: The Next Wave (1998).

Leigh Davis, in 'Set Up' (1983) in AND magazine, viewed negatively the extent and persistence of Curnow's 'vision' of local writing, and the 'dependence on the insistences of Allen Curnow' of much critical thought $(1983,2)$. Davis's literary perception of New 
Zealandness - one shared with others including Alex Calder and Roger Horrocks, who together edited $A N D$ in 1983 and 1984 - was explicitly opposed to Curnow's ontological stance, which they regarded as being an entrenched and outmoded orthodoxy. Davis asserted that the aim of the magazine was to 'consider some present characteristics of the discourse of New Zealand literature, and ... to present an oppositional view' (ibid, 2).

In its combative stance, $A N D$ presented a direct challenge to the conventions of the literary constructions of New Zealandness that had amalgamated around Curnow's anthologies and that were advanced subsequently by the later literary nationalists who continued to support his literary paradigm. AND formed part of a succession of ephemeral publications including Frontiers (1968-70), Argot (1961-1972), Freed (1969-1972), ${ }^{46}$ Edge (1971-76), Morepork (1979-82), Spleen (1975-1977), Parallax (1982-1983), and Splash (1984-1986). These, in their diverse forms and foci, as well as in the symbolism manifested in their titles, together represented a movement of artistic resistance which expressed an alternative vision for local writing, different from that provided in the predominantly provincialist and realist focus of the New Zealand canon at the time. It included the recognition of the broader artistic and theoretical developments that were occurring in the international cultural environment, and attempts to adapt it to a local literary form.

In the first issue of Freed, the editors' rejection of the constraints imposed by Curnow's narrowly-drawn template for local literature was vehemently expressed in Alan Brunton's admonition that 'the rule of the Elders must describe its own poverty and will itself gracefully into non-being' (Freed, 1969, 1). The forcefulness with which Brunton and others considered that they must express their independence from the 'Elders' was an indication of the extent to which the influence of Curnow's anthologies continued to dominate the form of New Zealand creative literature, particularly verse, and local criticism.

\footnotetext{
${ }^{46}$ Freed was published under several variants of its title.
} 
Stead, in 'From Wystan to Carlos - Modern and Modernism in Recent New Zealand Poetry' (1981), was more nuanced in his challenge to the primacy of what he termed 'Curnow's critical viewpoint' which he saw as 'very much a product of the literary thinking of the 1930s', suggesting that it was 'surely time for a change' (139). What Stead proposed in his essay was 'to enquire whether we can't discover another set of terms ... because a new point of observation is likely to alter the picture' (ibid). Later he returned to this position, addressing the 'Curnow tradition' that had dominated the centre of New Zealand literary criticism since at least 1945, and stating: 'The terms in which New Zealand poetry had been discussed for twenty years had been the terms of Curnow's introductions ... why not shift the terms?'. 47

Others have contested the dominance of Curnow's faction, and rejected what was viewed as its disproportionate influence over the construction of a literary self-representation of New Zealandness. The sometimes acerbic expressions of these concerns formed an echo of dissension which itself composed a distinctive theme of resistance within the discourse of identity, that persisted at least until the end of the twentieth century. In a 1946 review in Arena of Curnow's Caxton anthology, Paula Hanger is scathing in regard to some of his selections, deriding them for their 'artificial eagerness' and 'verbosity', which she considers express the 'conventional twang of the modernist who is ... already dated', and 'a peculiar falseness' (20). In a clear reference to Curnow's statements of literary nationalism set out in his Introduction to the collection, Hanger is dismissive of 'the extraordinary selfconsciousness which afflicts certain schools of thought'. Rejecting Curnow's directives, Hanger asserts:

\footnotetext{
${ }^{47}$ Stead's comments are cited in Harry Ricketts's Talking About Ourselves, 1986, 112.
} 
I do not think that, in poetry, it matters greatly what a New Zealander is, or shall become. ... The great poet is first of all a soul expressing as truthfully as possible his attunement to the forces of nature and the fundamental ideals that inspire his utterance. ... New Zealanders need not zealously work at founding a deep local awareness in their poetry ... it will fall naturally ... let the poets write about whatever they are impelled to express, as the creative mood sweeps them. That is enough. $(1946,19,20)$

While Hanger's assessment is a rather trite and romantic expression of what she considers to be the 'ideals' of poetry and its relationship to place and identity, it represents a view resistant to the imposition of constraints requiring that 'the creative mood' must necessarily be harnessed to nationalistic objectives.

Later, Patrick Evans refers to Curnow, in his role as literary anthologist, not as a facilitator of the development of a diverse and representative local literature but instead as a 'bouncer at the doorway to New Zealand poetry', ejecting from potential inclusion in the local canon any work that portrayed alternative concepts of the nature of New Zealandness $(1990,106)$. Hugh Roberts $(2003,227)$ refers to Curnow as being the proponent of an austere and desolate vision of New Zealand, his 'myth of the empty land'. James Brown, also, while suggesting that Curnow was 'New Zealand's foremost technical practitioner', rejects his bleakly negative literary depiction of New Zealandness, with its 'gruesome, depressing subjects' and its view of the 'world as very fallen'(2007, n.p.).

Craig Calhoun, in Nationalism (1997) proposes that any version of national identity is socially constructed, and that '[t]he ideas of nation, nationality and the like are "essentially contested" because any particular definition of them will privilege some collectivities, interests and identities and damage the claims of others' (98). This contest can be seen in the intense and often acrimonious vying for dominance over the New Zealand literary scene that 
formed a cultural struggle to establish a particular version of New Zealand identity - a specific form of representation of the 'truth' of New Zealandness - that would be reflected in local literature. This is particularly evident in the critical response, both contemporary and subsequent, towards Curnow's views on the proper function of New Zealand writing, particularly those expressed most stridently in his introductions to his Caxton and Penguin verse anthologies.

Peter Simpson, for example, in his 1993 article in Landfall, 'Ways to the Museyroom: Poetry Anthologies in the Fifties', discusses what he observed to be a state of 'cultural schizophrenia' that coalesced around Curnow's 'legacy'. He refers to the hostility concentrated upon Curnow's anthologies as being 'generational feuding', so that 'poetics got increasingly confused with personalities', and issues of poetic practice 'tended to become obscured by the more clamorous personality politics of generational and local allegiance' (96). Writing of Curnow's 1960 Penguin anthology, Simpson describes the 'turbulence of the history from which it emerged', and the 'embattled context in which it was written' $(98,102)$. Others, also, have referred to the polarizing impact of Curnow's anthologies. There is no other New Zealand writer whose attitudes have aroused such a strongly emotional response, either of antipathy or of allegiance, and this ambivalence towards Curnow's influence on local literature, as being negative as well as positive, has continued, in muted form, into the present.

In his 1945 anthology and other critical work, Curnow set out what he viewed to be an important aspect of his function - establishing a new literary space and demarcating the verse that he considered to be authentic local writing from that of the past. However, the vision of New Zealandness that Curnow sought to impose was not always met with uncritical acceptance even by those whose work Curnow included within his exclusive rubric. Others proposed alternative translations of local experience. Mason, for example, in 1962 proposed 
an anthology that would present a vision of New Zealandness that was to be notably different from that presented in earlier collections, in particular those of Curnow. Intended by Mason to be 'the first national anthology to be published in New Zealand', and proposing that it was to be entitled 'We Speak Our Own Words', he clearly implied that while his collection would be representative of the broad spectrum of the range of voices in New Zealand society, Curnow's was not.

In Mason's anthology, 'full consideration was to be given for the first time to literature in languages other than English, namely "[t]he Scots Tongue", along with Welsh, Irish and Gaelic, and Māori, both classical and "post-European”. The work of women poets would be properly recognized (especially Jessie Mackay), as would "the role of poetry in making the modern Trade Union and Labour Movement" and the many "actual workerpoets": "the generally inculcated idea that New Zealand poetry is a University affair should be subtly made to appear ludicrous". Mason also proposed 'a list of some 40 younger poets for consideration'. However, Mason's anthology was never completed (Barrowman, 2003, 383). Had this collection, which presented a quite different view of local experience from that provided in Curnow's anthologies, achieved successful publication, it may have provided the basis for the development of an 'alternative' strand of New Zealand verse around which some of the writers rejected by Curnow could have coalesced.

\section{Locating the 'Point of Origin' of a New Zealand Literature}

This section analyses the various themes of national identity that are illustrated in the anthologies, and examines the relationship between the form of that identity and the contending views proposed by different anthologists as to the point in history when 'markers' indicating the existence of the new nation could first be considered to have become evident. 
A significant factor in the dissension that emanated from the construction of a local canon has been related to the contrasting views of anthologists in locating a specific point of origin at which the beginnings of a distinctive new literature could be identified. A determination to define the essential features comprising the concept 'New Zealand literature' became explicit in much of the work of local anthologists and critics, in particular during the period of overt cultural nationalism in the 1930 s to 1950 s. Underlying the problematic issue of determining a definition of New Zealand literature is the argument as to which particular poets and authors are to be considered the founders of an authentically local body of writing - that is, establishing a seminal 'point of origin', prior to which locally produced work is considered inauthentic and derivative of outmoded English models derided as being Victorian-colonial, faux-Romantic, or Georgian in form. Various competing claims have been made by anthologists and other commentators concerned to locate the originators of a national literature.

In seeking to promote a particular desired paradigm of local cultural identity, together with a particular version of its historical development from a specific defining point after the country's colonial beginnings, influential anthologists and critics have sought to assert their own authority as arbiters of literary value and as keepers of the canon. As discussed in Chapter One, there has been no consensus as to the point at which an authentic local literature commenced, with various poets and authors held out as being the 'first' recognizably New Zealand writer. In 1960, Curnow observed sardonically that '[i]t is remarkable how soon the habit grew, of spotting in this or that writer, a forerunner of the "national literature" which must one day be New Zealand's', and he noted that '[b]y 1883, the "first stray notes" of national song were detected ... in Bracken's Lays of the Land of the Maori and Moa' (27).

Curnow himself, in his Introduction to his 1945 Caxton anthology, located the origins of what he considered to represent a 'real expression of what the New Zealander is' in the 
early work of Mason published in 1923 (15). In his Introduction to Mason's Collected Poems (1962), Curnow described him as being 'New Zealand's first wholly original, unmistakably gifted poet' (9). Chapman and Bennett, in their 1956 Oxford anthology, considered that it was not until the 1930 s that a 'viable literary tradition' was established (xix). Earlier, however, Alexander and Currie had identified the point of the origin of a local literature as being dated from the 1850s, at the initial stage of the settlement's European colonization. In their Introduction to New Zealand Verse (1906), they reflected that '[i]n these islands ... there has existed from the very beginning a tradition that it was a good thing to write poetry' (xiv).

Others have proposed different points of origin of a local literature. Jane Stafford, for example, notes in an article on Jessie Mackay that she has been 'often referred to as New Zealand's first native born poet' (2008, n. p.). For Mackay, the Scottish and other regional ballads of the early colonial settlers, adapted to incorporate local settings and themes and portraying iconic New Zealand fauna and flora, represented the commencement of a distinctive local literature that represented a natural extension from its cultural origins. Considering them to represent an important feature of a 'New Zealand' literature, Mackay collected for publication an assortment of locally-produced ballads, initially under the title New Zealand Rhymes Old and New (1907), and republished in the same year as An Anthology of New Zealand Rhymes Old and New.

E.H. McCormick considered that Mackay’s own verse represented a significant component in the development of a distinct local literature. In his survey Letters and Art in New Zealand (1940), McCormick commented that, while MacKay had 'limitations', much of her work sprang from 'interests shared by all New Zealanders' (103). Reflecting subsequently on her place in New Zealand literature, McCormick noted in New Zealand Literature (1959), that Mackay, in her attempts to distinguish a new, locally-oriented focus in 
the creative work of the early settlers, demonstrated 'the first clear signs of national selfawareness' (71). ${ }^{48}$ Janet Maconie, in Landmarks of New Zealand Writing to 1945 (1990), similarly credits Mackay 'for being the first writer to speak of [the] need for self-awareness', referring to her stated aspiration to promote in her work 'the dawning of a national spirit' (4). Alan Mulgan discussed the significance of Mackay's place in the local canon in his Literature and Authorship in New Zealand (1943), claiming that she 'became an institution ... was throned as a queen, venerated and loved. Everybody who knew anything worth knowing about New Zealand poetry knew something of Jessie Mackay's' (18-21). Similarly, Jane Stafford and Mark Williams, in Maoriland (2006), observe that '[a]t the time of her death in 1938, Mackay was considered New Zealand's pre-eminent poet, the first truly local writer' (76).

In a 2008 article in Kōtare that analyzes the local and international cultural context in which Mackay's prolific output was produced, Stafford observes that the strident, emotional tone and the populist topics of much of her verse were a reflection of the accepted role of late-colonial poetry as being a 'communal voice' heralding the issues of the time (56). However, the late-Victorian version of New Zealandness portrayed by Mackay in her verse, and the contemporary positive evaluation of her contribution towards the evolution of an 'authentic' local literature, were later strongly rejected by those whose view of what represented an acceptably fitting New Zealand identity was substantively different. Within the literary record, the determination of Mackay's place shifted markedly over time, and after the 1950s she was no longer considered to hold importance as a representative of the foundations of a local literature.

While Curnow in 1945 acknowledged Mackay’s position within a group of colonial poets, including Reeves, in the early stages of development of local writing, he did not

\footnotetext{
${ }^{48}$ McCormick's view of Mackay was cited by Curnow in the Introduction to his 1960 anthology, 32.
} 
include any selections from her work in his anthologies. Subsequently, in his Introduction to The Penguin Book of New Zealand Verse (1960), Curnow openly rejects the contention that New Zealand's early balladeers should in fact be included as part of a genuinely New Zealand literature, asserting that ' $[\mathrm{n}] \mathrm{o}$ popular balladry or song has come down to ... claim recognition as part of our modern inheritance' $(1960,26)$. Curnow by then recognized in Mackay's anthology, and in the editorial comments she included in her collections, 'only the familiar pseudo-nationalism of the colony' $(1960,32)$. Curnow dismissed entirely her place in New Zealand literature, deriding her poems as being 'husks without a past or a posterity'. Stafford and Williams (2008) note that '[b]y the 1990s [Mackay] had become a literary joke' (77). Patrick Evans, for example, in his Penguin History of New Zealand Literature (1990), refers to Mackay's verse as being 'awful pseudo-Scottish stuff' (46). However, Stafford and Williams, in Maoriland (2006), their survey of local colonial writing, provide an analysis of Mackay's creative and critical work within its historical, cultural and political context. They note that Mackay's stance in fact represented 'an early form of Curnow's attention to the local, albeit a local conjured at times in terms of Victorian Romanticism', and that the motifs of localism evident in her verse, rather than being dismissed as mere empty sentimentalizing can be recognized as 'markers that can be fed into a specific literary nationalism of place' (79).

The work of Blanche Baughan has held a similarly ambivalent position in the local canon, being over time either lauded as an early progenitor of an authentic local literature, or rejected as a representative of unacceptable outmoded colonial traditions. The variously positive and negative responses towards Duggan's verse among different anthologists fit a similar pattern. ${ }^{49}$ For New Zealand's cultural nationalists, however, the country's colonial

\footnotetext{
${ }^{49}$ Despite commenting dismissively about Duggan's work, as discussed above, Curnow had attempted to include some of her poems in his anthologies. For an analysis of the reception of Duggan's verse, see Eileen Duggan:
} 
Victorian and Edwardian writers were associated with a rejected colonial tradition, not representative of a new and distinctive local literature. J.C. Reid, in his Creative Writing in New Zealand: A Brief Critical History (1946), chided the early New Zealand poets for their 'English-looking mood' (22). He considered that 'the use of images drawn from an English landscape orient the expression of yearning for English ways of life, as ... this mood made the poets live in a world of concepts not related to their own experiences as New Zealanders. ... This had a debilitating effect, not only in substance, but more especially in language, so that many of the poems are written in a stilted "poetic diction" or a self-consciously "literary" style'. In Reid's view, the bulk of the writing produced in New Zealand prior to the 1940s should be excluded from consideration as authentic New Zealand literature, directing specific criticism at Kowhai Gold, the contents of which he regarded as being representative of the period and particularly exhibiting such 'defects' (ibid).

Curnow, also, set up in his critical writing a clear historical parameter for the commencement of a body of 'real' local writing. In 1945, in his 'Dialogue by Way of Introduction' in the first issue of Year Book of the Arts in New Zealand, he described New Zealand identity as being, until then, largely a cultural tabula rasa, upon which the work of some authentically New Zealand poets was appearing (1). He claimed in the Introduction to his 1945 Caxton anthology that, in its contents, '[w]e have begun, but only begun' suggesting here that he saw a clear cultural demarcation between those literary constructs of New Zealandness that he accepted for inclusion in his collection, and those he rejected as belonging to a redundant, now discarded, inauthentic historical past (15). In his selections for the anthology, he claimed, it was evident that 'a number of young poets and one or two older ones ... [are] making a new discovery of their country' (41). 
In his Introduction to Mason's Collected Poems (1962), Curnow discussed his justification for his very selective choice of inclusions for his 1945 and 1951 Caxton anthologies, asserting his view that authentic New Zealand verse - the first that emerged without what he considered to be the 'pretence' of colonial writing - could be dated only from 1923, with the appearance of Mason's first manuscript collection, In the Manner of Men $(1962,9)$. However, the structure and contents of his 1960 Penguin Book of New Zealand Verse (1960) indicated that Curnow had retrospectively revised his commencement point for what he considered a local literature more generally, and proposed a broader outline of its historical development that was inclusive of 'the Maori tradition' and also of what he termed the successive 'phases' of verse up to the stage of its 'true orientation' in the 1930s and 1940s $(1960,19)$.

The majority of accounts of the development of New Zealand writing similarly recognize that period as the threshold of the formation of an authentic local canon. Lawrence Jones, for example, also commences his history of the creation of a distinctive New Zealand literature in the 1930s, attributing this stage of its evolution to the group of cultural nationalists who formed 'the first generation of the makers [of New Zealand literature] such as Sargeson and Brasch' with a later 'second generation ... represented by Frame and Campbell' $(1987,242) .^{50}$

Some others, however, have adopted a different perspective. Hugh Roberts, in his 2003 essay 'The Same People Living in Different Places', proposes that the colonial poets made an important contribution in the development of a distinctive local literature. Roberts provides an account of the nationalist sentiments of the late colonial poets, who viewed New Zealand as an 'imaginary space' over which they had 'uncontested ownership', an aesthetic

\footnotetext{
${ }^{50}$ Jones, in discussion in Barbed Wire and Mirrors: Essays on New Zealand Prose (1987), acknowledges the work of New Zealand's colonial writers, but treats these as a distinct group who were precursors to, but substantively separate from, later generations.
} 
'terra nullius', 'a blank slate on which hardy colonials would write a national history' - and who perceived no incongruity in utilizing British literary forms and traditions to portray the 'uniqueness' of local subjects and landscapes (232). Roberts observes that in '[t]he poetry of W.P. Reeves, Arthur Adams, Jessie McKay, ${ }^{51}$ and others, and the short-lived flurry of magazines such as Zealandia and the New Zealand Illustrated Magazine, [there was] conveyed a robust "nationalism" that was simply untroubled by the question of cultural differences from Britain' (232). In this narrative of the history of the development of New Zealand literature, the work of the settler and early colonial writers, including Mackay, formed an integral part within the story of the formation of a local canon, rather than representing merely the last unwanted vestiges of the culture of an irrelevant and discarded British imperial past.

Some poets hold a particularly problematic and anomalous place within the history of the development of a local canon, and their ascribed position within it has been based upon the preferences of particular anthologists at different times, rather than any more objective evaluation of the literary quality of their work. D'Arcy Cresswell's early verse was for a period considered, at least by Curnow, as providing a prototype for a distinctive New Zealand poetry. He included a substantial section of Cresswell's work in his 1945 and 1951 anthologies and retained it in his 1960 Penguin collection. Cresswell was also included in Robert Chapman and Jonathan Bennett's 1956 Oxford Anthology of New Zealand Verse.

William Broughton, in his essay 'Curnow's anthologies and the strange case of Walter D'Arcy Cresswell' (1997), assessed Cresswell's contribution to local literature, commenting that, despite Creswell's very 'mannered and archaic' style, Curnow had viewed it favourably, and had considered that his early work, together with that of Mason, 'marked the beginnings of "taking poetry seriously" in New Zealand' $(1998,118)$. Despite the apparent incongruity

${ }^{51}$ Roberts's spelling. 
of this favourable judgement, given the archaic Romanticism of the mode, themes and tone of Cresswell's work, Broughton here concurs with Curnow's earlier judgement of Cresswell's 'significant' place in the historical record, considering that he is 'important' to the development of local literature, in his contribution as 'a forceful and romantic advocate for New Zealand verse'. Broughton, noting what he terms Brasch's 'elegiac observation' that 'New Zealand literature in the thirties began in a real sense under [Cresswell's] banner', expresses his agreement with this evaluation, stating that this 'fairly summarised Cresswell's importance' (ibid). Broughton also credits Cresswell's influence as being an important stimulus for others, asserting that his early work 'served as starting points for the arguments of M.H. Holcroft as essayist and Allen Curnow as anthologist' $(1998,118)$. While not qualifying his own view of Cresswell's status, Broughton notes, however, that Cresswell's style subsequently fell into disfavour, and that 'no editor later than 1960 has to date included his work in a selection of twentieth-century poetry'.

Cresswell's own view of the evolution of local literature was expressed in his impression of Bethell, that she represented 'the first and most finished of our poets ... the most original, and the most significant' ${ }^{52}$ Under the pseudonym 'Evelyn Hayes', Bethell published in London the collection From a Garden in the Antipodes (1929). Bethell's work was subsequently accepted within the tenets of the emerging cultural nationalism being promoted by Brasch, Glover, Lawrence Baigent, Curnow and others associated in the 1930s with the Caxton Press in Christchurch. Two collections of Bethell's work, Time and Place (1936), and Day and Night (1939), were published by the Caxton Press, and Curnow included selections of Bethell's verse in his 1945 anthology, one of only two female poets (along with Hyde) that he included. ${ }^{53}$ Baigent, Brasch and Curnow were instrumental in achieving

\footnotetext{
${ }^{52}$ Cresswell's view of Bethell was cited by Curnow in the Introduction to his 1945 anthology, 51.

${ }^{53}$ Eileen Duggan was to have been a third; see page 59 supra.
} 
publication of Bethell's posthumous Collected Poems (1950) by Caxton Press. Articles in Landfall by Cresswell (1948) and Baigent (1951), that lauded Bethell's work, contributed to the favourable consideration of her place within New Zealand literature. In 1997, a volume of Bethell's Collected Poems, edited by Vincent O'Sullivan, was published by Victoria University Press.

The acceptance of Bethell's position within the local canon, however, has been subject to challenge. Nicola Chapman, in a 2006 review, 'Vibrant with Words and The Colour of Distance', notes that Bethell herself, '[f]or much of her adult life ... considered herself English, not a New Zealander' (n.p.). Sarah Quigley, in 'Among the Tussocks' (2006), discounts Cresswell's claim for Bethell as being the originator of New Zealand literature, stating that she

didn't begin writing till the 1920s, and she was swiftly followed by a generation that included R.A.K. Mason, A.R.D. Fairburn, Charles Brasch and Allen Curnow, all of whom might be better credited for the poetic "discovery" of New Zealand. These poets tackled the problem of New Zealand identity more energetically and with a greater intellectual vigour than Bethell, whose landscape verse was underpinned by a strongly traditional spirituality. (16)

Vincent O'Sullivan, in his Introduction to the 1987 edition of his Oxford Anthology of Twentieth Century New Zealand Poetry, concurs with Curnow's view that the first 'consistently serious' local poets were Mason and Bethell, with Duggan included later in this group (xxiii); and in the early 1930s '[a] number of young men were to look at writing more critically, at their country less complacently' (xix), forming the basis of a 'genuine' New Zealand literature. O'Sullivan observes two distinct stages in the development of a distinct local literature. He lists an 'early' group of New Zealand poets born in the nineteenth century, 
commencing with Tregear, and including Baughan, Adams, Bethell, Mansfield, J.R. Hervey, and Duggan; a later group, born in the twentieth century, is identified as commencing with Fairburn and Mason. Mason himself in 1962 referred to his own role as possessing the reputation of 'the founder of New Zealand poetry; literature even ... mentioned in all the official works ... [with an] international reputation' commencing from the $1920 \mathrm{~s}$ (Barrowman, 2003, 392). Fairburn considered that Curnow's 1945 anthology represented 'a landmark in New Zealand literary history, ${ }^{54}$

Baxter, among others, expressed in a number of essays and treatises a concern with defining the accurate specifications and true nature of the body of work he termed 'our literature', and with locating its proper place within the traditions of classical and English literature (and thereby placing himself and his own work firmly in the stream of the 'international' cultural centre, rather than within the considerably smaller circle constituting a 'new', uniquely local literature). In 'Aspects of Poetry in New Zealand' (1967), Baxter sought to define the 'archetype that best expresses the situation of New Zealand poets'. Stating that his aim was 'constructing a number of generalizations about New Zealand poetry', he acknowledged the difficulties inherent in his set task. He expressed 'an uncertainty that valid generalizations can yet be made', stating that '[o]ur literature, in both prose and verse, is various, uneven, and idiosyncratic'. Baxter does, however, 'make a series of chronological divisions', categorizing what he viewed as phases of the historical development of local literature. He expressly differentiated his own taxonomy of the categorizations of local literature and its historical development from those of Curnow, from whom, Baxter asserted, his own views 'diverged' (7).

\footnotetext{
${ }^{54}$ Fairburn's comment is cited in Patrick Evans's History $(1990,105)$.
} 
Baxter, while acknowledging Curnow's position as 'our most influential critic of poetry', vigorously challenged the paradigm of New Zealand literature that Curnow had sought to impose on the local canon. Baxter rejected Curnow's 'double standard of criticism' where he applied 'excessive piety towards the work of our transitional poets' - those poets whose themes and styles Baxter viewed to be suspended in a transitional stage of development between the production of the Georgian-colonials and the literary postnationalists. Identified in this group were Mason, Cresswell, Brasch, Hervey, Basil Dowling, Fairburn, Hyde, Bethell, Glover, Curnow himself, and others of whose work Curnow approved. Baxter challenged Curnow's claim that Mason was the first poet in New Zealand to write 'authentically' of a distinctive 'New Zealand life', instead asserting that Mason's verse represented 'a well-worn poetic diction', and that 'to read Mason is to learn how little poets of transition departed from Georgian or even from Victorian models' (1967, 15-17).

Other commentators also, have subjected Curnow's literary authority to vigorous analysis and challenge. Phillida Bunkle, Linda Hardy, and Jacqueline Matthews, in their 'Commentary' in the 1986 republication of Robin Hyde's novel, Nor the Years Condemn (originally published in 1938), provided a critique of the masculinist, elitist and traditionalist interpretation of national identity applied by Curnow and other literary nationalists, illustrating that concepts of literary value - and determinations of the required characteristics of a local literature - are subject to ontological considerations of gender, class, social status and politics, as well as other interpretative aspects of classifying identity. The editors asserted that Hyde, in her creative and critical work, 'was undoing two myths of origin - the literary myth, already in circulation, that New Zealand literature was originated by the predominantly male writers of the twenties and thirties, and the imperialist/colonial myth that New Zealand history began when white men first charted its waters and named its shores' (Commentary, 1986, 280). 
In this view, Hyde located the origins of an authentic local literature well before the 1930s, and 'firmly rejected the view that New Zealand, despite some early stuttering attempts at articulacy, had to wait till the generation of Mason, Fairburn, Glover and Curnow, to acquire the beginnings of a native literature in English ...' (ibid, 280). In rejecting the claims of influential critics to determine the originating point of a New Zealand literature, Hyde challenged their own self-ascribed place within the local canon. Bunkle reflected that 'Hyde is never more feminist (and "prophetic") than when she is engaged in dismantling claims to paternity, the male pretensions to authorise and originate' (ibid). Although selections from Hyde's verse were included in Curnow's anthologies, these were poems that were carefully chosen to most closely conform with his own view of what should constitute New Zealandness, rather than being representative of the range of her poetic concerns. The themes disclosed in the verse that was collected into the posthumously published Caxton Press edition, Houses By the Sea, and the Later Poems of Robin Hyde (1952), were barely illustrated in the selections of Hyde's work that Curnow made for his 1960 anthology. Hyde presented a different concept of local experience, one more personal, less sure and concentrated, and concerned with individual ways of learning to belong in an encompassing island home in the Pacific, rather than with intellectual alienation from an indifferent and lonely, distant and masculine land.

\section{An Essential 'New Zealand'?}

The concept of a 'national literature' can be defined as a body of creative and critical literary works that collectively 'create a shared idea of that nation in the minds of its people by articulating what is common in experience and purpose, and by critiquing behaviour and ideas which compromise the creation of that nation' (Opie, 2006, 288). A concern with defining the concept of a distinctive New Zealand literature, and whether this in fact exists, 
has pervaded local writing, in particular since the 1930s and 1940s. There has been a reiteration of two major issues in regard to determining the nature of New Zealandness - that is, whether specific characteristics of an essential New Zealand identity can be identified, and the related issue of whether there exists a unique, distinctive local literature that can be substantively differentiated from 'mainstream' English literature and from other 'world' literatures in English. The range of arguments arising from these questions has been fundamental to discussions of national identity, to notions of value in regard to New Zealand literature, and to the construction of a local canon, and they remain as issues of concern that underlie local criticism.

Most influential New Zealand commentators have been concerned with the proper nature of New Zealand literature, and much local criticism has expressed an assumption, often explicit, that in order for the country to demonstrate its independence and maturity, a distinctive New Zealandness and a separately identifiable New Zealand literature are necessary. The specific forms in which these should be expressed, however, have been less clearly defined. Some commentators have been cautious and hesitant in their assessment of the prospects for the development of a unique local literature. A.L. McLeod, for example, expresses hesitation in acknowledging that a separately distinguishable New Zealand literature can be identified. In The Pattern of New Zealand Culture (1968), McLeod considers the question: 'Is there any meaning ... in the term "New Zealand literature (as opposed to "literature which happens to be written in New Zealand")', and suggests that 'the question is still an item of contention despite the protest to the contrary' (6). James Bertram, similarly, in his 1971 essay 'Towards a New Zealand Literature' analysed the historical development of literary expressions of New Zealand identity, acknowledging that he had been 'tentative and unassertive in the [essay] title [he has] chosen'. Bertram considered that, in his view at the time of writing, the achievement of a distinctive local literature had not yet 
been fully realized, and might not, in fact be attained in future. In 1985, in Flight of the Phoenix: Critical Notes on New Zealand Writers, he was still reflective of these concerns, asking rhetorically: 'Is New Zealand literature always to be a becoming, never a Ding-ansich?' $(1985,76) .{ }^{55}$

A sense that an authentically 'New Zealand' writer should be concerned with the nature of being a New Zealander and with focusing on the determination of specific characteristics of New Zealandness, is a repeated trope in local writing. In 1937, Hyde wrote in a preface to her collection of poems, Persephone in Winter, 'it's just dawned on me that I am a New Zealander, and surely, surely, the legends of the mountains, rivers, and people we see should mean more to us than the legends of any other country'. ${ }^{56}$ Hyde's use of the modal suggests a questioning that underlies her expression. This reflection of uncertainty and ambivalence is indicative of the sense of anxiety regarding the nature of New Zealand identity that is pervasive throughout much of the body of local literature - how should New Zealandness properly be expressed? Is it the case, in fact, that local landscape, fauna and flora and archetypes of New Zealand 'experience' should be the focus of New Zealand writers in order for their work to be termed 'New Zealand literature'?

This lack of clarity, and self-doubt as to the nature of local identity, are commonly expressed in literature by representing New Zealandness in negative descriptors - that is, in terms of what it is not. A.L. McLeod, in The Pattern of New Zealand Culture (1968), observed contradictory characteristics in New Zealand's self-identity, observing that

New Zealanders ... tend to define their ... [self-image] with some difficulty and in negative rather than positive terms. When asked to sketch ... his national stereotype, the New Zealander ... answers, not with a positive statement that most of his

\footnotetext{
${ }^{55}$ Bertram's essay was first published as a pamphlet in 1971.

${ }^{56}$ Cited in Gillian Boddy, 1998, 252.
} 
countrymen are people of such and such a sort, but with ... negatives ... we're not as rough and crude as ... Australians (15).

Rhodes, in New Zealand Novels: A Thematic Approach (1969), suggested that a sense of identity for New Zealanders could only be established by means of contrasting oneself against external representations, which 'involves the experience of going overseas, of leaving the country of one's birth, and discovering ... a sense of one's identity and difference in relation to others' (24). Later, Rachel McAlpine, reflecting in 1989 on her status as a 'New Zealand writer', similarly emphasized New Zealand's identity in terms of its distinction from other countries, stating: 'One thing I do know is that I am a New Zealander, even if I don't quite know which part of New Zealand I live in'. ${ }^{57}$ McAlpine, as in the case of many other New Zealand writers, did not further define the experience and quality of New Zealandness in terms other than those describing its differentiation from other nationalities.

Curnow, also, while advancing the position that an authentic New Zealandness existed and should be identified, frequently did so by contrasting this country's literary production with that of other nations. In the Introduction to his 1960 Penguin anthology, Curnow asserted the existence of a 'true' New Zealand literature that was distinct and separate from its British colonial origins; however, he emphasized paradoxically that it was not unique and insular, but occupied a place within the parameters of the traditions of English literature - 'it is this vital discovery of self in country and country in self, which gives the best New Zealand verse its character, and such claim as it has to stand as a distinct addition to the range of modern poetry in English' $(1960,21)$. He noted essential differences in the design of a New Zealand anthology from those of English and American verse, 'which cannot be copied by a New Zealand editor without risk of losing touch with the realities of

\footnotetext{
${ }^{57}$ Cited in Heather Roberts's Where Did She Come From? (1989), 86.
} 
his special field' (19), suggesting that such 'essential differences' were evident in local literature. Curnow refers to what he identifies as a 'difference' in 'vision' inherent to New Zealand poets, who 'see differently, and see different things, from others', claiming that only poets who portray 'reality' (as Curnow defines this term) produce in their verse a true 'vision', a poetry that can be 'correctly compared with other verse in English' (18).

However, Curnow acknowledged that the determination of a sense of New Zealandness was uncertain, incomplete and 'awkward' in its expression, so that the country 'even yet [in 1960] wears its national identity hobbledehoyishly' (18). His assessment of the nature of New Zealand literature appears to be contradictory in its irreconcilable conclusions; while continuing to assert claims that local literature was recognizably unique and different from others, he also emphasized its links to and dependence upon the forms, structures, traditions and 'standards' of British literature - that is, simultaneously independent and dependent in its status. His own background and education inculcated him into the traditions, conventions and values of classical literature; he presented a view of New Zealandness that was focused not only inwards towards New Zealand critics, but primarily outward, intended for the purpose of incorporation into an international cultural reception. Along with those of his contemporaries preoccupied in undertaking the creation of a distinctive local canon, Curnow's stated interests were centred on constructing a version of an authentic 'New Zealand' literature independent of the literary precedents inherited from the country's British colonial origins and from aesthetically objectionable Romantic and Georgian artistic models. However, Curnow's project of developing a new, culturally acceptable and authentically local model failed to address the paradox presented in the dominance of overseas (predominantly British and American) influences over New Zealand literature.

While insisting upon the requirement that to be considered as 'poets of their country', local writers must reject 'false notes' and produce work that represents 'a real expression of 
what the New Zealander is' $(1945,45)$, Curnow himself, and others whose verse he lauded and incorporated within his anthologies, readily assimilated overseas literary models and influences into their own modes of expression. He expressly emphasized the links he drew between current Modernist English literary models, and the material included in his own anthologies, by his inclusion of epigraphs and other references to modern British poets including Yeats, Pound and Eliot, and others. ${ }^{58}$ His own literary work reflected not the straightforward and unlayered regionalist approach that he promoted in the editorial comments of his anthologies, but one that was much more complex and nuanced. While he required that the focus of local writing should be on New Zealand 'reality', his own literary standards, forms and influences were based on those of mainstream English literature of his time, and reflected in particular the Modernist influences of Auden and others. In publishing at different times in Christchurch and London, he indicated that his intended readership was both local and overseas. In strongly asserting a position of cultural nationalism in his anthologies he reflected in his own position a portrayal of certainty and assurance; this did not, however, override the uncertainties of national identity that underlay literary perceptions of New Zealandness, and which became evident in the critical contention that his stance provoked.

While the concerns of Curnow and many other anthologists and critics have been focused on attempts to determine and define the particular characteristics of a separate national literature, a parallel discourse reflects doubt as to the existence of a unique and readily identifiable 'New Zealand literature'. The view that New Zealand literature is not a discrete entity of itself, but an exemplar of a (minor) offshoot of British literature originating from the country's colonial history, is one that has been proposed by a number of

\footnotetext{
${ }^{58}$ Curnow included quotations from Yeats and Eliot as epigraphs in his 1945 Caxton, and from Yeats and Swift in his 1960 Penguin anthology.
} 
commentators. A related view is that New Zealand literature, rather than evolving in form over time to reflect a unique and more 'authentic' response towards local experience, is linked to, derivative from and imitative of overseas cultural developments, representing an exotic antipodean variant of the literature of the European cultural centre.

The assertion that a distinct and independent New Zealand identity failed to evolve successfully from the country's colonial origins has been an opposing concept, expressed as a counterpoint to the progressivist views promulgated by the country's cultural nationalists. Miles Fairburn, for example, argues against the case for an exceptionalist New Zealand identity, asserting that instead of being distinctive and discretely bounded, this country's cultural expression comprises a composite 'pastiche' that has been dominated by an 'unconscious yet powerful' Australia $(2006,146)$. Similarly, Shaun Goldfinch concludes that 'New Zealand's history and institutions ... are overwhelmingly derivative of Australia, Britain and North America. ... New Zealand's uniqueness lies perhaps paradoxically in its unusual dominance by others' cultures' $(2008,161)$. These views suggest that the contested positions adopted by Curnow and others as to the 'correct' literary representations of New Zealand identity can be perceived merely as oppositional generational responses towards changing overseas literary modes.

Stead, among others, observed that prominent 'trends' that became dominant at different periods in local writing were linked to analogous changes apparent in overseas literature. In 1981, reflecting on the shifts over time in the characteristics of a 'desirable' national identity that were expressed in the work of different proponents of local literature, Stead commented that the literary generation of Sargeson, Curnow, Fairburn, Glover ... like their contemporaries in England ... were in revolt against the generation that preceded them ... In poetry ... it was expressed (here as in England) as a "modern" revolt against 
"Georgian" romanticism. That is how Auden is usually placed in literary history, which in turn places (for example) Curnow and Glover. Each movement in New Zealand is a reflection largely of its counterpart in Britain. Just as the English Georgians wrote cosily about an England of cottages and country lanes, so their New Zealand counterparts wrote cosily and prettily about New Zealand (71). ${ }^{59}$

In illustration of his argument, Stead ascribes the extreme differences in the depictions of 'New Zealand' presented in the fictional and non-fictional work of John Mulgan and that of his father, Alan Mulgan, to their respective literary generations, stating that the latter produced 'conventional English stuff' while that of the former was 'both “modern"' and New Zealand' (ibid, 69). Stead compares the 'versions' of New Zealand presented in parallel by the Mulgans in their respective novels of the 1930s - the latter depicting a conventional, 'Georgian' view of an attractive palimpsest of traditional English countryside, and the former a bleak landscape of spoiled and corrupt wasteland 'in the style of Spender and Auden'. ${ }^{60}$ Stead states that both 'versions', positive and negative, represent 'a kind of romanticising', the son's 'a piece of frontier mythologising' as much as the father's- so that neither are 'authentic' representations of New Zealandness, but merely representative of a generational shift of overseas, literary conventions, adapted within a stylized local setting (ibid, 74).

\footnotetext{
${ }^{59}$ Stead's view that Auden's development into a Modernist was a 'revolt' against Georgianism over-simplifies his evolution as a poet, and ignores the strong influence of T.S. Eliot which attracted Auden into the new poetic form. In a similar manner, a number of New Zealand poets were attracted in their own development by the work of particular modernists.

${ }^{60}$ Stead uses as his particular comparators Alan Mulgan's A Pilgrim's Way in New Zealand (1935) and John Mulgan's Man Alone (1939). Stead's arguments in regard to the respective generational influences of the two Mulgans were anticipated by Paul Day in his 1968 biography, John Mulgan, and his 1974 study John Mulgan (1977) in the Oxford 'New Zealand Writers and their Work' series.
} 
Vincent O’Sullivan in his Introduction to his 1987 Oxford verse anthology acknowledged that, at that time, 'American poetry is the strongest influence on our recent verse' (xxii). Lawrence Jones similarly, in an analysis of the series of developmental 'periods' that he observes in New Zealand literature, implies that local writers emulate overseas trends rather than responding to the evolution of uniquely local conditions and experiences. Jones reflects that ' $[\mathrm{w}]$ hile it was the poets who opened the Post-provincial Period, poetry has since turned inwards to a more personalist mode, following the trends of British and American poetry, as usual, but half a generation later' $(1989,203)$.

Earlier, in Creative Writing in New Zealand (1946), Reid had questioned not only whether a distinctive 'New Zealand fiction' could be observed to exist, but whether the development of such a separately identifiable local literature should in fact be considered 'important' to the formation of the country's identity. Reid instead referred to the universality of writing of 'quality' in English, and the positive association of New Zealand literature with that of England and America. He reflected that

the desire to increase the number of specifically national characteristics embodied in our [New Zealand] fiction, when pushed as far as it has been in recent years, appears to ignore the principle of the continuity of literary tradition in the offshoot of a highly-developed culture and also to play down the universal character of all good writing. Again, those recent writers who are most frequently asserted as being representative of the growth of a distinctively national fiction are in fact heavily in debt in style, as least, to contemporary writers of England and America (58).

In 1966 in Landfall, Brasch had mused that '[c]ulture as such in New Zealand does not yet wear a recognizably New Zealand face' (216). Over subsequent decades New Zealand's 'face' became more recognizable - but mostly in terms of negative descriptors, as 
to what New Zealandness was not, and how it could be differentiated from other cultures, while efforts made in local criticism to determine the specific identifying characteristics and qualities of New Zealand writing often were reliant on comparators with overseas literatures.

\section{Special Interest Anthologies}

Outside the restrictive confines of the authoritative, unitary 'national' anthology, the notion of collective identity in local writing was modified by the reprise of regional anthologies, which had first been published, reflecting the country's provincial structure, in the nineteenth century. These reappeared later, particularly from the 1950s, indicating that, at the margins, the more dispersed focus of identity that had existed prior to the appearance of Alexander and Currie's first national collection had continued outside the formal canon of local literature. In 1949, Currie compiled A Centennial Treasury of Otago Verse, picking up a later version of the nineteenth-century focus on closer regional attachments and more immediate geographic sensibilities. A later example of such specifically regional collections was Lawrence Jones and Heather Murray's From the Mainland: An Anthology of South Island Writers (1995). In addition to collections with a specific regional locus, a variety of special interest anthologies, which focused on the concerns of particular sub-groups of New Zealand poets, were published in this period. These were varied in their literary quality and included, among others: Arthur Baysting's The Young New Zealand Poets (1973); Harvey McQueen and Lois Cox's Ten Modern New Zealand Poets (1974); Murray Edmond and Mary Paul's The New Poets: Initiatives in New Zealand poetry (1987); Lydia Wevers' Yellow Pencils:

Contemporary poetry by New Zealand women (1988); Peter Wells and Rex Pilgrim's Best 
Mates: Gay writing in Aotearoa New Zealand (1997); and Harry Ricketts and Hugh Roberts' How You Doing? A Selection of New Zealand Comic and Satiric Verse (1998). ${ }^{61}$

These diverse anthologies, which reflected a range of writing forms and styles, both demotic and hieratic, as well as varied interests, represented a focus not on promoting the concept of a broader national identity but one linked to a particular geographical region or the sensibilities and reading tastes of particular special interest groups. Their appearance suggested a blurring of the nature of collective belonging in this country, and indicated that, for many New Zealanders, a sense of identity has been more firmly located and represented in a disparate range of potential local and personal identities, rather than the reductionist concept of one that was singular, nationally encompassing and overriding of regional and individual differences.

Attempts to impose the concept of a unitary collective identity on New Zealand, such as in the form of an authoritative national anthology, have been only partially effective and temporary in their impact, providing only an illusion of consensus and collective selfconfidence. Instead, the responses they generated have highlighted the divisions and differences within society, in highlighting the inconsistencies and contradictions inherent in literary constructions of New Zealand experience and 'character', and often provoking critical dissension. These attitudes of concern have been intrusive and pervasive, recurring extensively throughout the secondary literature, and often adopting very similar forms of expression, so that characteristics of uncertainty and anxiety about self-identity have themselves become intrinsic to literary definitions of New Zealandness.

Despite apparent assurances that early insecurities and ambiguities regarding New Zealand's national identity, based on the country's colonial past and its uncertain place in the

\footnotetext{
${ }^{61}$ Further discussion of special interest anthologies produced in the twentieth century is included in the later chapters of this thesis.
} 
global present, were resolved over time, it has been evident in much New Zealand creative and critical literature that these doubts and anxieties persisted until at least the end of the last century. Successive national anthologies were produced with the purpose, often explicitly cited by their compilers, of presenting a definitive version of New Zealandness in their contents, but each apparent resolution of the questions of identity they portrayed was undermined by the different renditions imposed by subsequent collections.

A specific case that exemplifies this sense of uncertainty and insecurity of identity, and illustrates its sources, is that of the varied critical responses towards the presence of the expatriate writer in New Zealand's cultural production. These have illustrated the wider difficulties that have existed in the process of identity construction in this country, and this aspect within national anthologies is analyzed in the following chapter. 


\title{
CHAPTER THREE: 'WHAT IS A NEW ZEALANDER?' - THE PROBLEM OF THE EXPATRIATE WRITER
}

\author{
What is a New Zealander?
}

(Keith Sinclair, 1988, 337)

The issue of determining 'what is a New Zealander' - of specifying the particular characteristics of those considered to be New Zealand writers for the purposes of constructing a local literary canon - has been problematic for compilers of national anthologies. It provoked a considerable body of critical attention from the 1930s in particular, and remained of concern in subsequent decades, as indicated in the editorial commentary of later anthologists. The critical discussion focused on the problem of who is considered to 'belong' in this country, and of the expatriate writer in particular, has provided an illustration of the major issues within the broader discourse surrounding the nature of New Zealandness, and of the insecurities and anxieties underlying efforts to determine the nature of this country's collective identity. The term 'expatriate writer' is used in this chapter to refer in various contexts both to those who are immigrants or visitors to New Zealand and to those who have emigrated and settled overseas, however provisionally. Mansfield remained a New Zealander overseas; nevertheless like Greville Texidor and Anna Kavan, who were never more than transients in New Zealand, all three have proved problematic as 'expatriates' for New Zealand anthologists. Both types are, in different ways, marginal to the group who consider themselves bona fide 'New Zealanders', but they are so for different reasons, and they confront different challenges; for the former - those who are 'visitors' to the country - the question relates to when they can be accepted as belonging, while for the latter - expatriates like Mansfield - it is to determining the point at which they cease to be New Zealanders. 
This discussion forms the focus of this chapter, which commences with a consideration of Curnow's views on the definition of 'New Zealander', both because of the extent of his influence over local literature and the fact that he explicitly addressed this question in his critical writing over several decades. In his 1964 essay $^{62}$ 'New Zealand Literature: the case for a working definition', Curnow proposed that for writing to be considered as 'New Zealand literature' (Curnow's emphasis) it must be written by 'one of ourselves' (87). His view, that only those who are 'authentic' New Zealanders can create a truthful literary portrayal of New Zealandness, was one that he had earlier outlined as being the basis for his selection policies for both his Caxton and Penguin verse collections. ${ }^{63}$ Curnow's principles of selection for constructing a collection of local work were adopted in their general terms, overtly or tacitly, by the compilers of most subsequent authoritative anthologies, and applied to their own selection decisions. Vincent O'Sullivan, for example, reflecting on his own criteria for inclusion in his 1987 Oxford poetry anthology, states that '[a]ll poets ... write from what they know and see around them. ... Their own country ... inevitably will emerge in some form' (1987, Introduction, xxiv). This is a much more muted acknowledgement of nationalism than Curnow's, and allows that a sense of a country emerges in an unconscious process, but similarly accepts it as being integral to the poetic process.

The concept of literary veracity, in this perception, is based on the notion that 'authenticity' in local literature is tied intrinsically to a writer's sense of belonging to one's 'own country'; it assumes that those who do not 'belong' to New Zealand are unable, therefore, to produce creative work that can be considered fully acceptable as local writing,

\footnotetext{
${ }^{62}$ This essay had previously been presented as a lecture at Auckland University, in 1963.

${ }^{63}$ Curnow set out these views in the introductions to his anthologies, as well as other critical writing. For example, discussing the work of the poets that he included in his 1960 Penguin anthology, he stated that the 'character' of New Zealand verse is identified in the 'discovery of self in country and country in self' (1960, 21).
} 
and should be rejected. This assertion has been a dominant strand in the discourse focused on the concepts 'New Zealand writer' and 'New Zealand literature', and has formed a distinctive marker for the determination of a critical position, both for those who concur with its basic premises and those who oppose them. While Curnow's definition of a New Zealand writer in its basic premises commonly has been accepted by most other authoritative anthologists (as indicated in their own editorial comments), the specific terms of his descriptor 'one of ourselves' have provoked sometimes strong contention, and have been subject to wide variation in their application. In particular, determining the status of expatriate writers within this definition has posed significant complexities for compilers of collections of national literature. Responses from anthologists and critics towards individual poets in regard to their inclusion within the local canon have ranged from deference towards those having acquired an 'international' reputation, to rejection on the basis of the unacceptability of their overseas affiliations.

Concerns regarding the status of expatriate writers, both emigrant and immigrant, were voiced most strongly during periods of cultural nationalism, but at other times also they have formed a significant feature of local criticism. The response towards particular writers whose national status was considered ambiguous, such as Mansfield, Adcock, Wendt, Iain Lonie, Peter Bland, John Sligo, Rewi Alley, and Basil Dowling, among others, has been varied at different times and in different contexts. Yorkshire-born Bland, for example, whose verse was published in New Zealand and overseas from the late 1950s, appeared in Charles Doyle's 1965 Recent Poetry in New Zealand, and in O'Sullivan's several Oxford poetry anthologies. However, he was otherwise absent from national anthologies apart from a 
section of his verse being included in Bornholdt, O'Brien and Williams's 1997 Oxford poetry collection. $^{64}$

After the 1960s, a seemingly more inclusive and less parochially prescriptive approach towards a writer's national and cultural affinities became evident, as the dominance of the earlier literary nationalism of Curnow and others diminished and new influences on local writing, both internal and external, challenged previous concepts of New Zealand identity. However, in the later decades of the twentieth century, the issue of the origins and nationality of individual contributors to anthologies continued to be a cause for critical notice, indicating that these remained as important evaluative criteria. The work of more recent immigrants, such as Bulgarian Kapka Kassabova and Niuean John Pule, for example, has been readily incorporated into the local canon; their presence within New Zealand literature, however, remains noted in terms of their exoticism and distinctiveness, and the critical reception of their work continues to be marked by reference to the perceived differences of their cultural and national backgrounds from those of mainstream writers. Kassabova, for example, in a contemporary review of her verse collection All Roads Lead to the Sea (1997), which was published by Auckland University Press when she was resident in New Zealand, was referred to as being a 'transplant' in this country (Baskett, 1997, 2).

In 1906, when Alexander and Currie produced the country's first national verse anthology, the bulk of the contributors had overseas origins. At this time, while the majority of the population was locally-born, the country's political and cultural institutions were dominated by British-born immigrants. ${ }^{65}$ The editors' prefatory comments in the anthology, and in its 1926 extended edition, made no reference to the issue of poetic identity in regard to any of the contributors, at a time when it was taken for granted that residents retained strong

\footnotetext{
${ }^{64}$ Bland does not appear, for example in Stafford and Williams's 2012 Anthology of New Zealand Literature. ${ }^{65}$ The shift in the dominance of overseas to locally-born population within the New Zealand Pākehā cohort, is reported in the census results of the late nineteenth and early twentieth centuries; this is summarized in Frank Rogers's 'The New Zealanders' (2008, n.p.).
} 
cultural and emotional, if not active social and physical links with Britain. ${ }^{66}$ Subsequently, however, the issue of origins and the status of 'belonging' developed significance in the country, and over the course of the twentieth century concerns regarding a poet's nationality and relationship of identity with New Zealand became a critical focus.

This chapter considers the arguments proposed by anthologists, critics and other commentators in regard to the definition of the notion 'New Zealand writer', particularly in the context of the construction of a national anthology, as well as the relationship of this discourse to the broader issues surrounding the concept of national identity. In particular it examines the ways in which expatriate writers have evoked an ambivalent and often contradictory critical response, as efforts to determine their appropriate position vis-à-vis a local canon have been a key issue in the justification of selection policies regarding those writers who are to be included, and those excluded, from collections of 'New Zealand' literature. The arguments regarding nationality provoked by expatriatism were linked inherently to those of the country's identity, and the critical responses towards the notions of origins and belonging provide an illustration over time of the insecurities and ongoing sense of anxiety that underlie the discourse focused on determining an essentialist definition of New Zealandness.

The pattern of New Zealand's Pākehā settlement of the country has been marked, in different forms, by flows both of immigration and emigration throughout its history, commencing from the earliest stages of colonization and continuing to the present. Local historians, such as Keith Sinclair in his essay, 'The Native Born: the Origins of New Zealand Nationalism' (1986a), and James Belich in Making Peoples (1996) and Paradise Reforged (2001), among others, have described the effects over time of these large population flows on

\footnotetext{
${ }^{66}$ Studies such as Keith Sinclair's The Growth of New Zealand Identity, 1890-1960 (1987) describe the social and cultural relationship between New Zealand settlers and Britain after colonization.
} 
the country's concepts of collective identity. A persistent sense of movement, fluidity and transience, and an uncertainty in regard to the nature of belonging, have become distinguishing features that are incorporated into the defining characteristics of the country's cultural representation. ${ }^{67}$ This has formed a strong challenge to attempts to ascribe notions of fixedness and certainty in expressions of local identity. ${ }^{68}$ The immigrant population (predominantly from the United Kingdom, often via other British colonies, particularly Australia) has had an extensive influence on the country's social, political and cultural institutions. Sinclair, among others, in his studies including A Destiny Apart: New Zealand's Search for National Identity (1986), has outlined the extent to which the impact of the presence of a large proportion of overseas-born residents has been pervasive in its influence upon all aspects of the country's development, as have the outward flows of emigration, both temporary and permanent.

Commenting on historical census data, Frank Rogers, in his study 'The New Zealanders: the decline of immigrant dominance in New Zealand' (2008), points out that it was not until the decade of the 1930s that locally-born New Zealanders comprised the majority of those whose influence dominated important social, political and cultural institutions within society (n.p.). ${ }^{69}$ Prior to that period, most of those holding authoritative positions in the country, and influential in shaping and implementing its decision-making processes, were immigrants. Rogers suggests that it was from this time that such a

\footnotetext{
${ }^{67}$ This effect in New Zealand, a country with a small underlying permanent population base, has been notably different from that evident in Australia and the US, which have much larger patterns of migration yet had no hesitancy in asserting nationalism.

${ }^{68}$ Historians who have promoted views of the uncertain, fluid and mobile nature of New Zealand identity include, among others, Alex Calder and Stephen Turner; see, for example, their Introduction to the 2002 'Settlement Studies' special issue of Journal of New Zealand Literature. Discussion outlining revisionist views of Curnow's place in the literary construction of a New Zealand identity was presented in the special issue of Journal of New Zealand History focused on the theme 'Curnow, Caxton and the Canon', published in two parts (issue numbers 15, 1997, and 16, 1998) - these present papers selected from the proceedings of the Association of New Zealand Literature conference held in Dunedin in 1996 with that title.

${ }^{69}$ Rogers notes that the proportion of the total population that was locally-born reached fifty per cent in the 1880 s, but it was not until this group reached mature adulthood in later decades that they became dominant in civic activity and public institutions.
} 
demographic shift in the population, replacing overseas dominance with a preference for local experience, provided a stimulus for social and cultural change that was reflected in a desire for overt expressions of a distinctive national identity in the country's art and literature.

The task of determining the place of the expatriate writer in regard to a distinctive local literature has proved problematic for those who have undertaken a 'gatekeeper' role in regard to the local literary canon. In the Introduction to his 1945 Book of New Zealand Verse 1923-45 Curnow had declared that in order for creative work to be considered acceptable for inclusion as local literature it must be 'a real expression of what the New Zealander is' (14), implying clearly that only those writers who were locally-oriented could correctly and authentically interpret and express the uniqueness of such experience. Further emphasizing his insistence that an authentic New Zealand literature could be sourced only from direct local experience, Curnow asserted in the Introduction to his 1960 Penguin Book of New Zealand Verse that ' $[\mathrm{w}]$ hatever is true vision belongs here, uniquely to the islands of New Zealand', and he claimed that an authentically constructed local literature will bear the recognizable marks and moulding of its particular physical and social surroundings, as well as the historical background of the society from which it originates $(1960,1)$. He referred to the existence of what he perceived to be the difference in 'vision' of truly New Zealand poets, who 'see differently, and see different things, from others' (ibid, 18). In this view, therefore, the work of expatriates can depict only an inauthentic and artificially contrived view of New Zealandness, one distorted by physical and emotional alienation and dislocation.

However, the expatriate writer has also represented a challenge with the potential to undermine the claims of Curnow, and others holding similar views, that only the work of those whose lived experience is based upon the authentically local can be considered New Zealand literature. Such figures include Mansfield, who adopted Europe as her base, and 
much later, Wendt, a Samoan immigrant who retained strong cultural ties to his original home, who are among a range of those whose national status has been obscured by separation from their birthplace and the ambiguity of their relationship with New Zealand. The creative work of particular expatriates and others whose literary sensibilities encompassed a more eclectic range of cultural, emotional and aesthetic values than those incorporated within Curnow's concept of 'real' New Zealandness, has often posed a quandary for those engaged with compiling material for national anthologies. Some critics, including Baxter, Johnson, Wedde, and Erik Schwimmer, have, from their own different perspectives, challenged Curnow's restrictive criteria, claiming that such rules often have worked to exclude poets in cases where perceived failure to conform with prescribed expressions of local identity have been treated as synonymous with poor literary quality, rather than merely different forms of perspective and representation.

Iain Lonie is an example of a locally-published poet whose biographical details fit only awkwardly within Curnow's rubric, and whose work does not readily meet the descriptor of being poetry written by 'one of ourselves'. Lonie was born in England, immigrating to New Zealand as a boy, then returning to England to read Classics at the University of Cambridge, followed by academic work in Australia. He returned to New Zealand to teach at the University of Otago, and later spent a further period working in Sydney and London, before returning finally to Dunedin. ${ }^{70}$ Lonie's poems were first published in the $1950 \mathrm{~s}$, notably in Landfall..$^{71}$ His collections, all published by New Zealand presses, comprise Recreations (1967, second edition 1970), Letters from Ephesus (1970), Courting Death (1984), The Entrance to Purgatory (1986), and Winter Walk at Morning (1991) (published posthumously).

\footnotetext{
${ }^{70}$ Peter Whiteford provides an outline of Lonie's biographical details in The Oxford Companion to New Zealand Literature, 1998.

${ }^{71}$ Lonie's 'Poems of Sickness', for example, appeared in Landfall in March, 1958.
} 
With its emphasis largely on classical references and imagery, traditional themes that reflected his education and interests, and often deeply introspective tone and lyrical form, Lonie's work was perceptibly at variance from that of his mainstream contemporaries whose verse had adapted more recent poetic modes into a contemporary literary structure and idiom. It was not anthologized until well after Lonie's death in 1988, and since then has appeared only rarely. The critical response to Lonie's verse from local anthologists and critics, both contemporary and later, has been mixed in its assessment not only of its literary quality but also of its appropriate place in relation to local literature, and of whether the characteristics of his poetic concerns could be regarded as being fitting to a New Zealand poet. Alan Roddick, in a 1968 review of Recreations in Landfall, is reserved in his evaluation of the poems, commenting that they are often 'obscure' and lacking 'any clear unifying element', while their emphasis on re-working of 'classical themes' is without local referent $(1968,226,227)$.

Charles Croot, in a 1990 article in the Journal of New Zealand Literature that provided an overview of recent poetry in New Zealand, referred to Lonie as being 'a sensitive, skilful and undervalued poet ... a talent whose potential had not been fully exploited nor fully recognised' (17). Brian Turner, in a review of Winter Walk at Morning (1991), reflected on what he considered to be the poet's 'unjust exclusion from the anthologies', claiming that Lonie's work was rejected by national anthologists because it failed to conform to the particular expressions of New Zealand identity that they sought for their collections at that time $(1991,21)$. Peter Whiteford is largely positive in his 1992 review in Landfall of Winter Walk. He concludes that in Lonie's work, 'strong feeling and acute intellect are combined with a powerful lyric gift', and suggests that 'the time is surely right for ... an assessment [of Lonie as a poet]' $(1992,119,120)$, but leaves open his own evaluation of Lonie's place. Michelle Leggott in 2004 commented that Lonie was 'the invisible man' in New Zealand letters, due to his almost total absence from the anthologies 
and the failure of his work to achieve critical acceptance during his lifetime (2004, n.p.). More recently, Lawrence Jones notes that Lonie is among those that he describes as 'missing' from Stafford and Williams's 2012 Auckland University Press Anthology (Jones, 2013, n.p.).

The earliest formal recognition of Lonie's published work occurred when he was selected as a finalist, along with Curnow, Elizabeth Nannestad and Vincent O'Sullivan, in the poetry section of the 1987 New Zealand Book Awards, for The Entrance to Purgatory (1986). ${ }^{72}$ Lonie's work does not appear in any of the three editions of Vincent O'Sullivan's Oxford University Press Anthology of Twentieth Century New Zealand Poetry (1970, 1976, 1987), Fleur Adcock's Oxford Book of Contemporary New Zealand Poetry (1982), or Wedde and McQueen's Penguin Book of New Zealand Verse (1985). There is, however, a section, comprising six of Lonie's poems, included in Bornholdt, O’Brien and Williams's 1997 Oxford Anthology of New Zealand Poetry in English. More recently, Lonie's work was included, alongside that of many mainstream New Zealand poets including Curnow, Baxter, Bethell, Brasch, Ruth Dallas, Fairburn, Glover, Vincent O’Sullivan and Kendrick Smithyman, among others, in James Brown's anthology The Nature of Things (2005).

The different perceptions of Lonie's work that are held in regard to whether its place should be within, or outside of, the New Zealand canon, are largely related to broader concerns regarding the nature of the country's cultural identity. For many anthologists and critics, the condition of being regarded as 'belonging' to New Zealand has required the expression of particular (but often unspecified) qualities beyond merely that of residence in the country. Patrick Evans, for example, observed in Landfall in 1977 that 'writers who live in New Zealand are not necessarily New Zealand writers'. ${ }^{73}$ The marginality of Lonie's

\footnotetext{
72 The joint winners of the award that year were Curnow, with his collection The Loop in Lone Kauri Road, and Nannestead, with Jump.

${ }^{73}$ Evans made the comment in response to a question posed by Rob Jackaman in the latter's 1977 'Survey', in Landfall 122, 111.
} 
status in regard to local literature is associated in part with issues of his uncertain nationality, but also with concerns as to whether his poetic style and themes have been considered to be properly representative of New Zealandness. A number of other expatriate writers, at different times - including Adcock and Bland - have had a similarly ambiguous and uncertain status in relation to their position in national anthologies. The discourse that has been generated by the presence of such writers illustrates the problematic issues related to attempts to structure, define and shape the characteristics that are deemed to be representative of particular versions of New Zealand identity.

Some anthologists have explicitly supported an inclusive approach to New Zealand writing, one that is generally accepting of expatriates and others commonly regarded as 'marginal' to the local canon. Vincent O'Sullivan, for example, in his Introduction to The Oxford Book of New Zealand Short Stories (1992), has broadly drawn his definition of a 'New Zealand' story as being 'one by a born New Zealander, by someone who has chosen to live here, or by a writer who has written specifically from or on New Zealand experience' (1992, x). He included Rudyard Kipling's 'One Lady at Wairakei', even though Kipling's association with New Zealand was limited to a brief tour of the country in1891, as in O'Sullivan's view, the story 'compellingly' met this definition (ibid).

Another exotic 'outsider' whose writing has been accepted as local literature - her status less marginal within the canon than that of Kipling - is British-born Greville Texidor, who lived in this country in the 1940s. Texidor's short fiction has been published in a number of influential anthologies of New Zealand writing, appearing in Sargeson's Speaking for Ourselves (1945), and several later collections including O'Sullivan's 1992 Oxford Short Stories. While in New Zealand, Texidor associated with a number of influential local writers, in particular Sargeson, and the majority of her short stories and novellas were written during this period. However, she holds an ambiguous place within the body of New Zealand writers 
on the basis of her national identity. Dale Benson, in 'Why is Greville Texidor Part of the Canon?' (1997), points out that English-born Texidor 'wasn't even a New Zealand citizen', but only a temporary immigrant who 'resided in this country from 1940 to 1948 and died in Australia in 1964', and who 'didn't like New Zealand' (n.p.). Benson accredits Texidor's acceptance within local literature primarily to her having been Sargeson's protégé, and to his active intervention in securing the publication, promotion and acceptance of her work, with which he shared a similar 'vision of the human condition' (n.p.). Sargeson was the main advocate for Texidor's work, and others often were more muted in their reception.

Texidor's writing has been generally included within the body of local work considered canonical. However, there is a sense in which the validity of her 'belonging' remained subject to question. Her inherent status as an expatriate continued to evoke comment, such as that provided by Benson, who stated that 'although she only lived in New Zealand for eight years nearly fifty years ago, her work has been criticised, anthologised and collected by some of this country's most prestigious literary commentators' (n.p.). Texidor's life and writing have elicited varying perceptions of her status and her place within New Zealand literature - Kendrick Smithyman, for example, in his Introduction to In Fifteen Minutes You Can Say a Lot: Selected Fiction by Greville Texidor (1987), reflects reservedly: 'insofar as Texidor is a writer, she is a New Zealand writer' (8).

Anthologists commonly have sought to assert the New Zealand bona fides of their selections in validation of their inclusion in a particular collection, especially where a writer's evident association with this country appears tenuous. The nationality of contributors to anthologies of New Zealand literature is commonly specified by a book's editors, and, if their place of birth, or current residence, is 'overseas', their relationship to and cultural links with New Zealand are emphasized, as if to compensate for their uncertain national identity. It has been a common practice of anthologists for biographical details for each contributor, 
including nationality, to be provided. In Curnow's 1960 Penguin Book of New Zealand Verse, for example, an extensive section of 'Notes on the Poets' is provided, setting out for each contributor the details of their place of birth and links to New Zealand. Curnow had included New Zealand-born expatriate Rewi Alley in both his 1951 Caxton and 1960 Penguin anthologies, represented by poems entirely set in and thematically focused upon China, without any New Zealand referents. Alley had spent almost the entirety of his adult life in that country, but Curnow defended his inclusion in the anthologies with his statements that Alley 'was born in Springfield, Canterbury' and his 'ties with New Zealand have never been broken' $(1960,311,312) .^{74}$

Rhodes, in his 1968 critical survey of New Zealand Fiction Since 1945, similarly had provided detailed biographical references, including place of birth and residence, for each of the twenty-five local and expatriate authors included within his analysis. Phoebe Meikle, also, in her Introduction to Ten Modern New Zealand Story Writers (1976), identifies the gender and ethnicity of the writers in her collection, as well as their religious background (for example, '[t]wo of them are of Irish-Catholic descent'), which she considers to be 'significant historical and literary facts', in addition to noting their nationality (xi).

It has been a typical practice of anthologists to specify the nationality of contributors if they are expatriate or otherwise viewed to be anomalous within the definition of New Zealander, such as 'Pacific' writers, while also assiduously stressing their links to this country. This is evident for example, in the anthology New New Zealand Poets in Performance (2008), compiled by Jack Ross and Jan Kemp, where typical entries include those for Serie Barford (described as: 'born in Aotearoa New Zealand ... of Samoan, European and Algonquin Indian descent and lives and works in Waitakere, Auckland'); and

\footnotetext{
${ }^{74}$ Of Alley's inclusion in the 1951 collection, Curnow stated that despite Alley being 'long exiled' and his 'heart' being in China, he considered the poems to 'belong' in the anthology because 'a rare integrity' speaks through his verse $(1951,49)$.
} 
Lynda Chanwai-Earle ('born in London in 1965 ... spent a large part of her childhood in Papua New Guinea. ... currently lives ... in Wellington'). Kapka Kassabova is noted as having been '[b]orn in Sofia, Bulgaria ... she emigrated with her family to New Zealand aged eighteen ... [currently] lives in Edinburgh' $(19,66,121)$. While being included within a 'New Zealand' anthology, their status of difference, and a sense that their assimilation is limited, is retained.

The responses of those concerned with determining the place of the expatriate writer in relation to the concept of New Zealand literature have varied widely between different commentators and at different times. The national identity accorded to an author for the purposes of inclusion or exclusion within the New Zealand literary record, has proved to be a subjective and arbitrary classification imposed according to the preferences of individual critics. McCormick, for example, commenced his survey Letters and Art in New Zealand (1940) with an account of the life of Samuel Butler, who was, as Curnow pointed out in his Introduction to his 1960 anthology, 'a great Victorian who was [not] ... a New Zealander' (23). Bertram in 'Antipodean Hybrid', a 1951 review of the Oxford Book of Australian and New Zealand Verse (1950) in the New Zealand Listener, objected vehemently to the inclusion of Eve Langley within the 'New Zealand' section of the Australasian anthology, on the basis that she was 'an Australian', even though Langley at that time had been resident in New Zealand for more than two decades $(1951,89)$. Frank Sargeson, however, included in his anthology of New Zealand short fiction, Speaking for Ourselves (1945), without any qualification as to national identity, an Australian-oriented story by Melbourne author Max Harris. $^{75}$

\footnotetext{
${ }^{75}$ Michael King $(1995,263)$ notes that Sargeson's motivation for including Harris's story in the anthology was the fact that Harris was its potential publisher in Australia.
} 
For some anthologists and commentators, the perceived requirement to distinguish 'New Zealand' writing from that of other literatures was of primary significance. Joan Stevens commenced her survey, The New Zealand Novel 1860-1965 (1966) with the query: 'what exactly are we to regard as a "New Zealand novel"?' (9) - and in order to delimit the scope of her study, formulated a set of criteria for 'New Zealand literature' which considered critically the position of expatriate writers within the local canon. Reflecting on the status of particular writers, Stevens pondered how to 'classify' the national identity of London-based Sir Hugh Walpole, 'who was born here', as well as others with a variously ambiguous relationship to New Zealand literature, including Will Lawson, Samuel Butler, Ngaio Marsh, Dan Davin, and Hector Bolitho. Stevens decided that: 'It is not enough for the purposes of this book that a novelist lives here; a "New Zealand novel" will be taken to be one which is related to this country, or to its people, or to the experience of life as human beings meet it in these islands' (ibid). Applying her definition to consideration of two war novels, Dan Davin's For the Rest of Our Lives (1947), and Guthrie Wilson's Brave Company (1950), Stevens concluded that despite both being published overseas ${ }^{76}$ and depicting an overseas setting, they were significant in having 'our citizens for subject' and therefore encompassed within its criteria (ibid). Further, Stevens determined that her definition would incorporate 'all the others who have written of us at any stage in our history', but would exclude 'purely non-New Zealand fiction even of New Zealanders' (ibid). This implied, therefore, the rejection of the 'overseas stories', written by those including Ngaio Marsh, Holcroft, Jean Devanny, Ruth Park, and James Courage (ibid).

The parameters that Stevens establishes for determining which particular characteristics properly constitute a New Zealand literature are highly prescriptive and

\footnotetext{
${ }^{76}$ Brave Company was published first in New York by Putnam in 1950, then by Hale in London, in 1951. Later, in 1962, it was published in Auckland by Paul's Book Arcade.
} 
narrowly-drawn. While Stevens does not refer specifically in her analysis of the novel to the contemporary discourse on national identity in regard to poetry promulgated by Curnow and other cultural nationalists, her perspective conforms closely with their view that local writing should indicate a 'search for reality'. Except within this specific paradigm, the work of expatriate writers is largely rejected, particularly where this is focused on a 'different' cultural canvas or depicts alternative portrayals of New Zealandness within a wider international context.

Critics and anthologists in following decades, however, have taken a more inclusive approach towards expatriate and overseas writers, interpreting the term 'New Zealand literature' more broadly while also acknowledging positively the contribution that the unique interpretation of New Zealandness by the 'outside' writer may bring to local literature. In regard to Katherine Mansfield, for example, Gillian Boddy, in her 1988 biography, ${ }^{77}$ reflected that 'there seems little point in debating whether it was [Mansfield's] experiences in New Zealand or in England which had the greater influence on her work - she could not have written as she did without the particular combination of both those very different worlds' (159). In Boddy's view, the major impact of expatriation on Mansfield's work was the development of what she terms a condition of 'cultural schizophrenia', which was the source of her dynamic creative impetus and the unique ontological perspective of New Zealand experience that informed Mansfield's writing $(1988,159,160)$.

Vincent O’Sullivan adopted a generally subjective and idiosyncratic approach towards the concept of 'New Zealand writer'. For example, in his Introduction to New Zealand Poetry in the Sixties (1973), ${ }^{78}$ he makes reference to a distinctive category of local writer - the 'New Zealand poet' - yet does not define specific, delimiting characteristics for

\footnotetext{
${ }^{77}$ Katherine Mansfield, the Woman and the Writer (1988).

${ }^{78}$ New Zealand Poetry in the Sixties was written as a bulletin for schools, rather than anthology per se, and not intended to represent serious criticism; however, O'Sullivan's comments provide insights into his views on the relationship between writers' national identity and their work, that are also evident in his other work.
} 
this group. Similarly, while he makes frequent reference to the term 'New Zealand poetry', the broad descriptors that O'Sullivan provides suggest that, while clearly he does consider this to represent a distinctive genre, he does not characterize it specifically as being geographically-located, either in its source or subject matter. This implies that his approach towards making selections for inclusion in his collections is more flexible and inclusive, and determined less prescriptively, than that of earlier anthologies (implying their differentiation, in particular, from those of Curnow).

However, while adopting a generally broader paradigm for defining local writing, O'Sullivan indicates a lingering sensitivity in regard to Curnow's earlier dictate that, in order to be considered within the rubric 'local', it must be bounded within a 'circumscribed area of experience' (Curnow, 1964, 106). For example, in contrasting the work of Michael Jackson with that of Hone Tuwhare, of whose verse he comments that it is 'very much localized in his own country', O'Sullivan refers to Jackson under the separate rubric 'New Zealanders Abroad' (O'Sullivan, 1973, 14). This classification indicates that he feels it necessary to justify certain of his own decisions, and a need to outline his rationale for including writers who might otherwise be considered marginal to, or falling outside, the mainstream of New Zealand writing in terms of Curnow's established canon.

Discussing the impacts of expatriatism on a number of contributors' creative work, O’Sullivan remarks that '[i]n recent years, several New Zealanders have written poems which come from their involvement with foreign countries' (ibid, 14). He makes specific reference to Rewi Alley's relationship with China, Owen Leeming with France, Ian Wedde with the Middle East, Louis Johnson with New Guinea, Adcock with Britain, and Michael Jackson with Africa. Rather than the status of expatriatism disqualifying such poets from categorization as 'New Zealand writer', however, O'Sullivan refers positively to the 'exoticism' of overseas experience that 'brought a new richness and a larger scope to New 
Zealand poetry' (15). He also refers positively to the contribution to local literature of immigrants in New Zealand, identifying Raymond Ward and Peter Bland as belonging within this class (15). He comments on the different lens through which these writers from 'outside' observe society, so that Bland 'virtually ignores the natural features of the country, where so much of our verse, until recent years, placed its visual centre', and he draws contrasts which illuminate the contradictions between the 'familiar', received version of New Zealandness and a reality 'where most New Zealanders live' (17). While accepting the basic assumptions of Curnow's poetic tenets, O’Sullivan, however, makes indirect reference to the confining restrictiveness of his manifesto for a local canon, and instead assesses more positively the potential value to be introduced by an expatriate perspective. Modifying Curnow's fundamental principle that, to be considered as 'New Zealand verse', it must be written by 'one of ourselves', O'Sullivan asserts a divergent view in marking out his own determinants of literary worth, stating that 'good poems have been written by New Zealanders in other countries, [and] many have come from those born elsewhere' (15).

These liberal views towards identity are represented in the range of selections, as well as his editorial comments, in O'Sullivan's subsequent verse and short fiction collections. In the later decades of the twentieth century most anthologists adopted a comparable selection policy, commonly incorporating the work of expatriate and overseas writers into compilations of 'New Zealand' writing. While this seemingly indicated a rejection of an outdated and narrowly restrictive prescription for New Zealand writing, they exhibited, still, a concern with the need to rationalize and justify such choices, rather than these being treated as commonplace.

Since the 1920s, when national identity became a specific focus of the wider issue of 'belonging' within the then Dominion of New Zealand, there have been some writers in particular whose ambiguous status and the opacity regarding their nationality have posed 
challenges to those concerned with defining the concept 'New Zealand literature'. An analysis of the critical reception of Katherine Mansfield, Fleur Adcock and Albert Wendt

illustrates the nuances as well as the range of concerns and anxieties that have existed within the discourse of national identity underlying the construction of New Zealand anthologies. The first two of these, Mansfield and Adcock, are representative of New Zealand-born writers who, decades apart, left this country to become assimilated into an overseas culture; Samoan-born Wendt came to New Zealand where he became established as a writer, but remained strongly identified with his cultural background. These present three examples of expatriate writers whose standing in relation to the local canon, while being very different in form and context from each other, has each been subject at times to dissent and contention, demonstrating the complexities that have existed within the discourse of New Zealand identity. For national anthologists, while the lives of all these three writers involve expatriation, they present its opposite faces.

\section{Katherine Mansfield}

Mansfield's verse and short fiction, (the latter more than the former), have been regularly included in New Zealand anthologies since her poem 'To L.H.B. (1894-1915)', taken from her Poems (1923), appeared in Alexander and Currie's 1926 Treasury of New Zealand Verse. However, her 'place' in relation to New Zealand literature has been one that has been shifting and contingent upon its varying contexts, and she has remained a contentious figure within local criticism. Since the 1920s, the critical reception of her work frequently has been characterized by conflict and unease, with the ambiguities of nationality stemming from her ultimately permanent geographical and cultural dislocation from New Zealand forming grounds for dispute in regard to acceptance of her place as an 'authentic' local writer. The 
majority of the local commentary on Mansfield's life and work makes reference to the ambivalence with which her expatriatism has been viewed, and how this issue has dominated the assessment of her creative work. Gillian Boddy, for example, noted the dichotomized views of Mansfield's status that are purveyed in New Zealand literary criticism, observing with irony that while ' $[\mathrm{h}]$ er international status is unquestioned $\ldots$ and the annual Katherine Mansfield fellowship to Menton remains the most prestigious prize for writers ... some have questioned the extent and nature of her contribution to New Zealand literature' (2012, n.p.).

The uncertainty and resistance with which Mansfield's position as a New Zealand writer commonly has been regarded since the 1920s is evident in the range of variant views expressed towards her work by local anthologists and critics. Eric McCormick, in Letters and Art in New Zealand (1940) included Mansfield among those he categorized as 'literary émigrés' who had adopted 'self-imposed exile' so as to find their literary voice overseas (132). Bertram, in his survey Towards a New Zealand Literature (1971), questioned Mansfield's New Zealand bona fides, asking: 'Was ... [Mansfield] a New Zealand writer?' (14), implying with this query that he considered her work to fall outside the fold of the New Zealand artistic canon, in a manner analogous to his earlier rejection of Australian-born poet and novelist Langley as a New Zealand writer. ${ }^{79}$ Sargeson, among others, rejected claims for the incorporation of Mansfield's writing within the centre of New Zealand literature on the basis of its 'inauthenticity' and what he considered to be its associations with 'a different tradition' $(1983,28-33)$.

The reservations expressed by many anthologists and critics towards Mansfield's status as an 'authentic' New Zealand writer is evident in the mixed pattern of inclusion of her work in national anthologies of verse and short fiction. As discussed in Chapter Two, Mansfield was not included among the exclusive group that Curnow selected for his initial

\footnotetext{
${ }^{79}$ Refer to the discussion on Langley in Chapter Five.
} 
anthology, the Book of New Zealand Verse 1923-1945 (1945), or its extended 1951 edition, and is represented by only a single poem in his 1960 Penguin volume. ${ }^{80}$ Other anthologists have varied in their treatment of Mansfield's work and its place in relation to New Zealand writing. Following her inclusion in Alexander and Currie's Treasury in 1926, a selection of eleven of Mansfield's poems appeared in Quentin Pope's Kowhai Gold (1930), and Chapman and Bennett included two poems in their 1956 Oxford verse anthology. O.N. Gillespie, who compiled the first 'national' anthology of local short fiction, New Zealand Short Stories (1930), included Mansfield among its contributors. ${ }^{81}$

C.R. Allen, however, in his 1938 collection Tales by New Zealanders, omitted Mansfield's work. The Foreword to Allen's anthology was provided by Sir Hugh Walpole, a New Zealand-born emigrant English novelist, who commented that the anthology presented 'stories about New Zealanders by New Zealanders ... to give you their idea of New Zealand', and that it 'creates for those who have not seen it a country', indicating that the collection was intended primarily for an overseas readership (v, vii). Of Allen's selections, Walpole stated that he knew of no other book that gave him 'so clearly the smell and sound and touch of New Zealand country' (v). Reflecting on the nature of what constituted a 'New Zealand' story, however, Walpole considered that Mansfield's work did not fit within that descriptor. He mused that the anthology's inclusions 'are of the unsophisticated kind ... they are not sophisticated stories in the sense of Katherine Mansfield. ... There is no story in this volume that approaches the art of Katherine Mansfield, and yet I have from it a more actual sense of New Zealand than she ever gave me' (vi). He justified her exclusion from the collection on the basis that her work did not reflect what he considered to be an authentic picture of the country, as, to his eye, it 'always seemed to be too clearly derivative' (ibid).

\footnotetext{
${ }^{80}$ In his 1960 anthology, Curnow included eight pages of selections from Cresswell's verse, indicating his perception of the relative importance of the two poets within New Zealand verse.

${ }^{81}$ Gillespie included Mansfield's 'The Voyage', from The Garden Party and Other Stories (1922).
} 
Others, however, have viewed the 'sense of New Zealand' that Mansfield portrayed in her work to qualify it as local literature. In 1953, Dan Davin, himself a New Zealand expatriate, included three of Mansfield's stories in his Oxford University Press New Zealand Short Stories (1953), ${ }^{82}$ acknowledging in his Editor's Note that Sargeson and McCormick had been influential in making the selections he included (ix). Davin set out his selection principles for a national anthology, which included what he termed a writer's ability to portray a 'background the author and his public really knew'; he considered that Mansfield's stories, written decades earlier, possessed this quality, portraying a still recognizable view of their Wellington setting (Introduction, 1-3). Despite her expatriatism, therefore, Mansfield's work, because it fulfilled Davin's criteria, could be accepted as being New Zealand literature for the purposes of the anthology. ${ }^{83}$

Since 1960 in particular, Mansfield's verse and short fiction have been regularly anthologized. As referred to previously in Chapter Two, Curnow included one of Mansfield's poems, 'To Stanislaw Wyspianski', in his 1960 Penguin anthology, which also incorporated contributions from a number of other expatriate writers. O'Sullivan included Mansfield's 'The Wind Blows' and 'An Indiscreet Journey' in his 1992 Oxford Book of New Zealand Short Stories. Later, Mansfield's short fiction was anthologized by Marshall and others. Kidman referred to Mansfield's continuing influence as being that of 'an icon of New Zealand letters' $(2005,14)$.

The majority of anthologists and critics, however, while accepting Mansfield into the local literary canon, have not done so unconditionally, instead emphasizing her state of expatriatism and self-exile from New Zealand. O'Sullivan in 1988, in an inaugural address at

\footnotetext{
${ }^{82}$ The three Mansfield stories that Davin included were 'At the Bay', 'The Voyage', and 'Her First Ball'.

${ }^{83}$ While acknowledging the influence on New Zealand literature of many European and American writers who have 'all left their mark' which has been 'assimilated' into local writing, Davin, as editor and compiler of the anthology does not discuss his own expatriatism, or the potential influence of this status on the view of New Zealandness that is expressed in its contents $(1953,6)$.
} 
Victoria University of Wellington entitled 'Finding the Pattern, Solving the Problem:

Katherine Mansfield, the New Zealand European', qualified Mansfield's position within local literature. He described her as a cosmopolitan rather than New Zealand writer, who expressed 'a modern ... twentieth century voice', representative of an international literary style rather than that of a New Zealander $(1989,15) .^{84}$

Mansfield's international identity and established overseas recognition, while according status to her work, have been problematic for some local critics and anthologists who have been concerned with defining a local literature that is distinguishable from the generic categorization of 'British' writing. Robinson observed the critical ambivalence that had been expressed towards Mansfield's position within the local canon, and which was still evident at the end of the century, stating that she was

at best a qualified national icon in New Zealand. ... No other New Zealand figure has troubled or challenged so many writers to irreverent, defiant or merely exploitative responses. ... Mansfield stands for elusiveness, instability, fragmentation, incompleteness and absence (1998, 342).

As an exemplar of the perceived threat that she has represented to New Zealand cultural nationalism, and the oppositional and often vitriolic responses that Mansfield has evoked, Robinson referred to '[t]he resistance in 1988 even to the idea of a Mansfield Centennial' (ibid). The controversy over Mansfield's place within New Zealand literature, and whether her life and work should be formally celebrated, formed a dispute in Landfall in 1989, in which Robinson, in his article 'Mansfield Celebrated', was himself a major combatant in support of her position within the canon. ${ }^{85}$

\footnotetext{
${ }^{84}$ O’Sullivan's address was published by Victoria University Press in 1989.

${ }^{85}$ The December 1989 issue of Landfall, which was guest edited by Sophie Tomlinson, was focused on Mansfield.
} 
Linda Hardy, also, contributed to this sustained critical commentary in Landfall regarding Mansfield's 'place' in New Zealand writing in her essay 'The Ghost of Katherine Mansfield' (1989). In this she discussed the complexities that Mansfield's writing, in the context of her deliberate expatriatism and the nuances of national belonging and identity, presented for the concept of a local literature. She stated that

[t]he inscription of Mansfield by contemporary New Zealand writers might suggest a desire to recover her as an analogous figure of origin and continuity - but what we find instead are split or divided representations: the signs ... of cultural hybridity, rather than cultural identity $(1989,427)$.

Hardy pointed out that the condition of alienation and exile from a position within the local canon is not dependent singularly upon a writer's national origins or state of physical expatriatism, but upon the concession of the status of 'belonging' granted by those who have constructed and seek to defend the essentialism of a New Zealand literature. She observed that the New Zealand canon has been structured around particular identifiers that reflect not only characteristics of localism but those that are also masculine in their orientation, so that 'Mansfield is spoken of as a European writer, not really one of "us"; the New Zealand short story claims no inheritance from her, though it acknowledges a “father" in Sargeson' (1984, xiv). ${ }^{86}$

Hardy's view proposes that all portrayals of national identity and cultural belonging are socially constructed, being formulated by those in positions of power to promulgate particular ideologies of cultural value. This suggests that concepts of those who are deemed to 'belong' will shift over time in accordance with other changes in social and cultural values, and that these changes will be applied retrospectively to alter earlier depictions of the place of

\footnotetext{
${ }^{86}$ Hardy's comment about Mansfield is made in her 'Critical Note' introducing the 1984 republication of Hyde's autobiographical account of her time in China during the Sino-Japanese War, Dragon Rampant, which was first published in 1939.
} 
particular writers in the historical record. In this way, the position of expatriate writers such as Mansfield will be deemed to alter in accordance with the particular perspective provided through the cultural lens of the present, and will alter again in the future.

This concept is emphasized in Mark Williams's assessment of John Mulgan, in his 2004 review of Vincent O'Sullivan's biography, A Long Journey to the Border (2003). Williams commented in regard to the Oxford-based New Zealander:

Displaced, unsettled, he is closer to the exile of Mansfield than to Curnow, for whom the writer must stick to a knowable world. ... Man Alone became an iconic text of New Zealandness ... fundamental to the self-imagining of the nation ... yet Mulgan completed it in England not New Zealand, and never returned to the land that it represents so potently (Williams, 2004b, 170, 171).

Despite the fact of Mulgan's expatriatism, however, which was as complete as Mansfield's, very few have similarly questioned Mulgan's status as a New Zealand writer, either at the time of the publication of Man Alone or subsequently. Permanent physical separation from the country, therefore, has not, in all cases, been a primary determinant of whether a writer no longer continued to 'belong' within the canonical group of local writers, and other factors have been important in establishing acceptance or rejection within this group.

While early marginalization of Mansfield's work in New Zealand could be attributed to masculinist dominance of the country's literary culture, however, as suggested by Hardy, later critical analysis of her work emphasizes concern regarding issues of national identity, rather than gender. The continuation of an often sharply dichotomized critical view towards Mansfield's position in relation to New Zealand literature, and a reluctance to accept her work unconditionally within the local literary canon on this basis, remained evident at the end of the century. This attitude reflected the existence of a broader ambivalence and sense of 
unease within New Zealand society in response to the impacts of overseas cultural influences, and their potential for undermining and diluting what was perceived as 'authenticity' in representations of the country's identity. While her verse and short fiction, particularly the latter, were commonly included in national anthologies, often they were accompanied by commentary that was defensive in arguing for her acceptance as a New Zealand writer despite her expatriatism, indicating that her acceptance in fact remained provisional and incomplete.

\section{Fleur Adcock}

While Mansfield is representative of the expatriate whose writing portrayed New Zealand from a perspective of permanent physical displacement, Adcock exemplifies another type of marginalization. The critical assessment of the place of New Zealand-born, British-domiciled poet Adcock, in regard to defining the characteristics of New Zealandness, is paradigmatic of the ambivalent and uneasy status of the expatriate within New Zealand literature. She was born in New Zealand, then spent much of her childhood in England, returning to New Zealand at the age of thirteen, before emigrating to England permanently in 1963 at the age of twenty-nine. ${ }^{87}$ (This pattern of physical movement, apart from the difference in their ages, and subsequent events, forms a close parallel to Mansfield's life. $)^{88}$ Of her own sense of identity and relationship to this country, when visiting New Zealand in her role as editor of The Oxford Book of Contemporary New Zealand Poetry (1982), Adcock reflected that 'the poetry did seem, as New Zealand did, quite foreign - interesting, but not really familiar'. ${ }^{89}$ Here she acknowledged her own sense of separation and distance, the characteristics of

\footnotetext{
${ }^{87}$ Refer to Emma Neale's entry for Adcock in The Oxford Companion to New Zealand Literature, $1998,4$.

${ }^{88}$ This parallel is not complete, however. While Adcock has visited New Zealand repeatedly since settling in England, Mansfield did not return to this country before her death at age 34 in Fontainebleau, France, in 1923.

${ }^{89}$ Adcock's comment is cited in Ricketts, 1986, 126.
} 
expatriatism, which existed in conjunction with the emotional, personal and professional bonds that also held her to this country.

Janet Wilson, in her 2003 article 'Fleur Adcock: Ambivalent Expatriate, 1964-1974', describes the process of Adcock's adaptation to her new surroundings, subsequent to her leaving New Zealand, as involving 'a reconstruction of her cultural identity' (54). This entailed the experience of 'existing on the cultural border-zones of the migrant', and a 'rediscovery of her New Zealand identity and yet also ... a disengagement from New Zealand', where Adcock occupied 'interstitial spaces, in-between zones' $(54,55)$. This indeterminate position, of simultaneously belonging yet being on the 'outside', manifested itself in a perspective at variance from that of her New Zealand-based contemporaries. This was expressed both in her need to provide justification of her credentials of identity, but also in providing an opportunity to exert her status of 'otherness' in reshaping the local canon.

Subsequently, as editor of the 1982 Oxford anthology, Adcock imposed a conceptual model for the term 'New Zealand poetry' that was different from that of her predecessors, both in her choice of selections and the tone of her introduction to the anthology. The extent of critical acceptance of her position within local literature was varied, with some questioning her being granted the role of anthologist of New Zealand literature, and her claim to provide an 'internationalist' perspective towards local writing. Her expatriate status dominated analysis of her work and the focus of discussion of her place in local literature.

Curnow, for example, in an interview with Harry Ricketts published in Talking About Ourselves (1986), mused on Adcock's verse and on her role as editor of the 1982 Oxford anthology, focusing his discussion upon her expatriate status and upon her assertion that 'a "subtle but distinct" change of sensibility' inevitably resulted from being domiciled in "“a 
world whose focus is elsewhere". ${ }^{90}$ He commented dismissively upon Adcock's claim to have experienced 'a change, a strange transformation of the self' due to the experience of her time spent settled overseas, referring to what he considered an attitude of anxiety to 'expatriate herself, almost as if this conferred some special status'. Instead of enhancing her stature, however, Curnow viewed this to be 'an old-fashioned Kiwi posture'. ${ }^{91}$ The portrayal of New Zealandness that Adcock presented in her anthology differed markedly from the view of local 'reality' that Curnow had constructed and promoted in his own collections; however, he dismissed Adcock's selections in the anthology she compiled as being merely 'a sampling of people I don't read very much'. ${ }^{92}$

In the ambiguous position of being an expatriate herself in the role of editor of a national anthology of New Zealand verse, Adcock contemplated at length the uncertain position of the overseas writer within New Zealand literature, and sought to justify her rationale for particular inclusions and exclusions. In her Introduction to the 1982 Oxford, she detailed the specific principles that formed the basis for her selection policy for the collection, including her stance vis-à-vis the work of other expatriate and 'overseas' writers. Adcock established strict 'geographic guidelines' for the writers she included, stating explicitly that '[f]or the purposes of this anthology a New Zealand poet is one who was brought up (not necessarily born) here and has stayed'; and she was overt in stating her intention of presenting in her anthology only that which she viewed as unequivocally 'New Zealand' writing. She defined a specific version of New Zealandness, providing guidelines for the exclusion of writers and work which, in her view, did not conform with the parameters she established for what she defined as being 'New Zealand-bred' (ix, x).

\footnotetext{
${ }^{90}$ Curnow's comments are cited in Ricketts's Talking About Ourselves: Twelve New Zealand Poets in Conversation with Harry Ricketts, 1986, 98.

${ }^{91}$ Ibid.

${ }^{92}$ Ibid.
} 
In a parallel to Curnow's earlier anthologies of New Zealand verse, but clearly adopting a stance that differentiated her own position from his, Adcock provided an extended rationalization for the particular contents of her collection. Stating that her aim was to provide 'an anthology of native New Zealand poetry', she asserted that 'the word “indigenous" needs to be understood as silently present in the title' (1982, viii). Outlining her stance towards the verse of expatriate writers, she stated that: 'It is the home-grown product that I have set out to exhibit, not the work of visitors to this country or expatriates from abroad'. Explaining why she has rejected for inclusion a number of locally-based expatriate poets, she reflected:

Poems by immigrant Englishmen and Americans and Australians did not arise out of the particular circumstances which fostered the writing of New Zealand-bred poets, and it was poetry created in the light of these circumstances, of this social and political climate, that the title of the anthology seemed to me to imply (1982, viii-xi).

Outlining a graduated and nuanced stance towards the potential literary contribution of various 'categories' of expatriates, Adcock affirmed that she had included the work only of 'poets actually living here', and that 'a year or two spent overseas was no disqualification rather the opposite: it is usually good for the imagination'. She stated that 'the decision to settle permanently in another country leads to a subtle but distinct alteration in one's consciousness and attitudes; without ceasing to be a New Zealander one develops a view of the world whose focus is elsewhere, and it seems to me that poetry written from such an outlook cannot rightly be called New Zealand poetry' (viii-xi).

Adcock considered the complexities for the anthologist of a national literature confronted by the New Zealand expatriate writer based overseas, whose work she considered to pose a 'trickier' problem than that of the immigrant to New Zealand. While 
acknowledging that "certain immigrant writers have influenced the work of their [local] contemporaries', and that the work of expatriates may add 'variety' to the canon, she considered that it should be excluded on the grounds that it 'belongs to a different tradition'. In making this determination, Adcock disqualified her own work, as 'it was clear to me that ... [it] should be excluded, together with that of several others, on the grounds that it has for many years been published abroad' (ibid).

In support of her general principle of excluding expatriates from the anthology, Adcock stated the view that such poetry was fundamentally different from that of New Zealanders. It 'did not arise out of the particular circumstances which fostered the writing of New Zealand-bred poets, and it was poetry created in the light of these circumstances, of this social and political climate, that the title of the anthology seemed to me to imply' (viii-ix).

Adcock disqualified her own work, on the basis that her expatriatism meant it was not compliant with the selection criteria she had set for the anthology. However, some other anthologists and critics, drawing a different interpretation of what comprises local writing, have assimilated her poetry within the margins of the local canon. Frank MacKay, for example, in his New Zealand Poetry (1970), included Adcock's work in his study. Selections from Adcock's verse are also included in Wedde and McQueen's 1985 Penguin and in O’Sullivan's 1987 Oxford Anthology. Emma Neale in 1998 described Adcock as being a 'New Zealand' writer '[d] espite her absences and ambivalences', summarizing the complexities of the critical reception of Adcock's place as an expatriate within the local canon, referring to her award of an Order of the British Empire in 1996 'for her contributions to New Zealand literature' (4).

Louis Johnson, however, commented upon the impact of expatriatism on Adcock's identity, referring to the 'argument about nationality' in the case of her writing and noting that she 'has chosen against being "one of us" in a nationalistic sense', a decision that 
Johnson regards as 'a difficult question' for a writer between the 'artistic' and the 'patriotic'. ${ }^{93}$ Adcock herself, reflecting on the ambiguity of her national identity, described the hybrid status of 'what it was to be a New Zealander; when you thought you weren't one any longer, but still sort of were underneath.' She concluded that ' $[t]$ his sense of having a dual identity ... can seem like having no identity at all'. ${ }^{94}$ As in the case of Mansfield, the question of Adcock's cultural nationality - the argument as to whether or not she 'belongs' as a New Zealander - has defined the outcome of the discourse on the determination of whether or not her writing belongs within a local literature.

\section{Albert Wendt}

As self-exiles living overseas, the claims to New Zealand identity and national 'belonging' in the case of emigrant writers such as Mansfield and Adcock have evoked critical dispute, as discussed above. Similarly, an uncertain and often contradictory response frequently has been directed at immigrants to New Zealand. For example, the ambiguous national and cultural identity of Samoan-born, New Zealand-based academic, poet and fiction writer Albert Wendt has provoked controversy regarding the determination of his 'correct' place within New Zealand literature, a critical reception that Paul Sharrad has described as one that 'continues to swing between irritation and excitement' $(2003,244)$.

Although Wendt's literary work has been published in New Zealand since the early 1960s, he has over a long period occupied senior positions in New Zealand academia, and in 2000 was awarded the position of Companion of the New Zealand Order of Merit for his services to literature, his verse and fiction have at times been subject to rejection or uncertainty on the basis that the cultural identity it reflected did not 'fit' within the accepted parameters of the local canon. Briar Wood's entry for Wendt in The Oxford Companion to

\footnotetext{
${ }^{93}$ Cited in Ricketts, 1986, 155.

${ }^{94}$ Ibid, 129.
} 
New Zealand Literature (1998) outlined the complexity of his position in relation to the form of national identity expressed in local literature, and illustrated the terms of the debate framing his displacement to the outside of the mainstream of 'New Zealand' writing. Wood - whose own critical and creative work itself forms part of the body of Pacific literature acknowledged that Wendt 'has been an influential figure in the developments that have shaped New Zealand and Pacific literature since the 1970s'; however, she also recognized the intricacies of his status within New Zealand literature, narrowly defined, and its canon, rigidly construed, in her statement that ' $[\mathrm{h}] \mathrm{e}$ has always been a versatile international writer as well as a committedly Pacific one' (emphasis added) $(581,582)$. This conceded that Wendt's work did not fit clearly within the terms set by the protagonists on either side in the regionalist/internationalist debate, ${ }^{95}$ and therefore has been subject to criticism from both for the perceived inadequacies and indeterminacy of his position.

In categorizing Wendt's position within the separate (sub) genre of Pacific writing, and emphasizing his 'internationalist' stance, Wood has located him geographically, conceptually and artistically at an angle to the traditions of the New Zealand literary centre. Her account served further to 'exile' Wendt in her spatial description of 'Pacific literature', which outlined the very marginal and tenuous place that the Pacific Islands have occupied in the consciousness of mainstream New Zealand literature: 'Pacific and New Zealand literatures were originally inextricable through Polynesian myths of migration ... The preoccupations of settler society and those concerned with New Zealand nationalism were less spacious, however. The Pacific islands became ... less visible in New Zealand writing' (ibid). Paradoxically, writing of and from the Pacific region has been accommodated less easily within this country than that from some other, far more geographically distant places, such as, in the case of Yvonne du Fresne, Denmark.

\footnotetext{
${ }^{95}$ The regionalist/internationalist debate is discussed in the following chapter.
} 
Other critics, also, in their assessment of Wendt's place, have accentuated his 'otherness' in relation to mainstream New Zealand literature. Ken Arvidson, in 'The emergence of a Polynesian literature' (1975), an early assessment of Wendt and other Pacific Island writers in World Literature Written in English, placed him culturally in a broadly Pacific context, focusing upon the exoticism and 'difference' of his work. Sharrad, also, in his 1999 essay 'Imagining the Pacific', in Australian literary magazine Meanjin ${ }^{96}$ stressed Wendt's 'alien' status as an outsider in relation to New Zealand writing rather than that of 'belonging' within his adopted country of residence. Similarly, Jack Hill, in his 2003 essay, 'Images of Religion in South Pacific Fiction' emphasized the Pacific identity of Wendt's writing, not its association with New Zealand literature.

Roger Robinson, in his 1980 article in Landfall, 'Albert Wendt: an assessment', stressed the complex and contradictory nature of Wendt's position as an expatriate writer, emphasizing his Samoan roots and ongoing cultural attachments. Robinson referred to the 'obligations and expectations' that arise from Wendt's 'big responsibility to be producing ... the primary material for a modern image of the South Pacific' and considered that these 'create problems on the placement and estimation of such a writer'. Noting the 'contradictions' inherent in Wendt's multiple literary roles, Robinson viewed Wendt as the 'chronicler of his country and voice of his region', but also considered that Wendt's 'artistic territory lies at the same time in the immigrant psyche' that 'must create problems for him in choosing his ... identity' $(275,276)$. That is, Robinson portrayed Wendt both as a Pacific writer and an 'internationalist', but not, unequivocally, as a 'New Zealand' writer, implying that these uncertainties of identity underlie an asthenia in the creative work he has produced.

\footnotetext{
${ }^{96}$ Meanjin was published originally, from its first issue in 1940, under the title Meanjin Papers; in 1947 it was retitled as Meanjin; in 1961 it changed to Meanjin Quarterly; and in 1976 it reverted to Meanjin. These variations in the title have been applied in the thesis.
} 
A desire to determine Wendt's proper classification, and to justify his inclusion or exclusion, have been frequently expressed concerns among anthologists of New Zealand 'national' collections, and his problematic, shifting position (that is, as a 'New Zealand', 'Samoan', 'Pacific', 'world', 'expatriate', or simply 'non-New Zealand' writer), has illustrated the provisional and arbitrary nature of such status. Since the 1960s, his verse and short fiction frequently has been included in mainstream literary journals and magazines including Landfall, New Zealand Listener, JAAM, Islands, New Zealand Books, Poetry New Zealand, Takahe, and others. It has also appeared regularly in New Zealand anthologies, since being first selected by McQueen and Cox for Ten Modern New Zealand Poets (1974). Despite this record of inclusion, however, commonly his work has been subject to review and editorial comment in terms of its Samoan orientation, for example in Hill's 2003 essay on Pacific fiction, which was subtitled, 'An Interpretation of Pouliuli'. Often, when Wendt's work was published in mainstream magazines, it was within a separate category of Pacific writing; for example, selections of his verse and short fiction had been included in a group of 'Maori and Polynesian writing' in the magazine Argot in 1962, relegating it to an ethnicallyfocused literary sub-genre. ${ }^{97}$

Also, his work has been extensively anthologized within collections of specifically 'Pacific' and 'Polynesian' writing, in both local and overseas publications. These have included, for example, Wendt's Lali: an Anthology of Pacific Literature (1980) and Nuanua: Pacific Writing in English since 1980 (1995), and Whetu moana: contemporary Polynesian poetry in English (2003), edited by Wendt, Reina Whaitiri and Robert Sullivan. These indicate that Wendt himself identified his work with the Pacific region rather than with New

\footnotetext{
${ }^{97}$ Wendt's work included in Argot 1 (4) in 1962, were the poems 'Now Chained' and 'Death of the Sun', and the short story 'Virgin-Wise: The Last Confession of Humble Man Who is Man Got Religion' (all unpaginated).
} 
Zealand literature, often choosing an overtly Pacific context for publication of his own writing.

Wendt's work, when reviewed in overseas journals, is commonly identified with the descriptors 'Pacific', 'international' or 'world' literatures, rather than 'New Zealand' literature. Examples of the identification of Wendt's work with his Pacific ethnicity include articles such Cliff Watego's 'Cultural adaptation in the South Pacific novel' (1984), in World Literature Written in English; Elizabeth Webby's 'The uses of fiction: Some recent novels from the South Pacific region'(1985), in Span; Sharrad's 'Imagining the Pacific'(1990), in Meanjin; and Subramani's 'Short fiction in the South Pacific'(1981), in New Literatures Review. Clearly, from a critical viewpoint that is located outside the geographical boundaries of New Zealand, Wendt is perceived not as a New Zealand writer, but one inextricably associated with his Pacific ethnicity, or as assimilated into a broadly 'internationalist' cohort.

Wendt's position from the perspective of New Zealand critics and anthologists, however, has been ambiguous, and inconsistently defined. Sturm, reflecting in 1991 in his Introduction to the Oxford History of New Zealand Literature in English upon what he viewed as "new uncertainties surrounding the term "New Zealand literature", commented on the challenges that Wendt's ethnicity and particular literary and cultural foci have presented to the traditional geographic, social and cultural determinants of the local rubric (xi-xii). Citing Wendt's study 'Pacific Maps and Fiction(s)' (1990), Sturm observed that Wendt drew attention to the ways in which maps of New Zealand literature which ignored the fact that the country is part of Polynesia and the Pacific "have determined even such things as the canons and content of so-called New Zealand Literature and Art, and their language and vocabulary" (xi, xii).

In drawing notice to Wendt's perspective in this way within his History, an authoritative account of literary New Zealandness, Sturm was himself promulgating the concept that, while 
the literary voice of Pacific writers belonged within the mainstream concerns of local literature, it remained a distinct category.

The view portrayed in Wendt's writing evades the monocultural and spatiallyconstricted determinants of New Zealandness earlier imposed by Curnow and others sharing his vision of local identity based primarily upon European concepts of cultural value and belonging, suggesting instead a perception of New Zealand's position within a much broader international cultural and physical space. The cultural specificities of identity sought by Curnow and others in the mid-twentieth century - those deemed to be represented by a small group of 'authentic' New Zealand writers 'united by ... "a common inheritance and a common cause" $" 98$ - later ceded to a more uncertain, unstable and eclectic version of New Zealandness, an identity encompassing the contradictory elements of a uniquely essentialist position located within a shifting, globalized context. This instability and diversity of identity is identified in the creative work of expatriate, immigrant and 'Pacific' writers, marginalized within the local canon but demanding a presence that confronts and destabilizes mainstream (Pākehā) representations of New Zealand identity.

Sturm, evaluating in 1991 the various contributions to New Zealand literature of expatriate writers, including Wendt, concluded that the internationalization of New Zealand creative experience had brought about substantive adjustments in notions of national identity, together with social and cultural transformations evident in the local canon. He considered that

a feature of New Zealand literature in the last decade of the twentieth century ... is a more outward focus on New Zealand's experience of the new global economy and environment, and

\footnotetext{
${ }^{98}$ Curnow made this comment, quoting from Eliot's 'The Function of Criticism' (1923), in his Introduction to his 1945 Caxton anthology, 45.
} 
the changed relationships and identities it has brought in its wake. ... The best of our recent literature is actively engaged in negotiating the multiple, uncertain, contested sites of identity, location, history, both within the geographical entity called "New Zealand" (or "Aotearoa") and in its larger, constantly shifting, global relations. It is not simply that the literature increasingly reflects [original emphasis] this global world of shifting, unstable identities (social, economic, linguistic, sexual, national, cross-cultural), and of new communications networks and technologies ... the contexts which sustained literature in English in the past - colony, Dominion, Empire, nation - are no longer "given". New contexts are having to be invented, in a condition of radical uncertainty (1991, xviii, xix).

Such uncertainties have been reflected in the uneasy stance and attitude of apprehension evident in the response of a number of literary commentators towards expatriate, overseas and Pacific writers of 'New Zealand' literature. Some anthologists and critics have sought to incorporate atypical authors such as Wendt within an extended canon of New Zealand writers, while others have marginalized and constrained them to a place firmly outside a narrow, geographically and culturally defined local literature. There was a binarism evident in much of the early discussion of Wendt's work, placing him either as a New Zealand writer or as a Pacific writer, but commonly rejecting the notion that he could be both. Until the 1990s, in particular, there was uncertainty and a lack of critical consensus as to Wendt's 'correct' place in relation to the New Zealand canon, and his assimilation within the paradigm of New Zealand literature at times incited controversy. Later discussion of his status, that was more accepting of Wendt, indicated a shift in the notion of 'New Zealand writer' that was linked to changes in the country's broader sense of national identity, as formerly accepted concepts of New Zealandness adjusted to acknowledge its historical and geographical location in the Pacific. 
Sharrad, in his study Albert Wendt and Pacific Literature: Circling the Void (2003), encompassed Wendt's writing within a separately-defined (sub) genre of 'Pacific Literature', the geographical and cultural focus of which relegates New Zealand interests to a position not at the centre of its sphere of interest, but only at its wider margins. Sharrad claimed that 'Albert Wendt is the most prolific and influential contemporary writer of the Pacific Islands of his native Samoa in particular, but including greater Oceania and New Zealand as well' (vii). To emphasize to the reader the geographic vision of Wendt's (and Sharrad's) literary viewpoint, illustrative maps indicating the micro- and macro-geographic parameters of the various Pacific nations have been provided, showing a range expanding to encompass not only New Zealand but Australia, Hawaii, Japan, Taiwan and the Philippines. He described Wendt as an 'anglophone Pacific Island writer' (ibid, 3), located culturally within an extensive and culturally exotic Pacific context. He pointed out, however, that '[f]rom the national standpoint of Samoa, [Wendt] falls mostly into the always troubled category of "expatriate"" - so that, rather than being fully identified with either New Zealand or Samoa, his position 'invites comparison with "diasporic” writers', in a condition of literary statelessness (ibid, 12).

Wendt himself, in the early stages of his writing, adopted a stance that distanced his work from inclusion within the rubric of mainstream New Zealand literature, identifying himself as 'a man of Oceania' and as a 'Samoan-New Zealander', resisting comprehensive and conclusive incorporation into descriptors of either form of definitive national identity, and shifting freely between them $(1976,49)$. In his introduction to the anthology Nuanua: Pacific Writing in English since 1980 (1995), he classed his work as belonging within a 'Pacific literature', which he defined as 'that written by or composed by Pacific Islands peoples, especially the indigenous peoples' (2) (a categorization not unlike Curnow's definition of New Zealand literature). 
Disassociating himself from the Faber Book of Contemporary South Pacific Stories (1994), compiled by C.K. Stead, which included contributions by New Zealand Europeans among those of writers from a range of Pacific ethnicities, Wendt withheld his work from inclusion, resisting the appropriative 'mythologizing' imposed by the colonial process which was 'still being perpetuated in some of the supposedly post-colonial anthologies and in writing by the descendants of the Papalagi/Pakeha settlers. Today some writing considered by Papalagi/Pakeha writers to be post-colonial, we consider to be colonial' (Wendt, 1995, 2). Challenging the narrowly Eurocentric focus of traditional versions of New Zealandness, Wendt has adopted provocative anti-colonial and postcolonial stances both in his critical and creative work, contending that rather than occupying a position of secondary or marginal status vis-à-vis mainstream New Zealand literature, Pacific literature has 'indigenised and enriched the language of the colonisers and used it to declare our independence and uniqueness' (ibid, 2).

While the early critical reception of Wendt's work was ambivalent, ranging between attitudes of rejection, inclusion or indifference, by the 1990s critics generally had accepted the multiplicity of Wendt's identity, and his existence simultaneously in a number of discrete but overlapping categories of nation, region and style. They indicated an awareness that he belonged elsewhere, as well as here, and his status as a New Zealand writer, with rare exceptions, was no longer questioned. For example, in Elizabeth Alley and Mark Williams's In the same room: Conversations with New Zealand writers (1992), Michael Neill's interview with Wendt is included among those focused on other 'mainstream' New Zealand writers. Most anthologists since the 1990s, also, assumed a generally receptive stance in relation to the contributions of immigrant writers, including Wendt, adopting a view regarding the nature of New Zealandness that embraced and incorporated the country's historical ties and later links to overseas cultural centres, and its context within the broader 
Pacific region. Wendt's verse and short fiction have been selected, without qualification as to his immigrant background, in a number of national anthologies of New Zealand literature. Vincent O'Sullivan, for example, included Wendt, among other expatriates including Italian immigrant Renato Amato in The Oxford Book of New Zealand Short Stories (1992), and a section of seven of Wendt's poems was included in Bornholdt's 1997 Oxford poetry collection. Fiona Kidman and Owen Marshall have both included Wendt's stories in their respective anthologies of New Zealand short fiction.

From his earliest presence in New Zealand letters, a number of mainstream literary magazines published Wendt's work without qualification as to his nationality or ethnicity. Landfall, for example, in 1963 published two of Wendt's stories, both with a Samoan theme 'A descendant of the mountain'99 and 'The Name of the Game'100 - and other selections of his short fiction appeared in later issues. In 1969, Landfall included the three poems, 'Lava Field and Road, Savaii', 'Panthers', and 'For Sina', all with an explicitly Pacific Island setting; ${ }^{101}$ a further six of Wendt's poems appeared in $1970 ;{ }^{102}$ and over subsequent years, his verse appeared regularly. In 1962, in an outline of Landfall's publication policy, Brasch had expressed the magazine's strong attitude of cultural nationalism, stating that, 'In order to permit the growth of a distinctive consciousness and outlook, Landfall has limited itself, as a matter of policy, to printing work by New Zealand writers only (and writers living in New Zealand)'. The inclusion of Wendt's work within Landfall, therefore, indicated an acceptance by some critics that his artistic vision, while indicating measurable differences in topic, theme, cultural orientation and setting from those portrayed in mainstream New Zealand literature, could be assimilated into a view of New Zealandness that was broadly drawn to incorporate the country's Pacific and international cultural context.

\footnotetext{
99 Landfall 66, 1963, 113-118.

${ }^{100}$ Landfall 68, 1963, 328-332.

${ }^{101}$ Landfall 90, 1969, 116-118.

${ }^{102}$ Landfall 96, 1970, 337-341.
} 
Alan Brunton, Murray Edmond and Michele Leggott included selections of Wendt's verse in Big Smoke: New Zealand Poems 1960-1975 (2000), an anthology produced purposefully by its editors to present an alternative and more eclectic vision of New Zealand literature than those they considered were portrayed in 'mainstream' national New Zealand collections, in particular those of the Oxford University Press. In his editorial commentary, Edmond (26) includes Wendt in his list of influential New Zealand writers of the 1960s and seventies, without qualification as to Wendt's national identity and ethnicity. Phoebe Meikle had included Wendt's story 'The Dark Angel' in Short Stories by New Zealanders (1973); ${ }^{103}$ and in her Introduction to Ten Modern New Zealand Story Writers (1976), she expressed her 'regret' at her decision to exclude Wendt's stories from her study, not on the grounds of their content but because their length fell outside her selection limits (xi). She referred to Wendt as being both a 'Polynesian' writer and an 'honorary New Zealander' - the latter descriptor suggesting that Meikle accommodated Wendt's ethnicity on the basis of his literary achievements - and stated the view that 'Polynesian writers enrich and enlarge New Zealand fiction' (xi, xii).

There have been other critical responses to Wendt, however, that have indicated a less accepting approach towards Wendt's work. Fleur Adcock drew a clear demarcation between the genres of 'New Zealand' and 'Pacific' writing, rejecting Wendt's national and cultural credentials for inclusion within the former category. In pointedly excluding his work from her 1982 Oxford verse anthology, Adcock stated that she 'saw no harm in making a stance against the over-hospitable behaviour of those anthologists who claim Albert Wendt as a New Zealand writer [merely] because he happened to be educated here' (ix). Despite Wendt's international success, his long-term employment and residence in New Zealand, and his status as what she termed 'passport-holder', Adcock viewed the markedly Samoan focus

\footnotetext{
${ }^{103}$ This is one of several collections of short stories Meikle produced for use as a reader for secondary schools.
} 
of Wendt's work, and his distinct cultural and artistic differences from mainstream New Zealand identity, as disqualifying him from a place in the local literary canon. Some other anthologists also bypassed Wendt. Bill Manhire, for example, does not include Wendt in either his 100 New Zealand Poems (By 100 New Zealand Writers) (1993), nor in his 121 New Zealand Poems (2005), (although in the latter Manhire included a Pacific Island-themed poem by Tusiata Avia, a Samoan immigrant, whose work subsequently has been regularly included in mainstream New Zealand anthologies). ${ }^{104}$

The place of the expatriate within New Zealand literature, including Wendt, is a specific concern expressed in the Introduction to the 1997 Oxford Anthology of New Zealand Poetry in English. Reflecting on the historical developments of New Zealand society over the period since its colonial beginnings, and significant shifts in the country's international relationships in the later decades of the twentieth century in particular, the editors contextualize the position of the expatriate writer within New Zealand literature in relation to analogous social and cultural changes in New Zealand generally:

With the progressive disintegration since the sixties of residual loyalties to Britain, possible sources of influence have broadened so that the whole decentred world can be a rejuvenating force. ... Contemporary New Zealand literature includes poets who come from or reside elsewhere, and in whose work more than New Zealand influences of culture and geography are present - for instance, the Scot, Alan Riach, and the Samoan, Albert Wendt. In a sense to ask whether Fleur Adcock is a New Zealand or an English poet is to miss the point. ... her dual citizenship (in the poetic sense) enriches both

\footnotetext{
${ }^{104}$ Other factors, such as considerations of aesthetic and personal preference, and general 'fit' with regard to other contents in a collection, rather than primarily of a writer's cultural identity per se, also determine anthologists' particular selection decisions. For example, Manhire earlier had included Wendt's short fiction and poetry in other collections; 'The Dark Angel' was reprinted in the first volume of New Zealand Listener Short Stories in 1977, and several of Wendt's poems appeared in Soho Square IV in 1991, both edited by Manhire.
} 
countries. ... New Zealand poetry has been enlarged by what she has continued to bring to it (xxxii).

However, while the editors acknowledge that expatriate writers 'enrich' the local canon, it is evident that their status remains marginal and ambiguous, occupying an uneasy and shifting placement both 'inside' and 'outside' the bounds of local literature. The selections of Wendt's verse included in the anthology are overtly Samoan in character, both in their dislocated use of English in the form of pidgin, and their particular themes and settings, clearly emphasizing their difference from the other conventionally 'New Zealand' verse in the anthology. Despite the sentiments of inclusivity expressed in the anthology's Introduction, specifying the nationality and origins of contributors to the collection clearly remained of importance to the editors; biographical references were provided - in the case of Wendt, this stated that he was '[b]orn in Western Samoa' (ibid, 107).

The editors refer to Wendt's writing as belonging to an evolving literature of the Pacific region, suggesting that 'his work [is] opening up the Pacific as a field of reference for New Zealand writers', and that it 'eloquently broadens the scope of Pacific writing both within and beyond New Zealand' (ibid, xxxiii). They suggest that 'we abandon the notion of the Pacific Basin as an emptiness surrounded by a fullness from which important things come', and that, instead of an unpeopled void, '[i]t is the scene of journeys, encounter, traffic and exchange' (ibid). The view of New Zealandness proposed by the editors is one that is geographically inclusive, being culturally and ethnically diverse in its particular focus: 'The sense of New Zealand as part of the Pacific, drawing into itself many cultures and experiences, is to be found in the poetry of Ian Wedde, Alan Riach and Alistair Campbell as well as that of Albert Wendt' (ibid). However, while emphasizing the anthology's policy of inclusiveness towards the work of expatriate writers, the editors also have accentuated the aura of 'difference' and exoticism inherent in their position. This suggests that Wendt, along 
with other expatriates included in the collection whose national identity is ambiguous, has been allocated only a provisional place within an anthology of New Zealand literature.

Wendt's work frequently has been included in special interest anthologies of New Zealand verse and short fiction, which commonly focus more on the universality of their particular specialist themes than on a writer's nationality or ethnicity. Within such works, in those cases where a contributor's nationality is referred to, it is generally to emphasize the topical connections between the writers, regardless of their geographical origins, rather than their differences of national origins. Kidman, for example, included a story by Wendt, which was overtly Samoan in its characterization and theme, among a range of others she labelled the work of 'local writers', in the Oxford anthology of New Zealand Love Stories (1999), where its portrayal of the anthology's universalist subject matter was undifferentiated from that of other New Zealand and overseas writers in the collection. Terry Locke, Peter Low, and John Winslade include selections of Wendt's verse in their collection White Feathers: An Anthology of New Zealand and Pacific Poetry on the Theme of Peace (1990). As well as Wendt and Māori writers Hone Tuwhare and Hinewirangi Kohu-Morgan, the anthology includes a number of overseas-born and expatriate writers, including Adcock and Louis Johnson. The editors state that they drew their contributors from the broad range of ' $\mathrm{New}$ Zealand and Pacific' literature, so that the anthology is inclusive of writers from the whole geographic region without distinction in the text as to their nationality or origins. Within this context, Wendt's contribution has been subsumed within the general theme of the collection, without emphasis on his national or cultural identity. Wendt's Samoan-themed story, 'The truth of our love', was included by editor Michael Gifkins in his collection of Australasian short fiction, Tart and Juicy (1994). The thematic link between the stories, including Wendt's, was a reference to food within their text, rather than an emphasis on the nationality of the contributors. Paul Morris, Harry Ricketts and Mike Grimshaw, in their two 
anthologies of 'New Zealand spiritual verse', Spirit in a Strange Land (2002) and Spirit Abroad (2004), have included, without qualification as to their nationality or ethnicity, Pākehā New Zealand writers alongside a range of Māori and Pacific writers, including Hone Tuwhare, Te Ra Hou Henare, Apirana Taylor, Arapera Hiniira Kaa, Trixie Te Arama Menzies, Phil Kawana, and Wendt, as well as European expatriate writers including Fleur Adcock, Kapka Kassabova, Christodoulos Moisa, Emad Jabbar, Sonja Yelich, Russell Haley, and Mogli Lenz. All the poems in Spirit Abroad present an aspect of spiritual identity that provides a common trope in the collection that, in this setting, eclipses issues of cultural affiliation.

In such special interest anthologies, a specific common thematic concern generally is the primary focus of the editors, rather than simply producing a subset of New Zealand literature; while utilizing the term 'New Zealand' in their titles provides a structure to the collections, and suggests that creative work emanating from a particular region does illustrate some difference in literary perspective, this is generally not the compilers' major interest (as this is indicated in the content of their editorial commentaries). The national identities of the contributors, therefore, while having some relevance to a collection, has less significance than the relationship of their work to its core theme, and often a more flexible interpretation of 'New Zealand' is applied, and a more diverse range of writers accommodated, in order to achieve a compiler's end.

In the case of a collection where national or regional identity is itself an underlying theme of the collection, however - as it is in a 'New Zealand' anthology - the origins and nationality of a contributor, and the cultural orientation of their work, are considerations of more fundamental importance in decisions of selection (and rejection) of particular writers and specific pieces of work. The response of compilers and critics to Wendt's place in relation to anthologies of local literature parallels and emphasizes the discourse focused on 
New Zealand's place more broadly in a wider Pacific and international context, rather than as a minor and geographically distant satellite of the European cultural centre. The major reason proposed by those anthologists who have excluded Wendt's work is the perception that it properly belongs to a separate category of Pacific writing rather than within mainstream New Zealand literature. For those anthologists whose concept of New Zealandness has extended to assimilate Māori and Pacific cultures together with the work of local and expatriate European writers, Wendt's work readily has been incorporated within mainstream collections. Often, however, this is accompanied by a justificatory reference, either explicit or implicit, for doing so.

Despite other changes and an attitude of greater acceptance towards the presence of expatriates within New Zealand literature, this apparent need to rationalize the selection of particular writers, particularly those from a Pacific background, did not alter substantively after the end of the century. For example, Owen Marshall included Wendt in Essential New Zealand Short Stories (2002), and, in his Introduction, claimed that it was not his intention to follow the practice of other editors in seeking to 'highlight alternative work', nor 'an attempt at a balanced presentation of literary concerns and constituencies' (12). However, in his particular selections in the anthology, Marshall constructed those effects; as well as a Samoan-themed story by Wendt, Marshall included selections from a number of Māori writers, including Ngahuia te Awekotuku, whose creative work, despite being widely published, had not been included elsewhere at that time in a New Zealand national anthology. ${ }^{105}$ Marshall provided a definition of New Zealand literature that specified it was inclusive of 'the recent and vigorous Maori and Pacific voice in New Zealand writing', referring to these together as an entity distinct from the 'Pākehā' voice that was dominant in

\footnotetext{
${ }^{105}$ Te Awekotuku's work had been previously published in special interest anthologies, including Fiona Kidman's New Zealand Love Stories (1999).
} 
the anthology (ibid). Jack Ross, similarly, in the Preface to his anthology, New New Zealand Poets in Performance (2008), refers to 'the strong multicultural and indigenous tradition pioneered by poets such as Hone Tuwhare and Albert Wendt, which has borne fruit in the ... work of Pasifika poets such as Tusiata Ava and John Pule. ... [and] Robert Sullivan - a poet of Maori and Irish descent'(xi).

Earlier, Bernard Gadd, in Pacific Voices: An Anthology of Maori and Pacific Writing (1989), had included the work of a number of Māori and Pacific writers who, by the late 1990s, were also commonly included within mainstream anthologies of New Zealand literature. These include Alistair Te Ariki Campbell, Hone Tuwhare, Witi Ihimaera, Patricia Grace, Keri Hulme, David Eggleton, and Rowley Habib, as well as Wendt. In a number of such anthologies and a body of critical writing, there is an elision of Māori with 'Polynesian' literature, so that these are merged indivisibly as 'Pacific literature' to act as an exotic Other contrasted against mainstream 'New Zealand' literature. Examples of this synthesis include S.F.D. Hughes's 'Pakeha and Maori behind the tattooed face: the emergence of a Polynesian voice in New Zealand fiction' (1981); Peggy Nightingale's 'All any man with a club can do: Albert Wendt and Witi Ihimaera' (1982); and H. Isernhagen's 'Why novels? Why short stories? A note on the use of genres in the works of Witi Ihimaera and Albert Wendt' (1994).

The varying responses of different anthologists towards the work of Pacific writers, such as Wendt, reveal that, while in some contexts, and in the case of particular anthologists and critics, the demarcation between 'Pacific writing' and 'New Zealand writing' has over time become less definite and distinct, it is apparent that in others the distinction remains firmly manifest. The range and intensity of such responses reveal the ongoing uncertainties and anxieties that underlie constructs of New Zealand national identity, and, concomitantly, that are inherent in the term 'New Zealand literature'. The hybrid nature and multiplicity of potential national identity/ies evident in the work of such writers present a cogent challenge 
to national anthologies of New Zealand literature that threatens to undermine the notion that specific geographic and cultural margins of the local canon can, in fact, be clearly demarcated.

Sturm, in his Introduction to the 1991 Oxford History, proposed that the critical response towards the expatriate writer in local literature had changed substantively over time, and that the country's attitude demonstrated a wider acceptance of 'outside' cultural influences than it had in the past (xi, xii). He observed a marked shift in the later decades of the twentieth century away from the earlier exclusive nationalist and localist perspective of New Zealandness towards one more broadly multiculturalist, into which the expatriate was readily assimilated. David Eggleton and Iain Sharp similarly contended that 'New Zealand poetry has become more various in its voices', claiming that there had evolved 'a new poetry of multiculturalism' $(2000,1)$. They noted that recent anthologies of New Zealand literature were inclusive of an ethnically diverse range of contributors, including those they identified as 'Chinese-New Zealander Lynda Chanwai-Earle; Western Samoan Sia Figiel; Niuean John Pule; African-American Lewis Scott; [and] Bulgarian Kapka Kassabova', carefully specifying the national identity of the writers they referred to (ibid, 1,2).

However, while there was a broader ethnic and cultural diversity evident in the selections within the anthologies of New Zealand verse and fiction published in the 1990s, such as Bornholdt, O’Brien and Williams's 1997 Oxford poetry anthology, it was still the case that the overseas origins and nationality of expatriate contributors commonly were given emphasis by the editors, as well as the place of residence of those New Zealanders who have emigrated to other countries. This indicated that, rather than complete assimilation and unconditional acceptance, a sense of the exoticism and difference of such writers from what was considered to be the mainstream continued to be marked. The legacy of Curnow's early directive that, to be considered as an 'authentic' and 'real' New Zealand literature that 
expressed 'true vision', it could be written only by 'one of ourselves', had lingered on at least until the end of the twentieth century, and continued to be evident in later collections. An analysis of the critical discussion relating to the various concepts of 'authenticity' and 'reality' that have been promulgated by national anthologists, including Curnow, and how these have been represented in local literature, form the focus of the following chapter. 


\title{
CHAPTER FOUR: 'TRUE VISION' - THE LITERARY CONSTRUCTION OF NEW ZEALAND 'REALITY'
}

\author{
Reality must be local and special at the point where we \\ pick up the traces ... Whatever is true vision belongs \\ here, uniquely to the islands of New Zealand. \\ (Allen Curnow, 1960, 1) \\ [W]e ought to ... find the confidence that comes from \\ our knowing our place in the world, before we can \\ expect to write authentically. \\ (Patrick Evans, 1977, 111)
}

While the previous chapter considered the literary nationalist discourse on who should be accepted as a New Zealand writer for the purposes of inclusion within a local canon, this section addresses the associated critical debate that has focused on the question of what should be written and the appropriate forms in which local writing should be expressed in order for it to be properly considered as New Zealand literature. This deliberation within the literary culture has centred upon two distinct but related issues. The first is the concern of many New Zealand writers and critics with establishing the nature of 'authenticity' and 'truthfulness' in local writing, and with defining the particular characteristics of the 'reality' of New Zealandness as it ought to be represented in verse and fiction. The second is the desire to determine the appropriate nature of this country's ongoing relationship with the European cultural centre from which its social and artistic structures and values are descended, and the related dispute regarding whether localism or internationalism should be considered the 'correct' foundation for an identifiably New Zealand literature. These two particular aspects of local literary nationalism will be considered in turn in this chapter. This discussion draws upon and is informed by the critical and theoretical concepts of nationalism, authenticity and cultural dissension proposed by Craig Calhoun and others.

An insistence upon realism and the requirement that to be considered of value local writing must portray an authentic expression of the New Zealand 'character', landscape, 
experience and voice have been pervasive since the early colonial period, and applied both to verse and fiction. The production of local literature has been linked to the construction of a 'true' representation of the nation's identity, and some influential critics have been explicit in demanding that to be accepted into the canon it must portray an accurate version of New Zealandness. Typical of such comments is Holcroft's directive in 'The Flood Comes Down', an essay published in Tomorrow in 1937, that 'writings must be attempted which aim at the discovery of an essential New Zealand' (149). Realism was the dominant mode of local writing, with some notable exceptions, until at least the last decades of the twentieth century. In the 1980s, there had been an attempt to instigate what Evans, in The Long Forgetting (2007), terms an 'anti-realist' project', which was directed in particular at subverting the literary nationalists' restrictive influence over the conventions of local creative and critical writing (23). As discussed in Chapter Two, this was addressed, with different foci, by the editors of new magazines Parallax, Splash, And, and Antic, who promoted a conception of local literature and an analytical stance which Evans describes as being 'a detachment from an unquestioningly realist and New Critical past and a commitment to the new kinds of critical reading and thinking' $(23,24)$. This movement flared briefly with the lives of the magazines, however, and beyond the small centre within which this had originated, it had only limited impact on the predominance of realism at that time in the mainstream of New Zealand creative writing.

The portrayal of 'authenticity' had long been established as an essential requirement for positive critical assessment of local work. Baigent, for example, praised Bethell's verse for what he termed its 'realist' approach and the poet's 'realistic cast of mind', and considered the strengths of the poetry to lie in what he saw as its concern 'with fact, not fantasy; that it is objective rather than subjective, reflective rather than imaginative' (1951, 27). Baigent's concerns, and his emphasis on realism, were typical of New Zealand literary 
reviewers and critics of that time. Curnow, in particular, was a cogent advocate for the expression in literature of what he saw to be the reality of New Zealand experience, and insisted that its portrayal was the primary function of local writing. In his 1964 essay 'New Zealand Literature: The Case for a Working Definition', in which he set out his concept of a manifesto for constructing a local literature, he asserted that local writers, in order 'to write poems that transcend time and place ... must achieve a correct vision of their own time and place' (99). He claimed that writers should portray a vision of New Zealandness in which 'we recognize ... something of ourselves', and that 'a quickened awareness of the place and people ... is written into the writer's contract with reality' (ibid, 87, 96).

Also, emphasizing his view that the quality of 'authenticity' should be fundamental to the purpose of local writing, he insisted that the New Zealand people are 'the immediate other of which and to whom we must write' (Curnow's emphasis), and that '[o]ur fictions are to be true' (ibid, 96, 103). These comments, and his use of the term 'we', as a discrete and privileged community differentiated from those comprising the 'other', suggest that Curnow viewed those local writers who shared his views to be a distinct and separate group, apart from their local readership, and with a duty to construct in their creative writing a literary version of New Zealandness that he judged to be truthful and correct in what it portrayed that is, a view that 'authenticity' was created rather than simply reflected. Paradoxically, he wanted truthfulness to be expressed, yet allowed that it must be constructed rather than simply mirrored, to be fashioned rather than merely grasped.

Curnow's assertions in regard to national identity and its relationship to 'reality' in literature have been particularly influential, both among his contemporaries and many subsequent writers and critics who have considered his views to represent a manifesto for local verse. They articulated a firmly-delineated foundation that provided, for some, a sense of certainty and clarity in terms of shaping a defined concept of national identity; but for 
others, however, they have been a source of considerable critical contention that illustrated the issues of uncertainty and instability that underlay efforts to establish a notion of identity, rather than serving to resolve them.

The processes of nation-building, the development of national identity, and the impacts of a dominant cultural centre upon the development of collective self-identity in small nations that are located at the geographical, social and cultural periphery, have been the focus of a body of literature analyzing the development of post-colonial literatures. Craig Calhoun, in Nationalism (1997), analyzes the correlation between the process of developing a distinctive national identity, constructions of 'authenticity' in representations of identity, and the competing claims among different cultural factions for 'possession' of the site of the 'real' in identity-construction (107). Calhoun sees one of the processes intrinsic to establishing national identity as identifying and codifying the imagery, symbolism, and other literary and aesthetic devices that serve to construct and portray 'realness' of experience. He also describes the contestation for dominance among different factions that promote oppositional 'discourses of legitimation' and compete for domination of the cultural and other institutions that form a society's substructure of identity (ibid). In this process, Calhoun observes that

certain versions of collective culture were constructed as "authentic" ... others ... constructed as "deviant", or relegated to "minorities". This [process] involved not just inventing new traditions, but also the fixing of previously more flexible and continually renewed traditions and the institutionalization both of biases and of powerful agents of cultural regulation (83).

In this conceptual model, literary constructions are essential to framing and reflecting the forms in which collective identity are depicted and 'recognized', and oppositional groups vie 
for dominance and control over the particular mode and structure in which it is to be conceptualized.

Calhoun contends that members of nations 'understand themselves through the discursive framework of national identity', and that nations are 'commonly forged in the struggle carried out by some members of the nation-in-making to get others to recognize its genuine nation-ness' (99). He concludes that contention among opposing groups over the control of identity-construction is inexorable, and proposes that the 'ideas of nation, nationality and the like are "essentially contested" because any particular definition of them will privilege some collectivities, interests and identities and damage the claims of others' (98). In a section entitled 'Universalism and Parochialism', ${ }^{106}$ he examines the nexus between the individual, the nation, and a significant overseas centre. In this relationship, the construction of national identity is confronted with the problems of determining 'who was an insider, a citizen, and who was an outsider, a foreigner', so that the concepts 'inside' and 'outside' are required to assume boundaries that are concomitantly inconsistent with, but dependent upon, the existence of the 'centre' $(1997,87)$. In this view, nationalism is not simply the separate identification of groups within defined bounds set apart from what is defined as being 'overseas', but an ontological position defining an entire worldview, and which requires the determination of a common identity within the nation and also the assumption of a functional 'other', so that adopting a separate identity functions as a 'distinction from ... neighbours' (14). In Calhoun's reasoning, the proper purpose of a country's literature is to produce 'authenticity', which is equated to the accurate codification of the experience of place.

${ }^{106}$ The terms 'universalism' and 'parochialism' are discussed in Chapter Five of Calhoun's Nationalism, 1997. 
Why should it have been, however, that in a newly-settled, small and geographically distant country such as New Zealand, the nineteenth-century English convention of realism was transferred by the immigrants to its new context and so readily retained and promoted by writers and critics as the required literary form for local literature, and the means for representing concepts of 'authenticity'? In a number of other important aspects of the country's social and cultural structure, such as employment practices, women's suffrage, land ownership reforms, and the concept of ideals of egalitarianism, where the opportunity to implement experimentation and new political and social forms was taken, many other imported British conventions were curtailed or dispensed with. Why, then, was the Victorian cultural practice of literary realism - adapted later to incorporate the precepts of contemporary (1930s) English realism, and, to a lesser extent, that of American writers like Sherwood Anderson - retained as the required form for the newly-developing local literature?

A range of critics over time have pondered this issue, noting and commenting upon the dominance of the realistic mode in New Zealand literature, and have suggested a number of different reasons for its prevalence, most relating it to concepts of national identity. Lawrence Jones, for example, in a 1977 essay in Islands entitled the 'The Persistence of Realism, ${ }^{107}$ observed the continuing dependence in New Zealand fiction upon a strongly representational mode of expression, and a general resistance by local writers towards assimilating the international influences of modernism. Jones noted that in the 1930s and 1940s New Zealand writing developed a particular form of realistic expression, which he described as 'indigenous critical realism' $(1987,17)$. This local adaptation of the realistic mode is evident in particular in the short fiction of Sargeson and other literary nationalists,

${ }^{107}$ This essay was reprinted, under the same title, in Jones's Barbed Wire and Mirrors (1987). 
who assimilated it into their work in what became recognizable as a unique New Zealand style. $^{108}$

Curnow, as well as others, has commented upon the early emphasis placed by local writers of both verse and fiction on the criterion of artistic 'truthfulness', often linking it to a purposeful aim to construct a distinctive collective identity for the new country. Rhodes, for example, in New Zealand Fiction Since 1945 (1968), noted that, in local writing, 'increasing attempts [are made] to confront, to explore and to interpret the reality of human experience' (11). Rhodes himself assessed the quality of 'reality' to be a strongly positive feature of the best local writing (ibid). Later, reflecting on the importance of literature to the construction of a unique national identity, he stated:

As New Zealanders we do not know ourselves, except from statistical analyses and historical summaries, until we become enshrined in art; and it is through the novel that we may discover ourselves and each other. The dominant themes of the New Zealand novelist can help to give us further indications of the reality surrounding and including us ... [it is] only in the best of our more serious fiction ... [we] can achieve a significance that approximates to imaginative truth (1969, 4748).

Repeated similar assertions made by critics and other commentators at the time illustrate that the portrayal of what were perceived to be qualities of truthfulness and authenticity was associated with the highest standards of creative writing. The focus on reality in cultural nationalisms, especially in the 1930s and 1940s, was influenced by the legacy of social realism imported with settlement, and later a response to the prevailing

\footnotetext{
${ }^{108}$ Jones has discussed the pervasiveness of realism in New Zealand literature in other articles and reviews, also. For example, in 'New Zealand Realism: Retrospect and Prospect', in Landfall in 1986, he reviewed a number of local novels that together provided an overview of 'New Zealand realism, its origins, development, and present position', 472.
} 
imprint of the Depression. This is evident in the impact in the 1930s of the Left political and social ideals on many intellectuals in New Zealand, as overseas, which motivated an internationalist movement in the arts, and drew a number of local writers and critics towards the values and ideology of communism, including Mason and Rhodes, among others. These views informed their creative and critical writing, and provided an internationalist element to their perspective on the role of the arts and on the nature of New Zealand identity.

In New Zealand Novels (1969), Rhodes indicated his strong support for the cultural nationalist imperative of Curnow and others in local literature, but his approach towards an obligation for local writers to portray the 'reality' of New Zealandness in their fiction was paradoxical, and in significant ways fundamentally different from Curnow's. In contrast, Rhodes's stance in regard to depicting the country's collective identity was based on the social and human, rather than geographical and natural aspects of its nature. He stated, for example, that the New Zealand writer 'is vitally concerned with Man in Society', and that his proper role is to discover and portray this concept of 'reality' in order that 'men can know and understand each other' $(1969,47,48)$. This view of the function of the arts is suggestive of the internationalist manifesto of the social realist movement, and Rhodes's position in proposing fidelity to localism in the country's fiction was infused with the broader internationalist agenda of his political alignment. ${ }^{109}$

Stead also considered the issue of realism in local writing in 'From Wystan to Carlos - Modern and Modernism in Recent New Zealand Poetry', in Islands in $1979 .{ }^{110} \mathrm{He}$ ascribed

\footnotetext{
${ }^{109}$ Max Rieser, in 'The Aesthetic Theory of Social Realism' (1957), outlines the tenets of the social realist movement that required the intrinsic linking of artistic expression with political ideology to construct a 'true reflection of reality' in literature, as prescribed by Georg Lukács and others (247). The influence of the international Left movement on New Zealand writing in the 1930s, and of its emphasis on social rather than geographical affiliations as markers of identity, are discussed in Rachel Barrowman's A Popular Vision, 1991, and Stuart Murray's Never a Soul at Home, 1998.

${ }^{110}$ Stead's essay was reprinted in In the Glass Case (1981).
} 
the development of the local variant of realism to what he perceived to be the largely collective assumption among writers and commentators that, in order to be regarded as being of value, locally-produced creative work must confront the 'economic, political, social, [and] historical realities' of New Zealand life - a view that agreed with the tenets of the socially conscious and active form identified in Jones's 'critical realism'. Writing which failed to comply with this paradigm of realism would be considered inauthentic and aberrant, and rejected from inclusion within the local canon (1981a, 145).

Stead further addresses the focus on realism, and its fundamental role in local literature, in his Introduction to Kin of Place (2002). Here he discusses the essential task and complex nature - of developing a distinctive, separate New Zealand identity, and relates these difficulties to their wider context of the events of the country's history as a settler nation:

[T]he importance of the local in literature is immense - the more so if your region is only emerging ... from a phase of colonialism in which the sense of what is "real" has been in some degree compromised by an inherited literature and literary history which cannot deal at all with what is immediate to hand $(2002,3)$.

Stead here acknowledges that literary realism did not fit easily in colonial New Zealand with the available Victorian modes of writing, including the 'realist' novel. However, as discussed by Jane Stafford and Mark Williams in Maoriland (2006), the colonial writers, both poets and novelists, were themselves aware of this problematic issue, and drew attention to it; they recognized that the words they used did not fit the new place, and adapted their writing to reflect their own version of local reality. That this was itself a construct, however, is evident in the fact that cultural nationalists in later decades castigated those writers for the lack of 
reality in their writing, as it differed from subsequent perceptions of how this should be represented.

The critical requirement that 'reality' should be depicted in local literature - and that it was the only acceptable form for New Zealand writing - diminished over the later decades of the twentieth century. Criticism became more diverse and nuanced, and the canon subsequently more inclusive of a wider variety of stylistic modes, such as the magical realism and non-realistic imaginative devices presented in the fiction of writers including Frame, Elizabeth Knox, Lloyd Jones, Witi Ihimaera, Mike Johnson, Vivienne Plumb, and Stead, among others. However, the stipulation that realism was the required mode for New Zealand fiction did not dissipate entirely at the end of the century but remained, in different forms, as a dominant and persistent feature of what is regarded as authentically local literature. This can be seen, for example, in Sarah Quigley's 'Clear-eyed views of a real country', a contemporary review of the third edition of Marion McLeod and Bill Manhire's Some Other Country (1997). While noting the eclectic range of literary styles, subject matter and the 'many voices' included in the anthology, Quigley commended particularly what she considered to be the collective accuracy of its portrayal of New Zealand identity. She considered that the stories were marked by 'familiarity', and that '[a]11 are clear-sighted treatments of a real country - a reality summed up ... as cold and wet, horse-dung and broken eggs' $(1997,17)$. Such comments, that emphasize and laud a work's fidelity to the depiction of an 'authentic' and recognizable view of New Zealandness, continue to be a common feature of reviews and other critical writing, despite substantive changes over time in what this term represents. 


\section{Versions of the 'Real'}

The imperative that realism and authenticity should be intrinsic to the New Zealand artistic vision often has been linked in its source to the continuing uncertainties underlying concepts of Pākehā identity, correlated with a persisting ambivalence towards the nation's British colonial past. Reid, in New Zealand Non-Fiction (1968), noted that contemporary records indicate the extent to which New Zealand's early colonial settlers demonstrated 'a passion for documentation and descriptions of the new land ... recording and analysing life in this country and its physical appearance', aligning this affinity for recording 'reality' with its later expression in contemporary writing, even though in very different forms (1968, Introduction, n.p.). Although this kind of 'truthfulness' of reporting by the early colonial observers was very different from the kind of realism and authenticity favoured by the later cultural nationalists, it indicates an underlying similarity of purpose that carried forward into the following century.

The early colonial act of imposing the symbols and institutions of social and cultural possession upon the country - with modes of description, in the form of writing, functioning as a notional form of ownership - augmented the physical reality of occupation. This suggests a strong desire on behalf of the new settlers to establish a codified claim - and sense of legitimation - in the form of imposing new maps, descriptors and place-names in English over the landscape that they had appropriated commonly by means of occupation, violence and dispossession. This extended into the art and literature that was produced in the colonial period which utilized a form of heightened realism, mediated through the conventional European artistic conventions of the time, to portray a desired interpretation of the landscape and its settlement that would be both recognizable and attractive in its familiarity of expression to its overseas as well as local audience. 
An unresolved sense of unease associated with the historical legitimacy of Pākehā settlement in New Zealand has impacted upon the development of this country's national identity, and while commonly addressed obliquely rather than directly, is a characteristic perceptible throughout much of the body of New Zealand's creative and critical literature. This collective disquiet is evident as a particular characteristic inherent in New Zealand writing, and has formed the basis for its major thematic foci. It underlies a persistent apprehension that has evoked in local writers and critics an aspiration to formulate a distinctive identity that clearly distinguishes this nation from its colonial origins, and also from other analogous settler communities.

While it has taken specific forms in New Zealand writing, a closely representational realist mode of writing is common also in the literatures of other former British colonies, particularly those of Australia and Anglophone Canada. ${ }^{111}$ Stead, for example, in 'Les Murray: Authentic Oz', an article in Answering to the Language (1989), observes a similar emphasis on the requirement for authenticity and realism, and their link to the development of nationalism, in a study of 1950s Australian poetry (1989a, 123). ${ }^{112}$ Robert Lecker, also, in 'The Canonization of Canadian Literature' (1990) reflects upon how realism, in the form of what he terms 'idealized mimesis', has been a dominant feature in Canada's writing, and discusses its utilization as a means of verifying 'national consciousness' and 'cultural selfrecognition' (1990, 662). Lecker observes that Canadian literature, along with other European cultural forms and their related critical analyses in that country, have become inseparable from the wider issues of the determination of national identity, and have themselves become engaged with expressions of overt nationalism, based primarily on particular 'accepted'

\footnotetext{
${ }^{111}$ In some other postcolonial literatures, in particular those of a number of countries in South America, Africa and the Caribbean, representational realism has often been displaced by forms of magical realism as a characteristic literary mode. This can be seen in the work of Miguel Angel Asturias, Alejo Carpentier, Julio Cortázar, Gabriel García Márquez, Ben Okri, and others.

112 The parallels between developments in Australian and New Zealand poetry and national identity are discussed further in Chapter Five.
} 
forms of realistic representation (ibid). Similar patterns can be observed in New Zealand since the $1860 \mathrm{~s}$, in the incorporation of realism into local verse and fiction in the development of a distinctive New Zealand literature that is aligned to, and representative of, a collective (Pākehā) identity that would distinguish the newly emerging nation as a separate cultural entity. While some writers have moved away from realism, or at least its dominance, since the 1980s, it remains strongly present as a distinctive characteristic of much local creative writing.

The early emphasis on reality in artistic expression and its continuation in most New Zealand creative and critical writing has its roots in the country's historical background and its continuing uncertainties regarding the determination of its place within an international cultural environment. Anxieties relating to the complex processes of constructing a separate identity in the context of the country's colonial origins continued to be expressed in the literature long after the early stages of the country's emergence from its status of dependence upon Britain. Issues of determining the nature of national identity remain a preoccupation, indicating that these concerns are still unresolved. This desire to assert a unique, separate identity is evident in the development of a particular strand within the genre of realism in New Zealand literature, identifiable in particular from the 1930s onwards, that was expressed in the form of an introverted and self-isolating provincialism. The proponents of this separate, distinct local identity rejected both the 'taint' of New Zealand's colonial past, which they saw evident in the earlier Victorian and Georgian-styled writing based upon outmoded British traditions, and also the continuing perceived threat of its dilution and attenuation resulting from the assimilation into local writing of contemporary overseas literary trends. They considered that New Zealanders had become uniquely different from their colonial origins and from other nationalities, and should express this difference in their writing. This sentiment is evident, for example in Fairburn's remark in a letter he sent from England to 
Mason in 1932, that 'we really are people of a different race, and have no right to be monkeying about with European culture'. ${ }^{113}$

The intent to construct a discrete, locally-oriented cultural identity detached from its wider context, however, has been destabilized by the fundamental contradictions in the desire to assert the country's uniqueness and difference whilst seeking to retain its historical and ongoing associations with mainstream literature of the international cultural centres. This paradox has resulted in an impression of uncertainty, and a lack of clarity or consensus in defining the specific nature of a distinctive, separate local identity, or even of its discrete existence. Consequent to this irresolution in regard to defining the specific nature of New Zealandness have been attempts to impose highly prescriptive literary criteria - in particular those proposed by Curnow and other cultural nationalists - as a means to subsume these undermining contradictions within fixed representations of local identity.

Others, while commonly accepting the requirement that some form of realism is the appropriate genre for local writing, have reflected upon the reasons for its early establishment as the dominant mode, and have sought to trace the underlying causative factors for this being so, as well as the particular effects this has had upon the shaping of a distinctively New Zealand literature. Some, including Frank Sargeson, have proposed that a significant factor in the adoption of realism has been the particularly close self-identification of local writers with a version of national identity that has been shaped by the specific experiences of the country's settler history, and of its geographical and social 'realities'. In 'A Book of Stories', an article in Landfall in 1954, Sargeson expressed the view that the particular conditions of early colonial life formed the major driver of the New Zealand preference for realism in fiction. He considered that ' $[\mathrm{g}]$ iven a certain kind of society, you may reasonably expect a

\footnotetext{
${ }^{113}$ Fairburn's letter is included in Lauris Edmond's The Letters of A. R. D. Fairburn, 1981, 62, 63.
} 
certain kind of novelist', associating the development of the realistic mode in local literature to the particular societal context within which it developed in New Zealand, in the same manner that the specific environmental, social and political conditions of life in provincial nineteenth-century England had shaped the form of realistic expression in the novels of George Eliot (Sargeson, 1954, 22-26).

Often, writers and critics have interlinked what they have deemed to be examples of realistic and truthful writing with concepts of authenticity and value, with the aim of legitimizing their assertions in regard to the qualities of their own and others' work. Sargeson linked the mimetic realism of his own short fiction to his view that a major purpose of writing should be to hold up a 'mirror' to portray accurately the social as well as personal context within which it is written.

Sargeson's views were endorsed by those who considered that local writing should be used overtly as a vehicle for promoting particular concepts of national identity. Rhodes, for example, commended Sargeson for his aim of recreating a sense of a 'real New Zealand' in his stories. He stated that Sargeson had successfully portrayed 'characteristic elements of the New Zealand scene ... in a distinctive and localised setting', and had taken up the role of being its 'authentic interpreter' by 'looking with New Zealand eyes and hearing with New Zealand ears'. Sargeson, in Rhodes's view, had rejected the 'alien artificialities of contemporary English style', so that his writing 'created an analogue to something indefinably New Zealand' (1968a, 7, 16). In his assessment, the most vital and important quality of Sargeson's fictional work, therefore, was its alignment with reality, and its positive evaluation was based primarily upon what Rhodes viewed as its achievement in creating an authentic textual reproduction of New Zealand identity. These criteria have formed major factors in the measurement of value in local literary work, and 'authenticity' as it has been 
determined by influential critics, linked to realism, frequently has been utilized as the major basis for the evaluation of quality in writing.

While a number of commentators have associated the dominance of realism in the country's literature with factors present in the local cultural environment, others have also reflected on the strong influence of overseas literary models and trends, which they see as having been adopted and emulated by local poets. Stead, for example, noted in particular the impact in the early decades of the twentieth-century of the Georgian realist tradition. He cited as an example of these pervasive influences Wilfred Owen's injunction that “"'true poets must be truthful"' (Stead, 1981a, 145). ${ }^{114}$ Stead had earlier referred to Owen's dictum about 'truth' in an article in London Review of Books, 'What became of Modernism?' (1980), in which he noted the influential 'strand' in Georgianism that he describes as being 'urban and honest'. ${ }^{115}$ Another important influence on New Zealand poetry that Stead identified was the impact of the realist verse of Owen, among others, upon the political poets of the 1930s, which became evident later in the verse of a number of local writers (Stead, 1980, 14).

Hugh Roberts, also, in 2003 pondered the motivations that underlay the determination of Curnow and other literary nationalists to impose a restrictive set of defining rules for the establishment of a distinctive local literature, and links this to the conditions of New Zealand's colonial background. Roberts suggested that this desire to construct an impression of separateness and uniqueness is an attempt to counter a potential immersion of local identity in the context of a predominant overseas culture. Roberts considered that this reaction "emerges in response to some sense that the "authentic" identity of the nation has been threatened and that the work of literature is to recover that identity' $(2003,220)$. Further, Roberts proposed that this reflects the view of Curnow and others that the

\footnotetext{
${ }^{114}$ Owen's quotation is taken from his 1919 MS entitled 'Preface'. This was subsequently published by Chatto and Windus, London, in The Complete Poems and Fragments (1983), edited by Jon Stallworthy.

${ }^{115}$ The other strand that Stead notes is the 'sentimental and rural', which caused Georgianism to be become 'a term of abuse' $(1980,14)$.
} 
development of a strongly defined, separate local literary identity was essential in order to resist and overcome a perceived threat from outside, from '[s]ome initial psychic or cultural wound - a foreign invasion, a dominating cultural metropole' (ibid). In this view, only with such effective resistance could a local literature emerge and thereby allow the 'true expression of the national genius' to flourish, (ibid, 220). In the case of New Zealand, in the context of its colonial origins, lacking a strongly located individual identity, and always at risk of being subsumed into the far larger, dominant cultures within which it formed a minor sub-stream, this threat was perceived as a potentially overwhelming presence which required an act of literary resistance - the construction of what was perceived as an authentic and truthful local literature - with which to ward it off. This concept is evident both in local poetry and fiction.

\section{The 'Search for Reality'}

Curnow, in particular, emphasized the importance of a clearly-defined national identity in the construction of a separate, indigenous literature. At the beginning of his Introduction to The Penguin Book of New Zealand Verse (1960), Curnow proposed a manifesto for the definition of an authentic and distinctive New Zealand literary canon. In compiling the anthology, he stated explicitly that he viewed his own function, as critic and anthologist, as that of conducting 'a search for reality ... of which New Zealand has been the scene' (17). The vision of New Zealandness that Curnow expressed in his anthologies and criticism at that time, however, was one of exclusivity rather than comprehensiveness - and rather than being merely a searcher after reality, he, together with those literary nationalists who shared his views, was also the creator and promoter of a particular version of this quality of the 'real'. In setting specific parameters for the particular inclusions (and exclusions) for his 
anthologies, Curnow sought to institute his own perspective of which particular characteristics were to be deemed to comprise an authentic New Zealandness, and also to establish a set of standards, based on criteria of authenticity and truthfulness of expression, for gauging value in local literature.

In 1945, for example, he stated that his intention as an anthologist was to 'provide some ground upon which the worth of our verse can be estimated', and to display poets whose work seemed to him 'to serve, in New Zealand, what I take to be the purposes of good verse in any country' $(1945 \mathrm{a}, 15)$. He considered that 'anyone capable of poetry, feeling his own land and people, his footing on the earth, to be in any way inadequate, unstable, unreal, is bound to attempt a resolution of the problems set by his birth' (ibid, 22). Curnow continued in later decades to express similar views regarding the integral relationship between literature and nationalism; in 1960 he asserted that 'the best of our verse is marked or moulded everywhere by peculiar pressures ... arising from the isolation of the country, its physical character, and its history' $(1960,17)$. The notion that the very physical character of the land itself was different from that of other countries was an important factor in conceptions of New Zealand that were expressed from the early period of its colonization, and continued in the country's literature into later decades. Early poets such as William Pember Reeves, in 'A Colonist in his Garden', for example - which Curnow included in his 1960 anthology - referred to a land where settlers must 'stand where none before have stood/ And ... Fight Nature for a home'. ${ }^{116}$ Similar sentiments, explicit or implicit, regarding the newness, emptiness, uniqueness and hostility of the land, formed a common theme in much local verse, as well as fiction, and were considered by Curnow to be a mark of authenticity of experience of the country.

\footnotetext{
${ }^{116}$ This appears in a section of Reeves's poems included in New Zealand Verse (1960), pages 98-101.
} 
While he was arguing for a narrowly-focused prescription for local writing based upon a particular conception of national identity, however, Curnow's deliberations indicate also that he recognized the complexities that underlay attempts to define the nature of the country's identity in this way, and undertook to reconcile them. There are a number of references in his critical writing to the contradictions inherent in the proposed dualism of a concept of New Zealand artistic 'difference' that, while being based primarily on a notion of nationalism and literary exceptionalism, also acknowledges the country's ongoing dependence upon its European cultural heritage - that is, an identity comprising both localist and universalist elements in its composition. This issue is illustrated, for example, in Curnow's comment in a note included in the 1951 revised Caxton anthology, in which he reflected: 'If we are concerned with nationality it is because we recognise certain physical and social realities; that the poet, while his aims are universal, is yet the creature of a time and a place, even the creature of the audience he addresses' $(1951,49)$.

His acknowledgment that a melding of nationalism and universalism was intrinsic to New Zealand literature is reiterated in his Introduction to the 1960 Penguin anthology. In this, he stated that, in his view, there is 'no real contradiction' between his assertions that, while authentic New Zealand verse should reflect local 'reality', the language of poetry is 'frontierless'; that 'the poetic tradition has its custodians elsewhere', and that much creativity is sourced not from its immediate physical context but is 'attributable to "the clayless climate of the mind"' $(1960,17) .{ }^{117}$ Later, Curnow addressed this concept again, emphasizing his move away from his earlier cultural nationalist stance, in his Author's Note to his Collected Poems 1933-73 (1974), where he stated: 'I had to get past the severities, not to say rigidities, of our New Zealand anti-myth: away from questions which present themselves as public and

${ }^{117}$ Curnow is here referring to a phrase in Keith Sinclair's poem in the anthology, 'Waitara'. 
answerable .... The geographical anxieties didn't disappear; but I began to find a personal and poetic use for them ...' (xiii).

These later reflective statements significantly qualify Curnow's earlier restrictive injunctions that propose, prima facie, that, to be acceptable within a local canon, verse must portray a distinctive and authentic New Zealandness; they indicate more complex and nuanced concerns regarding the ambiguities that underlie notions of New Zealand identity that attempt both to reflect its singularity, uniqueness and difference, but also its dependence upon and inherent inseparability from its international cultural roots. In a 1981 lecture entitled 'Olson as Oracle: "Projective Verse” thirty years on', ${ }^{118}$ Curnow’s focus was not upon an assertion of local geographical determinism, but the view that New Zealand poetry and its proper foci belonged intrinsically within the context of the wider flows of international poetic movements. Curnow here referenced Pound's principle that 'poets should try to know, and learn from, all poetry, of all possible ages and languages, and to master all systems of metre' (Curnow's emphases), illustrating the historical nexus between local writing and the mainstream of English literature $(1982,33)$.

\section{'Fidelity to Experience' - Realism in New Zealand Fiction}

Curnow's critical writing after the 1960s indicates that he had largely moved away from a concern with the primacy of literary nationalism in relation to New Zealand poetry, towards a more inclusive frame of reference, and the earlier focus on concepts of reality and authenticity in expression became less emphatic in regard to local verse generally. However, other critics, whose attention was focused on local fiction rather than verse, continued to expound the view that realism and the depiction of authentic New Zealandness were the required modes of expression for the novel and short story. Many of the reviews and other

${ }^{118}$ This was later published in New Zealand through the Arts: Past and Present (1982). 
critical analyses of these genres in local writing, including short fiction anthologies, have based their assessments of the quality of a particular work on the extent to which it is considered to have succeeded in simulating a realistic vision of its New Zealand setting, and the degree to which it portrays recognizable geographical and societal features. Two exemplars of this emphasis on realism in local fiction are provided in the critical responses, both contemporary and subsequent, to the creative writing of W.H. [Bill] Pearson and D.M. [Dan] Davin.

While this thesis is focused primarily on New Zealand's literary anthologies, the nature of the reception in New Zealand of Pearson's novel Coal Flat (1963), including the responses of influential poets and critics such as Curnow, exemplifies the argument presented in the thesis in regard to the anthologies, so discussion of the novel is included here. At the time of its publication, Coal Flat received a strongly positive reception from influential cultural nationalists, including Curnow, Davin, Sargeson, Brasch, Rhodes, Stevens and others who shared Pearson's conception of authenticity and truth in literature and of the reality of New Zealandness. Curnow, in a contemporary review originally published in Comment under the title 'Coal Flat: the major scale, the fine excess' (1963), which was later reprinted under the title 'Coal Flat Revisited' (1976) ${ }^{119}$ had commended the novel for its 'fine ... observation of scene and character' $(1976,105)$. The views of most other commentators largely emphasized with approbation what Curnow described as its 'unexaggerated truth' what he saw as the accuracy and 'reality' of Pearson's textual reproduction of New Zealand landscape and life (Curnow, ibid, 105). In the later 'observations' that he added in 1976 to his original review in its reprinted version, Curnow's initial enthusiastic response to the novel was further enhanced, describing its portrayal of New Zealandness as having been 'keenly

\footnotetext{
${ }^{119}$ Curnow's review was reprinted, under the title 'Coal Flat Revisited', with the addition of later 'observations', in Critical Essays on the New Zealand Novel (1976).
} 
and humanly observed', and Pearson as being its 'faithful translator' (ibid, 126). Joan Stevens used similar positive terms in her appraisal of Coal Flat in The New Zealand Novel 1860-1965 (1966), in which she considered that the primary quality of the novel was the 'honesty' of its 'gritty social analysis', its ability to 'illustrate our common purpose' and to 'show ourselves to ourselves', and its realistic picture of a 'microcosm of New Zealand life' $(120)$.

Pearson himself, in 'The Recognition of Reality', a 1965 essay in Commonwealth Literature, ${ }^{120}$ written shortly after the publication of Coal Flat, asserted that 'fidelity to experience' - which he defined as being the closely mimetic portrayal of identifiable social and physical settings, as well as of his characters' psychological and emotional states - was the most essential component of good quality in fiction (Pearson, 1974, 137). He considered that New Zealand writing should aid New Zealanders in 'learning to recognize themselves in the limitations of their time and place', and in 'the recognition of reality' (ibid), and the 'recognition of truths about ourselves ... and about the country' (ibid, 149). Pearson's words echoed Curnow's in the latter's essay, published in the previous year in The Future of New Zealand (1964), in which he had stated his 'working definition' of a New Zealand literature.

Pearson wrote the Introduction to Sargeson's Collected Stories 1935-1963 (1964), in which he praised what he viewed as the 'truthfulness' of the portrayal of New Zealand experience in the collection. In Pearson's assessment, Sargeson's success lay in his artistic view that 'imaginative truth could be reached by being true to his country' (8), that his aim in the stories was to 'comment on New Zealand society' (10), and that he was 'writing from a particular time and place ... of the human situation ... which he has achieved with dedicated craftmanship' (17-18). In return, Sargeson was equally effusive in his appreciation of Coal

\footnotetext{
${ }^{120}$ Pearson's article was first printed in London in Commonwealth Literature (1965), and later reprinted in Auckland in Fretful Sleepers and Other Essays (1974).
} 
Flat, which he lauded for its realism and what he saw as its authenticity of its representation of the New Zealand life and 'character'. ${ }^{121}$

Dan Davin, also, in 'The Eye of the Expatriate', a 1969 article in which he assessed the qualities of Coal Flat, emphasized the features that he considered to portray its authenticity, reflecting that the novel's major literary value lay in the accuracy of its picture of a readily recognizable social and geographical New Zealand reality. Davin commended the realistic manner in which Pearson had represented its West Coast setting, noting that this was described in the same 'tones' with which he had depicted the Southland region in his own novels $(1969,10)$. Earlier, in his Introduction to the Oxford New Zealand Short Stories (1953), Davin had discussed the emphasis upon realism that was prominent in the work he had incorporated within the anthology. Setting out his selection criteria, Davin acknowledged the importance that he had placed on the realistic mode, including stories which in his view were 'if not anchored, at least tethered to a time and place that is recognizably New Zealand', and which 'should throw a sidelight on the history of New Zealand which historical documents more narrowly conceived could hardly give $(1953,1)$. He praised what he considered to be the accurate geographical detail and atmospheric veracity of the stories, noting that all those included in the collection displayed what he identified as a 'special New Zealand quality' (ibid, 7,9). Sargeson was commended, for example, for the 'obvious authenticity' with which he 'uses the speech rhythms and the vernacular of the anonymous every-kiwi', (7) and Davin noted that Sargeson had been 'influential' in the decisions made to include particular writers and stories in the anthology (Editor's Note, ix). ${ }^{122}$ Davin accentuated the importance he had placed on realism in the selections he had made for the anthology, including an essential requirement for what he termed a 'criterion of local setting'.

\footnotetext{
${ }^{121}$ Paul Millar discusses Sargeson's strongly positive response to Coal Flat in his biography of Pearson, No Fretful Sleeper (2010).

${ }^{122}$ Davin also acknowledged the 'assistance' he received from E.H. McCormick (ibid).
} 
In regard to Mansfield's stories, for example, he commented favourably that they portrayed accurately a vision of a Wellington 'not yet changed beyond recognition' (Introduction, 1-3).

Lawrence Jones refers to Davin's role as anthologist of New Zealand Short Stories (1953), in which Davin 'emphasised the quality of regional provincial history in the stories, all "tethered to a time and place that is recognizably New Zealand", and he even arranged them "approximately in the historical order of their settings"" (1976, vii-viii). Others, also, used similar terms to describe the focus on realism in Davin's own writing. Michael Beveridge, for example, in a contemporary review of Not Here, Not Now (1970) in Landfall, lauded Davin's work on the grounds he was 'a first-rate historian, the chronicler of Irish Catholic Southland (and other places)' (1970, 297). Rhodes, in a 1972 essay on Davin's novels, similarly praised his quality of being 'the historian and cartographer of a small enclave of Irish Catholics, farming and labouring within the confines of Southland' and of giving 'authenticity to the glimpses of provincial life' that he provides' $(1972,332)$.

\section{A 'Paper War'}

While realism per se was accepted in general as the most appropriate form for the literary expression of New Zealand identity, predominantly in the case of fiction, a particular feature of the critical debate regarding its application in the case both of local verse and fiction, has been the contestation among different groups vying to promote their own specific version of reality while rejecting others. Critical analyses were particularly preoccupied with identifying the specific characteristics of what was perceived to be the 'real' version of New Zealand, and rejecting what was considered to depict falseness and inauthenticity. Curnow, for example, insisted that to be of value, verse must portray an identifiable 'New Zealand referent' and decried what he viewed to be the 'spurious "universality"' that he saw to be 
'proliferating' in much of the country's recent published verse $(1964,94)$. He listed with approbation those particular poets whom he considered to have 'accepted the disciplines of uncompromising fidelity to experience, of an unqualified responsibility to the truths of themselves, in this place, at that time' (ibid, 97), with all the poets he included on this list having appeared in his 1945 Caxton anthology. ${ }^{123}$

The stress placed in the essay, in imposing a prescriptive definition of local writing, was that writers must be 'true' in their portrayals of their surroundings, and must reflect only their 'circumscribed area of experience' (ibid, 103, 106). Curnow's repeated, emphatic insistence that writers must confine the scope of their work to a limited and closely-defined vision of New Zealandness had significant impact upon local writers at the time, and continued to have resonance into future decades. While there have been prominent examples of alternative modes in local writing, as discussed earlier in this chapter, as well as new ways of critical reading that have identified non-realist elements in some other fictional work, Curnow's early influence on New Zealand writing has persisted, if in muted profile. The dominance of realism in local literature was still evident, in different forms, at the end of the century, despite substantive changes having occurred over time in the range of styles and expressions of the country's collective self-perception. The persistence of Curnow's authority and of his requirement for authenticity can be related to the underlying mechanisms of identity formation.

In the local context, the efforts by particular individuals or coteries to gain control over the processes of constructing and promoting particular concepts of identity, and to establish critical dominance over the version of New Zealandness that would prevail in local literature, have been evident since at least the early 1930s. For example, in an unpublished

${ }^{123}$ In his list of 'truthful' writers, Curnow also included fiction writers Roderick Finlayson, John Mulgan and Sargeson. 
article from this period entitled 'Why we can't write for nuts', Mason berated 'the gentlemen whose sacred mission it is to direct literary standards in N.Z. (sic)' for the extent of what he saw to be their influence and direction over local publishing media. Mason considered this group to be a clique comprising 'for the most part old men (or youths prematurely old) who have never even studied literature deeply', and whose major achievement, in his view, was 'to swell that almost unmitigated mass of sickliness which we so loftily dub "New Zealand literature"” (n.p., n.d.). ${ }^{124}$ Mason's diatribe against this older, more conservative, and in his view entirely passé group, including Schroder, Marris and Alan Mulgan, was an early volley in the factional struggle taken up in more concerted form in his anthologies by Curnow - and, even more vigorously and acerbically by Glover, notably in his 1937 lampoon The Arraignment of Paris, and Fairburn, in various letters and critical essays.

Others, also, have commented on the antagonistic and competitive atmosphere which prevailed at times between those who held different views of how New Zealandness should properly be portrayed, as well as which particular writers, and what selections of their work, should comprise the New Zealand canon. The terminology and metaphors used by New Zealand literary critics and historians to refer to this oppositional discourse on the nature of 'reality' in local literature are frequently that of physical battle. Stead, for example, in his Introduction to In the Glass Case (1981), describes what he refers to as episodes of 'literary/critical warfare' among factions as well as individual local writers and critics, indicating that the earlier divisions in local literature regarding the specific determinants of 'authenticity' and 'value' remained unresolved $(11,12)$. Lawrence Jones, also, in Barbed Wire and Mirrors (1987) describes what he terms a 'paper war' that was conducted between 'the Auckland provincial poets and the Wellington post-provincial ones', and describes Louis

\footnotetext{
${ }^{124}$ This manuscript document is among Mason's papers held in the Hocken Library, Dunedin.
} 
Johnson's Poetry Yearbook and Curnow's Penguin Book of New Zealand Poetry as being 'the primary battlegrounds' in which this dispute was openly conducted $(1987,12)$.

The open and particularly vehement conflict between the adherents of the different perspectives of Johnson and Curnow, in their views on what represented 'authenticity' and the appropriate foci and themes in New Zealand verse, largely subsided after the demise of the Poetry Yearbook in 1964. However, later comment indicates that it did not dissipate entirely. Mark Williams, for example, in his Introduction to Writing at the Edge of the Universe (2004), refers to the milieu of creative and critical writers in New Zealand as being 'a literary community where everyone knows one another, and where feuds can last for decades', and where a magazine with literary interests provides a 'venue where ancient animosities and memorable malice find new expression' (2004a, 15). ${ }^{125}$

Peter Simpson, similarly, in a 1993 essay on 'Poetry Anthologies in the Fifties' in Landfall, reflects on the intellectual antagonisms that have evolved between those with variant views on what constitutes the 'reality' of New Zealandness. Simpson discusses the various poetic 'camps' of the 1950s, outlining their artistic and philosophical (and personal) differences, that were played out largely in reviews and correspondence printed in Landfall and other contemporary literary media, but also in the editorial stances adopted by iconic anthologies. Simpson refers to these disputes as being 'canonical jockeying' among the opposing factions, and he observes what he terms bouts of 'cultural schizophrenia' in response to the 'Curnow school' (96), and 'generational feuding' (98).

In Simpson's view, there existed in the local literary milieu '[a] complex network of aesthetic and philosophical differences and affinities [that] complicated the regional and generational distinctions which constituted the evolving poetic discourse' (97). Simpson notes that after the publication of the Book of New Zealand Verse (1945), in which Curnow

\footnotetext{
${ }^{125}$ Williams notes that he is referring in particular to New Zealand Listener.
} 
set out his dictum specifying the required characteristics of local authenticity, '[a] marked deterioration in critical civility became evident from this time and poetics got increasingly confused with personalities', so that issues of poetic practice 'tended to become obscured by the more clamorous personality politics of generational and local allegiance' (102).

Describing what he considered to be the purposefully antagonistic ethos of Curnow's 1960 Penguin verse anthology, and the confrontational stance that it adopted, Simpson outlined the 'turbulence of the history from which it emerged', and the 'embattled context in which it was written' (102). (It was, however, not an evenly conducted battle, the older generation of writers having little active involvement in the warfare.) As with his 1945 Caxton anthology, Curnow included an extensive Introduction to his later Penguin. In this, and in his choice of selections, he made clear that he viewed the anthology as a vehicle for the promotion of his version of New Zealandness, and a means to ward off claims from others who were arguing at the time for an alternative vision of what it represented.

As discussed in Chapter Two, Curnow intended with the contents of the Penguin to establish a 'ground-pattern' and a 'core tradition', which was to consolidate an authoritative canon of New Zealand verse (Curnow, 1960, 19). He saw this as together comprising a direct line of cultural descent drawn from the beginnings of the country's history and extending up to its immediate present. This 'line' that Curnow constructed commenced with selections of the creative work of early Māori writers, then included a very small number of individual Pākehā poets from the nineteenth and early twentieth centuries representing the country's past, and concluded with those, including himself, who formed a carefully-chosen current group whose work comprised what he judged to be the 'best' contemporary poems (Curnow, 1960, 19). Curnow's aim, in asserting this clearly articulated and firmly delineated literary vision of New Zealand identity was to enclose in words - to effectively overwrite - the collective insecurities and self-doubt that were residues of the country's colonial past and its 
future uncertainties. However, Curnow's account had a dual effect, both providing a sense of resolution to underlying anxieties, and inciting ongoing dissension regarding the historical record of local literature, the character of New Zealandness, and the processes of canonconstruction.

Heather Murray, for example, in 'Not Tolling for Me', a review in New Zealand Books of Curnow's last published collection, The Bells of Saint Babel's: Poems 1997-2001 (2001), stated that 'to read the new volume of poems is to be seized by the blackness and negativity of his vision' $(2001,12)$. She strongly rejects what she observes to be 'the fondness of Curnow and the first generation of "real" New Zealand writers to see the country falling short in every way when matched against the European homelands. ... I no longer want to hear the old destructive myths. Allen Curnow may write all the books of verse he likes, but I am not listening any more' (ibid). Murray's negative assessment of Curnow's influence over New Zealand literature has been referenced by a number of other academics and critics, ${ }^{126}$ and the contention her review provoked is itself an illustration of the strongly divisive responses that Curnow's paradigm of New Zealand literature has generated. It is illustrative also of the degree to which his views continued to dominate the critical debate on local writing.

The stimuli for the various antagonisms surrounding the literary discourse relating to the nature of the terms 'authenticity' and 'reality' as they were applied to New Zealand literature have their basis in the local debate regarding the 'true' nature of the country's national identity, as well as in the broader international theoretical discourse regarding concepts of literary realism. The fabricated nature of literary reality is discussed, for example, by English writer and critic David Lodge in The Modes of Modern Writing:

\footnotetext{
${ }^{126}$ Murray's review is cited, for example, in Frank Rogers's The New Zealanders, 2008, n.p. Earlier, it had attracted a strong rebuke from Hugh Roberts in 'Cock of the walk', in New Zealand Books, October 2001.
} 
Metaphor, Metonymy, and the Typology of Modern Literature (1977). Lodge describes the 'realistic mode' as being 'a tradition that depends ... upon the assumption that there is a common phenomenal world that may be reliably described by the methods of empirical history', and refers to the application, in representational forms of art, of a 'typology' of recognizable references and conventions that may be applied to evoke a facsimile of tangible experience that is an impressionistic version of the 'real' (40).

While some, including Johnson, Baxter, Schwimmer, and later the group associated with Freed, in particular, articulately and often vehemently disputed Curnow's exclusivist and localist version of New Zealandness, and his narrowly-defined concept of what a local literature should represent, others shared his views - there are frequent references in the literature to the assumption of the existence of a shared, recognizable vision of a 'real' New Zealand, expressed in similar terms. Vincent O'Sullivan, for example, reflecting on his selections for the third edition of the Oxford New Zealand Short Stories (1975), referred to the representation of 'the shared common life' as being a distinctive feature of the 'realistic tradition' common in New Zealand fiction (1975, Introduction, ii); Frame lauded Curnow's 1945 verse anthology for the veracity of its expressions of local referents and sentiments 'haunting in their unique influence on our lives' and 'wakening in me an awareness of New Zealand' (1989, 192).

The assumption that there existed a single, 'correct' version of New Zealand identity that could be codified and then applied to judgements of literary quality coalesced around Curnow's critical writing. Simpson, in his 1986 essay, 'The Trick of Standing Upright: Allen Curnow and James K. Baxter', juxtaposes the work of these poets, and their different literary ideologies, as exemplars of the two major oppositional perspectives of the nature of the 'reality' of New Zealandness. Simpson portrays Baxter's position as being non-conformist in contrast to that of the orthodoxy of the 'norm' established by Curnow. Baxter, in his essay 
'Recent Trends in New Zealand Poetry' (1951), was an early challenger to Curnow's vision of the nature of New Zealand society, and questioned his view of the desired function of local writing. While conceding, in common with Curnow's vision, that the writer's proper role in society was to represent New Zealandness truthfully, Baxter, however, made clear that he considered his own version of the 'truth' of New Zealandness to differ markedly from Curnow's. Again, in Aspects of Poetry in New Zealand (1967), Baxter-disputed what he viewed as Curnow's claim that local literature must be restricted to 'but one subject', and proposed instead that the reality of New Zealand life was more broadly-based and 'universalist' in nature than what he considered to be the limited and restrictive view that Curnow espoused (16).

While this association between realism, authenticity, and literary value was most strongly evident in criticism during the 1930s to the 1950s, in particular, it persisted in various forms as a common means of evaluation into later decades. This is suggested, in a nuanced form, by McLeod and Manhire, for example, in Some Other Country (1984) - they reflect in their Introduction to the anthology that ' $[\mathrm{t}]$ he New Zealand to be found in these pages ... is a real place, composed of that blend of accuracy and vision which only the imagination, committed to language and experience, can supply' (1984, n.p.). Michael King applies analogous terms in a 1986 review of a republished edition of Hyde's 1938 novel Nor the Years Condemn, comparing the value of Hyde's work with John Mulgan's Man Alone by assessing the relative degree of what he considered to be their authenticity. King concludes that 'Hyde's novel is more real than Mulgan's ... which we were always taught was the first competent novel written by a New Zealander. It was not' [original emphasis]. Lawrence Jones, similarly, in an assessment in 1998 of David Ballantyne's The Cunninghams (1948), emphasizes the quality of the authenticity of the novel, stating that he considers it 'one of the 
finest works of New Zealand realism, unsurpassed as a picture of working-class family life' (1998b, 39).

Brian Turner, also, in a review of The Collected Poems of James K. Baxter (2004), edited by John Weir, ${ }^{127}$ lauds the poems because of what he views to be the accuracy with which they evoked a 'real', recognizable New Zealand, conflating his judgement of their literary value with their authenticity. In Turner's view '[Baxter] wrote about the South and what places I knew meant to him'. Turner eulogizes Baxter's work because of what he considers to be its 'honesty', stating that the poems are 'evocative of ... people ... and places. Baxter is great on New Zealand's coasts and mountains and open spaces; great on the seas within and the oceans without' (2003, E9). Clearly the critical stance held by many critics, that local literature must present a real, recognizable portrayal of an authentic New Zealand landscape and life was one that did not end following the decline of overt literary nationalism, but has continued in other forms.

\section{The Provincial Dilemma}

A particular strand of the argument in the critical literature concerned with defining the specific nature of New Zealand 'reality' and of authenticity in local writing has focused on determining the country's proper place in relation to its international literary environment. The issue of where Pākehā society is sited within this broader cultural space has formed one of the dominant thematic issues that have preoccupied the discourse of national identity since the country's earliest colonial period, and indicates a pervasive uncertainty and anxiety regarding New Zealand's position within its global social and cultural context. Mason, for

${ }^{127}$ Collected Poems: James K. Baxter, edited by John Weir, was originally published by Oxford University Press in 1980; it was reissued in 1981 and 1995 with corrections; it was again reissued in 2004 with a slightly different title, and two additional poems. Turner's review was published in 2003, prior to the publisher's date for the book's latest reissue. 
example, in his poem 'Sonnet of Brotherhood', which Curnow included in his 1945 Caxton anthology, refers to 'this far-pitched perilous hostile place/ ... fixed at the friendless outer edge of space'. This presents a perspective that the country's sensibilities occupy a position at the farthest periphery from the centre, both geographically and culturally, a marginality that has been problematic for the development of a distinctive New Zealand identity; this perception of distance and separation has been viewed as a barrier by many writers. For a few, this sense of space and apartness has been perceived as a source of individual poetic enablement, allowing freedom from the constraints of literary tradition and conformity - Bill Manhire, in a whimsical reference in his Milky Way Bar (1991) to the sentiment of Mason's 'Sonnet of Brotherhood', stated: 'I live at the edge of the universe/... I look out at the stars' (19). For most, however, at least until the 1970s, the dominating effect of being located 'at the edge' was not a sense of freedom but of shortcoming, instability and insecurity.

This concern regarding New Zealand's 'place' in the world underlies the directive of literary nationalists that writing should be focused on portraying the authenticity of local experience, and should address a defensive reaction towards the challenges to self-identity presented by the dominance of the cultural hegemony of Europe and, later, the United States. This response has been evident in the dichotomization of anthologies of local verse, in particular, into representations either of a nationalist, insular, exclusivist perspective characterized by expressions of provincialism, or of a more inclusivist, stylistically and culturally eclectic and diverse view that aligns New Zealand writing to its internationalist associations with mainstream literatures in English. The tensions between these two oppositional positions have mirrored the broader debate focused on issues of national identity and questions of how New Zealand, as a small, English-speaking former British colony, still comprised largely of those with a heritage of European settlers and physically located in the 
South Pacific, will be able to characterize itself as a notionally independent nation that is, however, inextricably interlinked with its international context.

The problems inherent in attempts to determine a distinctive and separate local canon representative of New Zealand reality, while the nation's independent development is confronted with the challenges posed by the presence of a dominating overseas cultural centre, have been addressed by a range of different commentators. Patrick Evans, for example, in his Penguin History of New Zealand Literature (1990), refers to the problematic issue of the 'provincial dilemma' - the predicament of the local writer whose aspiration is to conform to demands for local authenticity but who is confronted with the constraints to aesthetic expression that this seems to impose. Reflecting on what he terms the "problem of the provincial writer', Evans observes that '[t]he more faithfully language responds to its environment the more thoroughly it mirrors the limitations of the society it is set in, and the more absolutely it cuts off interesting things for a character to do, if those things are not likely to be done in the surrounding world' (188).

New Zealand's colonial origins and subsequent patterns of historical development have been founded on 'international' norms and values - its institutions, authority figures, 'experts' and systems of standards have always been established and upheld by 'outsiders'. Local economic historian J. D. Gould, in The Rake's Progress? (1982), illustrates the extent to which New Zealand political, economic, academic and social institutions have been dominated by immigrants, or those locally-born who were educated outside New Zealand (primarily in Britain), noting that '[i]t is only in very recent decades that New Zealand destinies have been predominantly led by her own sons ...' (230). The extent of overseas influence in determining New Zealand's self-perspective has always been a significant factor 
in the composition of local identity, ${ }^{128}$ but has been regarded with ambivalence. Curnow, for example, in 1945, mused that '[w]e are all beset by a kind of internationality these days, partly spurious, partly a necessary heritage', and referred to the incursion of 'falsity' from overseas influences (Curnow, 1945a, 33, 39); however, he also acknowledged the ineluctable nature of such influence, reflecting that the New Zealand poet, while 'the creature of a time and place' has aims that are 'universal' $(1951,49)$. Curnow's reflections are indicative of the problematic position, for those concerned with New Zealand's literary identity, of determining how this country should relate to the wider, overseas context of mainstream literatures in English, within which a New Zealand literature is to be located.

The stance of local critical and creative writers in response to this conundrum has taken two major forms: one has been to contend that the proper focus of local literature should be to assert the 'authentic' and unique experience of New Zealandness in a distinctively local form that purports to reject international influences; the other has been to emphasize the internationalism inherent in New Zealand's Pākehā history and its ongoing links to its European cultural origins, stressing the universality of (English) literature and human experience. In many other post-colonial literatures, these stances have been melded over time into a new, uniquely hybrid form that is an amalgam of both these positions, into what Calhoun in Nationalism (1997), describes as being 'creole nationalism', one that has been localized and adapted from its overseas origins into a distinct form $(1997,14) .{ }^{129}$

The cultural ideology of Curnow and other local literary nationalists is a structural analogy of the 'creole nationalists' in other formerly European colonial settlements, such as those in South America, Africa and Asia, who created new and unique cultures that were based upon, but emerged as being distinctively different from those of their colonizing

\footnotetext{
${ }^{128}$ The impact of expatriate writers upon New Zealand literature is discussed in Chapter 3.

${ }^{129}$ Benedict Anderson, in Imagined Communities (1991, 50), also discusses the concept of a 'creole' form of nationalism, in the context of the American colonies.
} 
powers. This concept is suggested by Curnow, in his poem 'The unhistoric story' from Island and Time (1941), indicating his awareness that the evolution of New Zealand from its past as a British settler society would result in 'something different, something / Nobody counted on'. $^{130}$

Assessing the legacy of colonialism in other countries, Calhoun noted that 'in each setting ... [creole nationalists] made something different of the nationalism they drew from international discourse. They innovated, they drew in different local features, and they contended in each setting with each other on what mix of local tradition, international discourse and innovation was right' $(1997,14)$. What was produced was a literature that was recognizable as a cultural pastiche of its 'parent' culture, but also separately identifiable and unique: 'elements of an international discourse [cannot be] transplanted without basic alteration to new cultural settings' (ibid). The literatures produced in these artistic factions each form a unique hybrid of internationalism and localism that blends aspects of both into a new form different from their separate status. Rather, therefore, than being analogous to regionalists such as Arnold and Hardy, New Zealand's literary nationalists, in particular Curnow, have been local variants of others who, in various ways, have adapted the features of their origin nations into an internationally recognized literary form, such as Naipaul, Achebe, Ondaatje, Garcia Marquez, Spivak, Bhabha, Fanon, Camus, and others.

A number of New Zealand commentators have addressed the contradictions inherent in attempts to assert a separate and distinctive 'localist' national identity that is also readily assimilable into an international context. Curnow reflected upon this conflict between the competing claims of localism and internationalism to determine the focus of New Zealand identity, in his statement in the Introduction to his 1960 Penguin anthology

\footnotetext{
${ }^{130} \mathrm{Curnow}$ included this poem in his later anthologies. He refers specifically to this line from the poem in his Introduction to his 1945 Caxton anthology (22).
} 
that ' $[w]$ hether open or implicit, it is this vital discovery of self in country and country in self, which gives the best New Zealand verse its character, and such claim as it has to stand as a distinct addition to the range of modern poetry in English' (21). Curnow here suggests both that local verse must be uniquely of, and focused upon, New Zealandness, whilst also being in conformance with the literary norms of internationalist (English) culture.

In Towards a New Zealand Literature (1971), Bertram reflected similar views. While expounding a localist perspective and asserting that local writers must always be 'genuine' in their approach towards the New Zealand experience, he commends Mason's verse on the basis that he is

a universal poet, speaking to all men ... because he consciously used, and did not at any time reject, the full resources of language and literature, of historical and religious association, that were available to him (16).

Bertram does not reflect upon the incongruity in his stance that the reality of New Zealand experience can be represented authentically in local verse only by means of universalist modes of expression. Fairburn, however, had been more considered in his 1945 essay, 'Poetry in New Zealand', which was originally published in the first Year Book of the Arts in New Zealand. ${ }^{131}$ In this he recognized the contradiction inherent in a localist position that is dependent upon universal forms in his statement that

The writing (and the appreciation) of poetry in New Zealand are inextricably mixed up with the course of life in Western civilisation. On the other hand, we should never forget that poetry, whatever its traditional origins, must always derive its

${ }^{131}$ This was later reprinted in The Woman Problem and Other Prose (1967), 131-135. 
nourishment from a particular patch of soil (Fairburn, 1945, 126).

O'Sullivan similarly reflects this ambivalence - a desire for the imprimatur of internationalism whilst simultaneously lauding localism - in his Introduction to his Oxford Anthology of Twentieth Century New Zealand Poetry (1976), stating:

Europe is the closest that a New Zealander has to an extensive birthright. How each poet goes about constructing for himself a coherent body of verse, aware that geography and history have deprived him of much that is valuable, even as they give what cannot be done without, is of permanent interest in New Zealand verse (xxviii).

Others also reflected on the problematic issue of how an authentically local literature, distinct from those of other nations, could be constructed in a form that would differentiate it as reflective of a separate and unique identity when it retained a basis fundamentally interlinked with other literatures. Simpson, for example, focuses on this question in 'Ways to the Museyroom', a 1993 essay in Landfall analysing New Zealand's verse anthologies of the 1950s. He identifies several substantive concerns in New Zealand poetry that he viewed as forming a set of binary stances, representing different facets of the literary nationalist debate - 'national versus international, local versus universal, the human condition versus the "condition of being a New Zealander"' (102). While offering no solution that could reconcile these apparently oppositional positions, however, Simpson implies a comparison to Irish literature. The title of Simpson's essay references a phrase in James Joyce's Finnegan's Wake, a novel that is associated iconically with Ireland, but is expressed in a language not restricted to place, and which, while identifiably Irish in its physical location, forms part of an international literary canon. 
This hybrid conception of 'place' - the sense of occupying a position simultaneously both localist and internationalist - emphasizes the contradiction inherent in the term 'national literature', exposing the artificiality of categorizing writing in accordance with a rubric of geographic limits. This concept is specifically placed in its national/geographical referents, yet is inherently located within the wider context of literary traditions, conventions, genres, languages and readership that form part of a universalist body of literature that transcends national boundaries. In this way, Simpson links New Zealand literature to the wider international corpus of English literature, but, conversely, also to the notion of a distinctively local literary culture, analogous to Joyce's creative portrayal of Ireland.

The paradox inherent in the need to link localist themes to an internationalist cultural context has been reflected on by others, also. Stead, in the Introduction to his essay collection Kin of Place (2002), addressed the conflict between localism and internationalism in his effort to 'place' New Zealand writing, contextualizing it in relation to the overseas literary mainstream by drawing on overseas exemplars. He concludes that the concepts of localism, exceptionalism and internationalism are not in fact separable in any regional literature, but are intertwined with it, asserting that there is a sense in which, wherever you come from, the poetry of your own region speaks with a voice, an accent, and a quiver of references which make it special. To say this of Curnow and Baxter for New Zealand readers is no more significant than to say it of Yeats and Heaney for the Irish, Hardy and Larkin for the English, William Carlos Williams for Americans or Les Murray for Australians. Major poetry is international; but it usually has also a strong regional aspect (3).

Stead's assertion here is that Baxter's and Curnow's 'regionalisms', while superficially different in the approaches they adopt, are congruent with a broader pattern of the 
internationalism of literary culture, reflecting qualities that incorporate both the local and the universal.

\section{A Double Standard of Evaluation}

While some writers and critics have attempted to reconcile the localist and universalist positions, recognizing their essential relationship in regard to the construction of a local canon, others have instead adopted a hierarchical view. A particular aspect of the problematic nature of the localist and universalist debate is the existence of a 'double standard' applied to the measurement of value of local literature - the act of assessing the quality of the work of local writers utilizing a set of criteria different from, or applied in a less exacting fashion than those applied against 'overseas' literature. While this practice was the common basis of reviews and criticism of local writing in the 1940s and 1950s, in particular, and applied in the case both of verse and fiction, it remained persistent in later decades. John Geraets, for example, writing in the 1990s, identifies different (inferior) measures of 'quality' applied in the assessment of local literature. He views this as a defensive critical reaction to the insecurities and threats to local identity posed by the perceived superiority of the paradigms of value represented in the body of 'international' (that is, British and American) literature. In his 1993 essay, 'A Second Life - Literary Culture and Landfall in the 1950s', an analysis of published reviews of local and overseas literature, Geraets suggests that ' $[\mathrm{t}]$ he use of a double standard allows dual assessments to be made in a consistent framework, by which New Zealand texts assume an importance normally reserved for acknowledged English texts' (117).

Citing a number of influential reviewers of local literature who, in his view, practised such a dual standard in their criticism, Geraets reflects upon the ambiguities and uncertainties 
inherent in New Zealand's self-identity that are revealed in the existence of a binary evaluative system. Geraets concludes that, while the application of such a double standard is 'an acknowledgement of inferiority and subservience ... [it] is at the same time empowering, equalizing. It is the means by which regard for the work reviewed is elevated' $(1993,117)$. An early local example of the application of such a dual value system of evaluating literary significance is provided in Baigent's assessment of Bethell's Collected Poems (1950), published by Caxton Press, in which he assessed Bethell's importance as being that of 'a major poet in terms of our own literature, a minor poet in relation to the English poetic tradition' (24). Baigent acknowledged that he applied a dual set of qualities by which local work should be assessed against different measures from those for overseas writers, stating that such a distinction was necessary as 'the time is not yet come when criticism of New Zealand literature can profitably dispense with a double scale of values' (ibid).

A further example of the dualism inherent in the measures applied to the critical evaluation of local literature is evident in Louis Johnson's Introduction to the first volume of the New Zealand Poetry Yearbook (1951). Johnson states that the collection demonstrates that local poetry 'is developing its own traditions and characteristics', suggesting that it is evidence of the maturation of a distinctive, discrete body of New Zealand verse. However, rather than being an unreserved expression of confidence in the development of an assured cultural independence and separate identity, Johnson's praise is modified with the qualifier that local verse 'at its best, will stand alongside the poetry of any English-speaking country' $(1951,7)$. The implication of Johnson's conclusion is that critical acceptance of the local literature of the colonial periphery remains subject to its favourable assessment against the standards of value imposed by the overseas (colonizing) cultural centre.

A preoccupation with determining New Zealand's status within its international context and with measuring local achievement in relation to that of other nations has been a 
constant thematic concern in the country's critical literature. Claudia Bell, for example, suggested that the historical impact of New Zealand's self-perception of its relatively minor geographical dimensions, and of its extreme remoteness from international commercial and cultural centres, has been instrumental in shaping the nation's sense of collective self-identity into expressions indicating a sense of insecurity and inferiority. Conversely, this position has also invoked defensive declarations extolling the nation's positive differences and uniqueness. Bell proposed that these expressions of 'collective egoism' are necessary for 'morale' in what is

an otherwise remote ... globally insignificant group of islands. ... New Zealand cannot be economically autonomous and independent. It is part of a world-wide political and economic system. ... [subject to] a permeation of cultural boundaries ... and an invasion of values from elsewhere. This ... has meant increasing uncertainty about its sense of place, and has undermined traditional local identification and diversity (1996, 17).

Bell considered that this sense of uncertainty, coupled with a perception of 'smallness' in the world, has provoked a 'desire in New Zealand to assert distinctiveness' $(1996,17,21)$. This notion would suggest that the insistent stance of local literary nationalists towards developing an exclusive, closely-defined canon was a defensive response against the risk of international insignificance, rather than one that was primarily a positive expression of selfhood and independence.

Sturm, also, in his Introduction to The Oxford History of New Zealand Literature in English (1991) considered the country's concern with its position in relation to the world, and addressed the contradictory stances of provincialism and internationalism in local literature. 
He identifies a shift over time towards the internationalization of New Zealand identity, and observed that towards the end of the twentieth century there is expressed in local writing

a more outward focus on New Zealand's experience of the new global economy and environment, and the changed relationships and identities it has brought in its wake. It is not simply that the literature increasingly reflects [original emphasis] this global world of shifting, unstable identities (social, economic, linguistic, sexual, national, cross-cultural) ... The best of our recent literature is actively engaged in negotiating the multiple, uncertain, contested sites of identity, location, history, both within the geographical entity called "New Zealand" (or "Aotearoa") and in its larger, constantly shifting, global relations. ... New contexts are having to be invented, in a condition of radical uncertainty (1991, xviii, xix).

Sturm identifies the intricacies, risks and challenges that confront the project of constructing a distinctive national identity, and its related task of creating a separate local literature, within the complexities of the context imposed by an internationalist cultural environment. In Sturm's view, a determination to adopt a culturally separatist and narrowly inward-focused, localist position risks leading not to artistic originality and independence but to the state of marginalization correlated with provincialism. Geographical and cultural distance, while it can lead to the accentuation of a separate and distinctive identity, often results instead in an attenuation of creative vitality.

'Provincialism' is defined in the Oxford English Dictionary as being, inter alia, a 'concern for one's own area or region at the expense of national or supranational unity'; but the term also implies 'narrow-mindedness, insularity, or lack of sophistication' ${ }^{132}$ This definition emphasizes the concept of a dominant overseas 'centre' in its evaluation of the

${ }^{132}$ Definition in Oxford English Dictionary Online (n.d., n.p.). 
cultural production and ethos of a related 'peripheral' group. It suggests also that the connotations inherent in the term relate potentially to both positive and negative aspects of the provincial status, and can signify a stance either of psychological independence or of dependence. For New Zealand's writers and critics with an interest in the development of a distinctive local identity to be rendered into the forms of a separately identifiable literature, the condition of provincialism - in the form of a concern focused primarily upon local experience, landscape, social institutions and 'character' - represented, therefore, an ambiguous, indeterminate position that offered both opportunities and threats. The issue of whether localism or 'universalism' most appropriately represented the authenticity of New Zealandness was contested strongly in the critical literature.

Stead, for example, in 'Wedde's Inclusions', his review in Landfall of Wedde and McQueen's 1985 Penguin verse anthology, delivered a strongly negative evaluation, both of its contents and of the editors' stated aims, as previously referred to in Chapter Two. Among his other criticisms, Stead accused the editors of rejecting the European heritage of New Zealand literature, and of adopting a stance emphasizing an overtly separate, localist national identity. Stead deliberated upon the subtleties of the complex relationship between the interrelated strands of localism and universalism in New Zealand literature, and specified the weaknesses he observed in the anthology's inclusions and also in the objectives expressed in its editorial comments, commenting for example, that '[c]olonial writing, as distinct from genuine regional writing, takes its cues from whatever is conceived to be the "centre", and looks there anxiously for applause' $(1985,290)$.

Stead stated that it is essential that a minor literary community within a small national population, such as New Zealand's, should 'maintain communication with a wider world .... Not to be overborne by it, or to let it be the determinant of what we value, but to act as a point of reference, a way of getting outside ourselves and our collective solipsism' (ibid). 
Dismissing Wedde and McQueen's collection with the reproach that it reflected 'an insular feel ... both in its physical appearance and in its selection and introduction', so that its 'late local echoes seem more than ever provincial', and consisted of 'eavesdropping and copying' from the 'wider world' (ibid), he negatively contrasted the 1985 anthology against Curnow's 1960 Penguin, comparing their relative values and highlighting the weaknesses and inadequacies that he saw in the former. He noted that the 1960 collection, published by the English Penguin, was directed primarily towards an 'international' readership, rather than that of New Zealand. This 'British Penguin', in Stead's view, 'signified a status', and represented a superior quality both in its production standards and in its content, and was assured of attaining a significant circulation among overseas readers (ibid, 289). Conversely, Stead considered that Wedde and McQueen's later volume, being published in Auckland under the rubric 'New Zealand Penguin', embodied an inferior 'local' status, and consequently would attract only a smaller, more localized audience, so that '[a] few copies may go abroad; but local Penguins are mostly books for which there is no significant market outside New Zealand' (ibid). In contrast, Stead stated that when Curnow's 1960 collection was published

the poets Curnow had chosen were being given some kind of international airing. And even if, in the longer term, Curnow's selection and introduction would be statements for New Zealand to consider ... in the first instance they were addressed to a wider world (ibid, 289, 290).

While asserting the view that the overseas status of Curnow's publication bestowed upon it greater literary value, Stead, however, also conceded that this might undermine its claim to authenticity as a 'local' publication, reflecting that 'there's a danger of posturing when you think you have a larger stage' (ibid, 290). Of Wedde and McQueen's anthology, 
Stead stated that what he considered to be the undiscriminating inclusivity of their selection policy and attempt at being 'fashionable' - which allowed, among other outcomes, a broader representation of women and Māori writers - catered principally to the presumed popular interests of a local readership (291). He regarded this to have resulted in a collection inferior in its achievement of literary value in comparison with that of Curnow's principle of exclusivity, which, Stead concluded, represented 'excellence' and acknowledgement of 'the fact that talent is undemocratically distributed' (291); also, calibrating it against hieratic overseas literary values as his 'point of reference', Stead considered Curnow's anthology to be representative of a significantly higher standard than the attempt at demotic values he attributes to Wedde and McQueen (290).

In Stead's perception, the editors ${ }^{133}$ deliberate policy of attempting to 'balance' the literary record by presenting a set of inclusions they thought to be more representative than those of earlier authoritative anthologies had instead produced a collection that Stead dismissed as being 'insular' and 'provincial' in tone rather than truly 'national', and representing a flawed and inadequate interpretation of New Zealand identity (290). While Stead's conclusion - that assessments of literary value are, or properly should be, based upon what he judged to be 'universal' standards of quality - is one that has been supported, overtly or tacitly, by most local critics, a number of other commentators have observed with uneasiness that there should be such reliance on an overseas imprimatur in place of a set of local evaluative criteria. They have contended that, rather than an expression of universality, this attitude instead indicates an ongoing state of dependence and cultural insecurity, reflecting a lack of national self-confidence and a sense of inadequacy in regard to a clear concept of local identity.

\footnotetext{
${ }^{133}$ The Introduction to Wedde and McQueen's anthology is signed by Wedde only.
} 
Other critics have addressed the argument of localism versus universalism from a different perspective, questioning the basic assumption of Curnow and other cultural nationalists that a distinct local identity, separate from that of 'overseas', does or should exist, and that it ought to be revealed in New Zealand literature. One of the alternative strands of the literary model of national identity locates local writing within the traditions and forms of English literature from which it originated, sometimes in the form of a subordinate tributary or minor sub-stream within this larger body of international literatures.

Some commentators have challenged the concept that the project of developing a uniquely 'New Zealand' literature was, or ever could be, successful. Reid, for example, in his study, Creative Writing in New Zealand (1946), questioned, during the early stages of the discourse addressing literary nationalism, whether a separate and distinct 'New Zealand fiction' could in fact be identified, or even whether this exceptionalist approach was, as others have claimed, 'important' to the nation's development $(1946,58)$. Instead, Reid, like Stead in a later period, attested to the inherently universal nature of literary forms and standards. He emphasized the historical and ongoing links between New Zealand literature and those of England and America, of which he considered this country's writing to be a minor outgrowth, stating that

the desire to increase the number of specifically national characteristics embodied in our fiction, when pushed as far as it has been in recent years, appears to ignore the principle of the continuity of literary tradition in the off-shoot of a highlydeveloped culture and also to play down the universal character of all good writing (ibid).

Asserting a position that contradicted the strongly localist assertions of literary nationalism expressed by influential New Zealand writers at that time, Reid outlined the extent to which, rather than being distinctively different, local literature was at its basis a 
facsimile of its overseas counterparts, so that 'those recent writers who are most frequently cited as representing the growth of a distinctively national fiction are in fact heavily in debt in style, as least, to contemporary writers of England and America' (58). Reid noted, for example, that

the issues of New Zealand New Writing published to date reveal not only a close imitation of the form and contents of the English Penguin New Writing series, but show also the indebtedness of many of the prose contributors to Ernest Hemingway, Gertrude Stein, William Saroyan, Sherwood Anderson, Leslie Halward, James Hanley and even Gerald Kersh. ... John Mulgan, in his single novel, and Frank Sargeson, in his short stories ... owe much to the technique and the mood of some modern American writers (ibid).

Bill Pearson, similarly, in his Introduction to Sargeson's Collected Stories (1964), assessed the value of the contents by utilizing international comparators to describe their qualities, likening them to those of Gogol and Sherwood Anderson $(1964,7,8)$. In making such judgements, in which the quality of local writing commonly is evaluated by the process of appraising it against that of overseas works, it is clear that reviewers considered 'international' literature, and a perceived set of universal literary standards, to set the measure of literary value. This also formed an implicit recognition that, despite the assertions of New Zealand's literary nationalists, it is simply not possible to consider local poetry in wholly local terms, as it belongs within larger international contexts. ${ }^{134}$

\footnotetext{
${ }^{134}$ From different perspectives, and with a focus on different writing genres, there have been a number of New Zealand critics concerned with issues regarding the 'double standard' of evaluation of local literature. Examples of these include Cherry Hankin, who, in her 1978 essay, 'Realism, nationalism and the double scale of values in the criticism of New Zealand fiction' in Landfall, considered the central issues for evaluation of local writing; earlier, D.F. McKenzie, in his 1965 review in Landfall of Sargeson's plays, A Time for sowing and The Cradle and the Egg, attacked the basis of the critical assessment of Sargeson's work.
} 


\section{The 'Mana of Overseas'}

A significant indicator of the continuing sense of ambivalence and uncertainty that underlay representations of New Zealand identity, and that also undermined the development of a separate and uniquely local literature, was the extent to which critics of local writing measured its value in terms of the prominence of its overseas reception. Other assessments of the importance and significance of the contribution of locally-produced literature, based solely upon New Zealand-relevant criteria, often were not accorded a status equivalent to those focused upon evaluations of 'international' recognition, so that a local writer's 'international reputation' was considered to be a proxy for the measure of the literary value of their work. This created a body of criticism that expressed a sense of insecurity and anxiety, and that strived to be simultaneously both internally and outwardly focused.

A critical dependence upon 'outside' judgements of quality in regard to the evaluation of local literature was noted in 1946 by F.L.W. Wood in This New Zealand, an historical study of the country's cultural achievements in its first century of European settlement. Wood observed the higher status accorded to local work that had achieved publication outside New Zealand, referring to this esteem as being the "'mana" of overseas' $(1946,152)$. Describing this condition as being 'the substitution of overseas recognition for local achievement', Wood considered this to be based upon the country's sense of its cultural inferiority and 'an instinct to prefer the imported article' (ibid). This view of local identity, that it was dependent upon external criteria of recognition, was contradicted in Brasch's comment in Landfall in 1963 that New Zealand is "more than normally self-centred. ... we take little notice of what goes on beyond our shores ...' (371). However, the frequency with which repeated references appeared in the body of local critical writing in reaction to the overseas response towards 
published New Zealand literature indicated that Brasch's observation was incorrect, both at the time and subsequently.

An example of the 'notice' accorded by local critics in regard to the overseas reception of New Zealand writing is evident in Michael King's description of Sargeson's creative and critical work. In describing the importance of Sargeson's work in the development of a local canon, King emphasizes what he views as its contribution to and place within the body of 'world literature in English' (2003, 382). Similarly, Gordon Ogilvie, in his biography of Glover, promotes the view that he was pre-eminent in New Zealand letters by means of reference to the significance of the poet's international reputation:

Overseas, [Glover] is seen as the quintessential New Zealand voice. ... Les Murray, one of [Australia's] most prestigious poets ... said some of our poetry was fine and ... the finest [New Zealand] poet was Denis Glover $(1999,469)$.

Earlier, Louis Johnson, in a 1946 review in Arena of Sargeson's Speaking for Ourselves (1945), lauded the anthology as being 'an achievement for New Zealand writers' in the body of international writing, that "fully justifies the claim that this book is different, comparable with overseas productions' $(1946,20,22)$. These, and many similar, repeated comments, indicate that the creative gaze of many New Zealand writers and their critics was focused outwardly, with an interest in achieving acceptance and the favourable response of an overseas readership.

This link between developments in overseas literature and their influence upon New Zealand writers can be seen in various stylistic and thematic changes that are identifiable over time in local poetry and fiction. Lawrence Jones, for example, in his 1989 essay, 'Versions of the Dream: Literature and the Search for Identity', observed that New Zealand poets in the 1960s were 'following the trends of British and American poetry, as usual, but half a 
generation later' (203). In a later essay, “'Colonial Like Ourselves”: The American Influence on New Zealand Fiction, 1934-65' (1996), Jones reflected on the extent of the reliance of local writers, both of prose and verse, upon developments in American writing. He noted that while some local poets and short fiction writers, such as Fairburn and Sargeson, expressed their strong rejection of what they viewed to be a continuing colonial dependency upon English literature, they, along with a number of other New Zealand writers, readily adopted American models for their own work (n.p.).

Sturm has reflected on the extent to which, in former colonial settlements such as Australia and New Zealand, concepts of literary value continued until late in the twentieth century to be dependent upon the sanction of their colonial parent. He noted that judgement was reflective of "valuations conferred in the more distant Anglo-American "international" community, reinforced by international publication' $(1987,247)$. He implies here that without the validation of overseas endorsement, local readers would lack adequate means or scale for ascertaining the value and significance of the work of local writers.

In a similar reference to the importance of overseas acceptance to local evaluation, Janet Frame described her experience upon returning to New Zealand in 1963 following the successful publication of her work in England and the United States, stating:

I had not realised that in the seven years I had been absent, the publication overseas and in New Zealand of several books had built a reputation known as an overseas reputation and therefore valued apparently more than a reputation within New Zealand - the reputation of excellent writers living in New Zealand was usually qualified by the phrase known within New Zealand only [original emphasis] $(1989,422) .{ }^{135}$

\footnotetext{
${ }^{135}$ Frame made this comment in The Envoy from Mirror City, which was first published in 1985 and reprinted in An Autobiography (1989).
} 
Hugh Roberts, in 2003, reflected upon the dual allegiances expressed by local writers both towards the heritage and traditions represented within the overseas literary mainstream, and their sense of obligation regarding their contribution to the development of a distinctive, separate local canon. Roberts noted that '[as] late as 1936, when Brasch had published several poems in New Zealand (in the Christchurch biweekly Tomorrow, one of the supposed hotbeds of the new Zealand literary nationalism of the 1930s), he still felt that "it was publication in England that counted, in England that reputations were made" ... indeed that he belonged to England even more than to New Zealand ...' (225). Roberts also noted the inextricability of overseas influence from local literature, referring to the disparity of experiences Frame recorded in her autobiography - ' $[\mathrm{t}]$ he associations that give content to her national identity also displace that identity to another land' (226). Frame had, for example, enthused that Curnow's 1945 Caxton Press verse anthology had 'given New Zealanders a literary home' - yet, on first travelling to London, she 'naturally' starts to recite Keats's 'La Belle Dame sans Merci' at the sight of 'tall brown rushes growing at the edge of the pond' (225).

Roberts also pointed out that Curnow's version of the 'authentic' New Zealand that he purports to be presenting in his 1945 anthology, and which was held in high esteem by Frame, is in fact devoid of 'real' local referents, instead presenting a close facsimile of the English subject matter and aesthetic concerns that Curnow had earlier castigated writers for having emulated. Roberts contrasted Curnow's version of New Zealand ‘authenticity' with that presented in Sargeson's anthology, noting the lack of New Zealand idiom evident in Curnow's collection compared with its strong emphasis in the latter (227).

Remarking on the paradox evident in Curnow's 1945 anthology - that, despite his published assertions that local writers should evince 'a common inheritance and a common 
cause', ${ }^{136}$ Curnow in practice did not himself adhere to these principles - Roberts observed that:

To read Curnow's Book of New Zealand Verse from cover to cover can be a curiously dissonant experience. The long introduction agonizes about what it means to be a "New Zealand" poet ... The poems, however, consistently avoid providing a content for that "common inheritance". Indeed, of the 123 poems in the collection, only 36 - fewer than one-third - have identifiably New Zealand referents. ... Few of the obvious tokens of a specifically New Zealand identity appear here ... [there is] the almost total absence of New Zealand idiom in the language. ... Not merely ignored, these easily available markers of national difference are explicitly rejected $(227,228)$.

While Curnow trenchantly promoted, in the Introductions to his anthologies and early critical writing, a strict adherence to localism in New Zealand literature, and a firmly delineated agenda of cultural nationalism, in practice his position was more nuanced and diverse, drawing more widely on international literary forms and values, and directing his work towards both local and international publication. In 1974, Curnow had stated that his own critical focus had moved 'away from questions which present themselves as public and answerable, towards the questions which are always private and unanswerable' (xiv). This appears to be a rejection of the certainties of the assertions his earlier nationalist position, and a movement towards a literary focus on personal and emotional concerns, and on an individual, rather than national identity.

\footnotetext{
${ }^{136}$ Curnow made this comment in his 1945 Caxton anthology, 45.
} 
In their portrayal in Curnow's anthology, it is some of the poets themselves (including Curnow) who could be considered the 'interlopers on an indifferent or hostile scene' (Curnow, 1945, 52), with more in common with the internationalism of the High Culture expressed in the verse of literary modernists such as Auden, Day-Lewis, Spender and Yeats, than with the 'authentic' localism more evident in the work of others Curnow had rejected. While Curnow's prescriptive views on the nature of New Zealandness and how his concept of cultural nationalism should be portrayed in local literature were widely accepted both at the time and subsequently, some strongly rejected his stance. Erik Schwimmer, for example in his 'Commentary' in the first issue of the New Zealand Poetry Yearbook (1951), argued that the particular mythology of New Zealandness created by Curnow - that of 'a lonely island-desert' - was an elitist view that was 'never widely believed by New Zealanders; in fact, only a handful of literati were ever touched by it' $(65,66)$. In Schwimmer's view, even at that time, the country had already embraced a 'vivid ... consciousness of the internationalization of culture' so that 'the period of preoccupation with the specific New Zealand experience is past' $(66,69)$. In this critique, the narrowly localist focus that Curnow insisted upon, despite being the dominant influence on local literature, was already outmoded, illustrating more in common in this respect with the generation of dated Georgians from whom they wished to dissociate themselves than with the form and content of the work of the modernists they aspired to emulate and replicate in a local setting.

From the 1970s and 1980s, others, also, presented challenges to Curnow's influence over the composition of the local canon. Arthur Baysting, for example, with his 1973 anthology, The Young New Zealand Poets, provided intentionally an alternative site within which new forms and themes in local verse could be presented, in direct opposition to the 'mainstream' Oxford and Penguin anthologies. A more emphatic but less nuanced response that challenged Curnow's model was set in the Introduction to 15 New Zealand Poets (1980), 
where editor Alistair Paterson set out his aim to position New Zealand verse within its international context, so that local verse 'can no longer be considered as primarily belonging to any one nation, but as part of a world literature [written in English]' (xiii). Paterson asserted that his anthology represented a 'new direction' in local verse, which illustrated the 'great changes and new emphases', and 'interesting and exciting directions in which poetry has been moving in New Zealand'. Paterson's stated objective was to discard 'the traditional "closed" form of English writing' that he saw as the basis of the work of Curnow and others, and instead to present 'innovative and inventive writing'. His intention in the anthology was to display work reflective of the recent developments in postmodernism in American poetry that was illustrative of an 'open form' in style, and in concept 'moves away from conventional "content"', requiring 'new and wider critical skills' (xi, xii). Paterson's editorial stance was intended to provide a deliberate contrast with Curnow's. He directly challenged what he saw as Curnow's hegemony, rejecting the cultural nationalism and modernist forms, along with the version of New Zealand 'reality', that were promoted by what he considered to be mostly a culturally passé and artistically defunct older generation.

Stead, in his Introduction to In the Glass Case (1981), addressed this clash of literary ideologies, suggesting that challenges to Curnow's dominance were personally motivated rather than indicative of artistic differences. The discord was, he claimed, fomented by 'a group of poets ... attacking Curnow ... because they felt under-represented in his anthologies. ... Some of the smoke of those old battles still hovers' $(11,12)$. Later, in Big Smoke: New Zealand Poems 1960-1975 (2000) - a title intended to echo the sentiments of Stead's comment - Alan Brunton, Murray Edmond and Michele Leggott compiled a verse anthology that in its aims and content, and the period of its scope, had the express objective of being combative, contesting the paradigm established in Curnow's model of New Zealand literature presented in his 1960 Penguin collection, as well as that of O'Sullivan, in his 1970 
and 1976 Oxford anthologies. In Big Smoke, the editors sought to provide an alternative interpretation of the concept of New Zealandness in the eclecticism of their range of selections, including in its variety of poets and verse. Some of their selections were markedly different from those of mainstream anthologies, and a large proportion had not been anthologized elsewhere. However, while the compilers of such 'alternative' anthologies actively sought to present views of New Zealand experience and of local writing that often were substantively different from those of the literary 'mainstream', and provided publication opportunities for a wide variety of other poets, none succeeded in displacing the authoritative national collections.

\section{Localism versus Universalism - Unresolved Ambivalence}

Local writers whose work focused on issues of national identity commonly became dichotomized into opposing protagonist groups, who promoted either a localist or universalist position (what Wedde referred to in 1985 as the 'here-anywhere' dispute [24]). However, a number of influential commentators have attempted to reconcile these seemingly oppositional elements in New Zealand literature, for example in Curnow's later 'vision' of national identity, which modified his earlier strong advocacy for localism in the country's writing.

The separation between localism and internationalism that some critics have assumed to exist in New Zealand literature is false, as these two aspects of New Zealandness coexist and both contribute an essential part of its nature. The dependence of New Zealand writing upon overseas models is not a new phenomenon, but one observable from the earliest colonial period, so that rather than being 'authentic', unique and separately identifiable, New Zealand literature has always been intrinsically linked and responsive to changes arising from international literary developments and broad social and cultural movements. Stuart Murray terms this the 'double gaze' that results from 'the unavoidable tension that comes with the 
colonial legacy of facing in two directions at the same time' $(1998,13)$. The outcome of this tension was the development of a New Zealand literature that incorporated both local and international aspects into the nature of its expression.

The act of merging of overseas influences with local writing into a new and original hybrid form renders division between localist and internationalist perspectives invalid.

Calhoun, reflecting on the process of nation-forming, points out that

The idea of nation is ... inherently international and works partly by contraposition of different nations to each other. Nationalist rhetoric offers a way of conceptualizing the identity of any one country that presumes the existence of other more or less comparable units $(1997,93)$.

This process, of a nation identifying itself not in discrete, individual terms but by its similarities and differences from others, can be observed in the case of New Zealand. Curnow alluded in his anthologies to the tension between localism and universalism in his assertion that '[w]hatever is true vision belongs here, uniquely to the islands of New Zealand', while also referring to 'the great audience that is addressed by a poem in English', statements that acknowledge the complexities, even contradictions, within the cultural nationalist project. ${ }^{137}$

New Zealand's national identity, and the cultural values that it represents, have been always dependent for their shape and contours not only upon local experience but also upon their reflection in the mirror of overseas appreciation, being subject to influences from other cultural centres and moulded by the country's relationship with its international context. Australia has been a major factor in the construction of New Zealand's self-perception, and influenced the development of its literature, particularly up to the mid-twentieth century.

\footnotetext{
${ }^{137}$ The first of these comments by Curnow was made in his Introduction to his 1945 Caxton anthology (17); the second in the Introduction to his 1960 Penguin (155).
} 
This country's literary relationship with Australia is the focus of the analysis in the next chapter. 


\title{
CHAPTER FIVE: "THE LOATHSOME AUSTRALASIAN" - THE ROLE OF AUSTRALIA IN THE CREATION OF NEW ZEALAND
}

\author{
New Zealand is not Australia. ${ }^{138}$
}

In the previous chapters of this thesis, major influences on the historical development of New Zealand's national identity have been examined, including the continuing effects they have had on its present conception, and how these have been represented in local creative and critical literature. In this chapter, a specific case of such influence is analyzed - that of New Zealand's relationship with Australia, both in the form of its political, economic, cultural and geographical 'reality', and as an imagined literary construct. A particular focus of this chapter is an examination of the response of New Zealand writers towards the Oxford and various other Australasian verse anthologies which were produced from the late nineteenth century until the 1950s. An analysis of this reaction, as it is presented in a range of critical literature and in the correspondence between the major protagonists involved in the construction of the anthologies, provides insights into the complexities of the historical trans-Tasman relationship and its influence on shifts in New Zealand's construction of national identity over the twentieth century.

The attitude of rivalry and hostility towards Australia that arose in New Zealand from the 1930s, and which was tangibly expressed in local literature, was sourced in the particular circumstances of their interlinked historical background. The patterns of change in the transTasman cultural relationship corresponded with and were reflective of those that occurred in the broader economic and political associations between the two countries. Initially very

\footnotetext{
${ }^{138}$ This statement is made in 'Australasian Poets Reculled', an unattributed contemporary review of A Book of Australian and New Zealand Verse (1950). An original cutting of this newspaper review is held in the Turnbull Library, Wellington, located inside the back cover of a copy of the anthology.
} 
close, New Zealand's inclination towards Australia declined until, by the mid-twentieth century, it ranged between indifference and antagonism, a state that has continued in various degrees into the present. ${ }^{139}$ While this cultural rift was, in some part, driven by and reflective of New Zealand's growing strength of national identity and independence, the relationship was also indicative of the lingering presence of more complex and difficult issues of selfperception. The at times marked vehemence of its rejection of a closer cultural association within a broader Australasian region, and the continuation into the present of a strong sense of antipathy towards Australia, are indicative of New Zealand's underlying sense of insecurity and anxiety in regard to being brought under the aegis of the larger and more influential country rather than confident expressions of the achievement of autonomy and national maturity.

During the period of their initial establishment, Australia and New Zealand had been administered by British authorities effectively as a single regional entity, a concept that has lingered in overseas perceptions to encompass the geographical area popularly known as the 'Antipodes' ${ }^{140}$ James Belich in Making Peoples (1996) describes New Zealand's status during its initial European settlement as being a de facto Australian colony, with this country being 'one of Sydney's most important hinterlands' over the nineteenth century (134). Up to the 1880 s, Australia was New Zealand's largest export market, after which, with the introduction of refrigeration technology to shipping, this focus shifted to Britain. From an initial period of cooperation and interaction in the nineteenth century, therefore, the two countries instead became strident rivals in trade and commerce, and in the 1930s this became tangible with the introduction of trade protectionist policies on both sides of the Tasman.

New Zealand's stance of economic rivalry and competition in regard to Australia at this time

\footnotetext{
${ }^{139}$ See for example Len Richardson's 'Bloody Australians', a 1988 review in New Zealand Listener of Keith Sinclair's Tasman Relations (1988).

${ }^{140}$ This term was still commonly in use in Britain in the twentieth century, for example in articles such as 'Myths in Antipodean Writing' in the Times Literary Supplement (14 June 1963), 420.
} 
was correlated with the development of cultural nationalism, which found expression in particular in the creative and critical writing of Curnow and other local poets, and reflected the termination of the formerly close trans-Tasman literary relationship.

From the earliest colonial period, Australia has been a major contributor towards the processes of defining New Zealand identity, forming a significant influence over the construction of the particular characteristics that comprise this country's self-concept of its national distinctiveness and difference. It has also has been an important factor in the development of a separate New Zealand literature, identifiably different both from Australian writing and that of other literatures in English. It has been Australia, rather than Britain, that has functioned for New Zealand, in important aspects of the relationship, as its cultural point of distinction, providing a converse focus against which the concept of a distinctive New Zealandness has been established. Since the early decades of the twentieth century, in particular, Australia has been perceived by New Zealanders as a focal point for cultural resistance, and strong opposition has been directed towards the concept that local creative writing should be subsumed into a generic notion of 'Australasian' writing.

This assertion of its difference from Australia has become an essential feature of this country's self-definition. Similar comments, that illustrate the difficult place that Australia has occupied in the processes of New Zealand's identity construction, have been repeated frequently in the critical literature, so that they have created a specific strand in the discourse of identity. Bell, for example, states that '[i]n New Zealand the juxtaposition of Pakeha against ... Australians ... is a way of affirming boundaries and differences' $(1996,194)$. As she asserts, maintaining a cogent sense of apartness and difference from Australia has itself formed a defining characteristic of New Zealandness, and of New Zealand writing.

However, such opposition was not always in evidence. In the nineteenth and early twentieth centuries, a considerable volume of verse, short fiction and other work by New 
Zealanders was published in Australian magazines and in Australasian, or even 'Australian', collections, usually without distinguishing the writers' country of origin. ${ }^{141}$ These

publications often were circulated widely in both countries, and assumed a common regional identity of sufficient similarity of experience to encompass both New Zealand and Australia under a single rubric. The extent of reference to Australia in early New Zealand literature, as outlined in this chapter, is an expression of its historical significance, in various ways, in shaping local culture and representations of the subjective experience of life in this country. Initially, there was a close literary association between the two countries, during a period referred to as New Zealand's 'Maoriland' phase - a term originally applied by writers including Thomas Bracken and J. Kerry-Nicholls as a distinguishing geographical locator, but in later decades derided as representing a form of false, inauthentic and sentimental local writing, and even now still sometimes excluded from the record of the development of an indigenous New Zealand identity. ${ }^{142}$ Australia, however, has since that time continued to impact significantly upon New Zealand's collective consciousness, providing a focus for cultural nationalism as a symbolic concept of difference against which this country's sense of separateness and uniqueness could be distinguished.

At the end of the twentieth century, this country's literary relationship with Australia remained one of ambivalence, indicating often not indifference but uncertainty or even hostility, representative of the broader unresolved problematic issues in this country's construction of a sense of uniqueness and a defined national identity in response to the close presence of a larger cultural entity. Fergus Barrowman, for example, in his Introduction to the Picador Book of Contemporary New Zealand Fiction (1996), observed that 'Australia has always held a problematic place in the New Zealand imagination' (xxxi).

\footnotetext{
${ }^{141}$ On those occasions in the early days of publishing when the nationality of New Zealand writers was referred to separately, it was commonly referenced as 'ML' ('Maoriland').

${ }^{142}$ This period, and the later negative response that it generated, is described in Jane Stafford and Mark Williams's Maoriland (2006).
} 
New Zealand's decision to decline Australia's invitation to join its six self-governing colonies when they together formed a Commonwealth in 1901 formed a defining event in determining the 'shape' of this country's self-perception. Instead of becoming an offshore appendage to that entity, New Zealand developed and retained its own political institutions independent of Australia, and, while still ceding significant sovereign power to Britain in foreign affairs and trade, among other aspects of its administration, the country had, with this decision, initiated its political and emotional development as a distinct and separate nation. Describing the impact of Australian federation upon the collective New Zealand consciousness, Sinclair, in his History of New Zealand (1969), observed that, in its decision to remain apart, New Zealand was henceforth able to 'fashion an "Other" against which to define itself' (232). Since this definitive act of political and psychological separation from the concept of a greater Australasian body, the sense of separateness has grown inexorably wider. Nearly three decades later, Barrowman commented that the concept 'Australia', as it has been constructed in the New Zealand imagination, was fundamental to the formation of New Zealand's collective identity, providing a symbolic form against which a strong sense of difference - of 'not-New Zealand'- could be projected (1996, xxxi). Australia's federation incited this antithesis, reducing New Zealand from being 'one of a group of more-or-lessequal Antipodean colonies' to the status of 'minor relation', so that subsequently the 'two nations have turned away from each other like two siblings just a little too far apart to play together naturally' (ibid). ${ }^{143}$

A similar cultural model, in which the concept of a larger and more powerful neighbouring country has been utilized to define the identity of one much smaller and less politically and commercially significant, can be observed in the case of England and Ireland.

\footnotetext{
${ }^{143}$ Barrowman notes the ambivalent nature of this relationship, noting that New Zealand's attitude reflects also that of 'envying Australia's size and economic potential', so that it has been 'a paralysing dream - Oz, and the place just over the ditch' (ibid).
} 
As discussed in Chapter Two, Curnow had in his own criticism reflected on the Irish Renaissance as being a potential model for New Zealand cultural nationalism. Curnow drew on the Irish nationalist movement and its literary supporters as being paradigmatic for the construction of a 'real' New Zealand, citing from Yeats's The Trembling of the Veil (1922) as the epigraph for his Introduction to his 1945 Caxton anthology, and from Yeats's essay collection, Letters to the New Island (1934) in his 1960 Penguin. Yeats' strident Irish nationalism, expressed in both his creative work and prose writing, provided a model which Curnow utilized in opposition to the 'universalist' camp in New Zealand literature:

... But to this universalism, this seeing of unity everywhere, you can only attain through what is near you, your nation ... One can only reach out to the universe with a gloved hand that glove is one's nation, the only thing one knows even a little of. $^{144}$

Declan Kiberd, in Inventing Ireland (1995), an historical analysis of the role of Irish literature in the 'invention' of modern Ireland, provides an analysis of the function of England in defining Ireland's historical narrative of national self-identity, asserting that

[t]he English helped to invent Ireland .... Through many centuries, Ireland was pressed into service as a foil to set off English virtues .... If Ireland had never existed, the English would have invented it ... Ireland was ... patented as notEngland (1,9).

In a way that is the inverse of that in which Australia has impacted upon New Zealand, England has provided the complementary, obverse role in the construction of Irish identity (if in a more vehement, at times violent form), being perceived as a defining 'marker' for all that

\footnotetext{
144 The quotation is from Yeats's Letters to the New Island (1934).
} 
Ireland and the Irish were not. New Zealand, however, 'invented' Australia as its Other, in a reversal of this role.

A comparable example is the case of North America (although, with its continuing legacy of European influence, this has greater complexity). There, the United States has functioned, in some ways, in a manner corresponding to that of Australia for New Zealand, in regard to the processes of the construction of national identity in Canada, which is confronted with the geographical contiguity of a much larger (in terms of population), politically more influential and commercially and culturally dominant country. In Uneasy Neighbours (2007), their study of Canada's political and cultural relationship with the United States since their colonization, David Jones and David Kilgour concluded that a major determinant of Canadian self-identity is its perceived difference from the national characteristics that define the United States. They state that 'Canadians are proud of what they are not - Americans!' (8). Australia has served in an analogous manner in the construction of New Zealand's identity, so that rather than forging a self-image compiled as a set of positive features, this country, also, perceives itself primarily in terms of what it is not: that is, New Zealand as 'not-Australia'. This also has been a determinant in the development of a local literature as one that is different and distinguished from a broader concept of 'Australasian' writing. This sense of difference in national identity has provided the basis and impetus for the divergence of the literatures of the two countries, so that they have become quite distinct, not simply in terms of geographic and social subject matter but also in their style, tone and thematic concerns.

The view of Australia has been presented in a variety of ways in New Zealand media and other writing over time. Often, this has been with reference to that country's obvious physical, political and economic superiority, but included in this depiction is that of a country representative of qualities and values that were contrary (and generally inferior) to those that 
were claimed to form the basis of the character of New Zealandness. For example, while English geologist J. W. Gregory wrote in 1906 of The Dead Heart of Australia, a concept of that country's arid spiritual and emotional, as well as physical state that influenced also New Zealand's perspective of the Australian interior, the land in this country was commonly presented in local literature, especially verse, in sentiments that emphasized it as being animate, inspirational, often benign, and, while untamed and physically challenging, symbolic of the potential for human freedom rather than of death. This view is illustrated in much colonial verse, but also in later work, for example, in Baxter's 'Poem in the Matukituki Valley', which Curnow included in his 1960 anthology. Baxter here refers to 'the land's heart' which, although 'remote', is personified as female, sensuous and vibrantly alive, 'with sound of water / Sibilant falling and high nested birds' (287).

This negative concept of Australia was a legacy formed not only from the obvious physical differences in the land but also in part due to the stigma of that country's early settlement as a penal colony and its subsequent development from that unfavourable foundation, in comparison with the Pākehā version of the history of New Zealand's colonization and settlement. Later, this was attributed to significant differences between the two countries in regard to issues of indigenous rights, immigration and international affairs. However, New Zealand's insistence upon its moral and intellectual superiority as a settler colony to its trans-Tasman neighbor is based not upon national self-confidence and a secure sense of cultural identity but to collective psychological stresses stemming from the competitive nature of the relationship between the countries, and a sense of inferiority on New Zealand's part due to its much smaller size in terms of geographical mass and population, economic activity, natural resources, and international influence. The ambivalence of this country's relationship with Australia is apparent in assessments such as Bob Catley's Waltzing with Matilda (2001), in which he describes the extent of current and 
past inter-relatedness between the two countries in such factors as international trade, regional politics, finance, business ownership, capital arrangements, military associations, legal institutions, tourism, transport, labour movements, and other infrastructural affiliations. As these have developed more closely and inevitably into linked regional cooperation, in contrast the two countries' distinctively separate cultural identities have been increasingly emphasized.

The association between the two countries became increasingly dichotomized, and developed into a state described by Australian writer Peter Pierce in 1998 as being of 'greater cultural distance than at any time since European settlement' (34). It is likely that this observation can be extrapolated into the future, as the factors driving the differences between the two cultures, as they are observed from the perspectives of the two populations - and despite growth in the harmonization of other aspects of the trans-Tasman relationship, in particular trade and commerce - remain inherent to the self-narratives of both countries. This early construction of a sense of cultural difference from Australia, rather than being mitigated over time, has grown in intensity while paradoxically other material and financial aspects of the association between the two countries have become closer.

The complexities and anxieties inherent in this multi-faceted relationship have formed a recurrent trope in New Zealand literature, although this influence has not been fully acknowledged in this country's literary histories. The extent to which a concern with Australia has, at times, preoccupied the New Zealand psyche, and has invoked a sense of cultural nationalism is apparent in the range of references to Australia that have appeared in local critical literature over time, and that continued to be evident at the end of the twentieth century.

Hugh Roberts is one of the critics who have reflected on the complex and multifaceted nature of the trans-Tasman relationship, and its impact on the development of a 
distinctive New Zealand literature. In 'The Same People Living in Different Places' (2003), Roberts observes how the history of Australia's colonial processes and its subsequent development has formed a counterpoint for the construction of New Zealand's self-image, and how this has been portrayed in local literature. An underlying ambivalence in the transTasman relationship is the marked difference in the two countries' responses towards the origins of their British colonial settlement. Roberts notes that a number of early New Zealand commentators as well as Britons commented favourably in regard to New Zealand's ‘typically Anglo-Saxon’ heritage which produced ‘splendid specimens of humanity' representing the very best of 'civilization', contrasting this heritage against Australia's 'low' origins (224). He suggests that

Australia's origins as a penal colony have increasingly ... become a focus of nationalist sentiment in that country ... a crucial contribution to Australian cultural nationalism ... [which] allow European Australians imaginatively to adopt an anticolonial stance toward Britain in which they become the victims rather than the beneficiaries of colonial expansion. By contrast, New Zealand, figuring itself as an ideal, conflict-free Britain, found it much more difficult to frame the emergence of its national identity as a process of decolonization (ibid, 223, 224).

New Zealand's often expressed sense of relative superiority in regard to the trans-Tasman relationship, based on such sentiments derived from the region's colonial past, has lingered into the present, uneasily coupled with an awareness of its inferior size and population in relation to that of Australia. This forms the basis both for New Zealand's paradoxically close but antipathetic relationship with Australia, and its own ongoing difficulties in constructing a firm concept of its post-colonial collective identity. 
Despite the differences between the two countries, and the often dismissive or even antagonistic attitude of New Zealand towards its trans-Tasman counterpart, it is evident from the extensive history of publication by local writers in Australian literary outlets that it has been an important and long-standing element in the development of a New Zealand literary canon. Notwithstanding the later aversion of New Zealand writers towards being subsumed under the descriptor 'Australasian', many over the period since the colonial origins of New Zealand, especially in the late nineteenth century, sought to have their work published in Australian literary outlets, most of which included a large range and volume of such work without qualification as to the writer's nationality. Initially, there existed a general fluidity with which the origins of Australian and New Zealand writers and their work were considered in the nineteenth and early twentieth centuries, and, as in the case of other occupations, their nationality was regarded as largely synonymous.

A particular example of the initial closeness of the two literatures is evident in the history of New Zealand's association with the Sydney-based Bulletin. Over the eight decades ${ }^{145}$ from the time of its establishment in 1880 , this weekly magazine included a significant array of New Zealand verse, short fiction and criticism among its Australian content, providing a regular publication outlet as well as a source of revenue for local work, often under the general rubric 'Australasian'. In his section on the Bulletin in The Oxford Companion to New Zealand Literature (1998), Sturm pointed out the extent of its contribution to New Zealand writing:

Nearly 300 New Zealand authors contributed over 4000 items of verse and 700 short stories, and there were numerous reviews and commentaries on New Zealand literature by both New Zealanders and Australians. New Zealanders were also

\footnotetext{
${ }^{145}$ In 1961 the Bulletin was restructured, and, among other changes, discontinued its literature section.
} 
influential literary editors of the Bulletin. Between $1906 \ldots$ and 1926 the Red Page was edited firstly by A. H. Adams (until 1909) and, after 1912, by David McKee Wright. In the later 1930s Douglas Stewart joined the magazine, and was its literary editor 1940-60 ... [publishing] 700 New Zealand poems and short stories ... alongside 400 reviews and comments by himself and others $(1998,77,78)$.

This analysis illustrates the extent to which inclusion in the Bulletin was sought by New Zealand writers until well into the 1930s, as well as the general commonalities of style, theme and tone between Australian and New Zealand short fiction and verse over that time.

However, the apparently parallel nature of the two country's identities suggested by the content of the Bulletin diverged markedly after the early decades of the century, and subsequent judgement of its contribution to the development of local literature was not always positive. Curnow, for example, in 1947, noting acerbically the historical role of the magazine in providing a ready publication outlet for local writers, commented that 'the Sydney Bulletin provided something like a matriculation test for writers in the country it called Maoriland' (1947, 142). By the 1930s, the Bulletin's importance to local literature had diminished as other literary outlets had emerged, both in New Zealand and overseas. Few of those associated with the Caxton Press, for example, were among the Bulletin's contributors. Its most significant contribution to New Zealand writing in the 1930s and 1940s was that it provided a publication outlet for the verse and short fiction of a number of women, including Duggan, Hyde, Langley and Rawlinson, for whom it provided an alternative to the version of New Zealand identity presented in the strongly nationalistic (and masculinist) cultural focus of critics such as McCormick, Holcroft, Rhodes and Curnow, among others.

Patrick Evans, in The Penguin History of New Zealand Literature (1990), describes the influence of Australian magazines on nineteenth- and early twentieth-century New Zealand 
writers, for whom Australia was 'the first version of Overseas and a seeming network of magazines that not only published but paid' $(1990,29)$. Local writers including Mansfield and Henry Lapham, among many others, published verse and short fiction in a range of early Australian magazines and newspapers, including the Bulletin, Native Companion, Australian Journal, Australasian, The Lone Hand, Aussie, Young Australia, Town and Country Journal, Art in Australia and Victorian Review. Subsequently, New Zealand writing has been included in, among others, Australian journals Southerly, Australian Author, Island, Australian Literary Review, Overland, Meanjin, Australian Coast to Coast, Quadrant, Scripsi, and AUMLA. ${ }^{146}$

From this record, it is clear that Australia was a significant outlet for local writing at least until the early decades of the twentieth century, particularly in terms of providing initial publication outlets for local short fiction. For example, in 1907, The Native Companion published Mansfield's early stories 'Vignettes', 'Silhouettes', 'In a Cafe' and 'In the Botanical Gardens' (under her nom de plume 'Julian Mark'). During 1908 and 1909 Mansfield also published work in the Triad and The Lone Hand. ${ }^{147}$ Australia continued to be an important publishing site for local short fiction writers in later decades - Frank Sargeson's first published story, 'Life is Like That', was published initially in Australian Women's Mirror in $1933 .^{148}$

A variety of Australian magazines in addition to the Bulletin have accepted for publication the work of New Zealand writers and of overtly New Zealand subject matter, either in their regular editions or in special 'New Zealand' issues. For example, from its beginnings in 1918 as a publication for soldiers, Aussie magazine published a variety of New

\footnotetext{
${ }^{146}$ AUMLA was the journal of the Australasian Universities Modern Language Association, now renamed the AULLA, the Australasian Universities Languages and Literature Association.

${ }^{147}$ Jean E. Stone discusses Mansfield's Australian literary connections in Katherine Mansfield: Publications in Australia, 1907-09 (1977).

${ }^{148}$ This appeared in the issue of 17 October, 1933.
} 
Zealand work. A New Zealand supplement to Aussie, edited by Patrick Lawlor, commenced in 1923 and ran to 1932. The range of New Zealand contributors included early work by Fairburn, Hyde, Alan Mulgan and James Cowan. Australian poet Mary E. Wilkinson's anthology, Gleanings from Australasian Verse (1917), published in Melbourne, included selections from writers in both countries.

New Zealand writers were also commonly included in early 'Australian' anthologies, such as Bertram Stevens's Anthology of Australian Verse (1906), published in Sydney in the same year as New Zealand Verse. An illustration of the contribution of Australia towards establishing an early New Zealand literature is evident in this country's first 'national' anthology of short fiction, New Zealand Short Stories (1930), which was compiled and edited by O.N. Gillespie, and published in London by J.M. Dent. The anthology's acknowledgements (n.p.) indicate that the majority of the stories included in the collection had appeared originally in Australian publications, including Bulletin, Lone Hand, Aussie, and Art in Australia.

Until the 1940s, and in particular with the establishment of Landfall and the Caxton Press, Australian publications had provided the major source of outlets for New Zealand creative writing. ${ }^{149}$ During the first half of the twentieth century, many New Zealand writers continued to publish their work in Australia even after local outlets became available. Melbourne-based magazine Angry Penguins, for example, published contributions by a number of New Zealand writers including Sargeson. ${ }^{150}$ Australian publishers Reed and Harris produced an Australian edition of Sargeson's novella When the Wind Blows (1945), published also by Caxton Press. As well as short fiction, a number of Australian journals published selections of New Zealand poetry. Louis Johnson was among a number of other

\footnotetext{
${ }^{149}$ See, for example, Patrick Evans's discussion of this period in local writing in his Penguin History of New Zealand Literature (1990).

${ }^{150}$ Sargeson included Harris's short story 'The Papeye and the Molacca' in his 'New Zealand' anthology, Speaking for Ourselves (1945).
} 
New Zealand poets whose work continued to be published into the 1950s in Australian literary magazines, including Angry Penguins. Several Australian magazines produced special issues focused on New Zealand work, such as Meanjin in 1946.

The close association between New Zealand writers and Australian publishing outlets up to the mid-twentieth century is seen in the archived correspondence of Patrick Lawlor, which reveals that from the 1930s to the 1950s, in particular, Angus and Robertson actively sought New Zealand writing for publication in Australia. ${ }^{151}$ This close interrelationship, which elided the two countries into a common trans-Tasman identity for a time, is illustrated in the case of Douglas Stewart's verse collections, Elegy for an Airman (1940) and Sonnets to the Unknown Soldier (1941). These were both published in Sydney, by F.C. Johnson and Angus and Robertson, after Stewart had taken up the position of literary editor of the Bulletin. Curnow included two poems from these collections in his 1945 and 1951 Caxton anthologies, even though, in one, 'The Breaking Wave', the contextual referent is not New Zealand but 'the hard Australian coast' ${ }^{152}$ These and other poems from the two collections were also later included in several Australian anthologies.

Despite the close association between local writers and Australia over a considerable time, this aspect of New Zealand's literary history subsequently became regarded in this country with critical ambivalence, and is now largely disregarded. John Salmond, in an essay in Tasman Relations (1987), reflected that the long period of 'shared antipodean culture' has been subject to New Zealand's 'general amnesia about its Australian connection' (302).

There is little acknowledgement in recent assessments of New Zealand's literary development, such as Evans's The Long Forgetting (2007), of the range and extent of New Zealand's previous close connections with Australia, or reflection upon its continuing impact

\footnotetext{
${ }^{151}$ Patrick Lawlor Correspondence Files, MS Archives, Alexander Turnbull Library.

${ }^{152}$ Curnow also included another of Stewart's poems in his Caxton anthology, which he sourced from Green Lions, which Stewart self-published and had printed by Whitcombe and Tombs in Auckland in 1937.
} 
on this country's self-perception. While New Zealand's literary relationship with Australia was closely intertwined until at least the early twentieth century, the nationalistic spirit that grew in fervour from the 1920s in both countries subsequently caused a widening rift in this association, and the earlier history of Australia's close association with New Zealand came to be largely rejected or ignored.

Despite this general disregard, however, there have been some New Zealand commentators who have taken a critical interest in Australian literature and its relationship to the evolution of local work. Alan Mulgan, in his 1943 study Literature and Authorship in New Zealand, while noting that there were significant differences between the two countries, recognized that Australian writers had provided early models for the development of New Zealand writing. He also acknowledged that literature provided an important collective forum for the assertion of a country's independent identity, observing that 'Australia taught New Zealand something of the national spirit in letters' (57).

Curnow, also, noted developments in Australian writing, stating, in a 1947 review in Landfall of Modern Australian Poetry (1946), edited by H.M. Green, that

$$
\begin{aligned}
& \text { we cannot avoid some acquaintance with the literature of our } \\
& \text { nearest neighbouring country, and we may be interested to } \\
& \text { improve that acquaintance, to attend occasionally to the } \\
& \text { neglected middle distance of our outward scene }(1947,142) \text {. }
\end{aligned}
$$

Here, Curnow reflects upon what he identifies as the major differences that had intensified between Australian and New Zealand verse since a period of closeness in the late nineteenth and early twentieth centuries, acknowledging the cultural distance that had grown between the concerns and literary styles of writers in the two countries which, in the previous century, had been largely sympathetic. Curnow's statements in the review provide an extension of the manifesto of cultural nationalism that he had outlined in 1945 in his Caxton verse anthology, 
rejecting a cultural association with a wider Australasia and emphasizing New Zealand's difference and its identity as a separate nation. In his analysis of the two cultures that he provides in the review, Curnow firmly distances New Zealand from its 'neighbour', and clearly differentiates the literatures produced in the two countries. He is disparaging of the work of all the major contemporary Australian poets in Green's anthology, asserting the view that:

There is abundant invention without imaginative synthesis; abundant energy without understanding; ready versification without form; a verbal excitability constantly mistaking its object; everywhere a rawness of the intellect $(1947,149)$.

The product of 'the Australian imagination' that Curnow presented in the review is one that is not simply different from the qualities he perceived in the verse of its New Zealand counterpart, but also considerably inferior. He stated that, while there might have been some parallels evident in the verse of the two countries in the earlier colonial period, this no longer reflected the status of recent New Zealand poetry, which he considered to have far surpassed the achievements of the Australians. He implied that there would be little to be gained in re-establishing a closer association between the two countries, asserting that the 'poetry Australians write, and the kind of poetry they most admire, concern us less than they did a generation or more ago’ $(1947,142)$. New Zealand poets, in his view, demonstrated creative and critical standards superior to those of their Australian counterparts (emphasizing obliquely the greater qualities inherent in his own 1945 anthology of New Zealand verse, in comparison with those of Green's).

That Curnow's views were, in general, shared by other New Zealand poets and critics was evident in their responses. Fairburn, for example, in 1948 expressed this attitude succinctly in a letter to Alan Mulgan, stating: 'I'm no admirer of Australian ideas or 
Australian writing, personally’. ${ }^{153}$ James Bertram, in a 1957 review of current Australian verse in Landfall, was similarly disparaging of the literary significance and value of Australian writing, contrasting it negatively with that of New Zealand. In his review, Bertram assessed five verse collections, including the major anthology Australian Poetry (1956) compiled by A.A. Phillips, referring disdainfully to Sydney-based publishers Angus and Robertson as being literary 'midwives', who failed to apply adequately selective critical standards in the work that they promoted $(1957,174)$. He was derisive of what he considered to be the poor quality of recent Australian literary output, dismissing the collections he analysed in his review with the conclusion that 'Australian verse, in losing its bellow, also lost its bite' (177), and was largely derivative of outmoded poetic styles and 'unadventurous' (176). Contrasting the poetry of Hal Porter with that of Louis Johnson, for example, Bertram concluded acerbically that the former was of significantly inferior quality to the New Zealander, and suffered from an excess of 'sound and fury' amounting to a 'clanging anvil' (ibid).

M.K. Joseph was another who compared Australian verse unfavourably with that of local writers, expressing the opinion that the quality of New Zealand work had, by the midtwentieth century, progressed far beyond that of its overseas counterpart. He presented a strongly negative evaluation of contemporary Australian poetry in his 1957 review in Landfall of A Book of Australian Verse (1956), edited by Judith Wright, which he dismissed as comprising largely 'bad verse', and 'poetastic wastes' $(1957,80,81)$. Joseph proposed that what was required to raise the generally poor standard of contemporary Australian poetry was what he considered that Curnow had already done with his 1945 anthology to improve the quality of published local work, that is, 'a ruthless editing-out of earlier poetry, and

\footnotetext{
${ }^{153}$ Letter from Fairburn, to Mulgan dated 14 February 1948, in the Alan Mulgan Correspondence Files, M.S. Archives, Alexander Turnbull Library, Ref. No: MS-Papers-0224-15.
} 
considerable discrimination in the present, and ... a more rounded presentation of the really worthwhile' (82). Joseph shared Curnow's nationalist views of the particular characteristics of identity that a New Zealand literature should portray, and his insistence upon asserting this country's difference from Australia.

As well as the general tone of dismissing or ignoring Australian literature as inferior, a number of influential New Zealand writers have expressed their strong antipathy towards attempts to incorporate the trans-Tasman region as a single cultural entity. Curnow, for example in his Introduction to New Zealand Verse (1960), stated that, in the New Zealand imagination, 'Australasia' is a 'banned term' (27). While Mulgan's views of New Zealand national identity and of local literature were very different from those of Curnow, he expressed similar sentiments towards the concept of New Zealand's assimilation into Australasia, noting in Great Days in New Zealand Writing (1962) that the term 'Australasian' was 'displeasing' to New Zealanders (49). Keith Sinclair, similarly, in A Destiny Apart (1986), observed that the dominant view held by New Zealanders was that their 'destiny lies apart' from that of their larger trans-Tasman 'sibling' (110).

However, not all New Zealand writers were dismissive of Australian literature. While New Zealand poets in general from the 1930s sought firmly to dissociate their work from the concept of an Australasian literature, some fiction writers continued a trans-Tasman association into later decades. Frank Sargeson, for example, acknowledged the considerable early influence of Australian literary models on his own work, and expressed an interest in Australian writers including Rolf Boldrewood, Charles Reade, Henry Kingsley, Henry Lawson and others, adapting features of their writing, including facets of characterization and style, into his own. As well as occasional articles on aspects of Australian literature, he periodically reviewed positively the work of Australian writers. For example, in a 1966 article in Landfall entitled 'Henry Lawson: Some Notes after Re-reading', he assessed the 
three volume set of The Stories of Henry Lawson (1964), and discussed Lawson's life and literary focus. Discussing the 'creed of mateship', which was a shared theme in their work, Sargeson refers approvingly to Lawson's 'great literary achievement', and judges his 'stature to have heightened with the years', also tacitly acknowledging Lawson's influence upon his own work $(1966,156,159)$. In a 1967 review of the Australian anthology Overland Muster published in Landfall, ${ }^{154}$ Sargeson stated that he 'admired' Australian fiction, preferring it to that of New Zealand writers at that time, and acknowledging that he had been influenced by several early Australian fiction writers, having become 'susceptible to the spell of the Australian continent' $(1967,206,207)$. Sargeson's attitude contrasted markedly with that of many New Zealand poets at that time, particularly Curnow and other cultural nationalists who had strongly rejected any association with Australian verse, which they considered to be inferior, and sought their literary models elsewhere overseas.

Since the 1960s, however, with some exceptions, there have been few New Zealand writers who have expressed a critical interest in the trans-Tasman literary relationship. Stead is one who has taken an ongoing interest in Australian writing, producing a number of articles and reviews focused on particular Australian literary topics and a range of writers. In 'Les Murray: Authentic Oz', an article first published in 1988 in London Review of Books, ${ }^{155}$ Stead assessed two collections of the poetry of Australian poet Les Murray. ${ }^{156}$ In this, he compared the development of nationalism in 1950s Australian poetry with that of New Zealand, observing that 'although the terms of the debate are not quite interchangeable between Australia and New Zealand, they are close enough to seem familiar' (1989a, 123). He drew a parallel between the regionalist and nationalist versus internationalist debate represented in

\footnotetext{
${ }^{154}$ This was reprinted under the title 'Australian Fiction', in Conversation in a Train and Other Critical Writing (1983), 135, 136.

${ }^{155}$ This article was first published as 'Standing up to the city slickers' in London Review of Books in 1988; it was subsequently included, under the title, 'Les Murray: Authentic Oz', in Answering to the Language (1989).

${ }^{156}$ The collections reviewed were Murray's Selected Poems (1986) and The Daylight Moon (1988).
} 
Australia respectively by Les Murray and Peter Porter, and in this country by the localist stance of Curnow vis-à-vis his younger challengers 'who argued that mature New Zealand writing ought now to be international, taking its local roots for granted' (1989a, 123). ${ }^{157}$ Stead's observation suggests that, rather than the literatures of the two former colonies evolving entirely in unique and independent paths after the end of the nineteenth century, there were underlying similarities in the development of national identity as it was portrayed respectively in the verse each produced, and that even though the specific concerns of the authoritative poets took different forms in each country, there remained some of the patterns of earlier associations, and their work was influenced more broadly by similar generational and cultural patterns.

Terry Sturm is another who has taken a critical interest in the impacts of Australian writing on New Zealand literature and on this country's national identity. His 1987 essay, ‘The Neglected Middle Distance: Towards a History of Trans-Tasman Literary Relations', (citing Curnow's 1947 article published in Landfall four decades earlier), addresses the paradox of difference between the two Australasian countries which are geographically and historically close, yet culturally antipathetic in significant ways, and discusses the impact of nationalism in both countries upon the nature of the trans-Tasman literary relationship. Sturm provides a concise analysis of the Australian vis-à-vis the New Zealand contributions to the various 'Australasian' anthologies of verse that were published over the period from the late 1880 s to 1950 . In the mid-twentieth century the Oxford series of joint Australian and New Zealand anthologies acted as a catalyst for the nationalistic response of Curnow and others towards asserting a sense of difference and separation of their work from Australian writing, bringing the series to an end.

\footnotetext{
${ }^{157}$ The regionalist and nationalist versus internationalist stance in New Zealand literature is discussed in Chapter Two.
} 


\section{The Australasian Anthologies of Verse}

The pattern of development of literary nationalism in New Zealand is clearly illustrated in an analysis of the history of the publication of joint Australian-New Zealand verse anthologies between the 1880s and 1950. The changing responses by New Zealand writers towards these anthologies indicate the broader shifts that occurred in this country's sense of national identity.

The desire that this country should be viewed as an entity entirely distinct and separate from its Tasman neighbour had grown in intensity from the early twentieth century, and was often vigorously expressed, particularly in the 1940s and 1950s. This clear assertion of difference reflected the nationalistic sentiments of a number of prominent New Zealand poets and other influential commentators at that time, whose arguments in opposition to the concept of a joint trans-Tasman literary publication form a précis for the ongoing complexities of the broader place of Australia within the historical record of New Zealand literature. For example, the emphatic statement 'New Zealand is not Australia' is made in 'Australasian Poets Reculled', ${ }^{158}$ a scathing, unattributed contemporary review of the anthology A Book of Australian and New Zealand Verse (1950), compiled by Walter Murdoch and Alan Mulgan. This declaration of strongly-felt national difference, which rejects any association with its seemingly close counterpart, exemplifies the problematic nature of New Zealand's relationship with Australia that has developed since the beginnings of this country's earliest period of European settlement.

The sentiments expressed in the review were made in response to the publication of the last in a series of joint anthologies of Australasian poetry by Oxford University Press, and

\footnotetext{
${ }^{158}$ Refer to Note 136 above.
} 
were representative of the views held by many local writers who rejected vehemently the concept that the literatures of the two former British colonies were sufficiently synonymous in nature that they could be categorized as a single geographic and cultural entity. This group included, among others, Bertram, Curnow, Fairburn, Glover, Mason, and Helen Simpson, all of whom, in the late 1940s, expressed their strong objection to the notion of a trans-Tasman collection. In their correspondence with Alan Mulgan, the anthology's New Zealand editor, they stated their forthright opposition to the continuation of the Oxford series of 'Australasian' anthologies of verse, on the basis that they considered such an association of their work with that of Australian poets under a single rubric to diminish its separate and unique identity. ${ }^{159}$

The patterns of the ambivalent and problematic nature of New Zealand's ongoing political, commercial, and cultural relationships with Australia - simultaneously cooperative and competitive, supportive and antagonistic - are closely mirrored in the history of the two countries' literary relationships, and reflected in microcosm in the history of the publication of 'Australasian' anthologies. The metaphor of a mirror that provides a (distorted) reflection of each other's society and culture is used frequently in the literature to describe the nature of the relationship between the two countries. For example, Barbara Petrie, in her Introduction to an anthology of trans-Tasman women's verse, Kiwi and Emu (1989), asks:

Is it because of the manifold similarities that there has been, still is, a certain coldness, aloofness, between the two countries? Their beginnings, as British colonies established in lands already occupied by other races, virtually guaranteed some kind of National Identity crisis, and perhaps there has been the fear of looking in the mirror of each other' (xxii).

\footnotetext{
${ }^{159}$ This correspondence is discussed later in this chapter.
} 
Initially, the distinction of nationality between writers from the two countries was not stressed, with the definition of 'Australian' or 'New Zealander' commonly left unspecified. Over a period of several decades before the publication of Alexander and Currie's first 'national' New Zealand anthology in 1906, New Zealand poets were regularly anthologized within 'Australian' collections, dating from the mid-nineteenth century. In these collections the creative literature of the two countries was jointly presented as representing a regional culture encompassing both societies. Later, in parallel with the publication of 'New Zealand' anthologies there appeared joint 'Australian and New Zealand' or 'Australasian' anthologies. An increasing opposition on the part of influential New Zealand writers, with the growth of cultural nationalism in the 1930s, particularly in regard to anthologies of Australasian verse, acted as a catalyst to strengthening a provincial concept of national identity in this country's literature.

Since its early usage, however, the term 'Australasian' has come to be, within the region itself, (and especially from a New Zealand stance), highly nuanced, and significantly altered in its original connotations. It is now largely perceived from a New Zealand perspective since the early twentieth century not as a merely neutral geographical descriptor, but one which privileges Australian regional and national identity over that of New Zealand. In the Oxford English Dictionary, the term 'Australasian' is described as 'now used to include Australia and its adjoining islands', a usage that firmly accentuates the ascendancy of the larger country. ${ }^{160}$ The references to the term in the Oxford Dictionary refer to a 1937 citation in which '[New Zealand] refuses to allow the term "Australasian" to be used in her hearing'. ${ }^{161}$ Harry Orsman, reflecting on the etymological and historical usage of the term 'Australasia' from its initial application in the early nineteenth century, remarks that from the

\footnotetext{
160 ‘Australasian', reference in Oxford English Dictionary Online (n.p.).

${ }^{161}$ Ibid.
} 
New Zealand perspective the term is considered 'patronising', and that it 'has had little literary currency.... The two literatures are now rarely seen as conjoint, even from a great distance ...' (1998, 32).

While a strong sense of difference from Australia grew in New Zealand, particularly after Australian federation, and over time the countries developed separate and distinctive national literatures, some New Zealand writers continued to observe trans-Tasman literary developments, and to comment on them. In 1952, the Melbourne-based Australian literary magazine Jindyworobak Anthology published a 'trans-Tasman' issue, edited by New Zealanders Gloria Rawlinson and Hart-Smith. Given the strongly nationalistic philosophy that overtly informed the publications of the 'Jindyworobak movement', it appears anomalous that the group was prepared to extend its scope to include New Zealanders. The presence of New Zealanders among the 'Jindyworobaks' can be largely attributed to the influence of William Hart-Smith, who was an active early member of the Jindyworobak literary group, and also to several other 'trans-Tasman' writers including Stewart and Langley. As Max Richards pointed out, in his 1992 article on the life of Hart-Smith in Journal of New Zealand Literature, he was a 'poet of two countries', having been claimed as a writer, widely published and regularly anthologized, on both sides of the Tasman (74).

The group's anthologies (published between 1938 and 1953) included the verse of a number of New Zealanders whose work displayed the general sentiments of the group towards expression of 'environmental values' and 'indigenous symbols'. While the nationality of the various writers was usually evident from the inclusion of regionally identifiable iconic motifs in their work, the 1952 anthology's 'Contents' page also carefully identified New Zealand contributors separately from Australians. ${ }^{162}$ In their introduction to

\footnotetext{
${ }^{162}$ A history of the aims, achievements and influences of the 'Jindyworobak movement' is outlined in Brian Elliott's The Jindyworobaks (1979).
} 
the 'trans-Tasman' issue (entitled 'From the Marae') the New Zealand editors reflected upon the development of a strongly-expressed divergence of Australian and New Zealand cultural identities. Noting the by then unusual 'Australasian' character of their own anthology, they asserted that 'this is the first time that a yearly anthology has linked Australian and New Zealand poets in a collection of recent work' (Rawlinson and Hart-Smith, 1952, n.p.). They mused that ' $[\mathrm{t}]$ hirty years ago this would have called for no comment: the ballads of Henry Lawson, C.J. Dennis and "Banjo" Paterson were perhaps better known here across the Tasman than anywhere outside Australia: David McKee Wright, Seaforth MacKenzie and Hubert Church were familiar names to Australian readers', they observed that '[s]ince the 'thirties, however, there has been a steady drift apart'. The editors of the New Zealand issue of the Jindyworobak Anthology note that the cultural nationalism of some New Zealand writers and their aversion to being associated with an Australian-based magazine, led to the absence of some 'familiar names' from the collection (1952, n.p.).

At other times, well after New Zealand writers were no longer routinely included within 'Australian' verse collections, literary magazines in that country provided publishing outlets for the work of a number of prominent New Zealand writers, indicating that a literary relationship between the two countries continued away from the overt nationalism of the authoritative anthologies. Sturm, in 1987, noted the frequency with which the work of local writers, focused on overtly New Zealand literary concerns, had been included in iconic Australian magazines:

Kendrick Smithyman appeared in Angry Penguins, in Meanjin in the 1940s (along with James K. Baxter and Allen Curnow), and on numerous occasions, later, in Poetry Australia. ... Other [New Zealand] poets who have appeared in recent decades in Poetry Australia and elsewhere include Alan Loney, Rachel 
McAlpine, Vincent O’Sullivan, Bill Manhire, Elizabeth

Smither, and Lauris Edmond $(255,256)$.

Meanjin, which advertised itself in its frontispiece as being 'a review of arts and letters in Australia', periodically printed articles about New Zealand literary matters. These were usually written by New Zealanders, but on occasion were authored by Australians. For example, Noel McLachlan’s study of current ‘Australian-New Zealand relations’ entitled 'The Kiwi and the Kangaroo:2', appeared in the March 1968 issue of Meanjin Quarterly (124-128). The same issue included 'Henry Lawson Among Maoris', an article by Bill Pearson (67-73). ${ }^{163}$

McLachlan observed that the trans-Tasman relationship was one of 'indifference', and that 'the characteristic attitude has been a profound, mutual apathy - wider and deeper than the Tasman Sea'. McLachlan also, however, noted ' $\underline{\text { both }}$ the degree of resemblance and the degree of difference in these two isolated ex-colonial cultures, only 1400 miles apart' (original emphasis) $(124,125)$. This was followed in the subsequent issue by articles by Rhodes, entitled 'Australian and New Zealand Literature' (1968, 124-128); 'The Kiwi and the Kangaroo', by Sinclair (1968, 194-196); and included verse by New Zealanders including Brasch, Manhire, Smithyman and Sinclair.

The inclusive manner in which Australian publishers viewed New Zealanders in the early history of trans-Tasman literary relationship parallels the highly fluid nature of the population movement between the two countries, which is outlined in studies of migration flows such as W.D. Borrie's 'The Peopling of Australasia, 1788-1988: The Common Heritage', in Sinclair's Tasman Relations (1987, 202-223 ), and Alan and Robin Burnett's 'Movement of People', a chapter in their historical study, The Australia and New Zealand

\footnotetext{
${ }^{163}$ Pearson's book-length account of Lawson's travels in New Zealand, with the same title as his article in Meanjin Quarterly, was published by Reed in Wellington in 1968, and the Australian National University Press, Canberra, in the same year.
} 
Nexus $(1978,16-55)$. These indicate the ease and frequency with which it was possible to transfer within the region, and the extent of interchangeability that occurred, driven particularly by desire for employment opportunities, between the regional population groups. Until the 1920s, there existed in effect a single labour market in the region, and the movements in population occurred to a similar extent in both directions, according to the countries' relative economic conditions at different times.

However, despite the easy assimilation of New Zealanders into Australia, this was not unreservedly reciprocated. Alexander and Currie, the compilers of New Zealand's first national literary anthology, New Zealand Verse (1906), were more selective than their Australian counterparts in regard to the 'nationality' of their contributors (at least in regard to excluding Australians), stating firmly in their editorial Introduction that the work comprised 'verses by New Zealanders'. They pointed out that their anthology 'does not include all verse written in and on New Zealand', and stated that they excluded the poem 'In the Days when the World was Wide' by Henry Lawson, for instance, as it 'is a ballad that belongs entirely to Australia' (1906, xv-xvii). While Alexander and Currie declined to include such overtly 'Australian' selections in their collection of 'New Zealand' verse, a number of Australian anthologists over the period from the mid-nineteenth to the mid-twentieth centuries had no such reservations about including New Zealand verse, without qualification, in 'Australian' anthologies. In compiling their own strictly 'New Zealand' collection, Alexander and Currie acknowledged that '[s]ome help has been derived from the Australasian anthologies of Mr. D.B.W. Sladen' (xxi), as these contained extensive inclusions of overtly New Zealand verse. No biographical details of the contributors identifying their nationality were provided in either of Alexander and Currie's 1906 or 1926 anthologies. The editors stated that their own selections were based largely on the New Zealand poetry that had appeared in the Bulletin during 'the previous 25 [sic] years' (ibid). The bibliographical references included 
in the 'Index of Authors' provided in the 1906 anthology disclose that the editors drew on a wide range of earlier New Zealand regional collections and English works, as well as a number of Australian sources in addition to the Bulletin, including Douglas B.W. Sladen's anthology, Australian Poets 1788-1888 (1888), and the Melbourne-based Victorian Review. In their 1926 A Treasury of NZ Verse, comprising what was largely an extension of their 1906 collection, Alexander and Currie added selections from the Sydney publication Young Australia, and from Mary E. Wilkinson's Melbourne publication, Gleanings from Australasian Verse (1917). Another early trans-Tasman 'regional' collection is Miscellaneous Verse from Australia and New Zealand 1850-1927 (1927), a scrapbook of material sourced from various newspapers and other media from both countries, the compiler of which is unnamed. From the mid-nineteenth into the early twentieth century, many writers could be referred to aptly under the general rubric 'Australasian', as their subject matter, and places of publication, ranged freely between both countries. Chapter Three supra provides a discussion on the nature of expatriatism, and its impact upon New Zealand's 'national' literature - that discussion is relevant here in considering the cultural and artistic impacts upon the work of local writers of their movement between the two countries. Dugald Ferguson is an example of many early writers who could be aptly described as Australasian. Ferguson lived for periods in both countries, and, among a number of publications, produced a novel on his transTasman experiences, Vicissitudes of Bush Life in Australia and New Zealand (1891), set in the outback of New South Wales and in the Otago goldfields. His verse was included in Sladen's anthology, A Century of Australian Song (1888), and the biographical details provided for Ferguson's selections identify him with both New South Wales and New Zealand.

Dora Wilcox has been similarly identified as a trans-Tasman writer, publishing in both Australian and New Zealand outlets, having verse anthologized in 'national' collections 
in both countries as well as in 'Australasian' collections, and being referenced in the literary histories of both countries. ${ }^{164}$ In her Preface to Verses from Maoriland (1905) Wilcox acknowledged that much of the New Zealand-themed material in the anthology was previously published in the Bulletin and the Australasian, as well as in a number of Australian verse anthologies. Subsequently, selections from this collection were anthologized in both New Zealand and 'Australasian' collections.

Thomas Bracken also was variously published and anthologized regularly in both countries. William Satchell, similarly, was published in the Bulletin, and was influenced by style and subject matter of the Australian 'bush school' including Henry Lawson and 'Banjo' Paterson. Satchell appears among the entries for 'Eminent Colonists' in The Dictionary of Australasian Biography (1892), in which Australian editor Philip Mennell refers in the Preface to the flourishing of 'the future Australasian empire', clearly viewing the two countries as a single, undifferentiated regional entity. This descriptor is appropriate also for Arthur H. Adams, a prolific writer whose verse is included in the literary accounts of both countries. Born and educated in New Zealand, in 1906 Adams took up editorship of the 'Red Page' of the Bulletin. Like Adams, Hubert Church was a 'trans-Tasman' literary figure who has been assimilated into the early canons of both New Zealand and Australian literary anthologies. His first verse collection, The West Wind (1902), was published by the Bulletin, while the Melbourne firm Thomas Lothian brought out his later works, Poems (1904) and Egmont (1908). Church is one of a number of writers - such as Adams, Dulcie Deamer, Jean Devanny, Hart-Smith, Will Lawson, Langley, Stewart, Dora Wilcox and Wright, among others - whose work has been assimilated into the 'national' literature of both countries, and represented in both the New Zealand and Australian versions of the Oxford Companion.

\footnotetext{
${ }^{164}$ These references include the entry on Dora Wilcox by Harvey McQueen and Roger Robinson in The Oxford Companion to New Zealand Literature (1998), and the entry on Wilcox in William H. Wilde's 1994 Australian edition of the Oxford Companion.
} 
While in general the distinction between 'Australian' and 'New Zealand' had been clearly established by the mid-decades of the twentieth century, in some cases the earlier trans-Tasman association lingered on. A.E. Woodhouse, for example, in the Preface to his 1950 anthology, New Zealand Farm and Station Verse 1850-1950, refers to the influence on New Zealand writers by Australian poets including 'Banjo' Paterson, Adam Lindsay Gordon, James McAuley, and W.H. Ogilvie, and he asserts that his anthology of New Zealand verse is intended to emulate that of similar Australian collections. Some other local anthologists, also, have included the work of 'trans-Tasman' writers among their selections. Vincent O'Sullivan, for example, in his 1992 Oxford Book of New Zealand Short Stories, incorporated stories from some writers not previously anthologized in a New Zealand collection, such as Henry Lawson, who O’Sullivan noted as having spent only brief periods in New Zealand. ${ }^{165}$ While this indicates that for some anthologists and critics the notion of national identity was sufficiently flexible to incorporate writers with links to both countries, this has not been the case in general. The ambivalence inherent in New Zealand's cultural relationship with Australia was most apparent in the response of New Zealand poets towards the publication of a succession of 'Australasian' anthologies of verse over the first half of the twentieth century, all of which were selected and introduced by Australians - Douglas W.D. Sladen, Bertram Stevens, Percival Serle, and Walter Murdoch. The history of this response reveals in microcosm the extent of the anxieties and insecurities of identity that were evoked in the New Zealand imagination by the presence of the physically and culturally larger country, which dominated the trans-Tasman relationship. While the Australian critical response to New Zealand writing can be described as one of general indifference, a rift of antagonism became evident on the part of New Zealand literary nationalists towards

\footnotetext{
${ }^{165}$ Details of Henry Lawson's nationality, along with those of the other contributors to the anthology, are provided in the biographical notes accompanying the anthology.
} 
Australian anthologists, particularly from the 1930s. Describing the strongly inimical response of New Zealand poets towards what they considered to be the 'inferior treatment' of New Zealand poets in trans-Tasman verse collections, Sturm observed:

Both Allen Curnow and A.R.D. Fairburn are example of poets who appear to have felt any Australian impingement on New Zealand literature as a pressure to be resisted in their art. ... There was the colonial hangover reinforced, in their view, by New Zealand's involvement in the Australasian anthologies as a kind of annex to Australia; and ... [that] had merely served to reproduce and intensify those failures of self-consciousness among New Zealand poets $(1987,254,255)$.

That this aversion felt by local writers at the time was justified can be seen, for example, in the case that when the third (1945) edition of the anthology was reviewed in Southerly by Australian Kenneth Slessor, under the title 'Australian Literature', his analysis was limited to the Australian poets, ignoring entirely the New Zealand contribution. The low esteem in which later New Zealand writers held the contents, as well as the concept, of the several editions of both The Oxford Book of Australasian Verse and A Book of Australian and New Zealand Verse - all of which were published in Australia, and, until the 1950 edition, all selected and introduced by Australian editors - is evident in the fact that no New Zealanders reviewed them, until James Bertram published his highly negative assessment of the final (fourth) version of the newly-entitled A Book of Australian and New Zealand Verse (1950). Several early ‘Australian’ anthologies of verse, including selections of New Zealand material, were compiled by Douglas Sladen. The first of these, Australian Ballads and Rhymes: Poems Inspired by Life and Scenery in Australia and New Zealand (1888), was published in London by the Walter Scott Company in their 'Canterbury Poets' series. In this, Sladen's frontispiece set out his artistic intentions of setting his collection firmly in the 
tradition of 'English' literature, and directing it largely at an 'overseas' readership: 'This Volume, Inspired by Life in the Greater Britain Under the Southern Cross, is Dedicated to the English of Three Continents'. (Sladen's own earlier verse collection, published in London in 1885, was entitled A Poetry of Exiles; in the frontispiece to this he referred to himself as being 'An Australian Colonist'.)

In the same year, Sladen brought out an expanded 'Centenary Edition' version of Australian Ballads and Rhymes, under the title A Century of Australian Song (1888), to commemorate the 1788 founding of the Australian colony. This edition was also published in London by the Walter Scott Company, ${ }^{166}$ with the same dedication as Australian Ballads and Rhymes. Another version appeared under the revised title, Australian Ballads and Other Poems (1888), also published in London by Walter Scott, and yet a further, enlarged version, which Sladen entitled Australian Poets 1788-1888 (1888), was published in London and Sydney by Griffith, Farran, Okedon and Welsh. In his frontispiece, Sladen described Australian Poets (1888) as comprising 'a selection of poems ... written in Australia and New Zealand during the first century of the British colonization', and added a section, 'Brief Notes on Their Authors'. The anthology included a significant number of selections of work by poets identified as being from New Zealand, and focused on distinctively New Zealand topics. For example, Sladen acknowledges selections from Bracken's Lays of the Land of the Maori and the Moa; Domett's 'Ranolf and Amohia'; Frederick Napier Broome's Poems from New Zealand; L. Avis's 'O Te-Kapuka'; Alexander Bathgate's 'On hearing a yellowhammer sing near Dunedin', 'Maungatua'; and a range of other local contributors to what Sladen identified only as 'New Zealand Paper'.

Later 'Australian' anthologies compiled and edited by Sladen, which also included selections of New Zealand verse, were a fourth edition of Australian Ballads and Other

\footnotetext{
${ }^{166}$ An 'Australian edition' of this collection was printed in Sydney in 1888 by Hugh Macready.
} 
Poems (1905), also published in London by Walter Scott Ltd, and Australian Lyrics, published in London and Sydney by Griffith. Sladen explained that his selections for the first two of these 1888 collections, Australian Ballads and Rhymes and A Century of Australian Song had been 'confined to poems inspired by life in Australia and New Zealand' (Note 'To the Reader', 1888, xix). His subsequent collection, entitled Australian Poets 1788-1888, was to include 'specimens of the best poems produced in the Antipodes, irrespective of subject ... a selection of poems produced in Australasia, though not necessarily inspired by the new conditions of Australasian life' (original emphasis) (1888, Introduction, xix). In his search for suitable 'Australasian' material, Sladen stated that he had sifted through 'two hundred volumes and pamphlets of Antipodean poetry', which formed the basis for his 'Materials for a Bibliography of Australian Poetry' included in A Century of Australian Song. Sladen's express intention was that the anthologies should 'lay [Antipodean poetry] before ... the British public' (1888, Introduction, xx).

In 1906, Australian Bertram Stevens produced An Anthology of Australian Verse, which included among its contents selections from fourteen New Zealand poets. Stevens's collection was exactly contemporaneous with New Zealand's first 'national' verse anthology, New Zealand Verse (1906), compiled by New Zealanders Alexander and Currie, but unlike the New Zealand collection, which the anthologists restricted to form a representation only of local verse, Stevens recognized no such nationalistic limitations. In his introduction to his anthology, Stevens stated that the term 'Australia' was 'used to include New Zealand', and within the contents of the collection, verse from the two countries was not differentiated. Clearly he did not observe any reason to distinguish the interests or culture of New Zealand, or to regard it as an entity separate from a broadly encompassing concept of Australasia in which his own country was dominant. In this regard his anthology continued a pattern 
established in the Bulletin and other Australian publications that routinely published New Zealand writers without indicating their different origins.

A revised version of An Anthology of Australian Verse, entitled Golden Treasury of Australian Verse, was brought out by Stevens in 1909. Published in Sydney by Angus and Robertson, he claimed that in this later edition he was able to make a selection that was 'more representative of the best short poems written by Australians or inspired by the scenery and conditions of life in Australia and New Zealand'. As well as verse by 'Australians', Stevens included ' $[\mathrm{a}]$ few poems ... by writers whose residence here has given their work an Australian interest', and included New Zealand poets (Stevens, 1909, Preface, v.). The list of sources for this 'Australian' anthology acknowledged selections from The Australasian magazine, as well as New Zealand sources including The Otago Witness and The Timaru Pioneer, and from New Zealand collections such as 'Verses from Maoriland', 'Maoriland, and other Verses', 'Musings in Maoriland', and 'New Zealand, and other Poems', with extracts from Domett's 'Ranolf and Amohia'.

The anthology also included such overtly New Zealand contributions as William Pember Reeve's 'The Passing of the Forest', Mackay's 'Dunedin in the Gloaming', Adams's 'The Dwellings of our Dead', Baughan's ‘The Hill', Johannes Carl Andersen's 'Maui Victor', and Domett's ‘A Maori Girl's Song', all resonant with distinctively local New Zealand motifs including the tui, bell-bird, kowhai, rata, manuka, and a range of other local fauna and flora. The anthology included in its section 'Notes on the Poems' a glossary of New Zealand terms (for example, 'Whare-Maori name for a hut or house'), as well as providing biographical details of the contributors, including their country of residence.

A number of New Zealand poets, including Adams, Baughan, Charles Bowen, Domett, Reeves, and Wall, among others, often represented by the same poems, appeared in Alexander and Currie's 1906 New Zealand Verse as well as Stevens's Australian Verse in 
1906 and 1909. However, the effect of these poems appearing in the national anthologies of the two countries was different in each case. While in the local anthology the poems had the appearance of being recognizably 'New Zealand' in nature, and together representative of a strongly nationalistic sense of identity, in Stevens's, under the rubric 'Australian', and being distributed randomly within a much greater volume of Australian selections, there was an effect of dilution of their identity, and they lost their sense of a separate country of origin. In later decades, this loss of local identity that inevitably occurred when New Zealand was linked with Australia would be a cause of antipathy for nationalistic New Zealand poets opposed to such combined anthologies.

A further series of 'Australasian' anthologies of verse, which included a variety of New Zealand material, was compiled by Australian Percival Serle. These included An Australasian Anthology (Australian and New Zealand Poems) (1927), published in London by W. Collins. Serle's anthology was evaluated by influential Australian academic H.M. Green as being 'easily the best of Australian historical anthologies', with Green making no reference to the contribution of the New Zealand component assimilated within the collection.

Serle had earlier produced A Bibliography of Australasian Poetry and Verse: Australia and New Zealand (1925), published in Melbourne by the Melbourne University Press. He later edited the two-volume Dictionary of Australian Biography (1949), published in Sydney and London by Angus and Robertson, which included references to a number of trans-Tasman 'New Zealand' writers, including, among others, Bracken, Stewart, Hart-Smith and Langley. Serle acknowledges in his Preface to the first volume of the Australian Dictionary that

[t]he term Australian has covered several men and women whose connexion with Australia was comparatively slight. If 
anyone ... was merely born in Australia that in itself was not considered sufficient ground for inclusion. As a general rule it has been thought necessary ... that he should have stayed long enough in Australia for his life to have been influenced by his education and surroundings (vii).

Serle and his two early assistants in compiling the anthologies, including the New Zealand selections, Frank Wilmot and Robert H. Croll, were Australian, as was Vance Palmer who assisted with the selection of the entries for the 1946 edition. The compilers had no specialist knowledge of developments in New Zealand literature. Therefore, while the Australian content of the anthology was revised and updated with each edition, in order to provide 'a reasonably accurate picture of the general development of poetry in Australia over the last twenty years [since 1927]' Serle acknowledged that '[n]o attempt has been made to select recent work by New Zealand poets.' This resulted in the New Zealand poetry included in the 1946 anthology being represented by selections of verse dating from the midEdwardian period, with none of the work of contemporary poets being included. In the section of Australian 'Additional Poems' appended to the 1946 edition, 'Native Born' by Eve Langley appeared. This same poem (which is strongly Australian-focused in its setting and imagery) was included in the 'New Zealand' section of the 1950 Oxford Anthology of Australian and New Zealand Verse, and its presence contributed to the highly negative New Zealand response directed towards such 'joint' anthologies. Serle also worked towards a 'history of Australian and New Zealand poetry', but this remained uncompleted at his death. $^{167}$

${ }^{167}$ Refer to the entry for Serle in the Australian Dictionary of Biography (1988). 


\section{'The Loathsome Australasian, 168}

The Oxford series of 'Australasian' anthologies compiled by Australian academic Walter Murdoch between 1918 and 1950 proved to be a major catalyst for the focus of cultural nationalism in New Zealand literature, and for the determination of a group of influential local writers to sharply differentiate their own work from that of their Australian counterparts. As outlined in the discussion above, after 1950 the distinction between 'Australian' and 'New Zealand' literature, which had been imprecise and elided in previous anthologies and histories, became fixed and firmly delineated. This cultural separation became particularly marked in the form of the national anthologies that each country produced after this time, in which the contents were distinctively different and assertively local in their nature.

In the collection Australian Short Stories (1951), published in the Oxford University Press 'World's Classics' series in London, New York and Melbourne, editors Murdoch and H. (Henrietta) Drake-Brockman were scrupulous in including in their selection of only Australian-themed stories, by indisputably Australian writers. Of those selected, only Stewart could possibly be claimed to have a New Zealand association, but with Stewart's by then firm credentials as an Australian writer - being a permanent resident of that country, and literary editor of the Sydney Bulletin - and with the selection of his Australian-themed anecdote, he could properly be accepted into the company of Murdoch's nationalistic volume. Among Stewart's other Australian literary contributions, he was joint editor with Nancy Keesing of Australian Bush Ballads (1955), published in Sydney by Angus and Robertson.

Earlier, Murdoch had expressed no such aversion towards incorporating New Zealand verse into his regional anthologies. The first, The Oxford Book of Australasian Poetry (1918), was revised and issued as a second edition in 1923 under the title A Book of Australasian 
Verse, and subsequently reprinted in 1928, and again in 1936. A further revised edition, under the same title, was published in 1945 in both London and Melbourne, and later reprinted under the revised title A Book of Australian and New Zealand Verse (1949). The final (1950) anthology in the series retained the title of the 1949 edition, which had been changed to Australian and New Zealand Verse.

In all editions of the anthology from 1918 to 1945, (and unlike the earlier Australasian anthologies of Sladen, Serle and Stevens), Murdoch made no attempt at segregating Australian and New Zealand poets. He did not discriminate in the body of the contents nor elsewhere in the text, including in the alphabetically-ordered 'Index of Authors', to distinguish between the Australian and New Zealand contributors, and no biographical notes or other indication of the nationality of the authors was made. Much of the verse itself is indeterminate in its setting, its pseudo-English Georgianism being in most cases generic in its 'location'. A number of pieces, both New Zealand and Australian, are, however, explicitly nationalistic, including Reeves's 'New Zealand', Church's 'Spring in New Zealand', and Baughan's 'The Old Place (New Zealand)', as well as Charles Harpur's 'A Midsummer Noon in the Australian Forest', Ethel Turner's 'A Christ-Child Day in Australia', and Victor Daly's 'The Muses of Australia'.

Murdoch acknowledged in his 'Preface to the 1945 Edition' of the anthology that the original 1918 version 'was woefully inadequate', but placed much of the responsibility for its 'defects' not to his own 'errors of judgement' as its compiler, but on the fact that wartime copyright restrictions 'compelled him to exclude the work of some writers without whom no book could claim to be really representative of the verse-work of Australia and New Zealand' $(1945, \mathrm{v})$. Murdoch asserted that he had aimed to rectify these defects in the second revised edition in 1923, published under the new title A Book of Australasian Verse, in which he made 'a thorough revision ... bringing out a version with so many additions and subtractions 
that it was practically a new book'. This revised version was reprinted without alteration in 1928 and 1936. All these editions were published in London, for the market there with an interest in literature from the colonies, with some copies later shipped to Australia. Later editions were published in Melbourne, from the newly established Australian office of the Oxford University Press, and printed by Brown of Melbourne, a publication decision based on economic efficiency as well as control. This also indicated a shift in their orientation from serving an overseas readership to one that was predominantly Australian, a change that was observed by New Zealanders for whom publication in England was viewed as desirable, but being relegated to merely a minor part of an Australian anthology was not. This fuelled the growing sense of animosity that New Zealand's nationalistic poets felt towards Murdoch's anthology.

In 1945, a new revised edition was produced, again under Murdoch’s editorship, which was intended to be 'a thoroughly revised and considerably enlarged edition' of the 1918 version'. However, the anthology attracted considerable dissension and rancor expressed by New Zealand poets towards the concept of an 'Australasian' anthology, particularly one in which the relatively much smaller New Zealand quota was represented by outdated and generally poor quality verse that neglected the work of more recent writers. A 'third version', which Murdoch had revised with 'further additions and ... further subtractions', was brought out in 1949 under a new title, A Book of Australian and New Zealand Verse, with which he sought to acknowledge the strongly expressed nationalistic sensibilities of some of the New Zealand writers.

In the 1945 revised edition, Murdoch had made the addition, among the 'New Zealanders' section, of trans-Tasman writer Hart-Smith (with the selection of his Australianset poem 'La Perouse'), but removed Bracken. This edition was structured similarly to its earlier versions. In a second significant change from the structure of the earlier editions, as 
well as altering the title of the 1949 publication, Murdoch sectioned the contents of the anthology according to the authors' New Zealand or Australian nationality. However, all the additional 'new voices' that Murdoch heard in the 'land' and included in the 1949 edition were Australian - despite significant developments in New Zealand verse since the earlier edition of the anthology was revised, Murdoch added no new poetry from New Zealand.

Responding to sharply-expressed New Zealand criticism of the inadequacies of the previous versions of the anthology, Murdoch attempted to defend his literary choices, in a lengthy justificatory 'Prefatory Note' to the fourth (1950) edition:

I was always aware that the New Zealand section of the book was entirely inadequate; and I am now happy to have washed my hands of it. It has now been entrusted to a well-known New Zealander ${ }^{169}$ who will have to face the music over yonder (vii, viii).

In all the various versions of the anthology, the tone of the contents was set consistently with the opening selection - an extract from Australian William Charles Wentworth's 1823 poem 'Australasia' - which clearly suggests that the region encompassed in its title refers to Australia only, making no reference whatever to a New Zealand presence within its text. Murdoch's stated intention, however, was to present an overview of the historical development of 'Australasian' literature (that is, encompassing New Zealand as well as Australia), asserting that:

The collection has a wide range; it opens with a poem written in 1823, and ends with a group of young living poets. If a country's poetry reflects that country's life, here is a mirror of

${ }^{169}$ The 'well-known New Zealander' was Alan Mulgan. 
life as it has been lived in Australia and New Zealand for more than a century. ${ }^{170}$

Further, in his Preface to the first (1918) edition, Murdoch stated:

[T]he book is mainly intended for readers in other parts of the world, readers interested in Australia and New Zealand. ... Here is a selection, as fairly representative as I know how to make it, from the mass of verse written by Australians and New Zealanders during the last hundred years or so .... From this gathering the reader will ... be able to get a fair idea of the kind of poetry these lands have been fashioning. ... (1918, v-vi).

Murdoch, however, found attribution of national identity to the poets he selected for inclusion to the anthologies to be problematic, and the distinction between 'New Zealander' and 'Australian' difficult to define. In regard to the earlier writers, this was understandable. As a large number of the anthologies' contributors were born overseas, rather than in Australia or New Zealand, and a number had since their initial immigration, spent lengthy periods of time in both countries, assigning to them a clearly defined nationality would be, in many cases, necessarily arbitrary. By the 1940s, however, when objection to the concept of an Australasian anthology by New Zealanders became more vehement, the degree of movement between the two countries had slowed considerably, and was also becoming more subject to official record, so that a defined country of origin was more easily identified.

However, in the anthology, no attempt at classifying the national identity of the contributors is made. Also in a substantial number of Murdoch's particular selections, the setting was not specifically located in either country, making attribution of nationality on the basis of its subject matter opaque. For example, Charles Wentworth's 'From “Australasia”, the opening verse, has specific references to 'Britannia' but none to either of the two Pacific

${ }^{170}$ Murdoch's statement was printed on front inside dust cover of the 1918 edition, and reprinted in 1945. 
countries. (It is clear, from Wentworth's allusions in the poem, that he intended 'Australasia' to refer only to 'Australia', and not also to New Zealand.) ${ }^{171}$ Sir Henry Parkes's poem 'Fatherland' also clearly implies that its subject is Britain - 'The brave old land of deed and song' - not the new colony in which it was written. Only those with specific regional references, for example Reeves's 'New Zealand'and Henry C. Kendall's 'September in Australia', are readily attributable to one country or the other. Within the body of the anthology, the poets from both countries are included without differentiation as to their country of origin.

Of the small number of specifically 'New Zealand' contributors to the early volumes, several, such as Adams and Hart-Smith, are represented either by Australian themes - the former by 'Written in Australia', and 'The Australian', and the latter by 'La Perouse' - or by geographically-neutral subjects, such as Dora Wilcox's ‘At Evening', Johannes Anderson’s 'Summer', and Wright's 'In the Moonlight'. The bulk of the Australian contributions, however, are strongly patriotic and sentimental in tone, and specifically local in their setting. The collective impression of Murdoch's selections is that the anthology is emphatically Australian, with no discernible New Zealand dimension included, a position that justified the objections by New Zealand poets that such a nationalistic editorial policy firmly favoured Australian literary interests over those of New Zealanders. Curnow, however, would not have supported this objection to the anthologies solely upon the grounds of their lack of New Zealand referents - he had, for instance, criticised Kowhai Gold not only for the generally poor quality of its inclusions but specifically because of the priority it gave to sentimentality in tone and insistence upon local motifs and iconic settings (1945a, 56). Instead, his exception towards Murdoch's collection was based on his view that by the mid-twentieth

\footnotetext{
${ }^{171}$ The many specific references in Wentworth's epic poem are to Australian features such as 'Sydney's infant turrets', 'Paramatta's am'rous touch', the 'bounding kangaroo/Or long neck'd Emu', 'Warragumba's rage', 'Bathurst's straggling honours', and 'reluctant Hawkesbury'; and to Australian historical figures such as 'Captain la Perouse'. There are no references to New Zealand in the poem.
} 
century New Zealand verse had attained considerably superior literary value to that of Australia.

The final edition in the Oxford 'Australasian' anthology series, the 1950 volume, included a separate New Zealand section at the rear of the book, with a two-page 'Introduction to New Zealand Section' provided by editor Alan Mulgan, who stated that he aimed in his selections 'to make a representative collection of New Zealand verse from the earliest times' (254). Also, this edition of the book was published in Wellington, as well as Melbourne and London, indicating that the publishers intended it to include a market in New Zealand, as well as Australia. However, the Index of Authors in this edition, in common with the 1949 version, is not divided into separate 'national' sections, but set out in alphabetic order of surname, with the selections structured in the body of the text in approximate chronological order of the poets' birthdates. This arrangement contributed to the sense that the work of the New Zealand poets was being subsumed, without national differentiation, within that of the larger Australian group.

The 1950 edition includes in its New Zealand section a range of recent work by 'new' poets, in addition to much of the older verse included in earlier editions. The thirty-four poets in this New Zealand section formed a representative cross-section of both contemporary and 'traditional' New Zealand verse at that time, comprising selections from the more recent group, Baxter, Brasch, Curnow, Cresswell, Duggan, Fairburn, Glover, Hart-Smith, Hyde, Langley, Mason, Rawlinson, Stewart, and Anton Vogt, as well as older material from Adams, Baughan, Beaglehole, Church, Mary Colborn-Veel, Arnold Cork, 'Evelyn Hayes' (Bethell), Philip Carrington, Hervey, Alice Kenny, Donald McDonald, Mackay, Mackenzie, Mansfield, Mulgan, Reeves, Wall, Anne Glenny Wilson, and Wright. Mulgan, in an apparent attempt to present historical inclusiveness in his 'national' section, also included two poems under the 
headings 'Old Time Maori' and 'Modern Maori', and credited as being '[t $\mathrm{t}$ ranslated by James Cowan'.

With the growth of a sense of literary nationalism in New Zealand from the 1920s, and a particular aversion on the part of a number of influential writers and critics within the New Zealand literary milieu towards a continuing literary association with Australia, the antipathy of a group of New Zealand writers towards Murdoch's various incarnations of the Book of Australasian Verse grew in their intensity of expression. Mulgan, in a chapter headed 'The Anthologists', a 1962 analysis of the history of New Zealand 'national' anthologies of verse in Great Days in New Zealand Writing, referred to the growing hostility of many local poets towards their work being subsumed within 'Australian' anthologies, and of the term 'Australia' being used inclusively to also incorporate New Zealand (49). Mulgan reflected that there was an increasing sense among the local literary community of their difference from Australians, and that there was an aversion on their part towards the concept of an Australasian anthology $(1962,49)$. Following the publication of Walter Murdoch's revised edition of the Oxford Book of Australasian Verse, the intense dissatisfaction with the book's tone and contents was expressed sharply by many influential New Zealand poets, as observed above.

\section{The Mulgan Correspondence}

The strength of this sentiment is evident in the correspondence during this period between these writers and Alan Mulgan. This is held at the Alexander Turnbull Library, Wellington, catalogued under the rubrics 'Letters from poets whose work was to be included in the Book of Australian and New Zealand Verse', and 'Miscellaneous letters relating to copyright of 
poems selected for the Book of Australian and New Zealand Verse ${ }^{172}$ These unpublished materials disclose an epistolary discussion, conducted over the period 1948 and 1949, between Mulgan and many of the influential New Zealand poets of the time, revealing the extent of feeling among the New Zealanders regarding the proposed 1950 joint Oxford anthology. The correspondence folders include letters, sometimes repeated exchanges, from Cork, Curnow, Fairburn, Glover, Hervey, Alice Kenny, Langley, Mason, Rawlinson, Stewart, and Wall, as well as Mulgan's marginal notes and copies of his replies. Several of the letters are undated, although they can be placed chronologically according to their context. The correspondence between Mulgan and others that is conducted in these letters provides an illustration of the processes of influence and intervention by which particular protagonist groups and individuals have been able to shape the structure of the specific version of cultural identity portrayed in the contents of authoritative national anthologies. As well as providing a record of the concerns of individual local poets, this correspondence reveals in microcosmic form the range and depth of the larger problematic issues concerning New Zealand national identity, particularly in regard to the complexities and insecurities of the country's relationship to Australia, and the dominance at this time of the strong cultural nationalism represented in Curnow's stance.

The 'Mulgan files' disclose, inter alia, a set of correspondence between Mulgan and Curnow, as well as a number of other New Zealand writers, whom Mulgan had approached for permission to include their work in the proposed 1950 Oxford anthology. The correspondence reveals the strong views held by some of the writers, and by Mulgan himself, on the importance that New Zealand verse (and the local writers involved) should be properly represented in all such publications, and the strong resentment of feeling against any

\footnotetext{
${ }^{172}$ This correspondence is held in the 'Alan Mulgan' file at the Turnbull Library Archives. The files are referenced respectively as MS-Papers-0224-15 and MS-Papers-0224-14.
} 
inference of New Zealand inferiority, express or implied, on the part of their Australian counterparts. There is also an expression of local writers' concerns that New Zealand, and New Zealand literature, should be clearly differentiated from Australia in the context of its representation to an overseas (that is, British) readership, and should be accorded full, separate acknowledgement in regard to the prestige that publication under the Oxford imprimatur implied.

The fact that all the writers concerned, including Curnow, did in fact finally give their consent to their work being included among Mulgan's selections is an indication of the latter's success in assuring them, after the publisher's agreement to alter the title from 'Australasian' to 'Australian and New Zealand Verse', that their concerns would be satisfactorily addressed in the presentation of the anthology in two separate 'national' sections. This also indicates the achievement of the cultural nationalist group, the majority of whom were also represented in Curnow's earlier Book of New Zealand Verse (1945), who were successful in their goal of decoupling New Zealand writing from that of Australia in the anthology.

In a letter to Mulgan dated 10 February 1948, Curnow outlines at length his arguments for withholding his work from the collection. Curnow's interest in establishing his own authority as spokesman for the group of New Zealand poets, and in placing his Caxton verse anthology at the centre of the local canon, is clearly in evidence in the arguments he presents in the letter. He states that 'a book more worth the O.U.P.'s attention could be built - by the right hands - of New Zealand verse alone', and he acknowledges that he 'may seem to be more personally concerned', because of his own national collection. The exchange between Curnow and Mulgan provides a succinct outline of the nationalistic views held at that time by many influential New Zealand poets in regard to their opposition to an association with Australian literature, and the desire instead for their work to be considered 
part of an entirely distinct and separate body of writing, not as merely a minor tributary of an 'Australasian' literature dominated by the thematic concerns and preoccupations of the larger country. Of the proposal for a further joint trans-Tasman anthology, whose principal market would be Australia, Curnow states his negative view that

it is a publication from which New Zealand is best dissociated. It served its turn, perhaps, 20 years ago, when there was less to distinguish poets in the two countries - less, anyway, on the surface. I can't see that, as an anthology, it has any basis in realities now. ....

In response to Mulgan's suggestion that the presence of New Zealanders in the anthology would improve their 'standing' in Australia, Curnow stated: 'I do not think it is worth it, at the price of a subordinate representation in a book like this'. His view was that it did not mean 'anything whatever to call ourselves Australians', and that local literary interests would not be 'served by appending ourselves to this Terra Australia Incognita inhabited by Professor Murdoch'. Curnow's discussion expresses clearly his view of the position of New Zealand literature in regard to that of Australian in his comment that while we 'may cheerfully and properly sink our identity in English poetry at large ... this ... would be trading our birthright for an Australasian mess with a famous imprint stuck on the outside'. At the end of Curnow's letter, it is noted in Mulgan's hand: 'Curnow changed his mind and came in'.

Mulgan also notes, in regard to Curnow's desire for an entirely separate Oxford New Zealand anthology, that for this 'the time is not ripe', a publishing judgement that, given the strongly nationalistic literary sentiment of the most influential New Zealand poets at the time, seems not to have been soundly based. A separate Oxford Anthology of New Zealand Verse was in fact published six years later in 1956, compiled by New Zealanders Robert Chapman 
and Jonathan Bennett. This was followed by Vincent O'Sullivan's Oxford Anthology of Twentieth Century New Zealand Poetry (1970), published in London, in which Curnow's verse is strongly represented. (The second (1976) and third (1987) editions of O'Sullivan's Oxford anthology were published locally, in Wellington and Auckland respectively.)

The Mulgan files also contain correspondence from Fairburn, stating his strong concurrence with Curnow's perspective. Fairburn, in a letter dated '14.2.48', refers to discussion with Curnow, and in regard to what he calls 'this "Australasian" business', expresses his disdain for Australian poetry generally. He states that in his view the concept of a joint anthology 'surely has no possible justification at this time of day, and belongs to ... the Colonial Office outlook, 1888.... I think we have the best case in the world for demanding of the O.U.P. that they chuck this Siamese-twin volume and let the Australians and ourselves each have our own'. Denis Glover and R.A.K. Mason expressed similar sentiments. ${ }^{173}$

Helen Simpson, joint literary executor with Lawrence Baigent of Ursula Bethell's papers, initially responded negatively to Mulgan's request for permission to include selections from Bethell's work in the proposed Oxford anthology, indicating her unfavourable reaction towards the concept of a further trans-Tasman anthology:

We feel ... that the time has come to make a stand against this "Australasian" business, and don't even like the idea of tagging along with Australia in a book of "Australian and New Zealand Verse".... ${ }^{174}$

\footnotetext{
${ }^{173}$ In this section of the Mulgan files there is a single letter from Glover, dated 20 July 1948, written below 'The Caxton Press' letterhead. Glover states: 'I certainly agreed with Curnow that the anthology had undesirable features ... To a certain extent these are removed by the change of title'. Mason, in a letter to Mulgan dated ' $12 / 2 / 48$ ', is similarly critical of what he terms the 'Murdoch anthologies', and expresses his support for a restructured anthology with a separate 'New Zealand' section.

${ }^{174}$ Letter from Helen Simpson to Alan Mulgan, dated 24 February [1948], ATL, A.E. Mulgan papers, reference number MS-Papers-0224-14.
} 
Despite this initial rejection, however, in a reply later that year to a further request from Mulgan that notified them about the proposed new title and structure of the anthology, Simpson stated that she and Baigent withdrew their objections, and that if there is going to be a separate new Zealand section Ursula should certainly be in it, and it is something to have disposed of the loathsome Australasian. ${ }^{175}$

The Mulgan correspondence indicates, however, that not all the responses reflected such opposition to the concept of an 'Australasian' collection; for example those made on behalf of Duggan, Hyde, Baughan, Langley and Mackay ${ }^{176}$ were positive in their agreement to be included in Murdoch's anthology, without qualification as to its title or structure. Mulgan's success in negotiating an agreement that the New Zealanders would be separately identified in the anthology overcame most remaining overt dissent, so that those initially opposed to the anthology subsequently reversed earlier decisions to withhold permission to include their work. When the 1950 edition of the Oxford Book of Australian and New Zealand Verse appeared, it contained Mulgan's separately compiled 'New Zealand' section. Murdoch, in an indication of his own negative view of the value of New Zealand verse being included within a trans-Tasman collection, stated in his Preface to the book: 'I am happy to have washed my hands of it'. Following publication of this 1950 anthology, no further attempt was made by Oxford to produce a joint 'Australasian' collection.

\section{The end of the Australasian literary relationship}

This severing of the formal trans-Tasman literary relationship by New Zealand writers is evident also in the Australian national literary anthologies produced after the last joint

\footnotetext{
${ }^{175}$ Letter from Helen Simpson to Alan Mulgan, 27 July, 1948, ATL, A.E. Mulgan papers, reference number MS-Papers-0224-14.

${ }^{176}$ In these cases, the responses were made by others on the writers' behalf.
} 
trans-Tasman Oxford collaboration was published in 1950. No reference to New Zealand poetry is included in either of Judith Wright's compilations of the Oxford Book of Australian Verse (1956 and 1968), Stewart's Modern Australian Verse (1964) published by Angus and Robertson, ${ }^{177}$ or Harry Heseltine's Penguin Book of Modern Australian Verse (1981). Sturm, looking back in 1987 to reflect on the early associations of trans-Tasman literature, observes that ' $[\mathrm{t}]$ he long history of Australian enterprise in the production of anthologies including both Australian and New Zealand verse begins in the later part of the nineteenth century ... It ends, effectively in 1950, with the final edition of Walter Murdoch's Oxford anthology' (258).

However, Sturm's conclusion that the trans-Tasman literary relationship terminated in 1950, is not entirely accurate. The number of joint Australian and New Zealand special interest - rather than 'national' - anthologies published since 1950 demonstrates that the relationship continued in the literary margins, outside the borders set by the cultural nationalisms of the two countries, well after the Oxford 'Australasian' anthology series bifurcated into separate authoritatively 'national' anthologies for each country - respectively, An Anthology of New Zealand Verse (1956), edited by Robert Chapman and Jonathan Bennett, and, in the same year, Judith Wright's compilation of A Book of Australian Verse (1956).

Examples of these special interest 'Australasian' literary anthologies published in the period from 1950 to 2000, which are of varying literary quality, include Robert Kalechofsky's Jewish writing from down under: Australia and New Zealand (1984); Elizabeth Webby and Lydia Wevers' Happy Endings: Stories by Australian and New Zealand Women 1850s-1930s (1987); Barbara Petrie's Kiwi and Emu: An Anthology of Contemporary

\footnotetext{
${ }^{177}$ Stewart's anthology includes selections of Australian verse by Hart-Smith and Australian-born Langley, as well as his own. All three poets had been previously published in New Zealand, but by the time of publication of Stewart's anthology, had become regarded as Australian writers.
} 
Poetry by Australian and New Zealand Women (1989); Cathie Dunsford and Susan Hawthorne's The Exploding Frangipani: Lesbian Writing from Australian and New Zealand (1990); and Michael Gifkins's The Good Tourist and the laughing Cadaver: Travel Stories from Australian and New Zealand Writers (1993). The number of these anthologies that have been produced, as well as their range and the eclecticism of the various concepts of collective identity that they encompassed, indicated a trend towards the production of special interest literature that continued into the new century.

Clearly not all New Zealand writers have viewed an association with Australia to be altogether negative, and some, from both countries, have asserted that the commonalities of the trans-Tasman experience have outweighed the differences, claiming that the collective affinities of Australasians differentiate them from the particular concerns and forms of cultural expression of other regions. Aorewa McLeod, for example, in a 1992 review in Spiral 7 of The Exploding Frangipani (1990), referred to the anthology as being an Australasian collection, stating that it comprised stories that enhance an understanding of local identity and belonging, and 'give us a sense of ourselves'. McLeod qualifies her sense of national identity when referring to the New Zealand contributors to the anthology, emphasizing that issues of nationality, ethnicity, and regional affinity intersect with those of sexuality, as equally essential components of and contributors to self-definition (1992, 31, $32)$.

While there was a diminishing of the trans-Tasman association after the mid-decades of the twentieth century, clearly the relationship continued in the form of the occasional joint anthologies produced, and also in other literary publications which have focused on the cultural interests of both countries, such as Eleonora Cuthbert's Index of Australian and New Zealand Poetry (1963). A number of New Zealand magazines, including Landfall, continued to include articles and reviews related to Australian writing, as discussed earlier in this 
chapter. Also, there have been occasional articles focused on the trans-Tasman relationship published in Australian magazines, usually by writers with New Zealand connections, including Rhodes's 1968 essay, 'Australian and New Zealand Literature', in Meanjin. Some Australian magazines have produced special issues with an 'Australasian', 'trans-Tasman', or even specifically 'New Zealand' focus, such as the 1965 'trans-Tasman' issue of Australian Book Review, which featured an editorial and several articles on New Zealand's literary relationship with Australia, the 1966 'New Zealand Issue' of Poetry Australia, and the 1994 'Aotearoa/New Zealand' special issue of Hecate. ${ }^{178}$ However, despite this evidence of the continuation of joint New Zealand and Australian anthologies after the 1950s, it is clear that this association existed only in a secondary, less authoritative form at the margins of the literatures of both countries, not within the mainstream of local writing. It indicates not a secondary or alternative stream of national identity but rather a fragmentation of such identity, so that, rather than contributing towards a singular representation of the nation's self-perception, it illustrates the existence of multiple, different literary versions of New Zealandness that mirror the disparate composition of its society.

Within the dominant forms of New Zealand literature, most traces of the former transTasman literary relationship have been discarded. Despite the extensive history of this connection, and the significant early influence of Australia on New Zealand identity and on the development of local writing, as discussed in this chapter, the dominance of cultural nationalism after the 1940s led to an increasing sense of indifference towards this background. By the 1980s the account of this association had been almost entirely erased from local literary history. In 1963, Brasch reflected in Landfall upon what he saw as this country's disregard of literary developments in Australia, considering New Zealand's

\footnotetext{
${ }^{178}$ These issues are: Australian Book Review 4 (February 1965); Poetry Australia 9 (April1966); and Hecate 20, 2 (October 1994).
} 
perspective to be excessively 'self-centred' and indifferent towards its 'neighbours' (1963, 371). An analysis of the literature indicates that, in the case of Australia (although not other centres), Brasch's assessment was largely accurate, and there have been few published studies that have reflected on Australia's influence on New Zealand writing.

An exception is Sturm's essay, 'The Neglected Middle Distance' (1987), which assessed the content of the Australasian verse anthologies and their impact on the development of a sense of cultural nationalism in New Zealand poets. From his findings Sturm concluded that '[f]rom the 1920s on there is an increasing gap between the representation of New Zealand poetry in the anthologies and the actual work being done', and that this gap was 'most apparent in the ... mid and later 1940s'; at that time, the Australasian anthologies portrayed 'a pre-World War I version of New Zealand poetry', a misrepresentation of local writing that fuelled a desire on the part of the New Zealanders for the association with Australia to be terminated (261).

In addition to the small number of articles and monographs on various aspects of the trans-Tasman issues, including Sturm's, there have been several essay collections produced by New Zealand writers focused on the general subject of the New Zealand-Australia relationship, such as Sinclair's Tasman Relations (1987). There are, however, no book-length studies focused on the subject of the two countries' historical literary association, despite its considerable early influence on the development of New Zealand's cultural identity. New Zealand's two major literary histories, Evans's Penguin History of New Zealand Literature (1990), and Sturm's Oxford History of New Zealand Literature in English (1991), both include a number of references to Australia in the context of individual writers or particular literary works, but do not include separate sections analysing the early influence of Australia upon the development of New Zealand literature. Similarly, The Oxford Companion to New Zealand Literature (1998), edited by Roger Robinson and Nelson Wattie - which was 
published not in New Zealand but in Melbourne - includes on the subject only a succinct two-page entry entitled 'Australia', a separate brief entry on New Zealand's historical response to the term 'Australasia', ${ }^{179}$ and a number of other short references to Australia in relation to items relevant to New Zealand letters. Earlier, E.H. McCormick, also, had made almost no mention of the presence of Australia in either of his surveys, Letters and Art in New Zealand (1940) and New Zealand Literature (1959).

Some assessments of this country's literary relationship with Australia have been produced - for example, G.A. Wilkes and J.C. Reid provided a general survey in separate 'national' sections of The Literatures of Australia and New Zealand (1970); and Ian Reid analyzes particular themes in Australasian literature in Fiction and the Great Depression: Australia and New Zealand 1930-1950 (1979). In addition, there have been a number of short studies on the general topic of the trans-Tasman literary relationship, and on specific individual works and writers, a number of which are referred to in the Bibliography to this study. However, the relatively small size of this body of critical literature on this subject does not fully represent the extensive nature of the previous association of local literature with that of Australia, as summarized in this chapter, nor does it fully indicate its significance to the processes of shaping New Zealand identity.

In The Long Forgetting (2007), for example, Patrick Evans's account of the influences on the development of New Zealand identity, there is no acknowledgment of Australia's part in general in this country's literary history, and only few, very brief, references to specific aspects of past trans-Tasman cultural interchange, such as to the Bulletin, and to the term 'Australasia' in relation to the 'frontier fiction' of Edith Lyttleton (141, n.35, 242). In Australian letters, also, the previously close association with New

\footnotetext{
${ }^{179}$ The entry 'Australia' was written by Australian Peter Pierce, professor of Australian Literature at James Cook University in Queensland; that entitled 'Australasia', by New Zealand lexicographer Harry Orsman.
} 
Zealand writers subsequently has been disregarded in the formal histories. In the 1985 Oxford Anthology of Australian Literature, edited by Australians Leonie Kramer and Adrian Mitchell, the early association with New Zealand writers and their common presence in early 'Australian' anthologies is entirely absent from the historical record they present, which commences from the earliest colonial period but ignores completely the existence of a past trans-Tasman relationship.

To those in New Zealand, particularly Curnow, who were actively engaged in constructing a separatist, distinctively New Zealand literary nationalism to their own specifications, the continuing existence into the 1940s and early 1950s of joint anthologies such as those of Walter Murdoch and Percival Serle had exacerbated a growing sense of alienation from Australia, and a desire to assert a sense of New Zealand exceptionalism, creating a further impetus for the 'need to go a separate road" ${ }^{180}$ - at least from Australia, if not at that time from Britain, or later, from the United States.

The success of the cultural nationalist group in attaining this 'separate road' is evident in the limited nature of the formal literary record regarding the scope of this country's past association with Australia. Despite its long history, and the ongoing literary affiliations that have continued between the two countries outside the confines of the nationalistic paradigm, this relationship is not fully acknowledged, and, with some exceptions, as outlined in this chapter, there remains a critical gap regarding the extent of Australia's past - and continuing - influence on New Zealand writing. This 'absence' in the literary record has itself been subject to analysis. Sturm observed that

there is no established discourse about Australian-New Zealand literary relations in the literary historiography or criticism of either country - very little documentation of the extent or

\footnotetext{
${ }^{180}$ Sturm, 1987, 258.
} 
pattern of literary influence, interaction, conflict, movement into or out of each other's culture - let alone any theoretical effort to account for such relations, or for their absence ... (1987, 247).

While the formal New Zealand account of the trans-Tasman literary relationship is now marked by a general disregard towards its shared past, the indifference and even animosity towards Australia that has been, in some cases, strongly expressed in this country since the 1940s, in particular, has not been universal - the relationship of local writers with Australia has been more complex and nuanced than simply one of dismissal or rejection. For example, in his Oxford Anthology of Twentieth Century New Zealand Poetry (1976), O'Sullivan included selections from the verse of Louis Johnson that had initially appeared in his collections Land Like a Lizard (1970) ${ }^{181}$ and Fires and Patterns (1975), both published by the Brisbane-based Jacaranda Press. This indicates that at times, even in the later decades of the twentieth century, there have been sufficient commonalities so that writing can be accepted as belonging to both countries, as well as to its own.

Also, it is clear that, while in the mainstream of New Zealand literature there was opposition to any association with Australian writing, other aspects of the trans-Tasman literary relationship did not end after the conclusion of the Oxford Australasian anthology series. Within the matrices of intersecting foci of personal and specialist interests, issues of national identity and of cultural nationalism now often form a secondary, rather than primary, concern of anthologists, so that the commonalities of the collective Australasian experience can outweigh essentialist national differences. It can be seen that, at the end of the twentieth century, the separatist discourse of cultural nationalism coexisted with a parallel, broadly inclusivist stance regarding the nature of identity and belonging, so that both perspectives of New Zealandness were in evidence. This attests both to the complexities and the recursive, ${ }^{181}$ Johnson's collection Land Like a Lizard is subtitled New Guinea Poems. 
oscillating nature of the trans-Tasman relationship, which is at different times and contexts, either close or adversarial.

The vehement opposition of New Zealand's cultural nationalists in regard to the association of local writers with Australian literature in the mid-decades of the century, in particular their antagonism towards the inclusion of New Zealand poets within a joint transTasman anthology, was in part driven by an assertion of independence and a desire to be considered as a separate and unique entity, distinct from a broader concept of Australasia, as well as an expression of belief in the superiority of local writing over its Australian counterpart. However, this opposition was not simply an expression of the country's sense of separate identity and indication of an assurance about the state of national literary culture. In its degree of vehemence it also indicated the underlying sense of the country's cultural insecurity in the face of a larger, stronger and more influential nation which was viewed as a threat to New Zealand's cultural independence. In 1987, Terry Sturm commented that New Zealand's attitude towards Australia was founded upon 'the sense of being dwarfed and patronized - incorporated - by a neighbouring culture [that] is inescapable' $(1987,261)$. At the beginning of the last century, New Zealand's literary relationship with Australia was one of closeness and, to a large extent, the writing of the two countries reflected cultural similarities and affinities linked to the shared aspects of their colonial histories, rather than differences. At the end of the century, however, the writing cultures of the two countries were clearly distinguishable, and their separate literary canons markedly different. This country's repeated, insistent assertions of its difference and separateness from Australia, however, were more indicative of an anxious resistance to the threat of a potential diminution of its identity, and a loss of cultural hegemony - the fear of being subsumed within a broader Australasian entity - than of assured self-confidence in the secure achievement of cultural maturity and independence. 


\title{
CHAPTER SIX: CONCLUSION - BECOMING NEW ZEALAND: 'A PROCESS NEVER COMPLETED'
}

\begin{abstract}
When does a nation become a nation? In the sense that a nation is a group of people who, for historical or other reasons, consider themselves to be a nation, its rise is a process never completed.
\end{abstract}

(Keith Sinclair, 1988, 231)

In an entry in The Oxford History of New Zealand Literature in English (1998), Peter

Gibbons reflects that

writing does not simply represent, as if transparently, an apparently fixed and given "real world", but is itself an act of making, continually inventing - and re-inventing - provisional notions of "New Zealand"; of its past and present, its "place" in the world $(32,33)$.

The preceding chapters of this thesis present an analysis of specific aspects of the processes of 'inventing and re-inventing' notions of 'New Zealand' over the twentieth century, particularly as these various provisional constructions of identity have been illustrated in the country's influential national literary anthologies, particularly those of verse, and in the body of critical literature that the anthologies attracted. The thesis argues that efforts to construct Pākehā concepts of a collective New Zealand identity over the period since its European settlement have confronted lingering problematic issues relating to this country's colonial origins, as well as to ongoing insecurities and uncertainties arising from efforts to determine its 'place in the world'. It is proposed in the thesis that, despite obvious change and progress having occurred since the colonial period, and the country's creative and critical literatures having developed to be markedly different and more varied in their form and expression since that time, there has been a constant return to key underlying questions of identity, which have been subject to repeated reassessment in different contexts. At the end of the last century, 
those questions had not been fully resolved - they remain as relevant as ever to defining the nature of New Zealandness and to the narrative of 'becoming New Zealand'.

Historical records of the construction of New Zealand's sense of collective selfperception have commonly portrayed a series of progressive advances through the stages of colonial dependency, provincialism and nationalism, towards the attainment of internationalism and multiculturalism in the present. This is the model that has been adopted in most accounts of the development of New Zealand literature. However, this thesis has illustrated instead that while shifts in perception over time are evident, the pattern of the country's literary development can be seen to be more complex, nuanced and diverse than such a unitary account would suggest. Particular concerns relating to the narrative of Pākehā history, together with this country's anxieties linked to locating its cultural place within an international context, have complicated and interrupted the processes of identity-formation, so that, rather than being linear in progression, they are reiterative and multi-faceted in nature. The expression of these concerns was mirrored in the various national literary anthologies published between 1906 and 1997, and in their critical reception. It can be seen that the problematic issues related to the construction of New Zealand's identity that had been evident at the beginning of the last century had continued, in different forms, to be important themes in local literature at its end.

Imposing defined parameters of periodization as a method to assist the study of particular aspects of literature is a useful and common device in historical analysis, but one that is by nature an artifice, drawing arbitrary, tidy lines in an inevitably 'messy' reality that lacks apparent coherence. Stuart Murray, for example, in Never a Soul at Home (1998), reflects on this 'problematic' concept, stating that 'any invocation of a period of culture is provisional, and a "shorthand" demarcation' (11). Most New Zealand literary histories have adopted some form of progressive periodized structure, and while this approach is helpful in 
that it aids in providing order and clarity of understanding, and in facilitating the examination of developmental shifts and associations, it is one that is pragmatic and retrospectively imposed, rather than representative of the actuality of historical momentum and change. The pattern of cultural evolution is, unavoidably, less coherent and linear, and is always subject to the vagaries of circumstance, randomness and contingency. While a progressivist account appeals because of the utility it offers, and its capacity to smooth and homogenize the natural untidiness and disorder of the movements of history, it is an artificial construct. Unmediated historical narrative is not linear in nature, but instead records the inexorability of the reiteration of unresolved problematic issues and their constant, reflective re-examination through a changing lens.

This thesis has, therefore, adopted a thematic rather than periodized approach to its analysis. It has identified a number of primary themes evident in local literature that exemplify the underlying nature of New Zealand's national identity, as these have been illustrated in influential anthologies of verse and short fiction produced over the twentieth century. The national and international historical context within which New Zealand identity has developed, and its impacts on the local literary canon, were considered in Chapter One; the second chapter outlined the different versions of New Zealandness that have been promoted in influential verse anthologies, and the different cultural arguments that coalesced around these; Chapter Three examined the place of the expatriate writer within the New Zealand literary tradition, and how the critical responses towards 'outsiders' have illustrated different problematic aspects of national identity; Chapter Four focused on the association of realism as a literary form with the critical arguments that have surrounded the concepts of 'reality' and 'authenticity' in defining the characteristics of New Zealandness; Chapter Five presented an analysis of New Zealand's cultural relationship with Australia, and the impact of 
the Oxford series of verse anthologies upon the determination of local poets, in particular, to 'go a separate road' of literary nationalism after $1950 .{ }^{182}$

Rather than comprising a set of discrete developmental stages indicating an inexorably forward momentum, the apparent shifts in the country's self-identity are repeated tropes that have echoed in local literature since its early development. New Zealandness, in this analysis, is perceived as a set of contradictory yet intertwined characteristics, marked by insecurities and anxieties that can be traced back to the historical circumstances of the country's colonial origins, and subsequently to its need to address adjustments and change in its international cultural context. The thesis conducts a study of New Zealand's national anthologies of verse and short fiction over the twentieth century and of the critical literature that these have generated, in order to consider, in the microcosmic form that the anthologies provide, the nature of the changes in representations of national identity that have occurred over time, as well as the factors that have influenced these perceptions. It is evident that the anthologies, as well as illustrating the development of local self-identity, have themselves contributed towards these processes. Influential anthologists and critics, Curnow in particular, determined that the construction of a distinctive national identity was an essential role to be undertaken by New Zealand's creative writers, and sought to determine the mould that this would take. Others, like O'Sullivan and Wedde, demurred from Curnow's strictures, while still offering a view of national identity on their own terms.

Throughout the literature, representations of identity have been marked by expressions of dislocation, uncertainty and insecurity as much as by progress towards the achievement of cultural maturity and a sense of the attainment of a unique and distinctive national identity. As discussed in Chapter One, the nature of New Zealandness is commonly

${ }^{182}$ As discussed in Chapter Five, Sturm uses this phrase in 'The Neglected Middle Distance', 1987, 258. 
identified by its differences from the national characteristics of other countries, so that a form of local identity can be distinguished only in the lacunae that exist between literary portrayals of New Zealand and those features that are taken to represent other cultures. The country's colonial history has been a primary source of the insecurities that are inherent in expressions of local identity; however, in a significant difference from the historical situation that exists in many other nations with indigenous populations, the country's Māori people and their culture have not here been determinative in forming a collective Other against which Pākehā society has defined itself. ${ }^{183}$

While the presence of Māori has been formally recognized by some anthologists acknowledged, in a sense, as precursive in Curnow's 1960 anthology, and as fully integrated in Wedde's in 1985 - this has not been a dominant factor in shaping the construction of Pākehā notions of New Zealandness or of a national literature, and it has been in general only of indirect influence in their development. In lacking firmly-grounded internal markers of unique identity, Pākehā New Zealand has from the period of its colonial settlement sought beyond its own boundaries to draw on cultural reflections from 'outside' in order to define itself. Curnow, in his Introduction to his 1945 Caxton verse anthology, stated that 'a common problem of the New Zealand imagination' is that New Zealanders have perceived themselves to be 'interlopers on an indifferent or hostile scene' (1945a, 52). Pākehā cultural products, including creative literature, have been focused on a self-conscious search for a national identity, one that has been absorbed in an ideological concern to disguise the illegitimacy of its existence as a displaced subculture which has sought to establish and maintain its dominance and an uneasy cohesion through the imposition of colonial power.

\footnotetext{
${ }^{183}$ As stated in Chapter One, the focus of this thesis is on questions of Pākehā identity; it does not consider issues of Māori identity or literature.
} 
From the time of the earliest locally-produced colonial literature, such as that of poet William Golder in the 1850s, local writers have been concerned with specifying the particular set of characteristics to be taken as defining the nature of New Zealandness, and with portraying particular versions of New Zealand identity. Golder stated that the aim of his verse was to induce 'a people to take a firmer hold of their country ... making them the more connected as a people' (Preface to New Zealand Minstrelsy, 1852, n.p.). M.H. Holcroft, in 1937, similarly directed that local writing should be purposeful, and that its aim should be 'the discovery of an essential New Zealand' (149). Six decades later, the concern with identity is still being expressed by the editors of An Anthology of New Zealand Poetry in English (1997), who stated in their Introduction:

While the anthology contains a narrative, it is not one of the triumphant evolution of consciousness from colonial dependence towards postcolonial national maturity, but rather the story of struggle and interaction between different versions of where we are and how we perceive ourselves (Bornholdt, et al, 1997, xxi).

Despite the passage of time since the country's first settlement, and its history of subsequent change and development, this statement echoes similar concerns with the nature of New Zealand identity and with the country's place in the world. The discovery of an 'essential New Zealand', as proposed by Holcroft, remained elusive, and the search for a unitary identity that was representative of the country had not quite been fulfilled.

A sense of cultural insecurity, and an anxious need for favourable comparison with the achievements of other nations, were first expressed in 1906 by Alexander and Currie, in the assertions made in their Introduction to New Zealand Verse that some of the work they selected for inclusion in the anthology 'comes well up to the level of modern minor poetry' 
(xiv). Despite the considerable changes that occurred in the development of local literature over following decades, and the strong assertions of national identity expressed by Curnow and others, the sentiment that the value of New Zealand writing was to be ascertained in terms of its comparison with that of other countries, rather than on its own terms, was one expressed by a number of critics. It was evident, for example, in the assurance given by Hugh Lauder, in an editorial comment in Landfall in 1985, that New Zealand poetry was 'as interesting as any being written in the English speaking world' $(1985,3,4)$.

An illustration of the incertitude and self-doubt that have been characteristic of New Zealand's national identity is provided in the country's critical response towards the expatriate and immigrant writer, as discussed in Chapter Three. While there were changes in the nature and focus of this response over the twentieth century, and a number of revisionist accounts of the contribution of some writers were published in later decades, there remained an indication that the place of the expatriate within the New Zealand canon continued to be one of ambivalence and complexity, illustrating a continuing uncertainty and insecurity regarding the concept 'New Zealander'. Their presence also presented challenges to the concept of constructing a discrete cultural boundary around New Zealand within which the 'New Zealand writer' - in Curnow's phrase, 'one of ourselves ${ }^{184}$ - properly belonged, while others did not.

As discussed in Chapter Four, the ostensible demarcation between the localist and internationalist versions of New Zealand identity has been one that was unstable and shifting, remaining in a state of tension. Rather than being discrete, alternative versions of New Zealandness, these have been interrelated and interdependent conditions, with variations in one impacting upon and altering the form of the other. In the same way, the two major

\footnotetext{
${ }^{184}$ As discussed earlier, Curnow used this term in his 1964 essay 'New Zealand Literature: The Case for a Working Definition', 87.
} 
strands of New Zealand 'reality' portrayed in the literature - the local and the universal were not separate but correlated conditions, shifting over time and each impacting upon the other. Sometimes markedly different and often contradictory and conflicting versions of 'New Zealandness' have been portrayed in the various anthologies that have been produced. The mid-decades of the twentieth century were dominated by the production of a number of influential anthologies that were focused purposefully to express national identity, notably the verse collections of Curnow in 1945 and 1960, and the oppositional and alternative collections that these provoked. However, in the later decades of the century, some reprise of the earlier regionalist stance of the 1900s can be perceived in the appearance of a number of collections again focused on particular geographical areas. Together with the publication of a number of special interest anthologies in this period, as discussed in Chapter Two, this suggests the existence of multiple 'New Zealands', and some fragmentation and broadening of the concept of a singular, encompassing, collective sense of New Zealandness, in favour of one represented by multiplicity and diversity. There was an indication that the focus of some later anthologies of verse, in particular, moved away from a concern with a collective national identity and instead was inclusive of other representations of belonging, such as a closer regional affiliation, as well as issues of gender, sexuality, ethnic and spiritual identity. These various anthologies usually have been produced on the margins of New Zealand literature, outside the canon and beyond the aegis of the authoritative national anthology.

What is evident in the analysis of the historical development of New Zealand's national identity presented in this thesis is that, despite the efforts of particular protagonist groups and individuals to dominate the discourse of identity and to 'create' and promote a particular desired version of New Zealandness, at no time has this been clearly contained within a single, commonly accepted set of images or concepts, but instead has always 
comprised a range of ambiguities, contradictions and multiplicities, so that an array of different and oppositional identities have always coexisted. This is described by Jack Ross, in his Preface to the anthology New New Zealand Poets in Performance (2008), as being a 'diversity, the rich jangle of clashing ideas, [multiple] voices ...' (xi). New Zealand culture does not comprise a single defined entity, but is chameleon-like, its appearance altering in response to its reflection against the 'mirror' of overseas perceptions of the country. In this view, New Zealandness is defined not by its uniqueness and difference, and an ascribable essentialism, but instead by its lack of such a unique, singular identity - it can instead be seen as a many-layered, often shifting cultural palimpsest, within which many possible versions of its identity are coexistent at any time.

A deterministic view of identity construction as being subject primarily to external factors, does not, however, provide a complete account of these processes. As well as being shaped by the impacts of movements of institutions and conventions extant at particular times, individual protagonists of particular literary positions also have played a substantive part. Lawrence Jones, in 'Versions of the Dream' (1989), points out that the correlation of a country's literature with the construction of cultural identity is indirect, and rather than the relationship being straightforward, is complex, layered and opaque:

Literature is an institution within a society, and as such it both reflects and projects an image of the society's cultural identity. It reflects the image that other institutions and forces have helped to form, but it also projects the writer's own image of his society, and that image may modify or even contradict the image put forth by the society's dominant class (187).

This emphasizes that specific interventions by individual authors, as well as the particular nationalist or other cultural agendas of influential groups, can be causative in promoting direction and change to the country's broader collective self-perception. 
An illustration of this multiplicity of characteristics comprising New Zealand identity, and its shifting, varied nature can be identified, perhaps ironically, in the form of Curnow himself. In his own various roles as poet, anthologist, and critic, he has represented, over time, a diversity of positions in relation to the defining characteristics of New Zealandness his early stance, as set out in his 1945 and 1960 anthologies, was an insistence upon localism in regard to content and towards exerting influence upon a local readership, and entrenching nationalism in the construction of concepts of identity; but his orientation, both in his own and others' verse, was always towards internationalism of form and artistic practices, and his interest was aimed at both overseas and local publication and critical reception. By the 1970s, he openly acknowledged a shift in his perspective away from questions that were 'public', towards those which were 'private and unanswerable' - indicating a change in the focus of his writing to an emphasis on concerns that were representative of universalist preoccupations related to the human and individual, rather than the collective, national, condition (1974, xiv). Curnow's statement is indicative of the shifts and movements, as well as the manifold nature of efforts to locate and express what it means to be a New Zealander to both a local and wider audience.

The focus in the thesis is on the twentieth century, and its conclusions are drawn from its study of New Zealand writing over that period. There were indications that, at the end of the century, there were changes in the country's self-perception that reflected change both in its own and its international cultural environment. Some of the earlier problematic issues of identity, however, continued to be evident in later writing. Anna Jackson and Jane Stafford, for example, in the discussion in their Introduction to Floating Worlds: Essays on Contemporary New Zealand Fiction (2009), focus on concerns with identity that are reflective of those of commentators in previous decades. They state that ' $[\mathrm{w}]$ riting about ... preoccupations [with identity] is ... a registration of more complex ways of being in the 
world, both actual and textual', and consider that such writing is an indicator of 'shifts in the literary representation of nation and identity' (15). They address the question of 'anxieties' about what particular writing comprises a 'New Zealand' literature, and about the complexities of the issue of 'expatriate New Zealanders' $(17,18)$; and they refer to the 'contention' that continues to arise in response to 'the move away from an instantly recognisable national and locally defined literature' (19). These are all issues of identity that had engaged critics during the twentieth century; the continued presence of those concerns in the creative and critical literature of the next indicates that they had not been settled.

In the thesis I present an account of New Zealand identity as it has been portrayed in local literature, that, rather than a coherent, linear progression culminating in a firmly grounded, generally acknowledged, unitary representation of New Zealandness, instead illustrates one more complex and multi-faceted, comprised not of a single element but multiple significations of national identity. While movement and change have been evident, earlier concerns, initially apparent in colonial literature, have been repeatedly reprised. New Zealand's collective self-concept has altered in response to changes in its international context, with successive reassessment occurring through a frequently shifting cultural perspective. Although there was evidence of significant change and difference in the country's self-representation over the period from the early century to the late 1990s, the development of national identity had remained provisional and incomplete at the end of that time, and indicated a sense of irresolution rather than the achievement of maturity and fulfilment. The national anthologies, particularly those of verse, together formed an important site that both contributed to and provided a reflection of the complexities inherent in the process of constructing a definition of the experience of New Zealandness, and of attempts at determining the essence of what it meant to be a New Zealander. The anxieties attached to Pākehā identity and to concerns regarding the legitimacy of European settlement in this 
country, that had been evident in the literature in different forms since the time of the production of its earliest creative and critical writing, had not been fully resolved at the conclusion of the twentieth century. 


\section{BIBLIOGRAPHY}

\section{Archives}

Alan Mulgan Correspondence Files. Located at MS Archives, Alexander Turnbull Library, Wellington. 'Miscellaneous letters relating to copyright of poems selected for the Book of Australian and New Zealand Verse': Ref. MS-Papers-0224-14; 'Letters from poets whose work was to be included in the Book of Australian and New Zealand Verse': Ref. MS-Papers-0224-15.

Patrick Anthony Lawlor Correspondence Files. Located at MS Archives, Alexander Turnbull Library, Wellington. 'Inward correspondence, reviews and other papers': Ref. 77067-3/4, and 77-067-4/3. 'Inward correspondence (General)': Ref. 77-067-1/1.

\section{Books and Articles}

Adcock, Fleur, ed. The Oxford Book of Contemporary New Zealand Poetry. Auckland: Oxford University Press, 1982.

Alexander, W.F., and A.E. Currie, eds. New Zealand Verse. London: Walter Scott Publishing, 1906.

---. A Treasury of New Zealand Verse. Christchurch: Whitcombe and Tombs, 1926.

Allen, C.R, ed. Tales By New Zealanders. London: British Authors’ Press, 1938.

Alley, Elizabeth, and Mark Williams, eds. In the Same Room: Conversations with New Zealand Writers. Auckland: Auckland University Press, 1992.

Anderson, Benedict. Imagined Communities: Reflections on the Origin and Spread of Nationalism. (Rev.ed.). London and New York: Verso, 1991.

Arvidson, Ken. 'The emergence of a Polynesian literature'. World Literature Written in English 1, 14 (April 1975), 91-116.

'Australasian Poets Reculled'. Review of A Book of Australian and New Zealand Verse (1950). Unidentified. Original held at Turnbull Library, Wellington, n.d.

Australian Dictionary of Biography. Bede Nairn and Geoffrey Serle, eds. Melbourne: Melbourne University Press, 1988.

Baigent, Lawrence. 'The Poetry of Ursula Bethell'. Landfall 5, 1 (March 1951), 23-30. 
Ballantyne, Tony, and Brian Moloughney, eds. Disputed Histories: Imagining New Zealand's Pasts. Dunedin: Otago University Press, 2006.

Barrowman, Fergus, ed. The Picador Book of Contemporary New Zealand Fiction. London, UK: Picador, 1996.

Barrowman, Rachel. A Popular Vision: The Arts and the Left in New Zealand, 1930-1950. Wellington: Victoria University Press, 1991.

---. Mason: The Life of R.A.K. Mason. Wellington: Victoria University Press, 2003.

Baskett, Pat. 'Kapka Kassabova: "Transplant thrives in calmer climate". New Zealand Herald, 23 August, 1997, G2.

Baxter, James K. Recent Trends in New Zealand Poetry. Christchurch: Caxton Press, 1951.

---. 'The Critic as Schoolmaster'. Numbers 4, 1 (October 1955), 2-3.

---. Aspects of Poetry in New Zealand. Christchurch: Caxton Press, 1967.

Baysting, Arthur, ed. The Young New Zealand Poets Auckland: Heinemann, 1973.

Belich, James. Making Peoples: A History of the New Zealanders from Polynesian Settlement to the End of the Nineteenth Century. Auckland: Penguin, 1996.

---. Paradise Reforged: A History of the New Zealanders from the 1880s to the Year 2000. Auckland: Penguin, 2001.

Bell, Claudia. Inventing New Zealand: Everyday Myths of Pakeha Identity. Auckland: Penguin, 1996.

Benson, Dale. 'Why is Greville Texidor Part of the Canon?'. Deep South, 3,1 (1997). Web. Accessed at: http://www.otago.ac.nz/deepsouth/vol3no1/dale.html

Berger, Peter L., and Thomas Luckmann. The Social Construction of Reality. New York: Penguin, 1966.

Bertram, James. 'Antipodean Hybrid'. Review of A Book of Australian and New Zealand Verse (1950). New Zealand Listener (22 June 1951), 12.

---. Review of Australian Poetry (1956), A.A. Phillips, ed. Landfall 42, 11, 2 (June 1957), 174-177.

---. Towards a New Zealand Literature. Dunedin: Hocken Library, University of Otago, 1971.

---. 'Dan Davin: Novelist of Exile'. Meanjin Quarterly (June 1973), 153-156. 
---. Flight of the Phoenix: Critical Notes on New Zealand Writers. Wellington: Victoria University Press, 1985.

Beveridge, Michael. Review of Not Here, Not Now (1970), by Dan Davin. Landfall 95 (September 1970), 296-302.

Boddy, Gillian. Katherine Mansfield, the Woman and the Writer. Ringwood: Penguin, 1988.

---. 'Robin Hyde'. In The Oxford Companion to New Zealand Literature. Roger Robinson, and Nelson Wattie, eds., 1998, 251-253.

Bornholdt, Jenny, Gregory O'Brien, and Mark Williams, eds. An Anthology of New Zealand Poetry in English. Auckland: Oxford University Press, 1997.

Borrie, W.D. 'The Peopling of Australasia, 1788-1988: The Common Heritage'. In Tasman Relations: New Zealand and Australia, 1788-1988. Keith Sinclair, ed. Auckland: Auckland University Press, 1987, 202-223.

Brasch, Charles. 'Notes'. Landfall 1, 4 (December 1947), 240-242.

---. 'Commentaries'. Landfall 68, 4 (December 1963), 371.

---. 'Notes'. Landfall 79, 3 (September 1966), 216.

---. 'Book Notes'. Landfall 125, 1 (March 1978), 93.

---. Indirections: A Memoir 1909-1947. Wellington: Oxford University Press, 1980.

Broughton, William. 'Curnow's anthologies and the strange case of Walter D'Arcy Cresswell'. Journal of New Zealand Literature 15 (1997), 26-39.

---. 'D'Arcy Cresswell'. In The Oxford Companion to New Zealand Literature. Roger Robinson and Nelson Wattie, eds., 1998, 118.

Brown, James. The Nature of Things: Poems from the New Zealand Landscape. Nelson: Craig Potton, 2005.

---. 'Leaf Salon: James Brown's Top Ten Poetry Books 2007'. New Zealand Book Forum (2007). Web. Accessed at: http://www.leafsalon.co.nz/archives/001158james_browns_top_ten_poetry_books.ht $\mathrm{ml}$

Brunton, Alan, Murray Edmond and Michele Leggott, eds. Big Smoke: New Zealand Poems 1960-1975. Auckland: Auckland University Press, 2000.

Bunkle, Phillida Linda Hardy, and Jacqueline Matthews, eds. 'Commentary'. In Nor the Years Condemn (1938; Republished 1986), by Robin Hyde. Auckland: New Women's Press: 1986, 268-292. 
Burnett, Alan and Robin Burnett. The Australia and New Zealand Nexus. Canberra: Australian Institute of International Affairs and New Zealand Institute of International Affairs, 1978.

Calder, Alex, ed. The Writing of New Zealand: Inventions and Identity. Auckland: Reed Books, 1993.

---. and Stephen Turner. Introduction to 'Settlement Studies' Special Issue of Journal of New Zealand Literature 20, (2002), 7-17.

Calhoun, Craig. Nationalism. Minneapolis: University of Minnesota Press, 1997.

Catley, Bob. Waltzing with Matilda: Should New Zealand Join Australia?. Wellington: Dark Horse Publishing, 2001.

Chapman, Nicola. Review, 'Vibrant with Words and The Colour of Distance'. Kötare 6 (2006). New Zealand Electronic Text Centre (NZETC). Web. Accessed 20 November 2010 at: http://www.nzetc.org/tm/scholarly/tei-Whi06Kota-t1-g1-t9.html

Chapman, Robert. 'Fiction and the Social Pattern: Some Implications of Recent NZ Writing'. Landfall 25, 1 (March 1953), 26-58.

--- and Jonathan Bennett, eds. An Anthology of New Zealand Verse. London: Oxford University Press, 1956.

Croot, Charles. 'Poetry in New Zealand 1988-89'. Journal of New Zealand Literature 8 (1990), 15-32.

Curnow, Allen. Island and Time. Christchurch: Caxton Press, 1941.

---, ed. A Book of New Zealand Verse 1923-1945. Christchurch: Caxton Press, 1945a.

---. With Ngaio Marsh. 'A Dialogue by Way of Introduction'. Year Book of the Arts in New Zealand 1. Wellington: H.H.Tombs, 1945b, 1-8.

---. Review of Modern Australian Poetry (1946), ed. H.M. Green. Landfall 1, 2 (June 1947), 142-150.

---, ed. A Book of New Zealand Verse: 1923-50. Christchurch, Caxton Press, 1951.

---, ed. The Penguin Book of New Zealand Verse. Harmondsworth: Penguin Books, 1960; (reissued) Auckland: Blackwood and Janet Paul, 1966.

---. Introduction to Collected Poems, by R.A.K. Mason. Christchurch: Pegasus Press, 1962, 9-16.

---. 'New Zealand Literature: The Case for a Working Definition'. In The Future of New Zealand. M.F. Lloyd Prichard, ed. Christchurch: Whitcombe and Tombs, 1964, 84107. 
---. Collected Poems 1933-1973. Wellington: A.H. and A.W. Reed, 1974.

---. 'Coal Flat Revisited'. In Critical Essays on the New Zealand Novel. Cherry Hankin, ed. Auckland: Heinemann, 1976, 105-127.

---. 'Olson as Oracle: "Projective Verse" thirty years on'. In New Zealand Through the Arts: Past and Present. Wellington: Friends of the Turnbull Library, 1982.

---. 'Distraction and Definition: Centripetal Directions in New Zealand Poetry'. In Look Back Harder. Peter Simpson, ed. Auckland: Auckland University Press, 1987, 213-229.

'Curnow, Caxton and the Canon'. Special issue of Journal of New Zealand Literature. Heather Murray, ed. Part I, 15 (1997); Part II, 16 (1998).

Currie, A.E., ed. A Centennial Treasury of Otago Verse. Christchurch: Caxton Press, 1949.

Davin, Dan [D.M.]. Review of I Saw in my Dream (1949), by Frank Sargeson. Here and Now (November 1949), 29-30.

---, ed. New Zealand Short Stories. London: Oxford University Press, 1953.

---. 'The Eye of the Expatriate'. New Zealand Listener (12 December 1969), 10.

Davis, Leigh. 'Set Up'. And 1 (October 1983), 1-8.

Day, Paul W. John Mulgan. New York: Twayne, 1968.

---. John Mulgan. In 'New Zealand Writers and their Work' Series. Wellington: Oxford University Press, 1977.

Doyle, Charles, ed. Recent Poetry in New Zealand. Auckland: Collins, 1965.

Dunsford, Cathie and Susan Hawthorne, eds. The Exploding Frangipani: Lesbian Writing from Australia and New Zealand. Auckland: New Women's Press, 1990.

Edmond, Lauris, ed. The Letters of A.R.D. Fairburn. Auckland: Oxford University Press, 1981.

Edmond, Murray and Mary Paul. The New Poets: Initiatives in New Zealand Poetry. Wellington: Allen and Unwin and Port Nicholson Press, 1987.

Eggleton, David and Iain Sharp. 'Live Poets Society'. Sunday Star-Times, 30 April 2000, F1-2.

Einhorn, Barbara. 'Gender, Nation, Landscape and Identity in Narratives of Exile and Return'. Women's Studies International Forum 23, 6 (2000), 701-713.

Elliott, Brian, ed. The Jindyworobaks. St Lucia, Australia: University of Queensland Press, 1979. 
Evans, Miriama, Harvey McQueen and Ian Wedde, eds. The Penguin Book of Contemporary New Zealand Poetry: Nga Kupu Titohu o Aotearoa. Auckland: Penguin, 1989.

Evans, Patrick. [Response to 'A Survey', by Rob Jackaman]. Landfall 122, 31, 2 (June 1977), 110-111.

---. The Penguin History of New Zealand Literature. Auckland: Penguin, 1990.

---. The Long Forgetting: Post-colonial literary culture in New Zealand. Christchurch: Canterbury University Press, 2007.

Fairburn, A.R.D. We New Zealanders. Wellington: Progressive Publishing Society, 1944.

---. 'Poetry in New Zealand'. Year Book of the Arts in New Zealand 1 (1945), 123-128.

---. The Woman Problem and Other Prose. Auckland: Blackwood and Janet Paul, 1967.

Fairburn, Miles. 'Mything our Myths'. In Under Review: A Selection from New Zealand Books 1991-1996. Lauris Edmond, Harry Ricketts, and Bill Sewell, eds. Lincoln: Lincoln University Press and Daphne Brasell Associates, 1997, 150-157.

---. 'Is There a Good Case for New Zealand Exceptionalism?' In Disputed Histories: Imagining New Zealand's Pasts. Tony Ballantyne and Brian Moloughney, eds., 2006, 143-167.

Fanon, Frantz. 'On National Culture'. In The Wretched of the Earth. New York: Grove Press 1991.

Farrell, Fiona, ed. The Best New Zealand Fiction 4. Auckland: Vintage/Random, 2007.

Frame, Janet. An Autobiography. Auckland: Century Hutchinson New Zealand, 1989.

Gadd, Bernard, ed. Pacific Voices: An Anthology of Maori and Pacific Writing. Auckland: Macmillan, 1989.

---, ed. Real Fire: New Zealand Poetry of the 1960s and 1970s. Dunedin: One Square Press, 2001.

Gellner, Ernest. Nations and Nationalism. Oxford: Basil Blackwell, 1983.

Geraets, John. 'The New Zealand Anthology - Initiating an Archaeology'. And 1 (1983), 6673.

---. 'A Second Life - Literary Culture and Landfall in the 1950s'. Landfall 185 (April 1993), 114-124.

Gibbons, Peter. 'Non-Fiction'. In The Oxford History of New Zealand Literature in English (2 ed.). Terry Sturm, ed. Auckland: Oxford University Press, 1998, 31-118. 
Gifkins, Michael. Tart and Juicy: Food Stories from Australian and New Zealand Writers Auckland: Vintage, 1994.

Gillespie, O.N., ed. New Zealand Short Stories. London: Dent, 1930.

Glover, Denis. The Arraignment of Paris. Christchurch: Caxton Press, 1937.

---. Hot Water Sailor. Wellington: A.H. and A.W. Reed, 1962.

Golder, William. The New Zealand Minstrelsy: Containing Songs and Poems on Colonial Subjects (1852). New Zealand Electronic Text Centre (NZETC). Web. Accessed at: http://www.nzetc.org/tm/scholarly/tei-GolMin.html

Goldfinch, Shaun. 'Doing Business'. In Remaking the Tasman World. Philippa Mein Smith, Peter Hempenstall, and Shaun Goldfinch, eds. Christchurch: Canterbury University Press, 2008, 122-142.

Gould, J.D. The Rake's Progress?: The New Zealand Economy Since 1945. Auckland: Hodder and Stoughton, 1982.

Green, H.M., ed. Modern Australian Poetry. Carlton: Melbourne University Press, 1946.

Gregory, J. W. The Dead Heart of Australia: A Journey around Lake Eyre in the Summer of 1901-1902, with some account of the Lake Eyre basin and the flowing wells of central Australia. London: J. Murray, 1906.

Hanger, Paula. Review of A Book of New Zealand Verse (1945), Allen Curnow, ed. Arena 12 (June 1946), 19-21.

Hankin, Cherry, ed. Critical Essays on the New Zealand Novel. Auckland: Heinemann, 1976.

---. 'Realism, nationalism and the double scale of values in the criticism of New Zealand fiction'. Landfall 128, (December 1978), 293-303.

Hardy, Linda. 'Critical Note', in Dragon Rampant (1939; Republished 1984), by Robin Hyde. Auckland: New Women's Press, 1984, xiv.

---. 'The Ghost of Katherine Mansfield'. Landfall 172, 43, 4 (December 1989), 416-432.

Heseltine, Harry, ed. The Penguin Book of Modern Australian Verse. Ringwood: Penguin Books, 1981.

Hill, Jack. 'Images of Religion in South Pacific Fiction: An Interpretation of Pouliuli'. Literature and Theology: An International Journal of Religion 2, 17 (June 2003), 182200. 
Holcroft, M.H. 'The Flood Comes Down'. Tomorrow 5, 3 (January 6), 1937, 149-152.

---. Mary Ursula Bethell. Wellington: Oxford University Press, 1975.

Hopkins-Weise, Jeff. Blood Brothers: The ANZAC Genesis. Rosedale, Auckland: Penguin, 2009.

Horrocks, Roger. 'The Invention of New Zealand'. And 1 (1983), 9-30.

Howe, K.R. 'The dating of Edward Tregear's "Te Whetu Plains", and an unpublished companion poem'. Journal of New Zealand Literature 5 (1987), 55-60.

Hughes, Shaun. 'Pakeha and Maori behind the tattooed face: the emergence of a Polynesian voice in New Zealand Fiction'. Modern Fiction Studies 27, 1 (Spring 1981), 13-29.

Hulme, Keri. 'Two Views of The Penguin Book of New Zealand Verse'. Landfall 155, 39, 3 (September 1985), 302-305.

Isernhagen, H. 'Why Novels? Why Short Stories? A Note on the Use of Genres in the Works of Witi Ihimaera and Albert Wendt'. Commonwealth Essays and Studies, 2, 16 (Spring 1994), 34-37.

Jackson, Anna and Jane Stafford, eds. Floating Worlds: Essays on Contemporary New Zealand Fiction. Wellington: Victoria University Press, 2009.

'James K. Baxter'. Unattributed. Poster published by Visual Production Unit, New Zealand Department of Education, Wellington, 1989.

Johnson, Louis. Review of Speaking for Ourselves (1945), Frank Sargeson, ed. Arena 11 (March 1946), 20-22.

---, ed. New Zealand Poetry Yearbook 1 (1951).

---, ed. Antipodes New Writing. Plimmerton: Antipodes Press, 1987.

Jones, David T. and David Kilgour. Uneasy Neighbo(u)rs: Canada, the USA and the Dynamics of State, Industry and Culture. Mississauga: John Wiley, 2007.

Jones, Lawrence. Introduction to Roads from Home (1949; Republished 1976), by Dan Davin. Auckland: Auckland University Press, 1976.

---. 'New Zealand Realism: Retrospect and Prospect'. Landfall 160, 40, 4 (December 1986), 472-486.

---. 'The Persistence of Realism: Dan Davin, Noel Hilliard, and Recent New Zealand Short Stories'. In Islands 6, 1977, 182-200. Reprinted in Barbed Wire and Mirrors: Essays on New Zealand Prose, 1987, 13-28.

---. Barbed Wire and Mirrors: Essays on New Zealand Prose. Dunedin: University of Otago Press: 1987a. 
---. 'Versions of the Dream: Literature and the Search for Identity'. In Culture and Identity in New Zealand. David Novitz, and Bill Willmott, eds. Wellington: G.P. Books, 1989, 187-211.

---. “'Colonial Like Ourselves”: The American Influence on New Zealand Fiction, 1934-65'. Deep South 2, 1 (Autumn, 1996). Web. Accessed at: http://www.otago.ac.nz/deepsouth/vol2no1/ljones.html

---. 'The Novel'. In The Oxford History of New Zealand Literature in English (2 ed.). Terry Sturm, ed. Auckland: Oxford University Press, 1998a, 119-244.

---. 'David Ballantyne'. In The Oxford Companion to New Zealand Literature. Roger Robinson and Nelson Wattie, eds., 1998b, 39-40.

---. Picking Up the Traces: The Making of a New Zealand Literary Culture, 1932-1945. Wellington: Victoria University Press, 2003.

---. 'Myth and Anti-myth in Literary Responses to the Centennial'. In Creating a National Spirit: Celebrating New Zealand's Centennial. William Renwick, ed. Wellington: Victoria University Press, 2004, 207-220

---. 'Amongst the Missing'. Review of The Auckland University Press Anthology of New Zealand Literature (2012), Jane Stafford and Mark Williams, eds. Landfall Review Online (1 March 2013). Web. Accessed at: http://landfallreviewonline.blogspot.co.nz/2013/03/amongstmissing.html\#!/2013/03/amongst-missing.html

Joseph, M.K. Review of A Book of Australian Verse (1956), Judith Wright, ed. Landfall 41, 11, 1 (March 1957), 80-85.

Kalechofsky, Robert. Jewish writing from down under: Australia and New Zealand. Marblehead: Micah Publications, 1984.

Kiberd, Declan. Inventing Ireland: The Literature of the Modern Nation. London: Vintage, 1995.

Kidman, Fiona, ed. New Zealand Love Stories: An Oxford Anthology. Auckland: Oxford University Press, 1999.

King, Michael. Being Pakeha. Auckland: Hodder and Stoughton, 1985.

---. Review of Nor the Years Condemn (1938; Republished 1986), by Robin Hyde. Metro 60, 6 (June 1986), 160-162.

---, ed. Pakeha: The Quest for Identity in New Zealand. Auckland: Penguin, 1991.

---. Frank Sargeson: A Life. Auckland: Viking, 1995. 
---. Being Pakeha Now: Reflections and Recollections of a White Native. Auckland: Penguin Books, 1999; (2 ed). Auckland: Penguin, 2004.

---. Wrestling With the Angel: A Life of Janet Frame. Auckland: Penguin, 2000.

---. The Penguin History of New Zealand. Auckland: Penguin, 2003.

Kramer, Leonie and Adrian Mitchell, eds. The Oxford Anthology of Australian Literature. Melbourne: Oxford University Press, 1985.

Kuiper, Koenraad. 'New Zealand's Pakeha folklore and myths of origin'. Journal of Folklore Research 44, 2/3 (2007), 173-183.

Laracy, Hugh. 'Australia and New Zealand: Two Parts of the One Story'. In Australia 1888 Bulletin 4 (1980), 52-54.

Lauder, Hugh. Editorial. Landfall 153, 39, 1 (March 1985), 3-4.

Lawlor, Patrick. Confessions of a Journalist: With Observations on Some Australian and New Zealand Writers. Auckland: Whitcombe and Tombs, 1935.

Lecker, Robert. 'The Canonization of Canadian literature: An Inquiry into Value'. Critical Inquiry 16, 3 (Spring1990), 656-671.

Leggott, Michelle. Iain Lonie: Capital of the Minimal. New Zealand Electronic Poetry Centre (NZEPC). Web. Accessed at:

http://www.nzepc.auckland.ac.nz/features/dunedin/lonie.asp

Locke, Terry, Peter Low, and John Winslade, eds. White Feathers: An Anthology of New Zealand and Pacific Poetry on the Theme of Peace. Christchurch: Hazard Press, 1990.

Lodge, David. The Modes of Modern Writing: Metaphor, Metonymy, and the Typology of Modern Literature. London: Arnold, 1977.

Mackay, Jessie, ed. New Zealand Rhymes Old and New (1907). Republished as An Anthology of New Zealand Rhymes Old and New. Wellington: Original Books, 1998.

Maconie, Janet. Landmarks of New Zealand Writing to 1945. Wellington: New Zealand Book Council, 1990.

Mane-Wheoki, Jonathan 'From Zero to 360 degrees: Cultural Ownership in a Post-European Age'. International Council of Museums, Council for Education and Cultural Action Conference, Christchurch, (2000). Web. Accessed at: http://web.archive.org/web/20061004071817/http://www.christchurchartgallery.org.n z/icomceca2000/papers/Jonathan_Mane-Wheoki.pdf

Manhire, Bill, ed. New Zealand Listener Short Stories. Wellington: Methven Publications, 1977. 
---. 'Dirty Silence: Impure Sounds in New Zealand Poetry'. In Dirty Silence: Aspects of Language and Literature in New Zealand. Graham McGregor and Mark Williams, eds. Auckland: Oxford University Press, 1991, 143-157.

---, ed. Soho Square Four IV. Wellington: Bridget Williams Books, 1991.

---, ed. 100 New Zealand Poems (By 100 New Zealand Poets). Auckland: Godwit Press, 1993.

---, ed. 121 New Zealand Poems, Auckland: Godwit Press, 2005.

Marshall, Owen, ed. Burning Boats: Seventeen New Zealand Short Stories. Auckland: Longman Paul, 1994.

---, ed. Essential New Zealand Short Stories. Auckland: Godwit/ Random, 2002

---, ed. The Best New Zealand Fiction 5. Auckland: Vintage/Random, 2008.

---, ed. The Best NZ Fiction 6. Auckland: Vintage/Random, 2009a.

---, ed. Essential New Zealand Short Stories. Auckland: Godwit/ Random, 2009b.

Mason, R.A.K. 'Why we can't write for nuts'. Unpublished essay. R. A. K. Mason Papers, MS 990/7, Dunedin: Hocken Library, University of Otago, (undated).

---. Collected Poems. Auckland: Pegasus Press, 1962.

McAuley, James P. A Map of Australian Verse: The Twentieth Century. Melbourne: Oxford University Press, 1975.

McCormick, E.H. Letters and Art in New Zealand. Wellington: New Zealand Centennial Survey, Department of Internal Affairs, 1940.

---. New Zealand Literature: A Survey. London: Oxford University Press, 1959.

---. New Zealand Literature: A Survey. Oxford, UK: Oxford University Press, 1959.

McCrystal, John. 'Celebrating the stories of us'. The Dominion Post (17 January 2004), E9.

---. 'Regrets, they’ve had a few'. 'Indulgence', The Dominion Post (26 November 2005), 2.

McDonald, K.C. Our Country's Story. Wellington: Whitcombe and Tombs, 1963.

McDonald, Nan. Australian Poetry 1953. Sydney: Angus and Robertson, 1953.

McEldowney, Dennis. Frank Sargeson in his Time. Dunedin: John McIndoe, 1976. 
---. 'Publishing, Patronage, Literary Magazines'. The Oxford History of New Zealand Literature in English (2 ed.). Terry Sturm, ed. Auckland: Oxford University Press, 1998, 631-694.

McGregor, Graham and Williams, Mark, eds. Dirty Silence: Aspects of Language and Literature in New Zealand. Auckland: Oxford University Press, 1991.

McKay, Frank. New Zealand Poetry: An Introduction through the Discussion of Selected Poems. Wellington: New Zealand University Press, 1970.

---, ed. James K. Baxter as Critic: A Selection from his Literary Criticism. Auckland: Heinemann Educational Books, 1978.

---. The Life of James K. Baxter. Auckland: Oxford University Press, 1990.

McKenzie, D. F. Review of A Time for sowing and The Cradle and the Egg, by Frank Sargeson. Landfall 75 (September 1965), 293-295.

McLachlan, Noel. 'The Kiwi and the Kangaroo'. Meanjin Quarterly 112 (March 1968), 124128.

McLean, Denis. The Prickly Pair: Making Nationalism in Australia and New Zealand. Dunedin: University of Otago Press, 2003.

McLeod, A.L., ed. The Pattern of New Zealand Culture. Melbourne : Oxford University Press ; Ithaca: Cornell University Press, 1968.

McLeod, Aorewa. Review of The Exploding Frangipani: Lesbian Writing from Australian and New Zealand (1990). Cathie Dunsford and Susan Hawthorne, eds. Spiral 7. Wellington: Spiral/ Daphne Brasell Associates Press, 1992, 29-32.

McNaughton, Trudie, ed. Countless Signs: the New Zealand Landscape in Literature. Auckland: Reed Methuen, 1986.

McQueen, Harvey, and Lois Cox, eds. Ten Modern New Zealand Poets. Auckland: Longman Paul, 1974.

---, ed. The New Place: The Poetry of Settlement in New Zealand 1852-1914. Wellington: Victoria University Press, 1993.

--- and Roger Robinson. 'Dora Wilcox'. In The Oxford Companion to New Zealand Literature. Roger Robinson and Nelson Wattie, eds., 1998, 588.

Meikle, Phoebe, ed. Short Stories by New Zealanders One. Auckland: Longman Paul, 1973.

---, ed. Ten Modern New Zealand Story Writers. Auckland: Longman Paul, 1976.

Mennell, Philip, ed. Australian Wilds and Other Colonial Tales and Sketches. London: Hutchinson and Company, 1889. 
---. The Dictionary of Australasian Biography: Comprising Notices of Eminent Colonists from the Inauguration of Responsible Government Down to the Present Time (18551892). London: Hutchinson, 1892.

Menzies, Trixie Te Arama. 'Kowhai Gold - Skeleton or Scapegoat?'. Landfall 165 (March 1988), 19-26.

Millar, Paul. No Fretful Sleeper: A Life of Bill Pearson. Auckland: Auckland University Press, 2010.

Miscellaneous Verse from Australia and New Zealand 1850-1927. (No author). Unpublished collection. Wellington: Alexander Turnbull Library, 1927.

Moon, Michael, and Cathy N. Davidson, eds. Subjects and Citizens: Nation, Race and Gender from Oroonoko to Anita Hill. Durham: Duke University Press, 1995.

Morris, Paul, Harry Ricketts, and Mike Grimshaw, eds. Spirit in a Strange Land: A Selection of New Zealand Spiritual Verse. Auckland: Godwit/Random House, 2002.

---, eds. Spirit Abroad: A Second Selection of New Zealand Spiritual Verse. Auckland: Godwit/Random House, 2004.

Morrissey, Michael, ed. The New Fiction. Auckland: Lindon, 1985.

Mulgan, Alan. Literature and Authorship in New Zealand. London: George Allen and Unwin, 1943.

---. The Making of a New Zealander. Wellington: A.H. and A.W. Reed, 1958.

---. Great Days in New Zealand Writing. Wellington: A.H.and A.W.Reed, 1962.

Murdoch, Walter, ed. The Oxford Book of Australasian Verse. London: Oxford University Press, 1918.

---, ed. A Book of Australasian Verse. Melbourne: H. Milford /Oxford University Press, 1924, (Rev. eds. 1936, 1945).

--- and Alan Mulgan, eds. A Book of Australian and New Zealand Verse. Melbourne: H.Milford/Oxford University Press, 1949.

--- and Alan Mulgan, eds. Australian and New Zealand Verse. Melbourne: Oxford University Press, 1950.

--- and Henrietta Drake-Brockman, eds. Australian Short Stories. London: Oxford University Press, 1951.

Murray, Heather. 'Not tolling for me'. New Zealand Books: A Quarterly Review11, 3 (August 2001), 12. 
Murray, Stuart. Never a Soul at Home: New Zealand Literary Nationalism and the 1930s. Wellington: Victoria University Press, 1998.

'Myths in Antipodean Writing'. (Unattributed). Review. The Times Literary Supplement (14 June 1963), 420.

Neale, Emma. 'Fleur Adcock'. In The Oxford Companion to New Zealand Literature. Roger Robinson, and Nelson Wattie, eds., 1998, 3, 4.

Neill, Michael. 'Albert Wendt'. In In the same room: Conversations with New Zealand writers. Elizabeth Alley, and Mark Williams, eds. Auckland: Auckland University Press, 1992, 100-118.

Nightingale, Peggy. 'All any man with a club can do: Albert Wendt and Witi Ihimaera'. In Myth and Metaphor. Robert Sellick, ed. Adelaide: Centre for Research in the New Literatures in English, 1982, 53-70.

Ogilvie, Gordon. Denis Glover: His Life. Auckland: Godwit/Random House, 1999.

Opie, Brian. 'The New Zealand Minstrelsy (1852): William Golder and the Beginnings of a National Literature in New Zealand'. Victorian Poetry 44, 3 (2006), 273-292.

Orr, Bridget. 'Reading with the taint of the pioneer: Katherine Mansfield and settler criticism'. Landfall 172, 43, 4 (December 1989), 447-461.

Orsman, H.W. 'Australasia'. In The Oxford Companion to New Zealand Literature. Roger Robinson and Nelson Wattie, eds., 1998, 32.

O’Sullivan, Vincent. 'Katherine Mansfield'. New Zealand Book Council Online, n.d. Web. Accessed at: http://www.bookcouncil.org.nz/writers/mansfieldk.html.

---, ed. An Anthology of Twentieth Century New Zealand Poetry. Wellington: Oxford University Press, 1970; (2 ed.) 1976.

---. New Zealand Poetry in the Sixties. Wellington: School Publications Branch, Department of Education, 1973.

---, ed. New Zealand Short Stories: Third Series. Wellington: Oxford University Press, 1975.

---, ed. Ursula Bethell: Collected Poems. Auckland: Oxford University Press, 1985.

---, ed. An Anthology of Twentieth Century New Zealand Poetry. (3 ed.) Auckland: Oxford University Press, 1987.

---. Finding the Pattern, Solving the Problem: Katherine Mansfield, the New Zealand European. Wellington: Victoria University Press, 1989. 
---, ed. The Oxford Book of New Zealand Short Stories. Auckland: Oxford University Press, 1992.

---. 'Funnier, meaner Sargeson beyond this good life'. In Under Review: A Selection from New Zealand Books 1991-1996. Lauris Edmond, Harry Ricketts, and Bill Sewell, eds. Lincoln: Lincoln University Press and Daphne Brasell, 1997, 36-40.

---. Long Journey to the Border. Auckland: Penguin Books, 2003.

Oxford English Dictionary Online. Oxford University Press, 2000. Web. Accessed at: http://www.oed.com/

Paterson, Alistair, ed. 15 Contemporary New Zealand Poets. Dunedin: Pilgrims South Press, 1980.

Pearson, W.H. [Bill]. Introduction, Collected Stories 1935-1963: Frank Sargeson. Auckland: Longman Paul, 1964, 7-19.

---. 'Henry Lawson Among Maoris’. Meanjin Quarterly 112 (March 1968), 67-72.

---. 'H. Winston Rhodes'. Landfall 24, 4 (December 1970), 389.

---. 'The Recognition of Reality'. In Fretful Sleepers and Other Essays. Auckland: Heinemann, 1974, 137-150.

Petrie, Barbara, ed. Kiwi and Emu: An Anthology of Contemporary Poetry by Australian and New Zealand Women. Springwood: Butterfly Books, 1989.

Phillips, Jock [J.O.C.]. 'Musings in Maoriland - or was there a Bulletin school in New Zealand?'. Historical Studies 20, 81 (October 1983), 520-535.

---. 'Exhibiting Ourselves: the Exhibition and National Identity'. In Farewell Colonialism: The New Zealand International Exhibition, Christchurch, 1906-07. John Mansfield Thomson, ed. Wellington: Dunmore, 1998, 17-26.

Pierce, Peter. 'Australia'. In The Oxford Companion to New Zealand Literature. Roger Robinson and Nelson Wattie, eds.,1998, 32-34.

Pirie, Mark, ed. New Zealand Writing: The Next Wave. Dunedin: University of Otago Press, 1998.

Pugsley, Christopher. Gallipoli: The New Zealand Story. Auckland: Hodder and Stoughton, 1984.

---. The ANZAC Experience: New Zealand, Australia and Empire in the First World War. Auckland: Reed, 2001.

Quigley, Sarah. 'Clear-eyed views of a real country'. Review of Some Other Country: New Zealand's Best Short Stories (3 ed.,1997). Marion McLeod and Bill Manhire, eds. 'Weekend', The Press (17 May 1997), 17. 
---. 'Among the Tussocks'. Review of Vibrant with Words: The Letters of Ursula Bethell (2005), Peter Whiteford, ed. 'Indulgence', The Dominion Post (4 February 2006), 16.

Rawlinson, Gloria, and William Hart-Smith, eds. Jindyworobak Anthology, 1951: TransTasman Issue. Melbourne: Jindyworobak, 1952.

Reid, Ian. Fiction and the Great Depression: Australia and New Zealand 1930-1950. Melbourne: Edward Arnold, 1979.

Reid, J.C. Creative Writing in New Zealand: A Brief Critical History. Auckland: Whitcombe and Tombs Ltd, 1946.

---. New Zealand Non-Fiction. Wellington: New Zealand University Press/Price Milburn, 1968a.

---. 'Literature'. In The Pattern of New Zealand Culture, A.L. McLeod, ed. Ithaca: Cornell University Press, 1968b, 17-48.

Renwick, W.L. 'Show Us These Islands and Ourselves ... Give us a Home in Thought'. Beaglehole Memorial Lecture, Massey University, Palmerston North (1987). Web. Accessed at: http://www.nzjh.auckland.ac.nz/docs/1987/NZJH_21_2_01.pdf

Rhodes, H. Winston. 'The Moral Climate of Sargeson's Stories'. Landfall 33 (March 1955), $25-41$.

---. New Zealand Fiction Since 1945: A Critical Survey of Recent Novels and Short Stories. Dunedin: John McIndoe, 1968a.

---. 'Australian and New Zealand Literature'. Meanjin Quarterly 113 (1968b), 184-193.

---. New Zealand Novels: A Thematic Approach. Wellington: New Zealand University Press/Price Milburn, 1969.

---. 'Dan Davin'. In Contemporary Novelists, James Vinson, ed. London: St. James, 1972.

Richards, Max. 'William Hart-Smith (1911-1990): Poet of Two Countries'. Journal of New Zealand Literature 10 (1992), 74-91.

Richardson, Len. 'Bloody Australians'. Review of Tasman Relations: New Zealand and Australia, 1788-1988 (1987), Keith Sinclair, ed. New Zealand Listener 121 (May 1988), 67.

Ricketts, Harry, ed. Talking About Ourselves: Twelve New Zealand Poets in Conversation with Harry Ricketts. Wellington: Mallinson Rendel, 1986.

--- and Hugh Roberts, eds. How You Doing? A Selection of New Zealand Comic and Satiric Verse. Lincoln: Lincoln University and Daphne Brasell / Whitireia Publishing, 1998. 
Rieser, Max. 'The Aesthetic Theory of Social Realism'. The Journal of Aesthetics and Art Criticism 16, 2 (1957), 237-248.

Roberts, Heather. Where Did She Come From? New Zealand Women Novelists 1862-1987. Wellington: Allen and Unwin/Port Nicholson, 1989.

Roberts, Hugh. 'Can Identity be Helped?': Landfall, Chaos and the Creation of a New Zealand National Literature'. Journal of New Zealand Literature 4 (1989), 24-60.

---. 'Cock of the walk'. New Zealand Books 11, 5 (October 2001), 3.

---. 'The Same People Living in Different Places: Allen Curnow's Anthology and New Zealand Literary History'. Modern Language Quarterly 64, 2 (1 June 2003), 219-237.

Robinson, Roger. 'Albert Wendt: an Assessment'. Landfall 135, 34, 3 (September 1980), 275-290.

---. 'Mansfield Celebrated'. Landfall 171, 43, 3 (1989), 332-340.

---. The Oxford Companion to New Zealand Literature. Roger Robinson, and Nelson Wattie, eds. Melbourne: Oxford University Press, 1998.

---. 'Katherine Mansfield'. In The Oxford Companion to New Zealand Literature. Roger Robinson, and Nelson Wattie, eds., 1998, 341-342.

---. 'H. Winston Rhodes'. In The Oxford Companion to New Zealand Literature. Roger Robinson and Nelson Wattie, eds., 1998, 465.

---. 'Patrick White'. In The Oxford Companion to New Zealand Literature. Roger Robinson and Nelson Wattie, eds., 1998, 587.

Roddick, Alan. Review of Recreations, by Iain Lonie. Landfall 86, 22, 2 (June 1968), 226229.

---. Allen Curnow. Wellington: Oxford University Press, 1980.

Rogers, Frank. 'The New Zealanders: the decline of immigrant dominance in New Zealand'. Professional Historians Association of New Zealand/Aotearoa (2008). Web. Accessed at: http://www.phanza.org.nz/node/177

Ross, Jack and Jan Kemp, eds. New New Zealand Poets in Performance. Auckland: Auckland University Press, 2008.

Salmond, John, 'A New Zealander in Australia'. In Tasman Relations: New Zealand and Australia, 1788-1988. Keith Sinclair, ed. Auckland: Auckland University Press, 1987, 298-314.

Sargeson, Frank. Conversation with My Uncle and Other Sketches. Auckland: Unicorn Press, 1936. 
---. 'The Making of a New Zealander'. Penguin New Writing 13 (June 1942), 92-97.

---, ed. Speaking for Ourselves. Christchurch: Caxton Press, 1945.

---. 'The Feminine Tradition'. New Zealand Listener 19 (6 August 1948), 476.

---. 'Life Abounding'. Review of Roads from Home (1949), by Dan Davin. New Zealand Listener (10 June 1949), 17-18.

---. 'A Book of Stories'. Landfall 29, 8, 1 (March 1954), 22-26.

---. 'Henry Lawson: Some Notes After Re-reading'. Landfall 78, 20, 2 (June 1966), 156-62.

---. Review of An Overland Muster: Selections from Overland, 1954-1964 (1965). Stephen Murray-Smith, ed. Landfall 21, 2 (June 1967), 206-207.

---. Sargeson. Auckland: Penguin Books, 1981.

Sayer, Andrew. 'Essentialism, Social Constructionism, and Beyond'. Sociological Review 45, 3 (August 1997), 453-487.

Scholefield, Guy H. Making a Nation. Wellington: Alexander Turnbull Library, 1907.

Schwimmer, Erik. 'Commentary’. New Zealand Poetry Yearbook 1 (1951), 65, 66.

Serle, Percival. A Bibliography of Australasian Poetry and Verse: Australia and New Zealand. Melbourne: Melbourne University Press, 1925.

---, ed. An Australasian Anthology (Australian and New Zealand Poems). London: W. Collins, 1927.

---, ed. Australian Anthology (Australian and New Zealand Poems). Sydney: Collins, 1946.

---, ed. Dictionary of Australian Biography. Sydney: Angus and Robertson, 1949.

Sharrad, Paul. 'Imagining the Pacific'. Meanjin 49, 4 (1990), 597-606.

---. Albert Wendt and Pacific Literature: Circling the Void. Auckland: Auckland University Press, 2003.

Simpson, Peter. 'From Colonial to Provincial: The Evolution of Poetry in Canterbury 18501950'. Historical News (November 1981), 10-16.

---. Review of The Penguin Book of New Zealand Verse (1985), Ian Wedde and Harvey McQueen, eds. Islands 36, 2, 2 (November 1985), 155-161.

---. 'The trick of standing upright: Allen Curnow and James K. Baxter'. World Literature Written in English (WLWE) 26, 2 (1986), 369-378. 
---. 'Ways to the Museyroom: Poetry Anthologies in the Fifties'. Landfall 185 (April 1993), 95-105.

---. 'Allen Curnow'. In The Oxford Companion to New Zealand Literature. Roger Robinson, and Nelson Wattie, eds., 1998, 122-124.

---, ed. Seven New Zealand Novellas. Auckland: Reed, 2003.

---, ed. Nine New Zealand Novellas. Auckland: Reed, 2005.

Sinclair, Keith. A History of New Zealand. (1959). (Rev. ed.). Auckland: Penguin, 1988.

---. Distance Looks Our Way: The Effects of Remoteness on New Zealand. Hamilton: Paul's Book Arcade for the University of Auckland, 1961.

---. 'The Past and Future of Australia-New Zealand Relations'. Australian Outlook 22, 1 (1968), 29-38.

---. 'The Kiwi and the Kangaroo: 2'. Meanjin Quarterly 113 (June 1968), 194-196.

---. A Destiny Apart: New Zealand's Search for National Identity. Wellington: Allen and Unwin/Port Nicholson Press, 1986.

---. The Native Born: The Origins of New Zealand Nationalism. Massey Memorial Lecture. Palmerston North: Massey University, 1986a.

---. The Growth of New Zealand Identity, 1890 -1960. Auckland, Longman Paul, 1987.

---. 'Why New Zealanders are not Australians: New Zealand and the Australian Federal Movement, 1881-1901'. In Tasman Relations: New Zealand and Australia, 17881988, Keith Sinclair, ed., 1987a, 90-103.

---, ed. Tasman Relations: New Zealand and Australia, 1788-1988. Auckland: Auckland University Press, $1987 \mathrm{~b}$.

---. Towards 1990: Nation and Identity. Dunedin: Hocken Library, University of Otago, 1990.

Sladen, Douglas B.W., ed. A Poetry of Exiles. London: Griffith, Farran, Okedon and Welsh, 1885.

---, ed. Australian Ballads and Rhymes: Poems Inspired by Life and Scenery in Australia and New Zealand. London: Walter Scott, 1888.

---, ed. A Century of Australian Song. Sydney: Hugh Macready, 1888.

---, ed. Australian Poets 1788-1888:_Being a Selection of Poems Upon all Subjects Written in Australia and New Zealand During the First Century of the British Colonization 
with Brief Notes on Their Authors. London: Griffith, Farran, Okedon and Welsh, 1888.

Slessor, Kenneth. 'Australian Literature'. Southerly 6 (1945), 31-36.

Smith, Elizabeth. A History of New Zealand Fiction: from 1862 to the present time with some account of its relation to the national life and character. Dunedin: Reed, 1939.

Smithyman, Kendrick. A Way of Saying: A Study of New Zealand Poetry. Auckland: Collins, 1965.

---, ed. In Fifteen Minutes You Can Say a Lot: Selected Fiction by Greville Texidor. Wellington: Victoria University Press, 1987.

Stafford, Jane. 'Jessie Mackay, 1864-1938'. In Kōtare 7, 3 (2008), 52-58. Web. Accessed at: http://ojs.victoria.ac.nz/kotare/article/view/703/514

--- and Mark Williams. Maoriland: New Zealand Literature 1872-1914. Wellington: Victoria University Press, 2006.

--- and Mark Williams. Auckland University Press Anthology of New Zealand Literature. Auckland: Auckland University Press, 2012.

Stead, C.K. Review of The Wandering Islands (1955), by A.D. Hope. Landfall 10, 3 (September 1956), 260-263.

---. 'What became of Modernism?'. London Review of Books 2, 8 (1 May 1980), 14, 15.

---. In the Glass Case: Essays on New Zealand Literature. Auckland: Auckland University Press, 1981.

---. 'From Wystan to Carlos - Modern and Modernism in Recent New Zealand Poetry'. In In the Glass Case: Essays on New Zealand Literature. Auckland: Auckland University Press, 1981a, 139-159.

---. 'John Mulgan: A Question of Identity'. Islands 25, 7, 3 (1979), 267-295.

---. 'Wedde’s Inclusions'. Landfall 155, 39, 3 (September 1985), 289-302.

---. 'Les Murray: Authentic Oz'. In Answering to the Language: Essays on Modern Writers. Auckland: Auckland University Press, 1989a, 123-132. First published under the title 'Standing up to the city slickers'. London Review of Books 10, 4 (1988), 11, 12.

---. 'A.D. Hope: Australia's Senior Poet'. In Answering to the Language: Essays on Modern Writers Auckland: Auckland University Press, 1989b, 94-97.

---. Kin of Place: Essays on Twenty New Zealand Writers. Auckland: Auckland University Press, 2002. 
Stevens, Bertram, ed. An Anthology of Australian Verse. Sydney: Angus and Robertson, 1906.

---, ed. Golden Treasury of Australian Verse. Sydney: Angus and Robertson, 1909.

Stevens, Joan. The New Zealand Novel: 1860-1965. (2 ed.). Wellington: A.H. and A.W. Reed, 1966.

---, ed. New Zealand Short Stories. Wellington: Price Milburn: 1968.

Stewart, Douglas, ed. Modern Australian Verse. Sydney: Angus and Robertson, 1964.

Stone, Jean E. Katherine Mansfield: Publications in Australia, 1907-09. Sydney: Wentworth, 1977.

Sturm, Terry. 'John Mulgan: A Question of Identity'. Islands 25, 7, 3 (April 1979), 267-295.

---. 'The Neglected Middle Distance: Towards a History of Trans-Tasman Literary Relations'. In Tasman Relations: New Zealand and Australia, 1788-1988. Keith Sinclair, ed., 1987, 246-262.

---, ed. The Oxford History of New Zealand Literature in English. Auckland: Oxford University Press, 1991.

---, ed. The Oxford History of New Zealand Literature in English. (2 ed). Auckland: Oxford University Press, 1998.

---. Bulletin. In The Oxford Companion to New Zealand Literature. Roger Robinson and Nelson Wattie, eds., 1998, 77-78.

Subramani. 'Short fiction in the South Pacific'. New Literatures Review 9 (1981), 7-15.

Thomson, J.E.P. Denis Glover. Wellington and New York: Oxford University Press, 1977.

Turner, Brian. 'Lonie's unjust exclusion from the anthologies'. Otago Daily Times (29 June 1991), 21.

---. 'A bloody great exhibitionist'. Review of The Collected Poems of James K. Baxter (Rev. ed, 2004). John Weir, ed. The Dominion Post (25 October 2003), E9.

Turner, Stephen. 'Settlement as Forgetting'. In Quicksands: Foundational histories in Australia and Aotearoa New Zealand. Klaus Neumann, Nicholas Thomas and Hillary Ericksen, eds. Sydney: University of New South Wales Press, 1999.

Walker, D.C. 'A World in Search of the World'. Landfall 96, 24 (4 December 1970), 356366.

Walpole, H. Foreword to Tales By New Zealanders. C.R. Allen, ed. London: British Authors' Press, 1938. 
Watego, Cliff. 'Cultural adaptation in the South Pacific novel'. World Literature Written in English 23, 1 (Spring 1984), 488-96.

Wattie, Nelson. 'New Zealand Literature: A Survey (1959)'. In The Oxford Companion to New Zealand Literature. Roger Robinson and Nelson Wattie, eds.,1998a, 400-401.

---. 'A.E. Currie'. In The Oxford Companion to New Zealand Literature. Roger Robinson and Nelson Wattie, eds.,1998b, 125.

---. 'William Hart-Smith'. In The Oxford Companion to New Zealand Literature. Roger Robinson and Nelson Wattie, eds., 1998c, 230-231.

Webby, Elizabeth. 'The uses of fiction: Some recent novels from the South Pacific region'. Span 21 (October 1985), 29-37.

---. and Lydia Wevers, eds. Happy Endings: Stories By Australian and New Zealand Women 1850s-1930s . Wellington: Allen and Unwin/Port Nicholson Press, 1987.

Wedde, Ian, and Harvey McQueen, eds. The Penguin Book of New Zealand Verse. Auckland: Penguin Books, 1985.

Wells, Peter, and Rex Pilgrim, eds. Best Mates: Gay Writing in Aotearoa New Zealand. Auckland: Reed, 1997.

Wendt, Albert. 'Towards a New Oceania'. Mana Review1, 1 (1976), 5-9.

---, ed. Lali: A Pacific Anthology. Auckland: Longman Paul, 1980.

---, ed. Nuanua: Pacific Writing in English since 1980. Auckland: Auckland University Press, 1995.

---, Whaitiri, Reina, and Robert Sullivan, eds. Whetu Moana: Contemporary Polynesian Poetry in English. Auckland: Auckland University Press, 2003.

---. 'Pacific maps and fiction(s): a personal journey'. In Migration and New Zealand Society: proceedings of the Stout Research Centre Sixth Annual Conference. Wellington: Stout Research Centre, Victoria University of Wellington, 1990, 59-81.

Wevers, Lydia, ed. Yellow Pencils: Contemporary Poetry By New Zealand Women. Auckland: Oxford University Press, 1988.

Whiteford, Peter. Review of Winter Walk at Morning, by Iain Lonie. Landfall 181, 46, 1 (March 1992), 116-120.

---, ed. Eileen Duggan: Selected Poems. Wellington: Victoria University Press, 1994.

---. 'Eileen Duggan'. In The Oxford Companion to New Zealand Literature. Roger Robinson and Nelson Wattie, eds., 1998, 151-152. 
---. 'Iain Lonie.' In The Oxford Companion to New Zealand Literature. Roger Robinson and Nelson Wattie, eds., 1998, 310-311.

---, ed. Vibrant with Words: The Letters of Ursula Bethell. Wellington: Victoria University Press, 2005.

---. 'Eileen Duggan, 1894-1972'. Kōtare 7, 3 (2008), 115-128.

Wilde, William H., Joy Hooton, and Barry Andrews, eds. The Oxford Companion to Australian Literature. (2 ed.). Melbourne: Oxford University Press, 1994.

Wilkes, G.A. and J.C. Reid, eds. The Literatures of Australia and New Zealand. Pennsylvania: Pennsylvania State University Press, 1970.

Williams, Mark. Leaving the Highway: Six Contemporary New Zealand Novelists. Auckland: Auckland University Press, 1990.

---, ed. Writing at the Edge of the Universe. Christchurch: Canterbury University Press, 2004a.

---. 'A Steady Accurate Eye'. Review of A Long Journey to the Border: A Life of John Mulgan (2003), by Vincent O'Sullivan. Journal of New Zealand Literature 22 (2004b), 170-175.

Wilson, Janet. 'Fleur Adcock: Ambivalent Expatriate, 1964-1974'. Journal of New Zealand Literature 21 (2003), 54-72.

Wood, Briar. 'Albert Wendt'. In The Oxford Companion to New Zealand Literature. Roger Robinson, and Nelson Wattie, eds., 1998, 581,582.

Wood, F.L.W. This New Zealand. Hamilton: Paul's Book Arcade, 1946.

Woodhouse, A.E., ed. New Zealand Farm and Station Verse 1850-1950. Christchurch: Whitcombe and Tombs, 1950.

Wright, Judith, ed. A Book of Australian Verse (1956). (2 ed.). Melbourne: Oxford University Press, 1968.

---. [Response to ‘A Survey’, by Rob Jackaman]. Landfall 122, 31, 2 (June 1977), 136-137.

Yeats, W.B. The Trembling of the Veil. London: T. Werner Laurie Ltd, 1922.

---. Letters to the New Island. Horace Reynolds, ed. London: Oxford University Press, 1934. 